\title{
Bedeutung der Homöodomäne des \\ Transkriptionsfaktors Pax6 für die Aktivierung des Glukagon-Gens durch Pax6
}

\author{
DISSERTATION \\ zur Erlangung des Doktorgrades \\ der Mathematisch-Naturwissenschaftlichen Fakultäten \\ der Georg-August-Universität zu Göttingen
}

vorgelegt von

SABINE TEICHLER

aus Stuttgart

Göttingen 2004 
D 7

Referent:

Prof. Dr. R. Hardeland

Korreferentin:

Prof. Dr. C. Gatz

Tag der mündlichen Prüfung:

30.06.2004 
Meinen Eltern 
INHALTSVERZEICHNIS

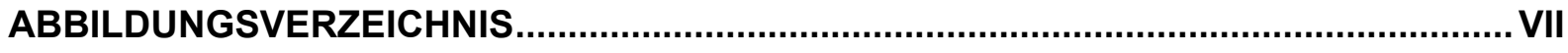

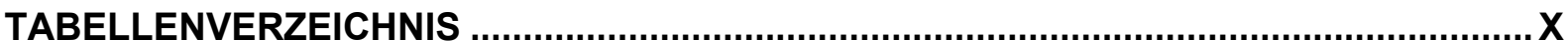

ABKÜRZUNGSVERZEICHNIS ....................................................................................

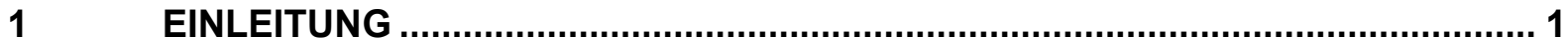

1.1 Der paired-Homöodomänen-Transkriptionsfaktor Pax6 ................................... 2

1.2 Das Peptidhormon Glukagon ...................................................................... 4

1.3 Regulation der Glukagon-Genexpression durch Pax6.................................. 5

1.4 Die Paired-Domäne und die Homöodomäne von Pax6 ................................... 8

$1.5 \quad$ Fragestellungen der Arbeit .............................................................................. 10

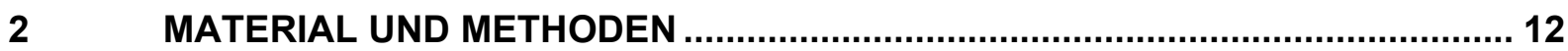

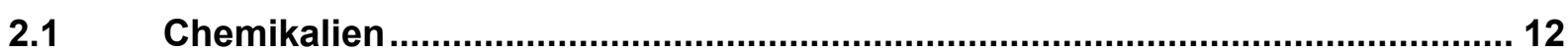

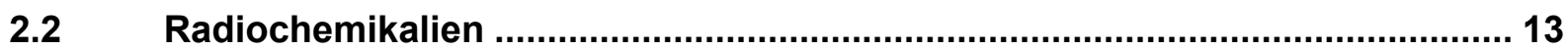

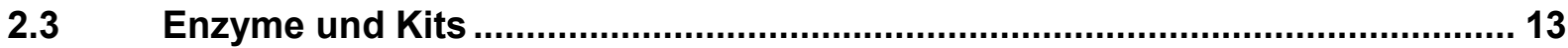

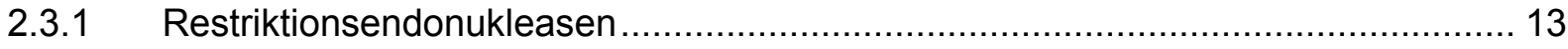

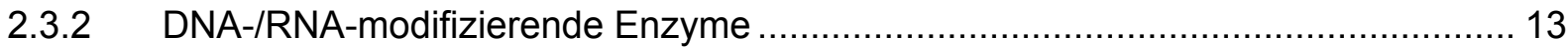

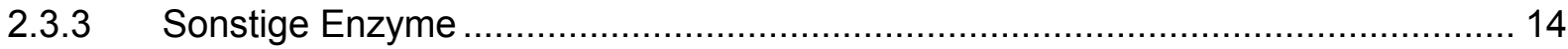

2.4 Antibiotika und Protease-Inhibitoren ............................................................. 14

2.5 Nachweis und Reinigungssysteme ........................................................... 14

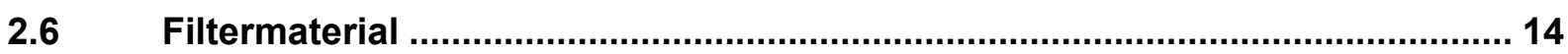

2.7 Materialien zur Anzucht von Bakterien ....................................................... 15

2.8 Material zur Kultivierung eukaryotischer Zelllinien ....................................... 15

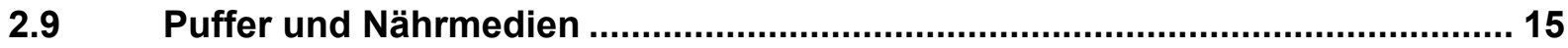

2.10 Medien für die Kultivierung eukaryotischer Zelllinien................................... 17

2.11 Art und Herkunft des biologischen und molekularbiologischen Materials..... 18

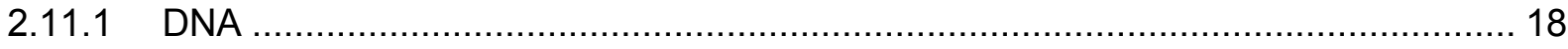

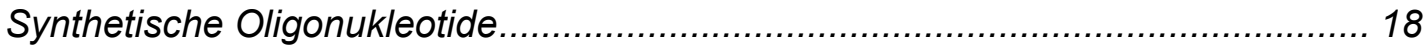

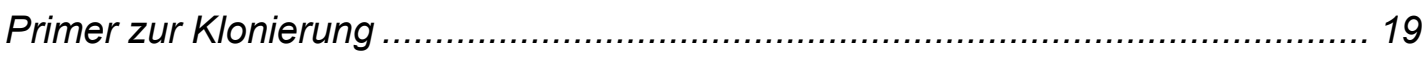

Primer zur Mutagenese doppelsträngiger Plasmid-DNA ................................. 21

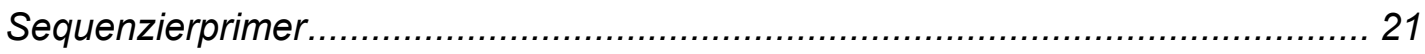

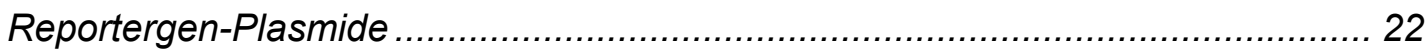

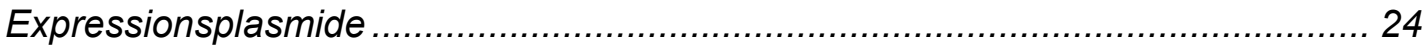

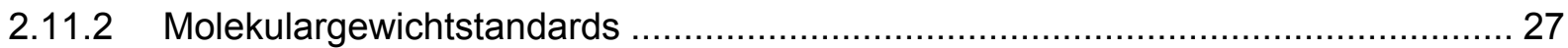

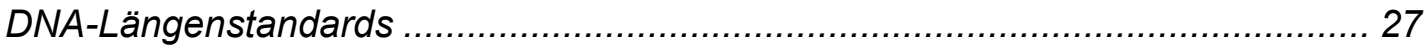

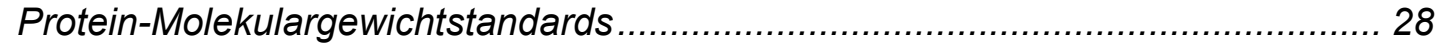




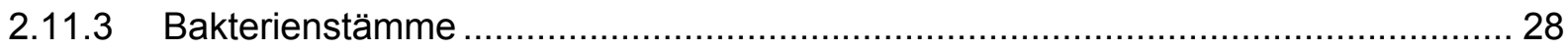

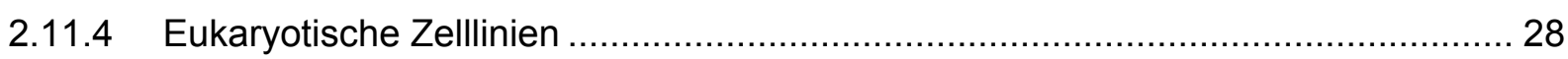

2.12 Nukleinsäure-Standardmethoden ................................................................ 29

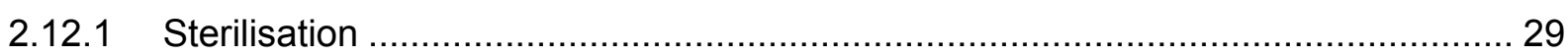

2.12.2 Phenol-Chloroform-Isoamylalkohol-Extraktion (Sambrook et al., 1989) ................. 29

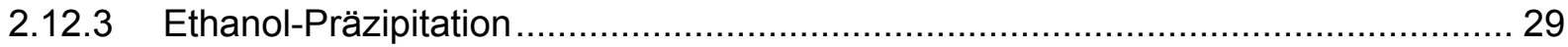

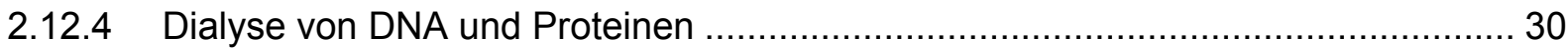

2.12.5 Konzentrationsbestimmung von Nukleinsäure-Lösungen (Sambrook et al. 1989) . 30

2.12.6 Herstellung von Doppelstrang-Oligonukleotiden („Annealing“)............................ 31

2.12.7 Radioaktive Markierung von DNA durch die Klenow „Fill-in"-Reaktion (Sambrook et al., 1989) ....................................................................... 31

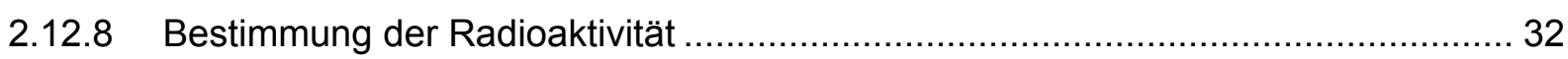

2.13 Gelelektrophorese von Nukleinsäuren ...................................................... 32

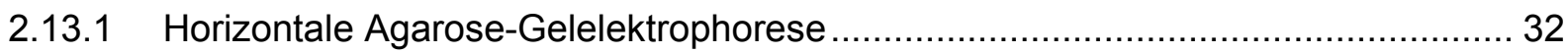

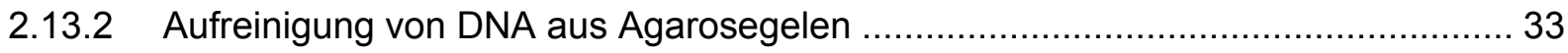

2.13.3 Denaturierende Polyacrylamid/Sequenzierungs-Gelelektrophorese ...................... 33

2.14 Nachweis von Nukleinsäuren im analytischen Maßstab.................................. 34

2.14.1 Ethidiumbromidfärbung in Agarosegelen ......................................................... 34

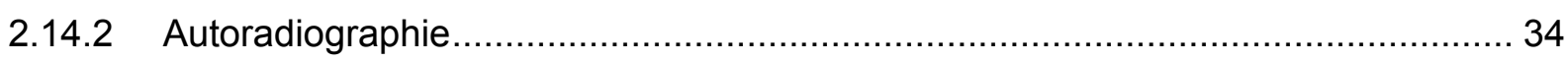

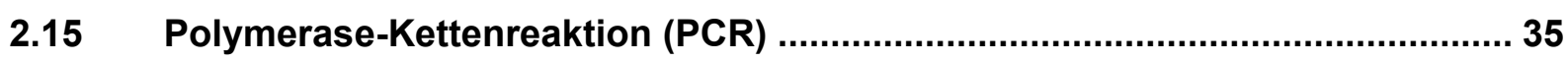

2.15.1 Amplifikation von DNA-Fragmenten durch PCR zur Klonierung.......................... 35

2.16 Enzymatische Modifikation von Nukleinsäuren ............................................. 39

2.16.1 Spaltung von DNA mit Restriktionsendonukleasen ........................................... 39

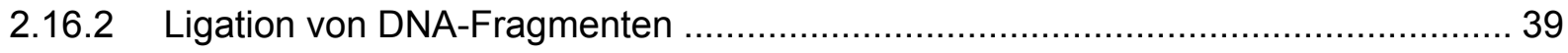

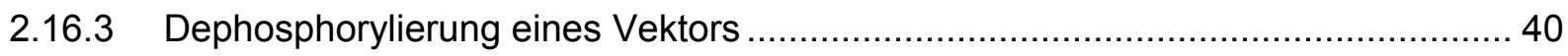

2.17 Methoden zur molekularen Klonierung........................................................... 40

2.17.1 Herstellung kompetenter E. coli (Dagert und Ehrlich, 1979) ................................ 41

2.17.2 Transformation kompetenter E. coli ............................................................ 41

2.17.3 Minipräparation von Plasmid-DNA (Le-Gouill et al., 1994) ................................. 42

2.17.4 Maxipräparation von Plasmid-DNA (Sambrook et al., 1989) .............................. 43

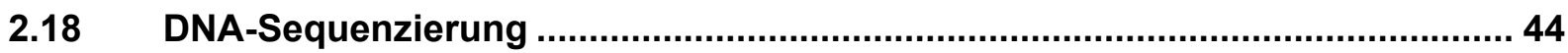

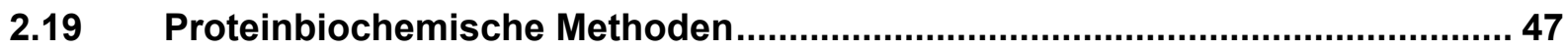

2.19.1 Bakterielle Expression und Aufreinigung von GST-Pax6-PD............................. 47

2.19.2 In vitro Transkription und Translation.......................................................... 48

2.19.3 Kernproteinisolierung aus transfizierten Tumorzelllinien (Dignam et al., 1983;

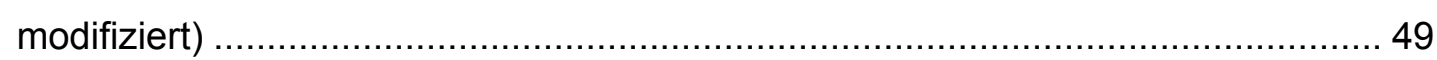

2.19.4 Konzentrationsbestimmung von Proteinlösungen (Bradford, 1976) ..................... 51 
2.19.5 SDS-Polyacrylamid-Gelelektrophorese (SDS-PAGE) von Proteinen (Laemmli, 1970)

2.19.6 Coomassie-Färbung von Proteinen im SDS-Polyacrylamidgel

2.20 Electrophoretic Mobility Shift Assay (EMSA) (Knepel et al., 1990b, modifiziert). 53

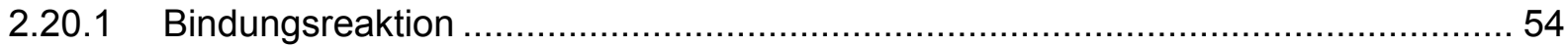

2.20.2 Nicht-denaturierende Auftrennung der Protein-DNA-Komplexe .......................... 54

2.21 Methoden zur Behandlung eukaryotischer Zellkulturen ................................ 55

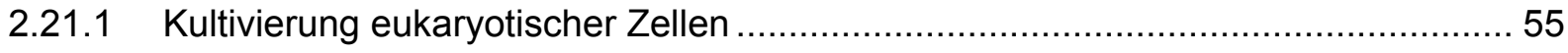

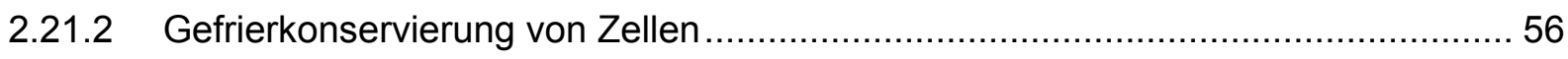

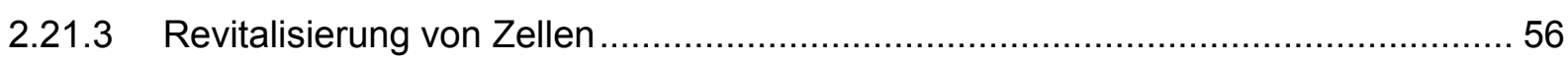

2.21.4 Transiente Transfektionen eukaryotischer Zelllinien.......................................... 57

Transfektion mittels DEAE-Dextran (Sambrook et al, 1989, modifiziert) ............... 57

Transfektion mittels Calcium-Phosphat (Ausubel et al, 1987) ............................. 58

2.21.5 Zellextrakt-Präparation nach einer Transfektion ............................................. 59

2.21.6 Bestimmung der Luciferase-Aktivität in transfizierten Tumorzelllinien ....................59

2.21.7 Bestimmung der GFP-Reportergen-Aktivität in transfizierten Zelllinien ................. 60

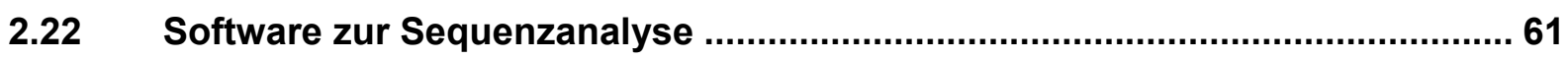

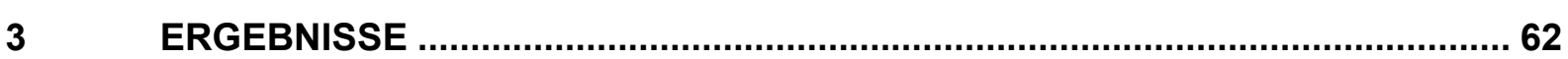

3.1 Hergestellte Reportergen- und Expressionsplasmide ................................62 62

3.2 Aktivierung von Glukagon-Promotorfragmenten durch Pax6 in den pankreatischen Insel-Zelllinien aTC2 und InR1G9 und der heterologen Zelllinie JEG-3

3.2.1 Wirkung von Mutationen innerhalb des G1- und G3-Elements auf die Aktivierung des Glukagon-Promotors in den pankreatischen Insel-Zelllinien $\alpha \mathrm{TC2}$ und $\operatorname{lnR} 1 \mathrm{G} 9$.

3.2.2 Wirkung von Mutationen innerhalb des G1- und G3-Elements auf die Aktivierung des Glukagon-Promotors durch Pax6 in der heterologen Zelllinie JEG-3. 65

3.3 Bedeutung der Pax6-Homöodomäne für die Aktivierung des GlukagonPromotors der Ratte durch Pax6.

3.3.1 Wirkung einer Deletion bzw. Mutation der Pax6-Homöodomäne auf die Aktivierung von Glukagon-Promotorfragmenten durch Pax6 im heterologen Zellsystem JEG-3. 69

3.3.2 Untersuchung des Expressionsgrades und der Kerngängigkeit der Pax6Homöodomänen-Mutanten 71

Untersuchung der Bindung von in JEG-3 exprimierten Pax6-Proteinen mit deletierter oder mutierter Homöodomäne mittels EMSA 
Wirkung einer Deletion bzw. Mutation der Homöodomäne auf die durch Pax6 induzierte transkriptionelle Aktivität des G3A-Elements des Glukagon-Promotors der Ratte

3.4 Charkterisierung der Bindung von Pax6-Proteinen mit deletierter oder mutierter Homöodomäne an das G1- oder G3-Element des GlukagonPromotors der Ratte

3.4.1 In vitro Transkription und Translation von Pax6-WT, Pax6-dHD, Pax6-dH3 und Pax6-3Ala und Darstellung der Expressionsprodukte in der SDS-PAGE .... 74

3.4.2 Analyse der Bindung von in vitro transkribiertem/translatiertem Pax6-WT, Pax6dHD, Pax6-dH3 und Pax6-3Ala an das G3-Element oder das G1-Element mittels EMSA.

3.5 Bedeutung der Pax6-Homöodomäne für die Aktivierung des Glukagon-Gens der Ratte durch Pax6 allein über das G1-Element oder allein über das G3Element

3.5.1 Aktivierung des Glukagon-Promotors mit mutierter Pax6-Bindungsstelle innerhalb des G1- oder des G3-Elements durch Pax6 oder Pax6 mit deletierter oder mutierter Homöodomäne

Analyse der Aktivierung des Glukagon-Promotors mit intern mutiertem G3-

Element durch Pax6 oder Pax6 mit deletierter oder mutierter Homöodomäne.

Analyse der Aktivierung des Glukagon-Promotors mit intern mutiertem G1-

Element durch Pax6 oder Pax6 mit deletierter oder mutierter Homöodomäne 78

Analyse der Aktivierung des Glukagon-Promotors mit intern mutiertem G1- und G3-Element durch Pax6-WT oder die Pax6-Homöodomänen-Mutanten.

3.5.2 Aktivierung des Glukagon-Promotors der Ratte mit deletiertem G3- oder G1-

Element durch Pax6 oder Pax6 mit deletierter oder mutierter Homöodomäne

Analyse der transkriptionellen Aktivierung von Glukagon-Promotorfragmenten mit deletiertem G3-Element durch Pax6-WT oder die Pax6-Homöodomänen-

Mutanten

Analyse der transkriptionellen Aktivierung von Glukagon-Promotorfragmenten mit deletiertem G1-Element durch Pax6-WT oder die Pax6-Homöodomänen-

Mutanten

3.6 Bedeutung der Domäne B des G3-Elements des Glukagon-Promotors für die Glukagon-Gen-Aktivierung durch Pax6.

3.6.1 Untersuchung der Wirkung von Mutationen in Domäne B auf die transkriptionelle Aktivität des G3-Elements in der pankreatischen Inselzelllinie aTC2 .

3.6.2 Untersuchung der Wirkung von Mutationen in Domäne B auf die durch exogenes Pax6 vermittelte Aktivität des G3-Elements in heterologen JEG-3-Zellen. 
3.6.3 Untersuchung der Wirkung einer Mutation in Domäne B des G3-Elements auf die Aktivierung des Glukagon-Gens in den Pankreasinsel-Zelllinien InR1G9 und aTC2

3.6.4 Untersuchung der Aktivierung des Glukagon-Gens mit mutierter Domäne B des G3-Elements durch exogenes Pax6 in der heterologen Zellinie JEG-3

3.7 Bedeutung der Domäne B des G3-Elements für die Aktivierung des Glukagon-Gens durch Pax6 mit deletierter oder mutierter Homöodomäne.... 92

3.7.1 Wirkung von Deletionen bzw. Mutation der Pax6-Homöodomäne auf die durch Pax6 induzierte Aktivität eines G3-Element-Oligomers in heterologen

JEG-3-Zellen.

3.7.2 Wirkung von Mutationen der Domäne B auf die durch die Pax6-HomöodomänenMutanten induzierte Aktivität eines G3-Element-Oligomers im heterologen Zellsystem JEG-3.

3.7.3 Wirkung einer Mutation von Domäne G3B auf die Aktivierung des GlukagonPromotors der Ratte durch die Pax6-Homöodomänen-Mutanten im heterologen Zellsystem JEG-3 96

Vergleich der Wirkung der Deletion oder Mutation der Pax6-Homöodomäne auf die Aktivierung des Glukagon-Promotors mit mutiertem G3B-Element in heterologen JEG-3-Zellen....

3.8 Charakterisierung der Bindung der Pax6-Paired-Domäne an Domäne B des G3-Elements des Glukagon-Gens der Ratte

3.8.1 Expression von GST-Pax6-PD-Fusionsproteinen und Darstellung der Expressionsprodukte in der SDS-PAGE

3.8.2 Analyse der Bindung von GST-Pax6-PD an das G3-Element mit Mutationen innerhalb Domäne B

3.9 Untersuchung einer DNA-unabhängigen Wirkung der Pax6-Homöodomäne103

4 DISKUSSION 105

4.1 Der paired-Homöodomänen-Transkriptionsfaktor Pax6 aktiviert synergistisch das Glukagon-Gen über die Pax6-Paired-Domäne-DNA-

Bindungsstelle im G1- und G3-Element des Glukagon-Promotors 105

4.2 Die Pax6-Homöodomäne ist für die Aktivierung des Glukagon-Gens durch Pax6 notwendig. 107

4.3 Bedeutung der Pax6-Homöodomäne bei der Bindung von Pax6 an das G1oder G3-Element des Glukagon-Promotors der Ratte. 108

4.4 Zur Aktivierung des Glukagon-Gens durch Pax6 über das G1-Element und/oder das G3-Element ist die Pax6-Homöodomäne notwendig 110

4.5 Die Domäne B des G3-Elements ist unabhängig von der Pax6-Homöodomäne für die Aktivierung des Glukagon-Gens durch Pax6 notwendig ..... 111 
4.6 Die Pax6-Paired-Domäne bindet nicht an Domäne B des G3 Elements 113

4.7 Die Pax6-Homöodomäne wirkt DNA-unabhängig inhibitorisch auf die Glukagon-Genexpression 114

4.8 Modell zur Funktion der Pax6-Homöodomäne bei der Aktivierung des Glukagon-Gens durch Pax6 115

5 ZUSAMMENFASSUNG 122

LITERATURVERZEICHNIS 124 


\section{ABBILDUNGSVERZEICHNIS}

Abb. 1: Aufbau des paired-Homöodomänen-Transkriptionsfaktors Pax6 2

Abb. 2: Die 5'-regulatorische Region des Glukagon-Gens der Ratte mit DNAKontrollelementen und bindenden Transkriptionsfaktoren. 6

Abb. 3: Sekundärstruktur der Paired-Domäne und der Homöodomäne von Pax6 8

Abb. 4: Darstellung der Struktur und der Bindung eines Paired-Homöodomänen-Dimers an DNA

Abb. 5: Schematische Darstellung der QuickChange-Mutagenese-Methode 38

Abb. 6: Glukagon-Reporterfusionsgene mit Mutationen innerhalb des G1- und G3Elements

Abb. 7: Die Mutation des G1 und/oder G3-Elements des Glukagon-Promotors der Ratte vermindert die Aktivität eines 1300 bp-Promotorfragments in den glukagonproduzierenden Zelllinien $\alpha \mathrm{TC} 2$ und InR1G9....

Abb. 8: Die Mutation des G1 und/oder G3-Elements des Glukagon-Promotors der Ratte vermindert die Aktivität eines 350 bp-Promotorfragments in der glukagonproduzierenden Zelllinie InR1G9.

Abb. 9: Die Mutation des G1 und/oder G3-Elements vermindert die Aktivierung des Glukagon-Promotors durch Pax6 in der heterologen Zelllinie JEG-3 66

Abb. 10: Pax6 und hergestellte Pax6-Mutanten 68

Abb. 11: Die Deletion bzw. Mutation der Pax6-Homöodomäne verringert die Aktivierung des Glukagon-Promotors der Ratte durch Pax6 in der heterologen Zelllinie JEG-3 ..... 70

Abb. 12: Pax6-Proteine mit deletierter oder mutierter Homöodomäne zeigen im EMSA eine Bindung an das G3A-Element des Glukagon-Promotors der Ratte.

Abb. 13: Reporterfusionsgen des G3A-Elements des Glukagon-Gens 72

Abb. 14: Die Deletion oder Mutation der Homöodomäne hat keinen Einfluß auf die durch Pax6 induzierte Aktivität des G3A-Elements in heterologen JEG-3-Zellen

Abb. 15: In vitro Transkription/Translation von Pax6-WT, Pax6-dHD, Pax6-dH3 und Pax63Ala in zellfreien Retikulozyten-Lysaten 
Abb. 16: Pax6 mit deletierter oder mutierter Homöodomäne zeigt im EMSA eine geringere Bindung an das G1-Element des Glukagon-Promotors als Pax6-WT

Abb. 17: Die Deletion bzw. Mutation der Pax6-Homöodomäne verringert die Aktivierung des Glukagon-Promotors der Ratte mit intern mutiertem G3-Element durch Pax6 in der heterologen Zelllinie JEG-3.

Abb. 18: Die Deletion bzw. Mutation der Pax6-Homöodomäne verringert die Aktivierung des Glukagon-Promotors der Ratte mit intern mutiertem G1-Element durch Pax6 in der heterologen Zelllinie JEG-3.

Abb. 19: Die Deletion bzw. Mutation der Pax6-Homöodomäne verringert die Aktivierung des Glukagon-Promotors der Ratte mit intern mutiertem G1- und G3-Element durch Pax6 in der heterologen Zelllinie JEG-3

Abb. 20: 5'-Deletionen der 5'-flankierenden Region des Glukagon-Gens der Ratte

Abb. 21: Die Deletion oder Mutation der Pax6-Homöodomäne vermindert die Aktivierung des Glukagon-Promotors der Ratte durch Pax6 nach Deletion des G3-Elements in der heterologen Zelllinie JEG-3.

Abb. 22: 3'-Deletionen der 5'-flankierenden Region des Glukagon-Gens der Ratte

Abb. 23: Die Deletion oder Mutation der Pax6-Homöodomäne vermindert die Aktivierung des Glukagon-Promotors der Ratte durch Pax6 nach Deletion des G1-Elements in der heterologen Zelllinie JEG-3.

Abb. 24: Reporterfusionsgene des G3-, G3A- und G3B-Elements des Glukagon-Gens 88

Abb. 25: Mutationen innerhalb Domäne B vermindern die Aktivität des G3-Elements in der glukagonproduzierenden Zelllinie $\alpha \mathrm{TC} 2$

Abb. 26: Mutationen der Domäne B vermindern die durch Pax6 induzierte Aktivität des G3Elements in heterologen JEG-3-Zellen

Abb. 27: Reporterfusionsgene der 5'-flankierenden Region des Glukagon-Gens der Ratte mit Mutationen innerhalb des G3-Elements

Abb. 28: Die Mutation des G3B-Elements vermindert die Aktivität des Glukagon-Promotors in den glukagonproduzierenden Zelllinien InR1G9 und $\alpha \mathrm{TC2}$

Abb. 29: Die Mutation von Domäne B des G3-Elements verringert die Aktivierung des Glukagon-Promotors durch Pax6 in der heterologen Zelllinie JEG-3 
Abb. 30: Die Deletion bzw. Mutation der Pax6-Homöodomäne hat keinen Einfluß auf die durch Pax6 induzierte Aktivität eines G3-Element-Oligomers in heterologen JEG-3-Zellen

Abb. 31: Mutationen in Domäne B führen zu einer Abnahme der durch Pax6Homöodomänen-Mutanten induzierten Aktivität des G3-Elements in heterologen JEG-3-Zellen

Abb. 32: Mutationen der Domäne A und B des G3-Elements hemmen die Aktivierung des Glukagon-Promotors durch die Pax6-Homöodomänen-Mutanten in der heterologen Zelllinie JEG-3.

Abb. 33: Die Mutation innerhalb des G3B-Elements vermindert die Aktivierung des Glukagon-Promotors durch die Pax6-Homöodomänen-Mutanten in der heterologen Zelllinie JEG-3

Abb. 34: Bakterielle Expression von rekombinantem GST-Pax6-PD-Fusionsprotein 100

Abb. 35: Die Paired-Domäne von Pax6 zeigt im EMSA eine Bindung sowohl an das G3Element als auch an des G3-Element mit mutierter Domäne B

Abb. 36: Hergestellte GAL4-Pax6-Fusionsgene.

Abb. 37: Reportergenfusionsgene mit in GAL4-DNA-Bindungsstellen mutiertem G1- und G3-Element.

Abb. 38: Die Deletion der Pax6-Homöodomäne steigert die transkriptionelle Aktivität eines GAL4-Pax6-Fusionsproteins am Glukagon-Gen in der heterologen Zelllinie JEG-3.

Abb. 39: Modell zur Funktion der Pax6-Homöodomäne bei der Aktivierung des GlukagonGens durch Pax6

Abb. 40: Modellierung einer Bindung der Pax6-Homöodomäne an das G3-Element des Glukagon-Gens. 


\section{TABELLENVERZEICHNIS}

Tab. 1: Herkunft und Bezeichnung der verwendeten Oligonukleotide .............................. 18

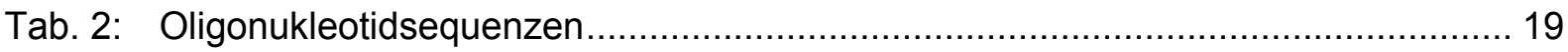

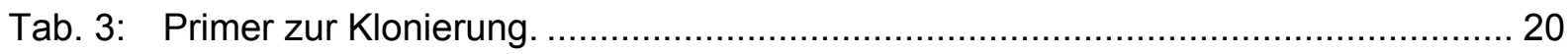

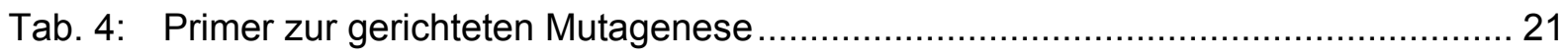

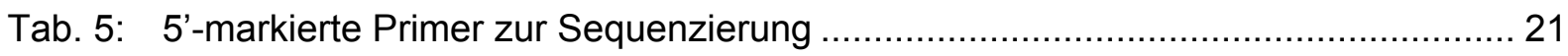

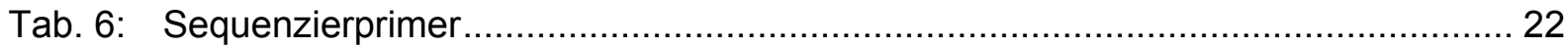

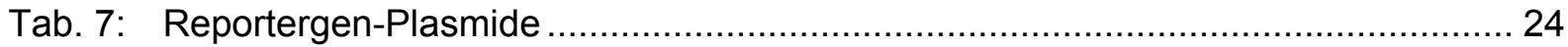

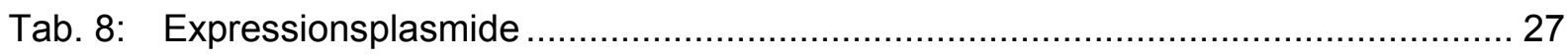

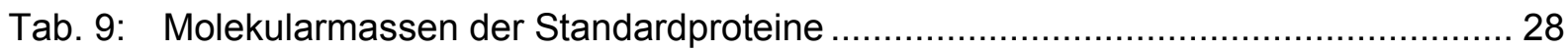

Tab. 10: Temperaturprofile der Sequenzierreaktion..................................................... 45 


\section{ABKÜRZUNGSVERZEICHNIS}

A

Abb.

abs.

Ac

Ala

Amp

$\mathrm{AP}$

APS

AS

Asn

BSA

bp

C

${ }^{\circ} \mathrm{C}$

CA

CAT

cAMP

cDNA

Chx

$\mathrm{Cdx}$

C/EBP

$\mathrm{Ci}$

CMV

Cpm

CRE

CREB

d

dATP

dCTP

dd

ddNTP

DEAE

dGTP

DMEM

DMSO

DNA
Adenin/Ampère

Abbildung

absolut

Acetat

Alanin

Ampicillin

Alkalische Phosphatase

Ammoniumpersulfat

Aminosäure

Asparagin

Rinderserumalbumin (englisch: bovine serum albumin)

Basenpaare

Cytosin

Grad Celsius

Chloramphenicol

Chloramphenicol-Acetyl-Transferase

zyklisches Adenosin-3', 5'-Monophosphat

kopierte (copy) Desoxyribonukleinsäure

C. elegans-like homeobox

caudal type homeobox

CCAAT/Enhancer bindendes Protein

Curie

Cytomegalievirus

counts per minute

cAMP-responsives Element

cAMP-responsives Element Bindeprotein

delta, deletiert

Desoxyadenosin-5'-Triphosphat

Desoxycytidin-5'-Triphosphat

Didesoxy

Didesoxyribonukleosidtriphosphat

Diethylaminoethyl

Desoxyguanosin-5'-Triphosphat

Dulbecco's Modified Eagle Medium

Dimethylsulfoxid

Desoxyribonukleinsäure 


\begin{tabular}{|c|c|}
\hline DNase & Desoxyribonuklease \\
\hline dNTP & Desoxyribonukleosid-5'-Triphosphat \\
\hline DTT & Dithiothreitol \\
\hline dTTP & Desoxythymidin-5'-Triphosphat \\
\hline E. coli & Escherichia coli \\
\hline EDTA & Ethylendiamin-Tetra-Acetat \\
\hline EGTA & Ethylenglykol-bis-(2-aminoethylether)-N, N'-Tetra-Acetat \\
\hline EMSA & Electrophoretic Mobility Shift Assay \\
\hline et al. & et alii \\
\hline $\mathrm{EtBr}$ & Ethidiumbromid \\
\hline g & Gramm \\
\hline G & Guanin \\
\hline G1 & Glukagon-Element 1 \\
\hline G2 & Glukagon-Element 2 \\
\hline G3 & Glukagon-Element 3 \\
\hline G4 & Glukagon-Element 4 \\
\hline G5 & Glukagon-Element 5 \\
\hline GCG & Genetics Computer Group \\
\hline GFP & Green Fluorescent Protein \\
\hline GLP & glucagon like peptide \\
\hline Glu & Glukagon \\
\hline GST & Glutathion-S-Transferase \\
\hline $\mathrm{h}$ & Stunde(n) \\
\hline HD & Homöodomäne \\
\hline HEBS & Hepes-gepufferte Salzlösung (englisch: Hepes Buffered Saline) \\
\hline Hepes & 2-(-4-2-Hydroxyethyl)-Piperazinyl---Ethansulfonat \\
\hline $\mathrm{HOM}$ & homeotic complex \\
\hline $\mathrm{HOX}$ & $\underline{\text { homeobox }}$ \\
\hline HNF-3 & Hepatocyte Nuclear Factor-3 \\
\hline IPTG & Isopropylthiogalaktosid \\
\hline $\mathrm{Kb}$ & Kilobasen \\
\hline $\mathrm{KDa}$ & Kilodalton \\
\hline KP-Puffer & Kalium-Phosphat-Puffer \\
\hline I & Liter \\
\hline L & Linker-Region \\
\hline LB & Luria Bertani \\
\hline Lhx & LIM homeobox \\
\hline Luc & Luciferase \\
\hline
\end{tabular}




\begin{tabular}{|c|c|}
\hline$\mu$ & mikro \\
\hline $\mathrm{m}$ & Meter; milli $\left(1 \times 10^{-3}\right)$ \\
\hline$\beta-\mathrm{ME}$ & $\beta$-Mercaptoethanol \\
\hline $\min$ & Minute \\
\hline mRNA & messenger Ribonukleinsäure \\
\hline MW & Molekulargewicht \\
\hline $\mathrm{n}$ & nano \\
\hline $\mathrm{NaAc}$ & Natriumacetat \\
\hline $\mathrm{NaOH}$ & Natriumhydroxid \\
\hline NLS & nuclear localization sequence \\
\hline NRF & nucleic respiratory factor \\
\hline OD & Optische Dichte \\
\hline $\mathrm{p}$ & Plasmid \\
\hline$\left[{ }^{32} \mathrm{P}\right]$ & Isotop 32 des Phosphors \\
\hline $\mathrm{Pa}$ & Pascale \\
\hline PAGE & Polyacrylamid-Gelelektrophorese \\
\hline pax & paired box \\
\hline Pax6-3Ala & Pax6 mit drei mutierten Aminosäuren in Helix 3 der Homöodomäne \\
\hline Pax6-dHD & Pax6 mit deletierter Homöodomäne \\
\hline Pax6-dH3 & Pax6 mit deletierter Helix 3 der Homöodomäne \\
\hline Pax6-dPD & Pax6 mit deletierter Paired-Domäne \\
\hline Pax6-dPD/E6 & Pax6 mit zum Teil deletierter Paired-Domäne \\
\hline Pax6-WT & Pax6-Wildtyp \\
\hline PBS & Phosphat-gepufferte Salzlösung (englisch: Phosphate-buffered Saline) \\
\hline pBS & Plasmid Bluescript \\
\hline $\mathrm{Pbx}$ & Pre-B-Cell-Homeobox-Protein \\
\hline PCR & Polymerase-Kettenreaktion (englisch: Polymerase Chain Reaction) \\
\hline PD & Paired-Domäne \\
\hline PEG & Polyethylenglykol \\
\hline Pfu & Pyrococcus furiosus \\
\hline PGC & PPAR $\gamma$-Coaktivator \\
\hline $\mathrm{pH}$ & $\mathrm{pH}$-Wert \\
\hline PISCES & 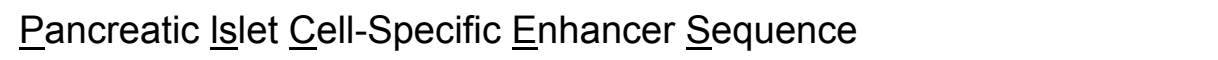 \\
\hline PMSF & Phenylmethyl-Sulfonylfluorid \\
\hline POU & pit oct une \\
\hline PPAR $\gamma$ & Peroxisomen Proliferator aktivierter $\underline{\text { Rezeptor } \gamma}$ \\
\hline Prep1 & 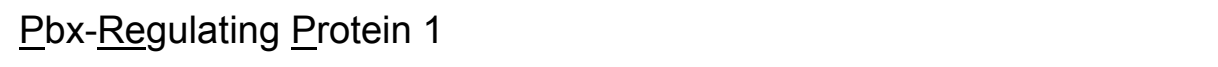 \\
\hline $\operatorname{Rax}$ & retina and anterior neural fold homeobox \\
\hline
\end{tabular}




\begin{tabular}{|c|c|}
\hline RNA & Ribonukleinsäure \\
\hline RNase & Ribonuklease \\
\hline RT & Raumtemperatur/Reverse Transkription \\
\hline s & Sekunde \\
\hline$\left[{ }^{35} \mathrm{~S}\right]$ & Isotop 35 des Schwefels \\
\hline SDS & Natriumdodecylsulfat \\
\hline SEM & Standardfehler des Mittelwertes (englisch: Standard Error of the Mean) \\
\hline Ser & Serin \\
\hline $\mathrm{SH} 2 / 3$ & src homology $2 / 3$ \\
\hline SV & simian virus \\
\hline Six & 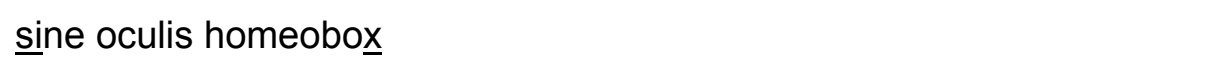 \\
\hline $\mathrm{T}$ & Thymin \\
\hline $\mathrm{T} 7$ & Bakteriophage T7 \\
\hline Tab. & Tabelle \\
\hline TAD & Transaktivierungsdomäne \\
\hline TAE & Tris-Acetat-EDTA \\
\hline TALE & Three-Amino Acid Loop Extension \\
\hline Taq & Thermus aquaticus \\
\hline TBE & Tris-Borat-EDTA \\
\hline TBP & TATA-Box-bindendes Protein \\
\hline TBS & Tris-gepufferte Salzlösung (englisch: Tris-buffered Saline) \\
\hline TE & Tris-EDTA \\
\hline TEMED & N', N', N', N'-Tetramethyldiamin \\
\hline TK & Thymidin-Kinase \\
\hline Tm & Schmelztemperatur (englisch: melting temperature) \\
\hline Tris & Tris-(hydroxymethyl)-aminomethan \\
\hline$U$ & Unit, Enzymeinheiten \\
\hline ü.N. & über Nacht \\
\hline UpM & Umdrehungen pro Minute \\
\hline UV & Ultraviolett \\
\hline $\mathrm{V}$ & Volt \\
\hline Val & Valin \\
\hline Vol. & Volumen \\
\hline $\mathrm{v} / \mathrm{v}$ & Volumen pro Volumen \\
\hline W & Watt \\
\hline WT & Wildtyp \\
\hline$w / v$ & Masse pro Volumen \\
\hline
\end{tabular}


Die Umwandlung der in der DNA gespeicherten genetischen Information in physiologisch aktive Proteine, die sogenannte Genexpression, ist einer der entscheidenden Vorgänge in der biologisch aktiven Zelle. In einem multizellulären Organismus enthalten alle Zellen dieselbe genetische Information. Dennoch exprimiert jeder Zelltyp daraus nur eine bestimmte Anzahl von Genen. Es existieren demnach Mechanismen, die eine sequenzspezifische Aktivierung eines Gens in einem speziellen Zelltyp regulieren. Einige Gene, die strukturelle Proteine und Enzyme zur Katalyse von Reaktionen des basalen Metabolismus kodieren, werden in allen Zellen und $\mathrm{zu}$ jeder Zeit exprimiert. Andere Gene werden nur unter bestimmten Bedingungen transkribiert (Calkhoven und Ab, 1996). Welche Gene transkribiert werden und welche nicht, wird unter anderem durch Transkriptions-Regulationsmechanismen gesteuert (Mitchell und Tijan, 1989; Tijan und Maniatis, 1994; Latchman, 1997). Bei der Transkription wirken verschiedene Strukturen zusammen. Am 5'-Ende eines Gens befindet sich die Promotor-Region, die mehrere kurze DNA-Abschnitte enthält, welche Promotorelemente oder cis-aktive Elemente genannt werden (Dynan, 1989; Tijan und Maniatis, 1994; Latchman, 1997; Merika und Thanos, 2001). Während der Differenzierung, in bestimmten Stoffwechselsituationen oder als Antwort auf extra- und intrazelluläre Signale (Alberts et al., 1997) binden an diese Kontrollelemente sequenzspezifisch Proteine, die sogenannten Transkriptionsfaktoren oder trans-aktiven Faktoren. Verstärkt ein Promotorelement die Transkription eines Gens, wird es als Enhancer bezeichnet, hemmt es dagegen die Transkription, als Silencer. Einige Transkriptionsfaktoren binden im inaktiven Zustand an die DNA und werden erst auf ein Signal hin, z.B. nach Ligandenbindung aktiviert. Transkriptionsfaktoren bestehen aus mindestens zwei funktionellen Domänen, einer DNABindedomäne und einer Transaktivierungsdomäne. Die DNA-Bindedomäne hat meistens eine charakteristische dreidimensionale Struktur, die dem Transkriptionsfaktor Spezifität verleiht. Die Sekundärstruktur dieser Domäne wird zur Klassifizierung von Transkriptionsfaktor-Familien herangezogen, deren Mitglieder ähnliche, aber distinkte Sequenzen binden. Die Transaktivierungsdomäne ist dagegen in ihrer Aminosäure-Sequenz häufig flexibel und weniger genau definiert. Zusätzlich besitzen viele Transkriptionsfaktoren eine Domäne zur Dimerisierung oder zur Bildung ternärer Komplexe, über die Interaktionen mit weiteren Proteinen hergestellt werden können.

Die Initiation der Transkription erfolgt nach Bildung des allgemeinen Transkriptionsapparats, einem Multiproteinkomplex am Transkriptionsstartpunkt des Gens, bestehend aus dem TATA-Box-bindenden Protein (TBP), basalen Transkriptionsfaktoren und der RNAPolymerase. Die Transkriptionsfaktoren binden über ihre DNA-Bindedomäne an entsprechende Kontrollelemente des Promotors und die Transaktivierungsdomäne 
interagiert direkt oder über Cofaktoren mit dem basalen Transkriptionsapparat, was die Zusammenlagerung beschleunigt oder den basalen Komplex aktiviert (Ptashne, 1988; Johnson und McKnight, 1989; Frankel und Kim, 1991; Tijan und Maniatis, 1994; Latchman, 1997). Transkriptionsfaktoren können nicht nur aktivierend auf die Transkription wirken, sondern auch hemmend. Transkriptionelle Aktivität kann durch Verdrängung eines transAktivators von seiner Bindungsstelle (kompetitive Hemmung), Verhinderung der DNABindung, Beeinträchtigung seiner transkriptionellen Aktivität durch Blockade der Transaktivierungsdomäne („Quenching“) oder die Kompetition um allgemeine Cofaktoren („Squelching“) aufgehoben werden. Es wurde aber auch die direkte Hemmung der Transkription durch trans-Repressoren in Abwesenheit aktivierender Faktoren beobachtet (Latchman, 1997). Mit jedem Gen hat sich ein eigener Regulationsmechanismus entwickelt, dessen Grundlage aber stets die spezifische Wechselwirkung zwischen trans-Aktivatoren und -Repressoren mit DNA-Kontrollelementen im Promotor-Bereich ist.

\subsection{Der paired-Homöodomänen-Transkriptionsfaktor Pax6}

Ein in der Evolution hoch konservierter Transkriptionsfaktor ist Pax6. Das Pax6-Protein der Maus besteht aus 422 Aminosäuren und hat ein Molekulargewicht von 48 kDa (Glaser at al., 1992). Pax6 ist ein Mitglied der Pax-Protein-Familie, die durch eine evolutionär hoch konservierte DNA-Bindungsdomäne, die Paired-Domäne charakterisiert ist (Bopp et al., 1986; Treisman et al., 1991) (Abb. 1).

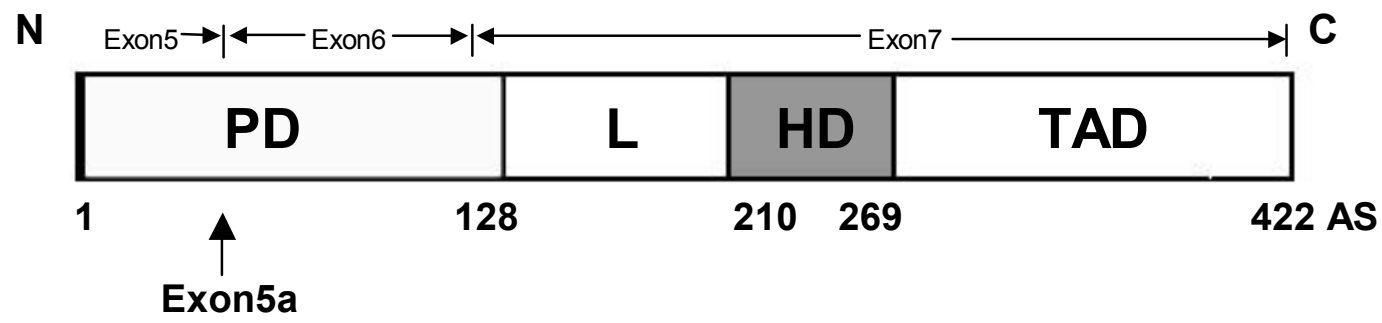

Abb. 1: Aufbau des paired-Homöodomänen-Transkriptionsfaktors Pax6. Das Pax6-Protein ist in verschiedene Domänen unterteilt, aminoterminal die Paired-Domäne (PD), eine Glutamin/Glycinreiche Linkerregion (L), eine paired-Homöodomäne (HD) sowie carboxyterminal eine Prolin-, Serin-, Threonin-reiche Transaktivierungsdomäne (TAD). Durch alternatives Spleißen kann es zur Insertion von 14 AS (Exon 5a) kommen. 
Während der Embryonalentwicklung, aber auch nach Abschluß der Differenzierung übt Pax6 in Vertebraten und Invertebraten wesentliche Funktionen aus. So steuert Pax6 die Entwicklung des Auges, der Nase, des Gehirns und der Pankreasinseln. Daneben spielt Pax6 im Prosencephalon, bei der Musterbildung des Neokortex (Bishop et al., 2000) und bei der Entwicklung des Di- und Mesencephalons (Matsunaga et al., 2000) eine Rolle.

Die Rolle von Pax6 während der Embryonalentwicklung wurde anhand von transgenen Tiermodellen untersucht: In der Maus (Hill et al., 1991) und in der Ratte (Matsuo et al., 1993) führten heterozygote Mutationen im Pax6-Gen zum Phänotyp small eye (sey), der sich u.a. durch Mikrophthalmie äußerte. Beim Menschen tritt Aniridie auf (Glaser et al., 1992; Jordan et al., 1992), wobei die Iris in Teilen oder vollständig fehlt; Cornea, Linse, optischer Nerv und Retina zeigen Defekte. Homozygote Sey-Mutanten und Pax6-/-Mäuse (St. Onge et al., 1997) versterben kurz nach der Geburt, u.a. fehlen Augen und Nase. Außerdem besitzen Pax6-/Mäuse eine stark reduzierte Anzahl an glukagonproduzierenden $\alpha$-Zellen in den Pankreasinseln und zeigen eine Desorganisation der Insel-Struktur (St. Onge et al., 1997).

Bislang sind nur wenige Zielgene des Transkriptionsfaktors Pax6 bekannt (Simpson und Price, 2002): Im Auge wird die Expression von Maf, einem Mitglied der v-Maf-OnkogenFamilie (Blank und Andrews, 1997) und die der basische-Region/Helix-Loop-HelixTranskriptionsfaktoren Mash1, Math1 und Neurogenin1 (Marquardt et al., 2001; Scardigli et al., 2001) von Pax6 kontrolliert. Die Expression von Strukturgenen des Auges, wie die der Keratin-Gene (Liu et al., 1999), wird auch von Pax6 beeinflußt. Pax6 ist Aktivator der $\alpha-$ Kristallin-Gene der Linse (Cvekl und Piatgorsky, 1996), und gleichzeitig Repressor der $\beta$ Kristallin-Gene (Duncan et al., 1998). Auch außerhalb des Auges reguliert Pax6 die Expression von Proteinen wie die des Zelladhäsions-Moleküls L1, einem Mitglied der Immunglobulin-Superfamile (Meech et al., 1999), oder die von Cadherinen, einer Superfamilie von Transmembran- und Zelloberflächen-Molekülen (Matsunami und Takeichi, 1995; Redies und Takeichi, 1996). Außerdem wurde für Pax6 ein onkogenes Potential beschrieben: Überexpression von Pax6 induziert in Mäusen die Tumorbildung und führt in Zelllinien zur Transformation (Maulbecker und Gruss, 1993).

Von entscheidender Bedeutung ist Pax6 in den Pankreasinseln. Einerseits ist Pax6 während der Entwicklung für die Differenzierung der glukagonproduzierenden $\alpha$-Zellen der Pankreasinseln notwendig (St. Onge et al., 1997; Sander et al., 1997). Ab E 9,0 entwickelt sich das Pankreas und ab E 9,5 können glukagonproduzierende Zellen detektiert werden, die Pax6 koexprimieren (Hill et al., 1999). Andererseits wird Pax6 in ausdifferenzierten Pankreasinseln exprimiert (St. Onge et al., 1997) und scheint im adulten Pankreas bei der Glukagon-Synthese eine Rolle zu spielen. 


\subsection{Das Peptidhormon Glukagon}

Das Peptidhormon Glukagon wird in den Langerhans'schen Inseln des Pankreas gebildet, die 1-2 \% des Pankreasgewebes ausmachen. Die differenzierten Pankreasinselzellen enthalten phänotypisch unterschiedliche Zellen, die aus einer gemeinsamen Vorgänger-Zelle abstammen und Glukagon ( $\alpha$-Zellen), Insulin ( $\beta$-Zellen), Somatostatin ( $\delta$-Zellen) und das pankreatische Polypeptid (P-Zellen) produzieren (Bonner-Weir, 1991). Im Zentrum der Pankreasinseln liegen die $\beta$-Zellen und stellen mit $60 \%$ den größten Anteil an Zellen im endokrinen Pankreas dar. Die restlichen Zelltypen liegen in der Peripherie verteilt, wobei die a-Zellen $20 \%$ der Inselzellen ausmachen. Das Polypeptid Somatostatin wirkt im Hypothalamus inhibierend auf das Wachstumshormon Somatotropin. Es hat eine parakrine Wirkung auf die benachbarten $\alpha$ - und $\beta$-Zellen und inhibiert die Sekretion von Glukagon und Insulin (Reichlin, 1983a; Reichlin, 1983b). Das Pankreaspolypeptid hemmt als Gegenspieler des Gastrins die Säureproduktion des Magens.

Glukagon steigert die Glukoseabgabe aus der Leber und ist somit zur Aufrechterhaltung eines ausreichenden Blutglukosespiegels während der Hungerphase notwendig. Als biologischer Antagonist des Insulins steigert Glukagon in der Leberzelle die Glukoneogenese und die Glykogenolyse und fördert die Ketonkörperbildung und die Lipolyse. Insulin dagegen senkt den Blutglukosespiegel, indem es die Aufnahme von Glukose aus dem Blut in Leber-, Muskel- und Fettgewebszellen stimuliert (Ashcroft und Ashcroft, 1992) und in der Leber die Glykogenolyse und der Glukoneogenese hemmt.

Störungen in der Glukagon-Biosynthese und -Sekretion tragen zur Pathogenese des Diabetes mellitus bei, der sich durch hyperglykämische Zustände äußert. Insulin hemmt die Glukagon-Produktion und Glukagon-Sekretion (Philippe et al., 1989). Durch die Insulindefizienz beim Diabetes mellitus kommt es zur Hyperglukagonämie, die zur Hyperglykämie beiträgt (Unger und Orci, 1981a/b; Léfèbvre, 1996). Neben der Expression in $\alpha$-Zellen der Pankreasinseln wird das Glukagon-Gen auch in enteroendokrinen Zellen des Darms (Habener et al., 1991) sowie in einigen Neuronen des Gehirns wie im Hirnstamm, dem Hypothalamus (Drucker und Asa, 1988) und im Thymus (Throsby, 1989) exprimiert. In allen Geweben wird ein Vorläufer-Molekül des Glukagons gebildet, das Proglukagon. Durch gewebsspezifische, posttranslationale Prozessierung wird aus Proglukagon in den Inseln des Pankreas Glukagon (Mojsov et al., 1986; Orskov et al., 1986) und das Glukagon-ähnliche Peptid GLP-1 (Glucagon-like peptide 1) freigesetzt (Habener et al., 1991). Im Darm werden in den intestinalen Zellen aus Proglukagon die biologisch aktiven Peptide Oxyntomodulin, Glicentin, GLP-1, GLP-2 und Enteroglukagon-37 gebildet. 


\subsection{Regulation der Glukagon-Genexpression durch Pax6}

Das Glukagon-Gen besteht aus 6 Exons und 5 Introns und ist ein single-copy-Gen (Habener et al., 1991). Die Pankreasinsel-spezifische Genexpression wird auf transkriptionellem Niveau kontrolliert. In vitro sind Transkriptionsfaktoren bekannt, die an die 5'-flankierende Region des Glukagon-Gens binden und in glukagonproduzierenden Pankreasinselzelllinien die Glukagon-Gentranskription steigern (Abb. 2). Da keiner dieser Transkriptionsfaktoren $\alpha$ zellspezifisch exprimiert wird, erfolgt die Aktivierung des Glukagon-Gens in den $\alpha$-Zellen der Pankreasinseln vermutlich durch eine zellspezifische Kombination von verschiedenen Transkriptionsfaktoren (Knepel, 2001). Bisher ist die Bedeutung dieser Transkriptionsfaktoren für die Aktivierung in primären $\alpha$-Zellen und in Pankreasinseln in vivo nicht gezeigt. Untersuchungen an Zellkulturen und in vitro-Untersuchungen demonstrieren, dass 350 Basenpaare der 5'-flankierenden Region des Glukagon-Gens der Ratte für eine spezifische Aktivierung der Genexpression in von pankreatischen $\alpha$-Zellen abgeleiteten Zelllinien ausreichen (Drucker et al., 1987; Philippe et al., 1988; Knepel et al.; 1993). Im Gegensatz zu Pankreasinselzelllinien sind 350 Basenpaare des Glukagon-Promotors der Ratte in transgenen Mäusen für eine $\alpha$-zellspezifische Aktivierung der Transkription nicht ausreichend (S. Beimesche, unveröffentlichte Ergebnisse). Dafür sind etwa 1,3 kb der 5'flankierenden Region des Glukagon-Gens der Ratte notwendig (Efrat et al., 1988). Für eine Expression des Glukagon-Gens in intestinalen Geweben der Ratte sind zusätzliche 5'flankierende Sequenzen nötig, insgesamt 2,3 kb (Lee et al., 1992).

Abbildung 2 zeigt 350 Basenpaare des Glukagon-Promotors der Ratte mit den bisher charakterisierten DNA-Kontrollelementen und dort interagierenden Transkriptionsfaktoren.

Der Transkriptionsfaktor Pax6 bindet in vitro über seine Paired-Domäne an ein Sequenzmotiv, PISCES (pancreatic islet cell-specific enhancer sequence (Knepel et al., 1991). Das PISCES-Konsensusmotiv aus 12 Basenpaaren zeigt eine hohe Homologie zu der Pax6-Konsensus-Bindungsstelle der Paired-Domäne (Abb. 2) und findet sich innerhalb des Upstream Elements (UE) des Somatostatin-Gens und des C2-Elements des Insulin I-Gens der Ratte (Knepel et al., 1991). Außerdem in zwei zellspezifischen Kontrollelementen des Glukagon-Promotors der Ratte: im proximalen G1-Element und im distalen Enhancer-artigen Element G3 (Sander et al., 1997; Andersen et al., 1999; Beimesche et al., 1999; Hussain und Habener, 1999; Ritz-Laser et al., 1999; Knepel et al., 1990b) (Abb. 2).

Das G1-Element (Basenpaar -63/-99; Abb. 2) zeigt nur eine geringe eigenständige transkriptionelle Aktivität, ist aber für die $\alpha$-zellspezifische Expression des Glukagon-Gens notwendig. Es enthält zwei nahezu identische AT-reiche Sequenzen (Morel et al., 1995), die von Homöodomänen-Transkriptionsfaktoren gebunden werden. Das 5'-AT-reiche Motiv bindet der pit-ọct-une (POU) Transkriptionsfaktor Brain-4, welcher spezifisch in pankreatischen $\alpha$-Zellen exprimiert wird und die Glukagon-Gentranskription steigert (Hussain 
et al., 1997). Das caudal-verwandte Protein Cdx2/3 (Jin und Drucker, 1996) bindet an das 3'AT-reiche Motiv. Pax6 bindet entweder als Monomer oder als Heterodimer mit Cdx2/3 an G1 (Jin et al., 1997; Andersen et al., 1999; Ritz-Laser et al., 1999). Ein weiterer positiv auf die Glukagon-Gentranskription wirkender Homöodomänen-Transkriptionsfaktor, der an G1 bindet, ist der LIM Homöodomänen Transkriptionsfaktor Isl-1 (Wang und Drucker, 1995).

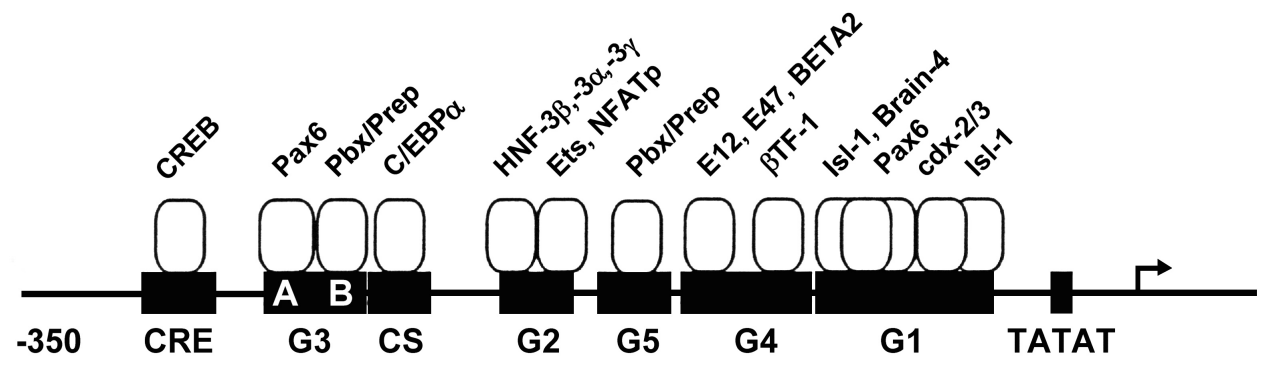

G1

AAAACCCCATTATTTACAGATGAGAAATTATATTGTCAGCGTAATATCTG TTTTGGGGTAATAAATGTCTACTCTTTAAATATAACAGTCGCATTATAGAC

PISCES

Paired

Brain 4

$\operatorname{cdx} 2 / 3$

G3

PISCES

Paired
ASTCCRCAYTTT

Y-MKT-ASTWCGCACTT--A

ATTATTT

ATTTATA

$\frac{\mathrm{A}}{\text { TAGTTTTTCACGCCTGACTGAGATTGAAGGG }}$
TTTYACRCCTSA
ANNTTCACGCWTSANTKMNY

Abb. 2: Die 5'-regulatorische Region des Glukagon-Gens der Ratte mit DNA-Kontrollelementen und bindenden Transkriptionsfaktoren. Oben: 350 Basenpaare der 5'-flankierenden Region des Glukagon-Gens der Ratte enthalten sechs wesentliche bisher charakterisierte DNA-Kontrollelemente. CRE, cAMP-responsives Element; CS, C/EBP-Bindungsstelle; G1, Glukagon-Element 1; G2, Glukagon-Element 2; G3, Glukagon-Element 3; G4, Glukagon-Element 4; G5, Glukagon-Element 5. Unten: Basensequenz des proximalen Promotorelements G1 und des Enhancer-Elements G3 mit Sequenzvergleichen. Domäne A des G3-Elements und des G1-Elements (in umgekehrter Orientierung) beinhalten das Sequenzmotiv PISCES (pancreatic islet cell specific enhancer sequence), $W=A / T ; K=G / T ; M=A / C ; R=A / G ; S=G / C ; N=$ beliebiges Nukleotid. 
Das G3-Element (Basenpaar -268/-238; Abb. 2) umfasst zwei Abschnitte: Domäne A und Domäne B (Knepel et al., 1990b). Pax6 bindet über seine Paired-Domäne an Domäne A. Die Domäne $B$ des G3-Elements dient als Bindungsstelle der praktisch ubiquitär exprimierten Homöodomänen-Proteine der TALE- (Three Ámino Acid Loop Exxtension) Familie Pbx/Prep1 (Berthelsen et al., 1998; Monica et al., 1991; Herzig et al. 2000), die in nichtglukagonproduzierenden Zelllinien die Glukagon-Gentranskription hemmen (Herzig et al., 2000).

Neben der Expression von Pax6 wurde im endokrinen Pankreas die von zwei weiteren paired-Homöodomänen-Proteinen gezeigt, die von Pax2 und Pax4. Beide kompetieren mit Pax6 um die Bindung an die 5'-regulatorischen Kontrollelemente G1 und G3 des GlukagonPromotors der Ratte (Smith et al., 1999; Petersen et al., 2000; Ritz-Laser et al., 2000). Pax2 aktiviert in glukagonproduzierenden Zellinien die Glukagon-Gentranskription (Ritz-Laser et al., 2000). Pax4 wird während der Entwicklung des endokrinen Pankreas exprimiert und ist in $\alpha$-Zelllinien ein Repressor der Glukagon-Gentranskription (Smith et al., 1999; Petersen et al., 2000). In Pankreasinseln werden zwei Isoformen von Pax6 exprimiert, die unterschiedliche DNA-Bindungseigenschaften besitzen (Epstein et al., 1994a). Durch alternatives Spleißen der mRNA kommt es bei der Isoform Pax6-5a zu einer Insertion von 14 Aminosäuren in die Paired-Domäne, dem sogenannten Exon 5a (Walther und Gruss, 1991; Glaser et al., 1992) (Abb.1), wodurch die Bindungsfähigkeit an das PISCES-Motiv unterbunden (Beimesche et al., 1999) wird. An das PISCES-Motiv im G1- und G3-Element bindet in vitro die Pax6Isoform ohne Exon 5a (Beimesche et al., 1999).

Pax6 scheint neben der $\alpha$-zellspezifischen Aktivierung des Glukagon-Gens auch an der Hemmung des Glukagon-Gens durch Insulin beteiligt zu sein. Sowohl die GlukagonSekretion, als auch die Glukagon-Synthese werden durch Insulin gehemmt (Philippe, 1989). Insulin hemmt die Interaktion zwischen proximalen Promotor- und distalen EnhancerElementen des Glukagonpromotors (Grzeskowiak et al., 2000), wobei das an G1- und G3bindende Pax6 eine wichtige Rolle spielt. Es ist für die Insulinresponsivität des GlukagonPromotors notwendig und kann diese auch vermitteln (Grzeskowiak et al., 2000).

Pax6 und das Glukagon-Gen werden mit der blutzuckersenkenden Wirkung der Thiazolidindione, einer Klasse oraler Antidiabetika, in Verbindung gebracht. Thiazolidindione, wie z.B. Rosiglitazon sind synthetische Liganden des Peroxisomen-Proliferatoren-aktivierten Rezeptors $\gamma$ (PPAR $\gamma$ ) (Saltiel und Olefsky, 1996) und hemmen die GlukagonGentranskription in glukagonproduzierenden Pankreasinselzelllinien sowie die GlukagonSekretion in primären Pankreasinseln. Die Glukagon-Gentranskription wird durch PPAR $\gamma$ und Thiazolidindione in einer DNA-unbhängigen Weise über eine Hemmung der transkriptionellen Aktivität von Pax6 am G1-Element blockiert (Schinner et al., 2002), was einer Hyperglykämie entgegenwirkt. 


\subsection{Die Paired-Domäne und die Homöodomäne von Pax6}

Das gemeinsame Strukturmotiv der Pax-Proteine ist die Paired-Domäne. Diese 128 Basenpaare lange DNA-Bindungsdomäne wird von der paired box (pax) kodiert, die zuerst im Segmentierungsgen paired von Drosophila identifiziert wurde (Bopp et al., 1986).

Die Paired-Domäne von Pax6 liegt am aminoterminalen Ende des Proteins und setzt sich aus zwei globulären Untereinheiten zusammen (Abb. 3), die unterschiedliche Bindungseigenschaften besitzen (Czerny et al., 1993). Die aminoterminale Untereinheit (PD$\mathrm{N}$, PAI-Domäne) enthält ein $\beta$-Sheet-Motiv mit $\beta$-Hairpin, auf das drei $\alpha$-Helices folgen (Abb. 3). Die carboxyterminale Subdomäne (PD-C, RED-Domäne) (Jun und Desplan, 1996) besteht aus weiteren drei $\alpha$-Helices (Abb. 3). Die beiden Untereinheiten sind über eine Linker-Region miteinander verbunden (Abb 3). Röntgenkristallstruktur-Untersuchungen zeigen, dass die dritte Helix jeder Subdomäne an jeweils sich gegenüberliegende große Furchen der DNA bindet (Xu et al., 1999), und dass die Linker-Region zur Gesamtbindung der Paired-Domäne beiträgt.

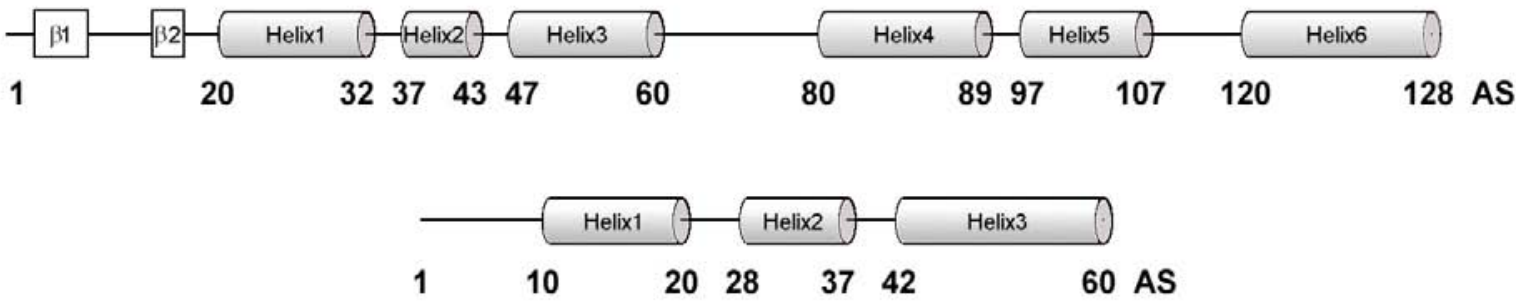

Abb. 3: Sekundärstruktur der Paired-Domäne und der Homöodomäne von Pax6. Oben: Sekundärstruktur der Pax6-Paired-Domäne. Die Pax6-Paired-Domäne gliedert sich in zwei globuläre Subdomänen. Sowohl die aminoterminale als auch die carboxyterminale Subdomäne beinhalten drei $\alpha$-Helices, wobei jeweils die dritte spezifische Kontakte mit der großen Furche der DNA-Doppelhelix ausbilden kann. $\beta 1, \beta 2, \beta$-Sheet-Motiv. Unten: Sekundärstruktur der Pax6-Homöodomäne. Die Pax6Homöodomäne besitzt drei $\alpha$-Helices, wobei die dritte Helix, die DNA-Erkennungshelix, basenspezifische Kontakte mit der großen Furche der DNA-Doppelhelix ausbilden kann.

Während die Paired-Domäne als primäre DNA-bindende Domäne gilt, ist die Funktion der zweiten potentiell DNA-bindenden Domäne von Pax6, die Homöodomäne, bei der Aktivierung der Glukagon-Gentranskription durch Pax6 unklar. Die aus 60 Aminosäuren bestehende Homöodomäne (McGinnis et al., 1984) wird von der hochkonservierten Homöobox kodiert und ähnelt der des Paired-Proteins in Drosophila (Walther und Gruss, 1991). Die Pax6-Homöodomäne besteht aus einem flexiblen, aminoterminalen „Arm“ sowie 
aus drei durch Schleifen voneinander getrennten $\alpha$-Helices (Billeter et al., 1990; Philips et al., 1991; Qian et al., 1994) (Abb. 3). Helix 3 der Homöodomäne dient als DNA-Erkennungshelix und geht bei der Interaktion mit DNA durch ein Helix-Turn-Helix-Motiv Kontakte mit der großen Furche der DNA ein (Otting et al., 1990; Kissinger et al., 1990; Wilson et al., 1995) (Abb 4). Zusätzlich erzeugt der aminoterminale „Arm“ Bindungen mit der kleinen Furche der DNA (Kissinger et al., 1990; Wolberger et al., 1991) (Abb. 4).

Die Superfamilie der Homöodomänen-Proteine umfasst eine große Zahl an sequenzspezifisch DNA-bindenden Transkriptionsfaktoren, die u.a. wichtige Regulatoren der Embryonalentwicklung sind. Sie werden z.B. von Genen des HOM-Clusters in Drosophila (Lewis, 1978) oder des HOX-Clusters in Vertebraten (Graham et al., 1989; Boncinelli, 1988; McGinnis und Krumlauf, 1992) kodiert. Homöodomänen der paired-Klasse, zu der auch die von Pax6 gehört, binden mit hoher Affinität als Dimere an eine palindromische DNASequenz, die sogenannte P3-Stelle (Wilson et al., 1993; Wilson et al., 1995), deren Sequenz das für Homöodomänen-Bindungsstellen typische Tetranukleotid ATTA als Core-Motiv enthält (Gehring et al., 1994). Sie unterscheiden sich damit von HomöodomänenTranskriptionsfaktoren wie z. B. Antennapedia oder Ultrabithorax in Drosophila (Regulski et al., 1985; Calzone et al., 1988), die über die Homöodomäne an ihre Zielsequenzen als Monomer binden. Bindungsexperimente zeigten, dass die Bindung von Pax6Homöodomänen-Dimeren an die P3-Sequenz kooperativ erfolgt (Singh et al., 2000).

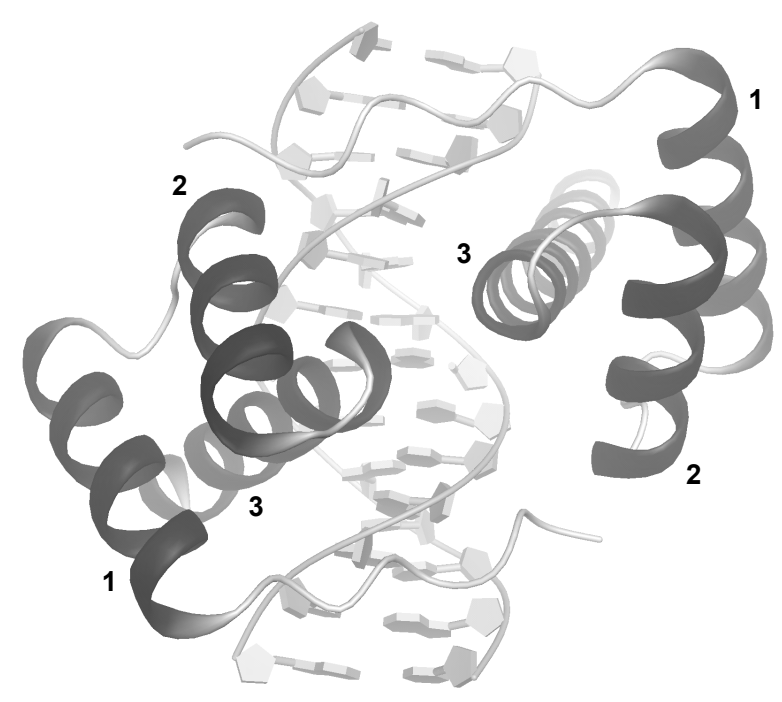

Abb. 4: Darstellung der Struktur und der Bindung eines Paired-Homöodomänen-Dimers an DNA. Bindung eines Drosophila paired-Homöodomänen-Dimers an die P3-Sequenz TAATCTGATTA (nach R. Krätzner). (1), Helix 1; (2), Helix 2; (3), Helix 3. 
Neben einer DNA-Bindung ist die Pax6-Homöodomäne auch zu Protein-ProteinInteraktionen in der Lage. So interagiert die Pax6-Homöodomäne mit dem pairedHomöodomänen-Transkriptionsfaktor Rax und einer Isoform von Pax6 mit deletierter PairedDomäne (Mikkola et al., 2001); sowie mit verschiedenen HomöodomänenTranskriptionsfaktoren, wie z.B. mit Cdx2/3 (Jun und Desplan, 1996), Prep1 (Mikkola et al., 2001), dem TATA-box-bindenden Protein (TBP) (Cvekl et al., 1999) und dem Retinoblastoma-Protein (Eberhard und Busslinger, 1999).

Ein weiteres Sequenzmotiv, das bei einigen Pax-Proteinen vorkommt, ist das Oktapeptid. Dabei handelt es sich um eine Nukleotidsequenz, die zwischen der Paired-Domäne und der Homöodomäne liegt (Burri et al., 1989; Goulding et al., 1991). Die Transaktivierungsdomäne von Pax6 befindet sich am Carboxyterminus des Proteins und ist reich an den Aminosäuren Prolin, Serin und Threonin (PST-Region) (Tang et al., 1998). Die Aktivität dieser Domäne wird möglicherweise durch Phosphorylierung durch MAP-Kinasen reguliert (Mikkola et al., 1999). In Drosophila existieren sieben Pax-Proteine, einschließlich Paired (Frigerio et al., 1986), in Mensch und Maus neun (Pax1 bis Pax9) (Chalepakis et al., 1993; Walther et al., 1991). Anhand der Sequenzähnlichkeit und der Genstruktur werden die Pax-Proteine in vier Klassen eingeteilt: Pax3 und Pax7 besitzen die Paired-Domäne, das Oktapeptid und die Homöodomäne; bei Pax4 und Pax6 fehlt das Oktapeptid; Pax1 und Pax9 enthalten keine Homöodomäne, während bei Pax2, Pax5 und Pax8 nur Helix 1 der Homöodomäne vorhanden ist (Walther et al., 1991).

\section{$1.5 \quad$ Fragestellungen der Arbeit}

Die Bedeutung der Paired-Domäne von Pax6 für die Aktivierung des Glukagon-Gens durch Pax6 ist umfassend untersucht worden. Bekannt ist, dass die Paired-Domäne die primäre DNA-bindende Domäne von Pax6 ist (Czerny und Busslinger, 1995; Chalepakis et al., 1992). Im Gegensatz dazu ist die Bedeutung der Homöodomäne von Pax6 unbekannt. Die Bedeutung der Pax6-Homöodomäne ist nicht nur für die Aktivierung der GlukagonGentranskription durch Pax6 unklar, sondern auch für die spezifische Regulation anderer Pax6-Zielgene (Simpson und Price, 2003) durch Pax6.

Die erste Fragestellung der vorliegenden Arbeit war, ob die Homöodomäne bei der Aktivierung des Glukagon-Gens durch Pax6 überhaupt von Bedeutung ist. Weiter sollten mögliche Funktionen der Pax6-Homöodomäne bei der Glukagon-Genaktivierung durch Pax6 untersucht werden. Die Funktion der Pax6-Homöodomäne bei der Aktivierung des GlukagonGens durch Pax6 könnte in einer zusätzlichen DNA-Bindung liegen. Geklärt werden sollte, ob die Pax6-Homöodomäne zur Bindung von Pax6 über die Paired-Domäne an das Glukagon-Gen beiträgt. Homöodomänen-Bindungsstellen finden sich im G1- und G3- 
Element des Glukagon-Promotors der Ratte. Zwar besitzt die Homöodomäne von Pax6 gegenüber einer optimalen synthetischen DNA-Bindungsstelle eine etwa hundertfach geringere Affinität als die Paired-Domäne (Czerny und Busslinger, 1995), dennoch wäre eine DNA-Bindung über die Homöodomäne zusätzlich zu der der Paired-Domäne innerhalb des Glukagon-Promotors möglich. Eine weitere Funktion der Homöodomäne könnten ProteinProtein-Wechselwirkungen sein. Es sollte daher untersucht werden, ob unabhängig von einer DNA-Bindung die Pax6-Homöodomäne bei der Wirkung von Pax6 am Glukagon-Gen eine Rolle spielen. 


\section{$2.1 \quad$ Chemikalien}

Sofern nicht anders angegeben, wurden alle aufgeführten Chemikalien des höchsten handelsüblichen Reinheitsgrades von der Firma Applichem (Darmstadt) bezogen. Daneben fanden folgende Chemikalien Verwendung:

Braun, Melsungen

Aqua ad iniectabilia (Ampuwa)

Merck, Darmstadt

Calciumchlorid-Dihydrat

Natriumacetat-Trihydrat

Amersham Biosciences, Freiburq

DEAE-Dextran (MW: $500000 \mathrm{~g} / \mathrm{mol}$ )

Desoxynukleotide (dATP, dCTP, dGTP, dTTP)

Ficoll-400

Serva, Heidelberg

Acrylamid

N,N-Methylenbisacrylamid

Sigma, München

$\begin{array}{lll}\text { APS } & \text { Ethidiumbromid } & \text { Triton X-100 } \\ \text { ATP } & \text { Glutathion } & \text { Tween } 20 \\ \text { BSA } & \text { IPTG } & \text { Xylen Cyanol FF } \\ \text { Bromphenolblau } & \text { Luciferin } & \\ \text { DMSO } & \text { TEMED } & \end{array}$




\section{$2.2 \quad$ Radiochemikalien}

$\left[\alpha-{ }^{32} \mathrm{P}\right]-d C T P$ (spezifische Aktivitat: $3000 \mathrm{Ci} / \mathrm{mmol}$ ) und $\left[{ }^{35} \mathrm{~S}\right]-$ Methionin (spezifische Aktivität: $1200 \mathrm{Ci} / \mathrm{mmol}$ ) wurden von der Firma Amersham Pharmacia Biotech (Braunschweig) bezogen.

\section{$2.3 \quad$ Enzyme und Kits}

\subsubsection{Restriktionsendonukleasen}

Die verwendeten Restriktionsendonukleasen wurden von der Firma Fermentas (St. Leon-Rot) bezogen. Es wurden die jeweils empfohlenen Restriktionspuffer verwendet.

$\begin{array}{ll}\text { Enzym } & \text { Erkennungssequenz } \\ \text { BamHI } & \text { G'GATCC } \\ \text { Bglll } & \text { A'GATCT } \\ \text { EcoRI } & \text { G'AATTC } \\ \text { HindIII } & \text { A'AGCTT } \\ \text { Xbal } & \text { T'CTAGA } \\ \text { Xhol } & \text { C'TCGAG } \\ \text { Scal } & \text { AGT'ACT }\end{array}$

\subsubsection{DNA-/RNA-modifizierende Enzyme}

Klenow-Fragment der DNA-Polymerase I

Pfu DNA Polymerase

RNase A (aus Rinderpankreas)

T4-DNA Ligase

Taq DNA Polymerase
Pharmacia (München)

Fermentas (St. Leon-Rot)

Roche Diagnostics (Mannheim)

Fermentas (St. Leon-Rot)

Promega (Mannheim) 


\subsubsection{Sonstige Enzyme}

Lysozym (aus Hühnereiweiß)

Sigma (München)

Trypsin/EDTA-Lösung (aus Rinderpankreas)

GIBCO BRL (Karlsruhe)

\subsection{Antibiotika und Protease-Inhibitoren}

Ampicillin

Chloramphenicol

Penicillin-Streptomycin-Lösung

(10000 U/ml-10000 $\mu \mathrm{g} / \mathrm{ml})$

PMSF
Roche Diagnostics (Mannheim)

Sigma (München)

GIBCO BRL (Karlsruhe)

Roche Diagnostics (Mannheim)

\subsection{Nachweis und Reinigungssysteme}

Bio-Rad Protein Assay

Easy Pure DNA Purification Kit

JETstar, Plasmid-Purification System

Mini Quick Spin Oligo Columns

Poly-Prep Chromatography Columns

Quick change site directed mutagenesis kit

Thermo Sequenase Fluorescent Labelled

Primer Cycle Sequencing Kit

TNT Coupled Reticulocyte Lysate System
Bio-Rad (München)

Biozym Diagnostik (Hess.

Oldendorf)

Genomed (Löhne)

Pharmacia (München)

Bio-Rad (München)

Stratagene (Heidelberg)

Amersham (Braunschweig)

Promega (Mannheim)

\section{$2.6 \quad$ Filtermaterial}

Das Blotting-Papier der Firma Schleicher \& Schuell (Dassel) wurde zum Trocknen von SDSund nicht-denaturierenden Polyacrylamid-Gelen verwendet. 


\subsection{Materialien zur Anzucht von Bakterien}

Die verwendeten Substanzen für Nährmedien wurden von der Firma GIBCO BRL (Karlsruhe) und Sigma (München) bezogen:

Select-Agar

Select-Peptone

Select-Yeast Extract

NZY Amin
GIBCO BRL (Karlsruhe) GIBCO BRL (Karlsruhe) GIBCO BRL (Karlsruhe)

Sigma (München)

Die Firma Greiner (Frickenhausen) lieferte die Petrikulturschalen (Durchmesser $10 \mathrm{~cm}$ ), in denen die Anzucht der Plattenkulturen erfolgte.

\subsection{Material zur Kultivierung eukaryotischer Zelllinien}

Die Zellkulturmedien DMEM und RPMI 1640 wurden von GIBCO BRL (Karlsruhe) bezogen. Dies gilt auch für das verwendete fötale Kälberserum (auf Mykoplasmen getestet) und das Pferdeserum (auf Mykoplasmen getestet). Die Kultivierung der Zellen erfolgte auf Falcon-Zellkulturschalen unterschiedlichen Durchmessers $(6 / 10 / 15 \mathrm{~cm})$, die von der Firma Becton Dickinson (U. K.) vertrieben werden.

\section{$2.9 \quad$ Puffer und Nährmedien}

Die Lösungen für den Routinegebrauch wurden nach Sambrook et al. (1989) angesetzt. Wenn nicht anders angegeben, wurden die Lösungen mit deionisiertem und destilliertem Wasser hergestellt und bei Raumtemperatur aufbewahrt.

\section{LB-Medium}

$\begin{array}{lll}\text { Select-Peptone } & 1 & \%(w / v) \\ \text { Select-Yeast Extract } & 0,5 & \%(w / v) \\ \mathrm{NaCl} & 1 & \%(w / v)\end{array}$

Das Medium wurde sofort nach dem Ansetzen autoklaviert. 
Herstellung von Agarplatten:

$\mathrm{Zu}$ dem LB-Medium wurden $15 \%$ (w/v) Select-Agar hinzugegeben und zur Isolierung ampicillinresistenter Bakterienklone $50 \mu \mathrm{g}$ Ampicillin/ml (Endkonzentration) hinzugefügt

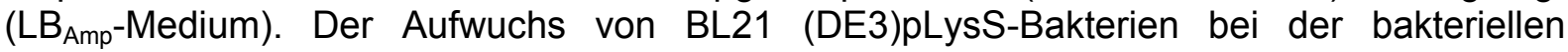
Expression von Proteinen (2.19.1) erfolgte unter Zusatz von $50 \mu \mathrm{\mu g}$ Ampicillin/ml (Endkonzentration) und $34 \mu \mathrm{g}$ Chloramphenicol/ml (Endkonzentration) (LB Amp, CA-Medium).

\section{NZY-broth}

NZ Amin

$$
\begin{array}{ll}
1 & \%(w / v) \\
0,5 & \%(w / v) \\
0,5 & \%(w / v)
\end{array}
$$

Select-Yeast Extract

$\mathrm{NaCl}$

Das Medium wurde sofort nach dem Ansetzen autoklaviert.

\section{$1 \times$ PBS}

$\begin{array}{lll}\mathrm{NaCl} & 140 & \mathrm{mM} \\ \mathrm{KCl} & 2,5 & \mathrm{mM} \\ \mathrm{Na}_{2} \mathrm{HPO}_{4} & 8,1 & \mathrm{mM} \\ \mathrm{KH}_{2} \mathrm{PO}_{4} & 1,5 & \mathrm{mM}\end{array}$

Der $\mathrm{pH}-$ Wert wurde mit $\mathrm{NaOH}$ auf 7,4 eingestellt.

\section{RNase A-Lösung}

RNase A

TRIS, $\mathrm{pH} 8,0$

$$
\begin{array}{ll}
0,1 & \mathrm{mg} / \mathrm{ml} \\
5 & \mathrm{mM}
\end{array}
$$

Zur Inaktivierung von DNase-Aktivität wurde die Lösung für 15 min auf $90{ }^{\circ} \mathrm{C}$ erhitzt, aliquotiert und bei $-20^{\circ} \mathrm{C}$ gelagert.

\section{$\underline{6 \times \text { Stopp-Mix (EMSA) }}$}

$\begin{array}{lll}\text { Glycerin } & 30 & \%(\mathrm{v} / \mathrm{v}) \\ \text { Bromphenol Blau } & 0,25 & \%(\mathrm{w} / \mathrm{v}) \\ \text { Xylen Cyanol FF } & 0,25 & \%(\mathrm{w} / \mathrm{v})\end{array}$

$\underline{6 \times \text { Stopp-Mix (DNA-Gelelektrophorese) }}$

$\begin{array}{lll}\text { EDTA } & 0,4 & \mathrm{~g} \\ \text { Ficoll400 } & 15 & \mathrm{~g} \\ \text { Glycerin } & 10 & \mathrm{ml} \\ \text { Orange G } & 1 & \text { Spatelspitze }\end{array}$




\section{$5 \times$ TBE}

TRIS, pH 8,0

$450 \mathrm{mM}$

Borsäure

EDTA, pH 8,0

$450 \mathrm{mM}$

$10 \mathrm{mM}$

\section{$5 \times \mathrm{TAE}$}

Tris/Eisessig, $\mathrm{pH} \mathrm{8,0}$

$40 \mathrm{mM}$

0,5 M EDTA, pH 8,0

$1 \mathrm{mM}$

$\underline{T E}$

TRIS, $\mathrm{pH} 8,0$

$10 \mathrm{mM}$

EDTA, pH 8,0

$1 \mathrm{mM}$

Stammlösungen

Ampicillin

$50 \mathrm{mg} \mathrm{Amp} / \mathrm{ml} \mathrm{H}_{2} \mathrm{O}$

Chloramphenicol

$34 \mathrm{mg} \mathrm{CA} / \mathrm{ml}$ abs. Ethanol

Ethidiumbromid

$10 \mathrm{mg} \mathrm{EtBr} / \mathrm{ml} \mathrm{H}_{2} \mathrm{O}$

2.10 Medien für die Kultivierung eukaryotischer Zelllinien

DMEM-Medium

DMEM-Pulver

$13 \mathrm{~g}$

$\mathrm{NaHCO}_{3}$

$3,7 \quad 9$

$\mathrm{H}_{2} \mathrm{O}$

ad $1000 \mathrm{ml}$

$\underline{\text { RPMI-Medium }}$

$\begin{array}{lll}\text { RPMI 1640-Pulver } & 10 & \mathrm{~g} \\ \mathrm{NaHCO}_{3} & 2 & \mathrm{~g} \\ \mathrm{H}_{2} \mathrm{O} & \text { ad } 1000 \mathrm{ml}\end{array}$

Die angegebenen Mengen DMEM-Pulver bzw. RPMI 1640-Pulver wurden zunächst in $\mathrm{H}_{2} \mathrm{O}$ gelöst und sterilfiltriert. Der Zusatz der jeweiligen Seren und Antibiotika (s. u.) erfolgte anschließend unter Sterilbedingungen.

aTC2-Medium

Pferdeserum

$75 \mathrm{ml}$

Fötales Kälberserum

$12,5 \mathrm{ml}$

Penicillin-Streptomycin-Lösung

$5 \mathrm{ml}$

DMEM-Medium

ad $500 \mathrm{ml}$ 
JEG-3-Medium

Fötales Kälberserum $\quad 50 \quad \mathrm{ml}$

Penicillin-Streptomycin-Lösung $5 \quad \mathrm{ml}$

DMEM-Medium ad $500 \mathrm{ml}$

$\underline{\text { InR1G9-Medium }}$

$50 \mathrm{ml}$

Penicillin-Streptomycin-Lösung $5 \quad \mathrm{ml}$

RPMI-Medium ad $500 \mathrm{ml}$

\subsection{Art und Herkunft des biologischen und molekularbiologischen Materials}

\subsubsection{DNA}

\section{Synthetische Oligonukleotide}

Die Oligonukleotide wurden von der Firma MWG-Biotech (Ebersberg) oder QIAGEN (Hilden) bezogen. Tabelle 1 zeigt die Herkunft und Bezeichnung der verwendeten Oligonukleotide. Die DNA-Sequenzen der kodierenden Stränge sind in Tabelle 2 zusammengefaßt.

Bezeichnung der Einzelstränge

(kodierender und komplementärer

Bezeichnung des

Oligonukleotid-Strang)

Doppelstranges

Herkunft

$5-G 3+3-G 3$

G3

QIAGEN

GUK1 + GUK2

G3A

MWG

5-G3Bm + 3-G3Bm

G3Bm

QIAGEN

5-G3M1 + 3-G3M1

G3M1

QIAGEN

5-G3M2 + 3-G3M2

G3M2

QIAGEN

GEk110 + GEk111

G1

QIAGEN

Tab. 1: Herkunft und Bezeichnung der verwendeten Oligonukleotide. Die angegebenen komplementären Einzelstränge wurden zum jeweiligen Doppelstrang vereinigt (2.12.6). 


\begin{tabular}{|c|c|}
\hline Oligonukleotid & Sequenz des kodierenden Einzelstranges \\
\hline & 5 - \\
\hline G3 & GATCCTGAAGTAGTTTTTCACGCCTGACTGAGATTGAAGGGTGTAGA \\
\hline G3A & GATCCTCACGCCTGACTGAGCG \\
\hline G3Bm & GATCCTGAAGTAGTTTTTCACGCCTGACTGAGATTGAAGGGTGTAGA \\
\hline G3M1 & GATCCTGAAGTAGTTTTTCACGCCTGACTGAGATTAGCGGGTGTAGA \\
\hline G3M2 & GATCCTGAAGTAGTTTTTCACGCCTGACTGAGAACGCGCAGGCTCA音 \\
\hline G1 & GATCCACAAAACCCCATTATTTACAGATGAGAAATTTATATTGTCAGA \\
\hline
\end{tabular}

Tab. 2: Oligonukleotidsequenzen. Gezeigt sind die Sequenzen der kodierenden Stränge in 5'- nach 3'-Richtung. Die unterstrichenen Sequenzen stellen angefügte Linker dar, die einen 5'-Überhang ergeben.

Die Doppelstrang-Oligonukleotide wurden im Electrophoretic Mobility Shift Assay (EMSA, 2.20) verwendet.

\section{Primer zur Klonierung}

Die Tabellen 3, 4, 5 und 6 fassen die Primer, die in den PCR-Reaktionen zum Einsatz kamen zusammen. Neben der Primer-Bezeichnung sind sowohl die 5'- nach 3'- Sequenzen als auch die Literaturnachweise aufgeführt. Zur Klonierung der PCR-Produkte enthielten die Primer Nterminal eine Restriktionsschnittstelle (unterstrichene Sequenz) und eine GC-reiche Sequenz.

\begin{tabular}{|c|c|c|}
\hline Primer & Sequenz & Referenz \\
\hline Pax6fl-5 & $\begin{array}{c}\text { 5'-GAGTCGGATCCGGAGGCTGCCAACCAGCT-3' } \\
(\text { BamHI) }\end{array}$ & Sander et al., 1997 \\
\hline Pax6fl-3 & 5'-CGCCGCAAGCTTTTACTGTAATCGAGGCCA-3' & Sander et al., 1997 \\
\hline Pax6dHD-3 & 5'-CGCCGCTCGAGATTTCTTTGCAGCTTCCG-3' & Sander et al., 1997 \\
\hline Pax6dHD-5 & 5'-CGCGCCTCGAGAGGAACCAGAGAAGACAG-3' & Sander et al., 1997 \\
\hline Pax6dH3-3 & 5'-GCGGCCTCGAGAGGTAGATCTATTTTGGC-3' & Sander et al., 1997 \\
\hline
\end{tabular}




\begin{tabular}{|c|c|c|}
\hline Pax6dPD-3 & 5'-GATTCCTCGAGCGGCAGTGGCCGCCCGTT-3' & Sander et al., 1997 \\
\hline Pax6dPD-5 & 5'-GATTCCTCGAGATGGGCGCAGACGGCATG-3' & Sander et al., 1997 \\
\hline Pax6E6-5 & 5'-CGCGCCTCGAGGTATCCAACGGTTGTGTG-3' & Sander et al., 1997 \\
\hline $\begin{array}{l}\text { Pax6E6-3- } \\
\text { Xba }\end{array}$ & 5'-GCGGCTCTAGAACTGGGTATGTTATCGTT-3' & Sander et al., 1997 \\
\hline $\begin{array}{l}\text { Pax6E6-5- } \\
\text { Xba }\end{array}$ & 5'-GATATTCTAGAATGGGCGCAGACGGCATG-3' & Sander et al., 1997 \\
\hline 5'Gal4-Pax6 & 5'-GAGTCGGATCCGGCTGCCAACCAGCTCCAGC-3' & Sander et al., 1997 \\
\hline 3'Gal4-Pax6 & 5'-GAGCGGGATCCCTCTTTACTGTAATCGAGG-3' & Sander et al., 1997 \\
\hline 5'-pGEX & 5'-GAGTCGGATCCATGCAGAACAGTCAC-3' & Sander et al., 1997 \\
\hline 3'-pGEX & 5'-GAGCGGGATCCTTACTGTAATCGAGG-3' & Sander et al., 1997 \\
\hline-350 up & $\begin{array}{l}\text { 5'-CGTACTCGAGATGGCCAAATAGCACATCAA } \\
\text { GG-3' } \quad(\text { Xhol })\end{array}$ & Nian et al., 1999 \\
\hline-350 down & 5'-GTAGAAGATCTCAGGTGGAGCTCCTTTGG-3' & Nian et al., 1999 \\
\hline
\end{tabular}

(Fortsetzung der Tabelle von der vorherigen Seite)

Tab. 3: Primer zur Klonierung. Übersicht über die Sequenzen der verwendeten Primer für die PCR (2.15.1) in 5'-nach 3'-Richtung. Die Referenzen verweisen auf Literatur, die die Sequenzen des Glukagon-Gens der Ratte und des Pax6-Gens der Maus beinhalten, nach denen die Primer entworfen wurden. 
Primer zur Mutagenese doppelsträngiger Plasmid-DNA

\begin{tabular}{lll}
\hline Primer & Sequenz & Referenz \\
\hline Pax6HDmCS & 5'-CCTGAAGCAAGAATACAGGCATGGTTTGCTGCTC & Sander et al., \\
& GAAGGCAAATGG-3' & 1997 \\
Pax6HDmNCS & 5'-CCATTTGGCCCTTCGAGCAGCAAACCATGCCTGT & Sander et al., \\
& ATTCTTGCTTCAG-3' & 1997 \\
CS-G1-M1 & 5'-GAACAAAACCCCATTATTTACAGATTAGAAATTTAT & Jin und Drucker, \\
& ATTGTCAGCGTAATATC-3' & 1995 \\
NCS-G1-M1 & 5'-GATATTACGCTGACAATATAAATTTCTAATCTGTAA & Jin und Drucker, \\
& ATAATGGGGTTTTGTTC-3' & 1995 \\
NCS-G3-M1 & 5'-GGAAATACACCCTTCAATCTCAGTCATAATTGAAA & Jin und Drucker, \\
& AACTACTTCAGCTCTCTGAAGTG-3' & 1995 \\
CS-G3-M1 & 5'-CACTTCAGAGAGCTGAAGTAGTTTTTCAATTATGA & Jin und Drucker, \\
& CTGAGATTGAAGGGTGTATTTCC-3' & 1995 \\
\hline
\end{tabular}

Tab. 4: Primer zur gerichteten Mutagenese. Übersicht über die Sequenzen der verwendeten Primer zur Mutagenese-PCR-Reaktion (2.15.2) in 5'-nach 3'-Richtung. Die Referenzen verweisen auf Literatur, die die Sequenzen des Glukagon-Gens der Ratte und des Pax6-Gens der Maus beinhaltet, nach denen die Primer entworfen wurden.

Sequenzierprimer

\begin{tabular}{ll}
\hline Primer & Sequenz \\
\hline M13 reverse & 5'-CAGGAAACAGCTATGAC-3' \\
CMV-Promotor & 5'-CAGAGCTGTTTAGTCAACC-3' \\
T7-Promotor & 5'-TAATACGACTCACTATAGGG-3' \\
LucP-Flu & 5'-CCATTTTACCAACAGTACCG-3' \\
\hline
\end{tabular}

Tab. 5: 5'-markierte Primer zur Sequenzierung. Übersicht über die Sequenzen der verwendeten Primer für die Sequenzierung. Die Primer waren jeweils am 5'-Ende mit dem Fluoreszenz-Farbstoff IRD800 (MWG-Biotech, Ebersberg) markiert. Sie wurden in die Sequenzierungsreaktion mit dem Sequenzierautomaten Li-Cor 4200 (2.18) eingesetzt. 


\begin{tabular}{ll}
\hline Primer & Sequenzen \\
\hline 5'-Gal4-sequ & 5'-GAATAAGTGCGACATCATCAT-3' \\
3'-Gal4-sequ & 5'-TTCAGGGGGAGGTGTGGGAG-3' \\
5'-pGEX-seq & 5'-GGGCTGGCAAGCCACGTTTGGTG-3' \\
3'-pGEX-seq & 5'-CCGGGAGCTGCATGTGTCAGAGG-3' \\
CMV-Promotor & 5'-CAGAGCTGTTTAGTCAACC-3' \\
pcDNAr & 5'-AGGCACAGTCGAGGCTGATC-3' \\
\hline
\end{tabular}

Tab. 6: Sequenzierprimer. Übersicht über die Sequenzen der verwendeten Primer für die Sequenzierung mit dem Sequenziergerät ABI PRISM (2.18).

\section{Reportergen-Plasmide}

Für funktionelle Untersuchungen in Tumorzellinien wurde das Reportergen-Plasmid -1300GluLuc hergestellt. Im -1300GluLuc Reportergen-Plasmid steht das Luciferase-Gen unter der Kontrolle des 5'-flankierenden Bereichs von Basenpaar -1254 bis +68 des Proglukagon-Promotors der Ratte. Ausgangsmaterial zur Herstellung von -1300GluLuc war der Luciferase-Vektor pSK-Luc (Jin und Drucker, 1995), der 2,3 kb (Basenpaar -2292 bis +68) des Proglukagon-Promotors der Ratte enthält. Durch Restriktionsverdau mit Xhol und Kpnl wurde ein DNA-Fragment isoliert, das den Promotor-Bereich -1254 bis +68 umfaßte. Dieses Fragment wurde in die Kpnl/Xhol-Schnittstelle des Luciferase-Reportervektors pXP2 (Nordeen, 1988) kloniert (2.17).

Ausgehend von dem Reportergen-Plasmid -1300GluLuc wurden die Plasmide -1300 (G1m)GluLuc, -1300(G3Am)GluLuc und -1300(G1m/G3Am)GluLuc hergestellt. Mit Hilfe des "Quick Change Site Directed Mutagenesis Kit" (Stratagene, Heidelberg) ist im Reportergen-Plasmid -1300(G1m)GluLuc ein Basenpaar mutiert worden (Position -79, $\mathrm{G} \rightarrow \mathrm{T}$ ), in -1300(G3Am)GluLuc vier Basenpaare (Position -259/-256, CGCC $\rightarrow$ ATTA) und in $-1300($ G1m/G3Am)GluLuc insgesamt fünf Basenpaare (Position -79 und -259/-256, G $\rightarrow$ T und CGCC $\rightarrow$ ATTA). In einer PCR-Reaktion mit dem Temperaturprofil $95{ }^{\circ} \mathrm{C} / 30 \mathrm{sec} ; 16$ Zyklen $95{ }^{\circ} \mathrm{C} / 30 \mathrm{sec}, 55^{\circ} \mathrm{C} / 1 \mathrm{~min} ; 68^{\circ} \mathrm{C} / 2 \mathrm{~min}$ (2.15.2, Tab. 4) wurde jeweils das gesamte Plasmid amplifiziert und die gewünschten Mutationen eingeführt. Zur Herstellung von -1300(G1m)GluLuc diente das Plasmid -1300GluLuc als Matrize für das Primerpaar CS-G1M1 und NCS-G1-M1 (Tab. 4); zur Herstellung von -1300(G3Am)GluLuc diente -1300GluLuc als Matrize für das Primerpaar CS-G3-M1 und NCS-G3-M1 (Tab. 4). Zur Herstellung von $-1300($ G1m/G3Am)GluLuc wurde -1300(G3Am)GluLuc als Matrize für das Primerpaar CSG1-M1 und NCS-G1-M1 (Tab. 4) verwendet. Das PCR-Produkt wurde mit der 
Restriktionsendonuklease Dpnl verdaut (2.15.2) und in kompetente XL1 Blue-Zellen transformiert (2.17.2).

Um die Reportergen-Plasmide -350(G1m)GluLuc, -350(G3Am)GluLuc und -350(G1m/G3m)GluLuc herzustellen wurden die Reportergen-Plasmide -1300(G1m)GluLuc, -1300(G3Am)GluLuc und $-1300(\mathrm{G} 1 \mathrm{~m} / \mathrm{G} 3 \mathrm{Am})$ GluLuc am 5'-Ende mittels PCR (2.15.1) mit dem Temperaturprofil $94{ }^{\circ} \mathrm{C} / 3 \mathrm{~min} ; 30$ Zyklen $94{ }^{\circ} \mathrm{C} / 45 \mathrm{sec}, 65{ }^{\circ} \mathrm{C} / 45 \mathrm{sec}, 65{ }^{\circ} \mathrm{C} / 45 \mathrm{sec}$; $72{ }^{\circ} \mathrm{C} / 10$ min, verkürzt. Sie dienten als Matrize für das Primerpaar -350 up und -350 down (Tab. 3). Die PCR-Produkte waren 408 bp groß und umfaßten den Bereich -350 bis +58 des Glukagon-Genpromotors der Ratte. Die Fragmente wurden aus einem DNA-Agarosegel (2.13.1) isoliert (2.13.2), mit den Restriktionsendonukleasen Bg/ll und Xhol geschnitten (2.16.1) und in den Bg/ll/Xhol-geschnittenen pT81-Luciferase-Reportervektor (Nordeen, 1988) kloniert (2.16.2).

\begin{tabular}{|c|c|}
\hline Bezeichnung des Plasmids & Herkunft/Referenz \\
\hline pT81Luc & Nordeen, 1988 \\
\hline 4xG3T81Luc & Diedrich et al., 1997 \\
\hline 4xG3AT81Luc & Wrege et al., 1995 \\
\hline 4xG3BT81LuC & Diedrich, 1996 \\
\hline 4xG3M1T81Luc & Herzig, 1999 \\
\hline 4xG3M2T81Luc & Herzig, 1999 \\
\hline-350 GluLuc & Schwaninger et al., 1993 \\
\hline$-350(G 3 B m)$ GluLuc & Herzig, 1999 \\
\hline-350 (mutG3)GluLuc & Grzeskowiak et al., 2000 \\
\hline-350 (mutG1/G3)GluLuc & Grzeskowiak et al., 2000 \\
\hline$-350($ G1m)GluLuc & Teichler, vorliegende Arbeit \\
\hline -350(G3Am)GluLuc & Teichler, vorliegende Arbeit \\
\hline$-350($ G1/G3Am)GluLuc & Teichler, vorliegende Arbeit \\
\hline$-1300($ G1m)GluLuc & Teichler, vorliegende Arbeit \\
\hline$-1300($ G3Am)GluLuc & Teichler, vorliegende Arbeit \\
\hline$-1300($ G1/G3Am)GluLuc & Teichler, vorliegende Arbeit \\
\hline pGFPtpz-cmv [R] control vector & Canberra-Packard (Dreieich) \\
\hline -292GluLuc & Fürstenau et al., 1997 \\
\hline-238 GluLuc & Fürstenau et al., 1997 \\
\hline -200GluLuc & Fürstenau et al., 1997 \\
\hline -169GluLuc & Fürstenau et al., 1997 \\
\hline-60 GluLuc & Fürstenau et al., 1997 \\
\hline$-350 /-210$ GluLuc & Fürstenau et al., 1997 \\
\hline
\end{tabular}




\begin{tabular}{ll}
\hline$-350 /-150$ GluLuc & Fürstenau et al., 1997 \\
$-350 /-91$ GluLuc & Fürstenau et al., 1997 \\
-350/-49GluLuc & Fürstenau et al., 1997
\end{tabular}

(Fortsetzung der Tabelle von der vorherigen Seite)

Tab. 7: Reportergen-Plasmide. Die Tabelle faßt die Bezeichnungen und die Literaturnachweise der verwendeten Reportergen-Plasmide zusammen.

\section{Expressionsplasmide}

Die Identität bereits in der Arbeitsgruppe vorhandener Expressionsplasmide wurde vor dem Einsatz in transiente Transfektionen oder bakterielle Expression im Restriktionsverdau (2.16.1) sowie durch Sequenzierung (2.18) überprüft. Die Tabelle 8 faßt die verwendeten Expressionsplasmide und deren Herkunft bzw. Referenz zusammen. Zur Herstellung von Expressionsplasmiden zur Expression in Säugetier-Zellinien wurde der eukaryotische Expressionsvektor pBAT14 (3896 bp) verwendet, dessen Expression über einen CMVPromotor gesteuert wird und der ein Ampicillinresistenzgen trägt. Es wurden die Expressionsplasmide pBAT-dHD, -dH3, -3Ala, -dPD und -dPD/E6 generiert. Der Ausgangsvektor für die Herstellung dieser Expressionsplasmide war das Plasmid pBAT14.mPax6 (pBAT-Pax6-WT) (German, San Francisco; 5208 bp), das die Pax6-cDNA außer Exon 5 a der Maus enthält.

Das Plasmid pBAT-Pax6-WT enthält die cDNA des Pax6-Wildtyps der Maus (1266 bp, 422 AS). In dem Expressionsplasmid pBAT-dHD wurden die Basenpaare 640 bis 813 der PaxcDNA deletiert und durch die Restriktionsschnittstelle Xhol ersetzt. Diese Sequenz kodiert die Pax6-Homöodomäne von AS 214 bis AS 271 bis auf vier Aminosäuren des Aminoterminus der Homöodomäne. Die vier Aminosäuren Lysin, Leucin, Glutamin und Arginin gehören zu dem Kernerkennungssignal-Motiv HNLS (Leucin, Lysin, Arginin, Lysin, Leucin, Glutamin, Arginin) von Pax6. Im Expressionsvektor pBAT-dH3 wurde Helix 3 der Homöodomäne, Basenpaare 751 bis 813 (AS 251 bis 271), deletiert und durch die Restriktionsschnittstelle Xhol ersetzt. pBAT-dPD umfaßt die Pax6-cDNA außer der Sequenz zwischen Helix 1 bis 6 der Paired-Domäne, was den Basenpaaren 67 bis 408 (AS 23 bis 136) von Pax6 entspricht. In PBAT-dPD/E6 wurden die Basenpaare 67 bis 141 (AS 23 bis 47), Helix 1 bis Ende Exon 5 der Paired-Domäne deletiert und durch die Restriktionsschnittstelle Xhol ersetzt. Weiter wurden die Basenpaare 352 bis 408 (AS 118 bis 136) deletiert und durch die Restriktionsschnittstelle Xbal ersetzt. Exon 6 blieb erhalten, da es ein weiteres Kernerkennungssignal-Motiv von Pax6 enthält. Im Expressionsplasmid, das Pax6-3Ala kodiert, wurden innerhalb der Pax6-Homöodomäne drei Basenpaare mutiert, um die für die DNA-Erkennung notwendigen Aminosäuren Valin-47, Serin-50, Asparagin-51 zu Alanin zu mutieren (QuickChange Site directed mutagenesis Kit, Stratagene). 
Die Expressionsplasmide wurden mittels PCR (2.15.1) hergestellt. Unter Verwendung der folgenden Primerpaare (Tab. 3) wurden pro Pax6-Mutante pBAT-dHD, -dH3 und -dPD je zwei PCR-Produkte erzeugt:
dHD:
1. Pax6fl-5/Pax6dHD-3
2. Pax6dHD-5/Pax6fl-3
dH3:
3. Pax6fl-5/Pax6dH3-3
4. Pax6-dH3-5/Pax6fl-3
dPD:
5. Pax6fl-5/Pax6dPD-3
6. Pax6dPD-5/Pax6fl-3

Die Annealing-Temperatur war $65{ }^{\circ} \mathrm{C}$, das Temperaturprofil der PCR (2.15.1) war $94{ }^{\circ} \mathrm{C} / 3$ min; 30 Zyklen $94{ }^{\circ} \mathrm{C} / 45 \mathrm{sec}, 65^{\circ} \mathrm{C} / 45 \mathrm{sec}, 65^{\circ} \mathrm{C} / 45 \mathrm{sec} ; 72{ }^{\circ} \mathrm{C} / 10 \mathrm{~min}$.

Die jeweiligen PCR-Produkte (dHD: 674 bp/468 bp, dH3: 785 bp/471 bp, dPD: 101 bp/ 873 bp) wurden aus einem DNA-Agarosegel aufgereinigt (2.13.2), mit dem Restriktionsenzym Xhol verdaut und die PCR-Fragmente 1 und 2, 3 und 4, 5 und 6 miteinander ligiert (2.16.2). Um zur Ligation mit pBAT14 ausreichende Mengen zu erzeugen, wurde der Ligationsansatz als Matrize für eine PCR mit dem Primerpaar Pax6fl-5/Pax6fl-3 verwendet, so dass die miteinander ligierten PCR-Produkte amplifiziert wurden. Die PCRProdukte wurden aus einem DNA-Agarosegel (2.13.1) isoliert (2.13.2), mit den Restriktionsendonukleasen BamHI und HindIII verdaut (2.16.1) und mit dem mit Bg/ll und HindIII geschnittenen Plasmid pBAT14 ligiert (2.16.2).

Um das Expressionsplasmid pBAT-dPD/E6 herzustellen wurden zwei PCR-Reaktionen mit insgesamt vier Primerpaaren (Tab. 3) durchgeführt.

dPD/E6: $\quad$ 7. Pax6fl-5/Pax6E6-3-Xba

8. Pax6E6-5-Xba/Pax6fl-3

9. Pax6fl-5/Pax6E6-3

10. Pax6E6-5/Pax6fl-3

Als Matrize für die PCR-Primerpaare 7. und 8. diente pBAT14-m.Pax6. Die beiden PCRFragmente (98 bp/1140 bp) wurden aus einem DNA-Agarosgel isoliert (2.13.2), mit der Restriktionsendonuklease Xbal verdaut (2.16.1) und miteinander ligiert (2.16.2). Die miteinander ligierten PCR-Produkte wurden als Matrize in einer zweiten PCR mit dem Primerpaar 9. und 10. eingesetzt. Die PCR-Produkte (323 bp/873 bp) wurden aus einem DNA-Agarosegel aufgereinigt (2.13.2), mit der Restriktionsendonuklease Xhol verdaut (2.16.1) und miteinander ligiert (2.16.2). Um zur Ligation mit pBAT14 ausreichende Mengen zu erzeugen, wurde der Ligationsansatz als Matrize für eine PCR mit dem Primerpaar Pax6fl-5/Pax6fl-3 verwendet, so dass die miteinander ligierten PCR-Produkte amplifiziert wurden. Das PCR-Produkt wurde aus einem Agarosegel isoliert (2.13.2), mit BamHI und HindlII verdaut (2.16.1) und mit dem mit Bg/ll und Hindlll geschnittenen Plasmid pBAT14 ligiert (2.16.2). 
In pBAT-3Ala wurden drei Basenpaare innerhalb der Helix 3 der Pax6-Homöodomäne verändert, um drei Aminosäuren zu Alanin zu mutieren. Diese gerichtete Änderung der Nukleotidsequenz an einem bestimmten Ort von doppelsträngiger Plasmid-DNA wurde mit dem "Quick change site directed mutagenesis kit" (Stratagene, Heidelberg) durchgeführt (2.15.2). Als Matrize für das PCR-Primerpaar HD-mut-CS/HD-mut-NCS (Tab. 4) mit den gewünschten Mutationen diente pBAT14-m.Pax6 (Pax6-WT). Die Mutagenese erfolgte mittels PCR (2.15.2) im TRIO-Thermoblock (Biometra $\mathrm{GmbH}$, Göttingen) nach folgendem Temperaturprofil: $95{ }^{\circ} \mathrm{C} / 30 \mathrm{sec} ; 16$ Zyklen $95^{\circ} \mathrm{C} / 30 \mathrm{sec}, 55^{\circ} \mathrm{C} / 1 \mathrm{~min} ; 68^{\circ} \mathrm{C} / 2 \mathrm{~min}$. Das PCRProdukt wurde mit $D p n l$ verdaut (2.15.2) und in kompetente E. coli XL-1 Blue-Zellen transformiert (2.17.2).

Das Plasmid pSG424 (3396 bp) ist ein eukaryotischer Expressionsvektor, der 147 Aminosäuren (AS 1-147) der DNA-Bindungsdomäne des Hefetranskriptionsfaktors GAL4 kodiert. Die Expressionsplasmide pSG-Pax6-WT und pSG-dHD wurden ausgehend von den entsprechenden pBAT14-Expressionsplasmiden mittels PCR hergestellt. Sie kodieren für GAL4-Pax6-Fusionsproteine, in denen Pax6-WT bzw. Pax6-dHD aminoterminal mit der heterologen GAL4-Domäne fusioniert sind. Die Expression in Säugetier-Zelllinien erfolgt über einen SV40-Promotor. Außerdem trägt pSG424 ein Ampicillinresistenzgen. Für die Klonierung der mutierten bzw. unveränderten Pax6-cDNA diente pBAT-Pax6-WT und -dHD, als Matrize für das PCR-Primerpaar 5'-Gal4-Pax6/3'-Gal4-Pax6 (Tab. 3). Die PCRReaktionen (2.15.1) wurden im Biometra TRIO-Thermoblock (Biometra $\mathrm{GmbH}$, Göttingen) nach dem folgenden PCR-Temperaturprofil durchgeführt: $94{ }^{\circ} \mathrm{C} / 3 \mathrm{~min} ; 30$ Zyklen $94{ }^{\circ} \mathrm{C} / 45$ sec, $65{ }^{\circ} \mathrm{C} / 45 \mathrm{sec} ; 72{ }^{\circ} \mathrm{C} / 10 \mathrm{~min}$. Die PCR-Produkte (WT: $1301 \mathrm{bp}, \mathrm{dHD}: 1139 \mathrm{bp}$ ) wurden aus einem DNA-Agarosegel isoliert (2.13.2), mit der Restriktionsendonuklease BamHI verdaut (2.16.1) und mit dem BamHI geschnittenen (2.16.1), dephosphorylierten (2.16.3) pSG424-Vektor ligiert (2.16.2).

Zur Herstellung der Proteine Pax6-WT, -dHD, -dH3 und -3Ala wurde das „TnT Reticulocyte Lysate System“ (Promega, Mannheim) verwendet (2.19.2). Da in diesem System die T7oder SP6-Polymerase verwendet wird, muß die zu transkribierende cDNA in einen Vektor kloniert werden, in dem entweder ein T7- oder SP6-Promotor vor der multiplen Klonierungsstelle liegt. Der Vektor pcDNA3 (5,4 kb, Promega, Mannheim) enthält neben einem prokaryotischen T7- und SP6-Promotor einen eukaryotischen CMV-Promotor und ein Ampicillin-Resistenzgen.

Ausgehend von den Expressionsplasmiden pBAT-Pax6-WT, -dHD, -dH3 und 3Ala wurde eine PCR-Reaktion (2.15.1) mit dem Primerpaar 5'-pGEX und 3'-pGEX (Tab. 3) unter Verwendung der Pfu Polymerase (Fermentas, St. Leon-Rot) durchgeführt. Die PCR erfolgte in einem TRIO-Thermoblock (Biometra, Göttingen) mit folgendem Temperaturprofil: $95{ }^{\circ} \mathrm{C} /$ 
$2 \mathrm{~min} ; 80{ }^{\circ} \mathrm{C} / 3 \mathrm{~min} ; 5{ }^{\circ} \mathrm{C} / 1 \mathrm{~min} ; 72{ }^{\circ} \mathrm{C} / 1 \mathrm{~min} ; 25$ Zyklen $94{ }^{\circ} \mathrm{C} / 1 \mathrm{~min}, 61{ }^{\circ} \mathrm{C} / 1 \mathrm{~min}, 72{ }^{\circ} \mathrm{C} /$ $1 \mathrm{~min} ; 72{ }^{\circ} \mathrm{C} / 10 \mathrm{~min}$. Die PCR-Produkte wurden nach gelelektrophoretischer Auftrennung (2.13.1) aus dem Gel isoliert (2.13.2), mit der Restriktionsendonuklease BamHI geschnitten (2.16.1) und mit dem mit BamHl-geschnittenen, dephosphorylierten (2.16.1 und 2.16.3) Vektor pcDNA3 ligiert (2.16.2).

\begin{tabular}{lll}
\hline Plasmid & Herkunft & Referenz \\
\hline pBAT14.mPax6/pBAT-WT & German (San Francisco) & Sander et al., 1997 \\
pBAT-dHD & Teichler, vorliegende Arbeit & \\
pBAT-dH3 & Teichler, vorliegende Arbeit & \\
pBAT-3Ala & Teichler, vorliegende Arbeit & \\
pBAT-dPD & Teichler, vorliegende Arbeit \\
pBAT-dPD/E6 & Teichler, vorliegende Arbeit \\
pSG-Pax6-WT & Teichler, vorliegende Arbeit \\
pSG-dHD & Teichler, vorliegende Arbeit \\
pGEX-2T/GST-Pax6-PD & Maas (Boston) \\
pcDNA-Pax6-WT & Teichler, vorliegende Arbeit & Epstein et al., 1994 \\
pcDNA-dHD & Teichler, vorliegende Arbeit & \\
pcDNA-dH3 & Teichler, vorliegende Arbeit & \\
pcDNA-3Ala & Teichler, vorliegende Arbeit & \\
pBluescript (pBS) & Stratagene, Heidelberg & \\
\hline
\end{tabular}

Tab. 8: Expressionsplasmide

\subsubsection{Molekulargewichtstandards}

DNA-Längenstandards

Als DNA-Längenstandard wurde $\lambda$-DNA (Fermentas, St. Leon-Rot) verwendet, welche mit den Restriktionsendonukleasen EcoR1 und Hindlll in Fragmente bekannter Größe geschnitten worden war: 21226/5148/4973/4268/3530/2027/1904/1584/1375/947/831/564 bp. Alternativ wurde der „GeneRuler 1kb-Marker“ eingesetzt (Fermentas, St. Leon-Rot), der aus DNA-Fragmenten der folgenden Länge bestand:

10000/8000/5000/4000/3500/3000/2500/2000/1500/1000/750/500/250 bp. 


\section{Protein-Molekulargewichtstandards}

Für SDS-Polyacrylamidgele wurde als Protein-Molekulargewichtstandard der „Prestained 7B Marker“ (Sigma, München) verwendet. Die enthaltenen Markerproteine zeigt die Tabelle 9.

apparente Molekularmasse (kDa)

Protein

a2-Makroglobulin 172.5

$\beta$-Galaktosidase

Fruktose-6-Phosphat-Kinase 86

Pyruvatkinase 62,5

Fumarase 53

Lactat-Dehydrogenase

Triosephosphat-Isomerase

Tab. 9: Molekularmassen der Standardproteine

\subsubsection{Bakterienstämme}

Die E. coli-Stämme DH5a (Abkömmling des Sicherheitsstammes K12) (Sambrook et al., 1989) und XL-1 Blue (JM 109 Derivat, Stratagene) wurden für die Amplifikation von Plasmiden verwendet und sind ampicillinsensitiv. Der E. coli-Stamm XL1-Blue wurde aus dem „QuickChange Site-Directed Mutagenesis Kit“ der Firma Stratagene entnommen.

Der E. coli-Stamm BL21(DE3)pLysS (Abkömmling des B-Stammes) wurde von der Firma Novagen (USA) bezogen. Er diente zur Expression der GST-Pax6-Fusionsproteine. Dieser Bakterienstamm ist ampicillinsensibel und aufgrund des DE3 Plasmids chloramphenicolresistent. Das Plasmid pLysS enthält das T7-Lysozymgen, dessen Expression durch IPTG induzierbar ist und somit für einen schnelleren Bakterienaufschluß sorgt. Zudem zeichnet sich dieser E. coli-Stamm durch Proteasendefizienz aus.

\subsubsection{Eukaryotische Zelllinien}

Alle verwendeten Tumorzelllinien waren im Labor vorhanden. Es wurde die humane Chorionkarzinom-Zelllinie JEG-3 (Kohler und Bridson, 1971) und die pankreatischen Tumorzelllinien InR1G9 und $\alpha$ TC2 verwendet. Die pankreatische Goldhamsterlinie InR1G9 
imitiert den $\alpha$-Zell-Phänotyp und synthetisiert überwiegend Glukagon (Takaki et al., 1986). aTC2-Zellen entstammen dem $\alpha$-zellspezifischen Tumor einer transgenen Maus und produzieren ebenfalls Glukagon (Powers et al, 1990).

\section{$2.12 \quad$ Nukleinsäure-Standardmethoden}

\subsubsection{Sterilisation}

Alle hitzestabilen Geräte und Lösungen wurden vor Gebrauch zur Inaktivierung von Mikroorganismen, DNasen sowie Proteasen $20 \mathrm{~min}$ bei $120{ }^{\circ} \mathrm{C}$ und $105 \mathrm{~Pa}$ autoklaviert. Hitzelabile Substanzen (z. B. Antibiotika, SDS, PEG, Lysozym) wurden den sterilen Puffern oder Wasser direkt zugesetzt, bzw. mit Nitrocellulose-Filtern (Minisart $200 \mu \mathrm{m}$, Sartorius, Göttingen) sterilfiltriert.

\subsubsection{Phenol-Chloroform-Isoamylalkohol-Extraktion (Sambrook et al., 1989)}

Zur Entfernung von Proteinen aus Nukleinsäurepräparationen wurde die DNA-haltige Lösung mit dem gleichen Volumenanteil Phenol versetzt, kräftig geschüttelt und zur Phasentrennung der entstandenen Emulsion 1 min bei RT und 14000 UpM (Biofuge pico, Heraeus, Hamburg) zentrifugiert. Die obere, wässrige DNA-haltige Phase wurde abgenommen und mit 0,5 Volumenanteilen Phenol und 0,5 Volumenanteilen Chloroform/Isoamylalkohol (24:1 (v/v)) versetzt, kräftig geschüttelt und zentrifugiert (1 min, RT, 14000 UpM). Zur Entfernung von Phenolresten wurde die obere Phase mit einem Volumenanteil Chloroform/Isoamylalkohol (24:1 (v/v)) extrahiert. Nach erneuter Zentrifugation (1 min, RT, 14000 UpM) wurde die obere Phase in ein neues Eppendorfgefäß überführt und die DNA präzipitiert (2.12.3).

\subsubsection{Ethanol-Präzipitation}

Bei der Fällung mit Ethanol, die zur Überführung der Nukleinsäure in neue Puffer, zum Ankonzentrieren der Proben oder als Reinigungsschritt dient, werden Nukleinsäuren präzipitiert. Die Präzipitation von DNA erfolgte unter Zugabe von zwei Volumina eiskaltem absolutem Ethanols und 1/10 Volumenanteil (v/v) 3 M NaAc-Lösung ( $\mathrm{pH} 4,8$ ). Nach gründlicher Durchmischung wurde der Ansatz für 20 min bei $-20{ }^{\circ} \mathrm{C}$ gefällt und anschließend 15 min bei $4{ }^{\circ} \mathrm{C}$ und 14000 UpM (Biofuge pico, Heraeus, Hamburg) zentrifugiert. Zur Entfernung von Salzresten wurde das Pellet mit 70 \%-igem (v/v) Ethanol gewaschen und 
erneut zentrifugiert (5 min/RT/14000 UpM). Das Sediment wurde für 5 min luftgetrocknet und anschließend in dem gewünschten Volumen Wasser oder TE-Puffer (2.9) gelöst.

\subsubsection{Dialyse von DNA und Proteinen}

DNA-haltige Lösungen und Proteinlösungen wurden zur Überführung in einen neuen Puffer oder zur Abtrennung niedermolekularer, löslicher Substanzen in Dialyseschläuche (GIBCO BRL, Karlsruhe) überführt, die anschließend mit Klemmen (Schütt Labortechnik, Göttingen) abgedichtet wurden. Vor Gebrauch wurden die Schläuche mehrfach mit destilliertem Wasser gespült. Die Dialyse erfolgte über $20 \mathrm{~h}$ bei $4{ }^{\circ} \mathrm{C}$ gegen TE-Puffer (2.9) bzw. $3 \mathrm{~h}$ gegen Dignam-Puffer D (2.19.3) unter einmaligem Pufferwechsel.

2.12.5 Konzentrationsbestimmung von Nukleinsäure-Lösungen (Sambrook et al. 1989)

Die Konzentrationsbestimmung von Nukleinsäuren in wässrigen Lösungen wurde photometrisch (Shimadzu UV-160-Spektralphotometer, Duisburg) in Quarzküvetten (Ultrospec Cells, $500 \mu \mathrm{l}$, Pharmacia Biotech) durchgeführt. Dazu wurde die Absorption bei einer Wellenlänge von $260 \mathrm{~nm}\left(\mathrm{OD}_{260}\right)$ gemessen, wobei für die $\mathrm{OD}_{260}$ von 1,0 folgende Referenz-Konzentrationen zugrunde gelegt wurden:

$\begin{array}{ll}\text { Doppelstrang-DNA } & 50 \mu \mathrm{g} / \mathrm{ml} \\ \text { Einzelstrang-Oligonukleotid } & 20 \mu \mathrm{g} / \mathrm{ml} \\ \text { RNA } & 40 \mu \mathrm{g} / \mathrm{ml}\end{array}$

Neben der $\mathrm{OD}_{260}$ wurde zudem die Absorption bei einer Wellenlänge von $\mathrm{OD}_{280}$ bestimmt. Aus dem erhaltenen Absorptionswerten wurden die Konzentration der Nukleinsäure und ihre Reinheit abgeschätzt; die Bildung des Quotienten aus beiden Wellenlängen ließ eine Aussage über den Reinheitsgrad der Nukleinsäure-Lösung zu. Proteine besitzen ihr Absorptionsmaximum bei $280 \mathrm{~nm}$. Proteinfreie DNA-Lösungen sollten einen $\mathrm{OD}_{260}: \mathrm{OD}_{280}$ Quotienten von 1,8-2,0 besitzen. Eine Abschätzung der Nukleinsäure-Konzentration erfolgte auch mittels Agarose-Gelelektrophorese (2.13.1). Der visuelle Vergleich der Bandenintensität einer DNA-Bande mit definierter Größe und Konzentration mit der DNA-Probe erlaubte die Abschätzung der Konzentration. 
2.12.6 Herstellung von Doppelstrang-Oligonukleotiden („Annealing“)

Zur Herstellung radioaktiv markierter Oligonukleotid-Sonden wurden DoppelstrangOligonukleotide verwendet. In einem Reaktionsansatz wurden jeweils 100 pmol der komplementären Oligonukleotid-Einzelstränge (Tab. 1 und 2) mit $1 \mu$ l 0,5 M NaCl-Lösung (Endkonzentration: $10 \mathrm{mM}$ ) und mit destilliertem $\mathrm{H}_{2} \mathrm{O}$ auf ein Endvolumen von $50 \mu \mathrm{l}$ gebracht. Die Denaturierung der DNA erfolgte durch Inkubation für $1 \mathrm{~min}$ bei $80{ }^{\circ} \mathrm{C} \mathrm{im}$ Wasserbad. Durch langsames Abkühlen des Reaktionsansatzes auf RT kam es zur Hybridisierung der Einzelstränge zum Doppelstrang, was durch die Anwesenheit des $\mathrm{NaCl}$ erleichtert wurde.

2.12.7 Radioaktive Markierung von DNA durch die Klenow „Fill-in"-Reaktion (Sambrook et al., 1989)

Nach der Herstellung von Doppelstrang-Oligonukleotiden (2.12.6) ergeben die zusätzlich angefügten Restriktionsschnittstellen an die Sequenzen der komplementären Einzelstränge einen 5'-Überhang, welcher mindestens eine Guanin-Base enthält. Unter Anwesenheit von $\left[{ }^{32} \mathrm{P}\right]$-markiertem dCTP wurden diese Überhänge mit Hilfe des Klenow-Fragmentes der DNA Polymerase I aufgefüllt.

Ein $20 \mu \mathrm{l}$ Markierungsansatz, der auf Eis pipettiert wurde, enthielt folgende Komponenten:

$\begin{array}{lll}\text { ds-Oligonukleotid }(2 \mathrm{pmol} / \mu \mathrm{l}) & 1 & \mu \mathrm{l} \\ \text { dATP, dGTP, dTTP }(\text { je } 1 \mathrm{mM}) & 1 & \mu \mathrm{l} \\ \text { Klenow-Fragment }(1 \mathrm{U} / \mu \mathrm{l}) & 2 & \mu \mathrm{l} \\ 10 \times \text { Klenow-Puffer } & 2 & \mu \mathrm{l} \\ \mathrm{H}_{2} \mathrm{O} & 12 & \mu \mathrm{l} \\ \alpha\left[^{32} \mathrm{P}\right] \text {-dCTP }(10 \mu \mathrm{Ci} / \mu \mathrm{l}) & 2 & \mu \mathrm{l}\end{array}$

\section{$10 \times$ Klenow-Puffer}

Tris $0,5 \mathrm{M}$

$\mathrm{MgCl}_{2} \quad 0,1 \mathrm{M}$

Der $\mathrm{pH}-$ Wert wurde mit $\mathrm{HCl}$ auf 7,6 eingestellt.

Der Markierungsansatz wurde für $1 \mathrm{~h}$ bei RT inkubiert. Zur Entfernung überschüssiger, nicht eingebauter Desoxyribonukleotidtriphosphate wurde der Markierungsansatz nach Reaktionsende auf eine „G-25 mini Quick Spin Oligo-Säule“ (Roche Diagnostics, Mannheim) 
aufgetragen. Diese wurde gemäß Herstellerangaben vorbereitet durch vortexen (5 sec) und Entfernung des Äquilibrierungspuffers durch Zentrifugation (1 min, RT, 3300 UpM; Biofuge 15R Heraeus, Hamburg). Die Säule wurde in ein neues Eppendorf-Gefäß gestellt. Nach Überführung der radioaktiv markierten DNA-Sonde auf die Säule wurde die gereinigte Sonde durch Zentrifugation eluiert (4 min, RT, 3300 UpM; Biofuge 15R Heraeus, Hamburg). Die radioaktiv markierten DNA-Fragmente wurden aufgefangen und der radioaktive Einbau mit Hilfe eines Szintillationszählers bestimmt (2.12.8). Die Lagerung erfolgte bei $4{ }^{\circ} \mathrm{C}$.

\subsubsection{Bestimmung der Radioaktivität}

Zur Bestimmung des Einbaus von radioaktivem $\left[{ }^{32} \mathrm{P}\right]$-dCTP in Doppelstrang-Oligonukleotide wurde $1 \mu \mathrm{l}$ der jeweiligen Markierungsreaktion mit $4 \mathrm{ml}$ Szintillations-Flüssigkeit (Quicksafe A, Zinsser Analytic, Frankfurt) versetzt und im Szintillationszähler (Beckmann LS 1801, München) gemessen.

\subsection{Gelelektrophorese von Nukleinsäuren}

Die gelelektrophoretische Auftrennung von Nukleinsäuren ermöglicht den Nachweis und die Größenbestimmung sowie die Isolierung einzelner DNA-Fragmente. Agarose- und Polyacrylamid-Gelelektrophoresen sind die Standardmethoden zur Auftrennung von DNA-Fragmenten unterschiedlicher Größe. Die Auftrennung im elektrischen Feld ist durch die negative Nettoladung von Nukleinsäuren bei neutralem pH möglich.

\subsubsection{Horizontale Agarose-Gelelektrophorese}

Zur Analyse oder Präparation von PCR-Produkten und Überprüfung der Identität durch Restriktionsverdau (2.16.1) isolierter DNA-Fragmente wurden diese in horizontalen Agarosegelen im elektrischen Feld aufgetrennt. Es wurden Gele mit $100 \mathrm{ml}$ Volumen in Horizontalgelkammern (H3-Set, Scie-Plas, England; alternativ: Wide Mini Sub Cell, Bio Rad, München) mit 1 x TAE-Puffer (2.9) als Gel- und Laufpuffer verwendet. In Abhängigkeit von der Fragmentgröße der zu trennenden DNA-Moleküle variierte die Agarosekonzentration zwischen 0,8-1,5\% (w/v). Die entsprechende Agarosemenge (Applichem, Darmstadt) und der 1 x TAE-Puffer wurden kurz in einer Mikrowelle aufgekocht, nach Abkühlung auf etwa $50{ }^{\circ} \mathrm{C}$ mit $5 \mu$ l Ethidiumbromid ( $10 \mathrm{mg} / \mathrm{ml}$, Endkonzentration: $0,5 \mu \mathrm{g} / \mathrm{ml}$ ) versetzt und auf die entsprechenden Gelträger gegossen. Vor dem Auftrag wurde den Proben zur Erhöhung der 
Dichte, zur Markierung der Lauffront sowie zur Denaturierung noch vorhandener Proteine $2 \mu \mathrm{l}$ Stopp-Mix (2.9) zugesetzt. Als Standard zum Größenvergleich wurde ein DNALängenstandard (2.11.2) eingesetzt. Die Elektrophorese wurde mit einer konstanten Spannung von $90 \mathrm{~V}$ durchgeführt. Nach Abschluß der Elektrophorese wurden die Gele im UV-Durchlicht fotografiert (Herolab E.A.S.Y., Wiesloch).

\subsubsection{Aufreinigung von DNA aus Agarosegelen}

Die Aufreinigung und Isolation von DNA-Fragmenten aus PCR-Reaktionen (2.15.1) oder aus Reaktionen nach enzymatischer Modifikation (2.16) ist notwendig, um spezifische DNAFragmente von verunreinigenden Salzen, Proteinen oder freien Nukleotiden zu trennen, welche nachfolgende Reaktionen beeinträchtigen könnten. Dazu wurde gemäß Herstellerangaben der „Easy Pure DNA Purification Kit“ (Biozym Diagnostik GmbH, Hess. Oldendorf) verwendet.

Bei präparativen Gelen wurde die interessierende DNA-Bande unter UV-Licht (366 nm, Herolab E.A.S.Y., Wiesloch) mit einem Skalpell aus einem Agarosegel herausgeschnitten und die DNA mittels „Easy Pure DNA Purification Kit“ (Biozym Diagnostik GmbH, Hess. Oldendorf) gemäß Herstellerangaben extrahiert.

\subsubsection{Denaturierende Polyacrylamid/Sequenzierungs-Gelelektrophorese}

Polyacrylamidgele eignen sich zur Auftrennung von DNA-Fragmenten, die sich um nur 0,2 \% ihrer Länge unterscheiden. Im Vergleich zu Agarosegelen weisen Polyacrylamidgele eine bessere Auflösung und eine höhere Sensitivität auf. Der Zusatz eines denaturierenden Agens (z. B. Harnstoff) zum Gel bewirkt ein von Basenzusammensetzung und Sequenz unabhängiges Migrationsverhalten (Sambrook et al., 1989). Für die Trennung von DNAFragmenten aus Sequenzierreaktionen ist dies von Vorteil. Polyacrylamid-Sequenziergele wurden aus der SequaGel XR-Acrylamid-Fertiglösung (Biozym Diagnostik, Hess. Oldendorf) angefertigt.

$40 \mathrm{ml}$ Gellösung enthielt folgende Komponenten:

$\begin{array}{lll}\text { SequaGel XR-Acrylamid Fertiglösung } & 32 & \mathrm{ml} \\ \text { SequaGel complete buffer reagent } & 8 & \mathrm{ml} \\ \text { DMSO } & 400 & \mu \mathrm{l}\end{array}$

Durch Zusatz von $300 \mu \mathrm{l} 10$ \% (w/v) APS wurde die Polymerisation der Acrylamid-Monomere gestartet. 
Nach APS-Zugabe wurde die Lösung zügig und luftblasenfrei zwischen die mit $10 \%(w / v)$ SDS und abs. Ethanol gereinigten Glasplatten der Gelapparatur ( $41 \mathrm{~cm}$ Gelapparatur für den Sequenzierautomaten Li-Cor 4200; MWG Biotech, Ebersberg) gegossen und der Vorkamm eingesetzt. Die Schichtdicke der Gele betrug 0,25 mm.

Nach vollständiger Polymerisation (ca. 45 min-1 h) wurde der Vorkamm entfernt und ein 48-Spur Haifischzahnkamm eingesetzt und die Pufferkammern mit 1 x TBE (2.9) als Laufpuffer gefüllt. Vor Auftrag der Proben erfolgte ein Vorlauf von 20 min bei einer konstanten Spannung von $800 \mathrm{~V}$, bis eine Betriebstemperatur von $50{ }^{\circ} \mathrm{C}$ erreicht wurde. Die $4 \mu \mathrm{l}$ Sequenzierreaktionen (2.18) wurde mit $1 \mu \mathrm{l}$ Stopp-Mix (EDTA/Formamid, Amersham Biosciences, Freiburg) versetzt. Anschließend wurde von jedem der vier nukleotidspezifischen Ansätze einer Sequenz $1 \mu$ in die gründlich gespülten Geltaschen pipettiert. Die Elektrophorese wurde bei einer konstanten Spannung von $1500 \mathrm{~V}$ und $50{ }^{\circ} \mathrm{C}$ gestartet und durch die Abschaltautomatik des Sequenziergerätes beendet. Die Auswertung der Bandenmuster erfolgte mit der Base ImagIR-Software (Base ImagIR, Data Collection, Version 4, Li-Cor Inc. Lincoln, USA). Die Sequenzen wurden abschließend mit dem GCG-Softwarepaket (2.22) bearbeitet.

\subsection{Nachweis von Nukleinsäuren im analytischen Maßstab}

\subsubsection{Ethidiumbromidfärbung in Agarosegelen}

Der Fluoreszenzfarbstoff Ethidiumbromid interkaliert zwischen die Basen von Nukleinsäuren; in ausreichender Menge akkumuliert, können diese somit im UV-Licht indirekt nachgewiesen werden. Der Zusatz des Ethidiumbromids erfolgte direkt bei der Herstellung des Agarosegels (2.13.1). Nach elektrophoretischer Auftrennung von DNA-Fragmenten wurde das DNABandenmuster mit einem UV-Transilluminator $(\lambda=254$ oder $366 \mathrm{~nm}$, UV-Kontaktlampe Chroma 41 bzw. Chroma 42, Vetter $\mathrm{GmbH}$, Wiesloch) sichtbar gemacht und mit Hilfe einer Geldokumentationsanlage (Herolab E.A.S.Y., Wiesloch) ausgewertet.

\subsubsection{Autoradiographie}

Der Nachweis radioaktiv markierter Nukleinsäuren erfolgte durch Autoradiographie unter Verwendung von Röntgenfilmen (Hyperfilm MP-Röntgenfilme, Amersham, Braunschweig). Getrocknete Polyacrylamid-Gele des EMSA (2.20) mit GST-Fusionsproteinen (2.19.1) bzw. Kernproteinextrakten (2.19.3) und [ $\left.{ }^{32} \mathrm{P}\right]$-markierten Oligonukleotid-Sonden (Tab. 2) wurden in Röntgenkassetten mit Verstärkerfolie (Kodak X-Omatic, Stuttgart) autoradiographiert. Die Expositionszeit eines Röntgenfilms betrug 3-10 Tage bei $-80{ }^{\circ} \mathrm{C}$. Zur Autoradiographie von 
getrockneten Polyacrylamidgelen des EMSA mit $\left[{ }^{35} S\right]$-markierten in vitro transkribierten/translatierten Proteinen (2.19.2) und [ $\left.{ }^{32} \mathrm{P}\right]$-markierte Oligonukleotid-Sonden wurden vier Röntgenfilme übereinander auf das Gel gelegt. Die unteren Filme sollten die $\left[{ }^{35} \mathrm{~S}\right]-$ Strahlung abfangen und der oberste Film die $\left[{ }^{32} \mathrm{P}\right]-S t r a h l u n g$ detektieren. Die Expositionszeit betrug 3-10 Tage bei $-80^{\circ} \mathrm{C}$. Getrocknete SDS-Gele zur Kontrolle der in vitro Transkription/Translations-Reaktion wurden 1 Tag bei RT in Röntgenkassetten mit Verstärkerfolie autoradiographiert. Nach der Exposition wurden die Filme für 1 min entwickelt (Röntgenentwickler LX 24, Kodak, Stuttgart), mit Wasser gespült und für 2 min fixiert (Röntgenfixierbad AL 4, Kodak, Stuttgart). Die Filme wurden intensiv mit Wasser gewaschen und getrocknet. Alternativ wurden die getrockneten Gele mit Hilfe eines Phosphor-Imagers (Fujix BAS-Cassette, BAS Analyzer BAS-1500, Raytest, Straubenhardt) dokumentiert. Die Expositionszeit betrug hier $1 \mathrm{~h}, 6 \mathrm{~h}$ oder 1 Tag.

\subsection{Polymerase-Kettenreaktion (PCR)}

Die PCR ermöglicht, ausgehend von einem Gemisch aus Nukleinsäuren, die selektive Vervielfältigung von spezifischen DNA-Fragmenten definierter Länge und Sequenz.

Die DNA wird durch Erhitzen in Einzelstränge zerlegt („Denaturierung“) und ein spezifischer Abschnitt durch Primeranlagerung („Annealing“) und DNA-Synthese mit Hilfe von dNTP’s und einer hitzestabilen Polymerase (Taq DNA Polymerase oder Pfu DNA Polymerase) amplifiziert („Elongation“). Es wird die Eigenschaft der DNA-Polymerase ausgenutzt, einen an denaturierte DNA gebundenen Primer zum komplementären Strang zu verlängern. Die erhaltene DNA wird in sich wiederholenden Reaktionszyklen kopiert und somit vervielfältigt.

\subsubsection{Amplifikation von DNA-Fragmenten durch PCR zur Klonierung}

Die PCR diente in der vorliegenden Arbeit zur Herstellung der Konstrukte -350(G1m)GluLuc, -350(G3Am)GluLuc und -350(G1m/G3Am)GluLuc, welche 350 Basenpaare, mutiert oder unverändert, des Glukagon-Genpromotors der Ratte umfassen (2.11.1). Außerdem wurden mittels PCR die Pax6-cDNA-Mutanten im Vektor pBAT14 erzeugt (2.11.1). Auch die Umklonierung der Pax6-Homöodomänen-Mutanten bzw. des Pax6-Wildtyps in die Vektoren pSG424 bzw. pcDNA3 erfolgte mit Hilfe der PCR (2.11.1).

Ein $50 \mu$ l Standardansatz entsprach folgender Zusammensetzung: 


\begin{tabular}{|c|c|c|}
\hline \multicolumn{3}{|l|}{$\underline{\text { PCR-Ansatz }}$} \\
\hline Matrizen-DNA & \multicolumn{2}{|c|}{$50-200 \mathrm{ng}$} \\
\hline 10 x PCR Puffer & 5 & $\mu \mathrm{l}$ (beinhaltet $15 \mathrm{mM} \mathrm{MgCl}_{2}$ ) \\
\hline dNTP-Mix (je 10 mM) & 1 & $\mu l$ \\
\hline 5'-Primer (10 pmol/ul) & 1 & $\mu l$ \\
\hline 3'-Primer (10 pmol/ $/ \mathrm{ll})$ & 1 & $\mu l$ \\
\hline 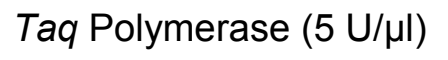 & 0,5 & $\mu l$ \\
\hline $\mathrm{H}_{2} \mathrm{O}$ & ad 50 & $\mu l$ \\
\hline
\end{tabular}

Die PCR-Reaktionen zur Klonierung von PCR-Fragmenten wurden im TRIO Thermoblock (Biometra, Göttingen) nach folgendem PCR-Temperaturprofil durchgeführt:

$\begin{array}{llll}\text { Zyklen } & \text { Temperatur } & & \text { Zeit } \\ 1 & 94{ }^{\circ} \mathrm{C} & 3 & \mathrm{~min} \\ 30 & 94^{\circ} \mathrm{C} & 45 & \mathrm{sec} \\ & \text { je nach } \mathrm{Tm} \text { des Primerpaars } & 45 & \mathrm{sec} \\ & 72^{\circ} \mathrm{C} & 45 & \mathrm{sec} \\ 1 & 72^{\circ} \mathrm{C} & 10 & \mathrm{~min} \\ 1 & 4{ }^{\circ} \mathrm{C} & \infty & \end{array}$

Jeweils $10 \mu \mathrm{l}$ der PCR-Produkte wurden mittels Agarose-Gelelektrophorese (2.13.1) analysiert und/oder zur Subklonierung aus dem Gel aufgereinigt (2.13.2). Die restlichen Reaktionsansätze wurden bei $4{ }^{\circ} \mathrm{C}$ gelagert.

\subsubsection{Site directed mutagenesis durch PCR}

Die in vitro Mutagenese von Plasmid-DNA wurde mit dem "Quick Change Site directed mutagenesis Kit“" (Stratagene, Heidelberg) nach Herstellerangaben durchgeführt. Es handelt sich dabei um eine ortsgerichtete, punktuelle Mutation mittels PCR-Technik unter Verwendung von PCR-Primern, die sich in 1 bis 3 Basen von der Sequenz des UrsprungsPlasmids unterscheiden und die gewünschte Mutationen in das Gen einführen.

Die für die ortsgerichtete Mutagenese benötigten Primer mußten folgende Anforderungen erfüllen: $\quad$ Primerlänge $\geq 25$ Basen

Mutationsstelle in der Mitte der Primer

Terminale Basen G oder C, GC-Gehalt $\geq 40 \%$

Schmelzpunkt $\mathrm{T}_{\mathrm{m}} \geq 78^{\circ} \mathrm{C}$ 
Die parentale doppelsträngige Plasmid-DNA wird zunächst durch Erhitzen auf $95{ }^{\circ} \mathrm{C}$ denaturiert. Die Anlagerung der Mutagenese-Primer erfolgt durch Abkühlen auf $55^{\circ} \mathrm{C}$, deren Elongation durch die Pfu-Turbo-DNA-Polymerase (Stratagene, Heidelberg) bei $68{ }^{\circ} \mathrm{C}$. Durch Wiederholung dieses Vorgangs wird ein Plasmid amplifiziert, welches die gewünschte Mutation enthält.

Der im TRIO Thermoblock (Biometra, Göttingen) amplifizierte Ansatz enthielt folgende Komponenten:

$\begin{array}{lll}\text { Matrizen-DNA } & 50 & \mathrm{ng} \\ \text { Sense-Primer } & 125 & \mathrm{ng} \\ \text { Antisense-Primer } & 125 & \mathrm{ng} \\ 10 \text { x Reaktionspuffer } & 5 & \mu \mathrm{l} \\ \text { Pfu Turbo DNA-Polymerase } & 1 & \mu \mathrm{l} \\ \text { dNTP-Mix (20 mM) } & 1 & \mu \mathrm{l} \\ \mathrm{H}_{2} \mathrm{O} & \text { ad } 50 & \mu \mathrm{l}\end{array}$

Der Ansatz wurde mit $30 \mu \mathrm{l}$ Mineralöl überschichtet.

Die PCR-Reaktionen zur Mutagenese doppelsträngiger DNA-Plasmide wurden nach folgendem Temperaturprofil im TRIO-Thermoblock (Biometra, Göttingen) durchgeführt:

$\begin{array}{lllll}\text { Segment } & \text { Zyklen } & \text { Temperatur } & & \text { Zeit } \\ 1 & 1 & 95^{\circ} \mathrm{C} & 30 & \mathrm{sec} \\ 2 & 16 & 95^{\circ} \mathrm{C} & 30 & \mathrm{sec} \\ & & 55^{\circ} \mathrm{C} & 1 & \mathrm{~min} \\ & & 68^{\circ} \mathrm{C} & 2 & \mathrm{~min} / \mathrm{kBp} \\ 3 & 1 & 4{ }^{\circ} \mathrm{C} & \infty & \end{array}$

Nach dem Abkühlen des PCR-Produkts wurde $1 \mu \mathrm{l}$ der Restriktionsendonuklease Dpnl zugegeben und $1 \mathrm{~h}$ bei $37^{\circ} \mathrm{C}$ inkubiert. Die Endonuklease Dpnl mit der Zielsequenz 5'$\mathrm{G}^{\mathrm{m} 6}$ ATC-3' ist spezifisch für methylierte und hemimethylierte DNA. Da Plasmid-DNA aus $E$. coli DH5 $\alpha$ dam-methyliert ist, erfolgt durch Dpnl der Verdau der parentalen DNA, während die neusynthetisierte, mutierte DNA erhalten bleibt. Kompetente E. coli XL-1 Blue Bakterien (2.11.3) wurden mit $1 \mu \mathrm{l}$ des Ansatzes transformiert (2.17.2) und die Brüche in den noch offenen zirkulären Plasmiden durch die zelluläre E. coli DNA-Ligase repariert. Der gesamte Transformationsansatz wurde auf $L_{\text {Amp }}$-Platten ausplattiert und für mindestens $16 \mathrm{~h}$ bei $37{ }^{\circ} \mathrm{C}$ inkubiert. Von den erhaltenen Kolonien wurden Klone gepickt und nach 
Minipräparation (2.17.3) der Plasmid-DNA erfolgte die Identifizierung erfolgreich transformierter Klone durch Sequenzierung (2.18).
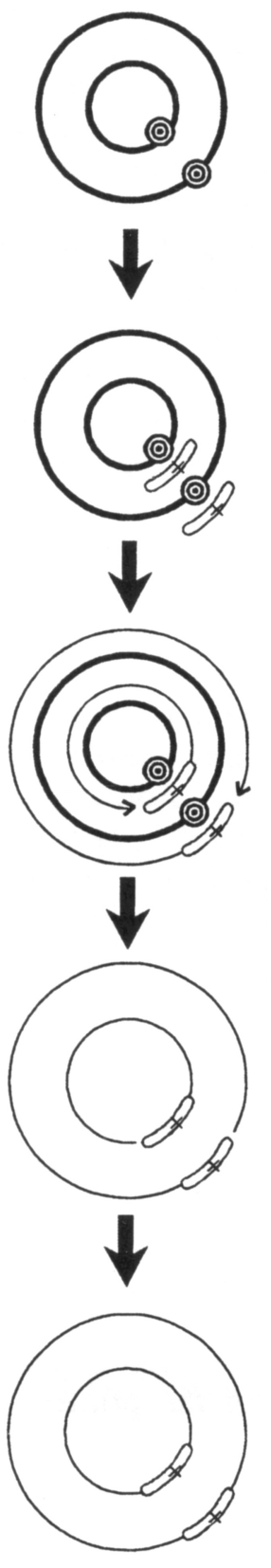

Plasmid-Präparation:

Plasmid mit dem gewünschten Gen und dem Zielpunkt der Mutagenese.

\section{Oligonukleotid-vermittelte Mutagenese}

Denaturierung und Anlagerung:

Nach dem Denaturieren des Plasmids folgt die Anlagerung der Oligonukleotide mit der gewünschten Mutation.

\section{Elongation:}

Durch die Pfu Turbo-Polymerase erfolgt die Elongation der Oligonukleotide, was schließlich zu zirkulären Strängen mit einem Bruch im Phosphatgerüst führt.

\section{Verdau:}

Die methylierte parentale DNA (ohne Mutation) wird mit dem Enzym Dpnl verdaut

\section{Transformation:}

Nach der Transformation der neusynthetisierten DNA in E. coli XL1-Blue werden die Strangbrüche durch bakterielle Enzyme repariert

Abb. 5: Schematische Darstellung der QuickChange-Mutagenese-Methode. Verändert aus "QuickChange Site-Directed Mutagenesis Kit Instruction Manual", Stratagene, Heidelberg. 


\subsection{Enzymatische Modifikation von Nukleinsäuren}

2.16.1 Spaltung von DNA mit Restriktionsendonukleasen

Die Spaltung von DNA erfolgte mit Typll-Restriktionsendonukleasen. Restriktionsendonukleasen erkennen spezifische, meist palindromische Sequenzen in doppelsträngiger DNA und hydrolysieren diese. Durch Spaltung der Erkennungssequenz (4 bis 8 Nukleotide) des jeweiligen Enzyms können DNA-Fragmente mit glatten („blunt ends") oder einzelsträngig überstehenden 3'- bzw. 5'- Enden („sticky ends") entstehen. Der Restriktionsverdau dient der Überprüfung von Reinheit und Identität von Plasmiden und wurde zur Umklonierung von DNA-Fragmenten verwendet. In einem Standardansatz wurde der Verdau für $2 \mathrm{~h}$ bei $37^{\circ} \mathrm{C}$ inkubiert. Es wurden jeweils $2 \mathrm{U}$ der Restriktionsendonuklease pro $\mu \mathrm{g}$ DNA in den empfohlenen Pufferlösungen der Hersteller eingesetzt (2.3.1). Das Volumen des eingesetzten Enzyms betrug maximal 1/10 Volumen des Gesamtansatzes. Die Reaktionsbedingungen entsprachen den Angaben der Hersteller. Der Restriktionsverdau wurde anschließend mittels Agarose-Gelelektrophorese (2.13.1) überprüft.

\subsubsection{Ligation von DNA-Fragmenten}

Die Enden von Nukleinsäure-Molekülen werden durch T4-DNA-Ligase verknüpft. Die T4-DNA-Ligase katalysiert unter ATP-Verbrauch die Bildung einer Phosphodiesterbindung durch Verknüpfung kompatibler 3'-Hydroxyl- und 5'-Phosphat-Enden (Goodman und MacDonald, 1979). Für den Ligationsansatz wurde ein molares Vektor:Insert-Verhältnis von 1:5 in Bezug auf die Molaritäten beachtet.

Ein $10 \mu \mathrm{l}$ Standardligationsansatz enthielt folgende Komponenten:

$\begin{array}{lll}\text { Linearisierter Vektor }(25 \mathrm{ng} / \mu \mathrm{l}) & 2 & \mu \mathrm{l} \\ 10 \text { x Ligationspuffer } & 1 & \mu \mathrm{l} \\ \text { T4-DNA-Ligase }(4 \mathrm{U} / \mu \mathrm{l}) & 1 & \mu \mathrm{l} \\ \text { PCR-Produkte } & 6 & \mu \mathrm{l}\end{array}$

Die Reaktion wurde für $16 \mathrm{~h}$ bei $16{ }^{\circ} \mathrm{C}$ im TRIO-Thermoblock (Biometra $\mathrm{GmbH}$, Göttingen) durchgeführt und bis zur Transformation kompetenter $E$. coli-Bakterien bei $-20{ }^{\circ} \mathrm{C}$ gelagert. Wurde ein Vektor vor Einsatz in eine Ligationsreaktion mit nur einer Restriktionsendonuklease gespalten, so wurde der Vektor zur Verhinderung der Religation und um den Anteil an Klonen mit Insert zu erhöhen, dephosphoryliert (2.16.3). 


\subsubsection{Dephosphorylierung eines Vektors}

Die Religation eines Vektors mit kompatiblen Enden nach der Spaltung mit nur einer Restriktionsendonuklease kann durch Entfernung der 5'-Phosphatreste („Dephosphorylierung“) verhindert werden. Die zur Ligation nötigen Phosphatreste beinhaltet nur das Fragment, welches in den Vektor kloniert werden soll (Sambrook et al., 1989). Zur Dephosphorylierung wurde die Alkalische Phosphatase (AP) aus Kälberdarm (CIP oder CIAP, Promega, Mannheim) verwendet.

Ein $50 \mu \mathrm{l}$ Standardansatz enthielt folgende Komponenten:

\begin{tabular}{lll} 
Linearisierter Vektor & \multicolumn{2}{c}{$100-500 \mathrm{ng}$} \\
$10 \times$ AP-Puffer & 5 & $\mu \mathrm{l}$ \\
$\mathrm{CIAP}(0,1 \mathrm{U} / \mu \mathrm{l})$ & 5 & $\mu \mathrm{l}$ \\
$\mathrm{H}_{2} \mathrm{O}$ & ad 50 & $\mu \mathrm{l}$
\end{tabular}

Der Reaktionsansatz wurde für 10 min bei $37^{\circ} \mathrm{C}$ inkubiert. Nach erneuter Zugabe von $5 \mu \mathrm{l}$ $\operatorname{CIAP}(0,1 \mathrm{U} / \mu \mathrm{l})$ wurde der Ansatz für weitere $10 \mathrm{~min}$ bei $37^{\circ} \mathrm{C}$ inkubiert. Anschließend erfolgte eine Inkubation für $20 \mathrm{~min}$ bei $65^{\circ} \mathrm{C}$ zur Inaktivierung der Alkalischen Phosphatase. Für alle folgenden Reaktionen wurde eine Fällung mit Phenol/Chloroform/Isoamylalkohol (2.12.2) durchgeführt.

\section{$2.17 \quad$ Methoden zur molekularen Klonierung}

Eine Klonierung ist die Einführung eines DNA-Fragments in einen Vektor, welcher in einem entsprechenden Wirtsbakterium amplifiziert werden kann. Neben einer erhöhten Stabilität der DNA verbreitert sich auch das Anwendungsspektrum. So erlauben RNA-PolymerasePromotoren im Vektor eine in vitro-Transkription und -Translation (2.19.2), während virale Promotoren eine Expression der cDNA in Säugerzellen erlauben (2.21.4). Die Klonierung umfaßt die Ligation von PCR-Produkten (2.16.2) oder DNA-Fragmenten restriktionsenzymatischer Spaltungen (2.16.1) in Plasmid-Vektoren sowie die Transformation kompetenter Wirtsbakterien (2.17.2), aus denen die amplifizierte Plasmid-DNA isoliert werden kann (2.17.3 und 2.17.4). 
2.17.1 Herstellung kompetenter E. coli (Dagert und Ehrlich, 1979)

Die spontane Aufnahme von in Lösung befindlicher Fremd-DNA durch Bakterien wird als Kompetenz bezeichnet. Durch die Behandlung von $E$. coli-Bakterien mit $\mathrm{CaCl}_{2}$ und die damit einhergehende Modifikation der Zelloberfläche kann dieser Zustand induziert und die Kompetenz erhöht werden. 100 ml LB-Medium (2.9) wurden mit 10 ml einer Übernachtkultur des jeweiligen E. coli Stammes (DH5 $\alpha$ oder BL21) (2.11.3) inokuliert und bei $37{ }^{\circ} \mathrm{C}$ mit 200 UpM im Schüttelinkubator (Inova 4300, NBS, USA) bis zu einer optischen Dichte $O_{600}=0,6$ (UV-160, Shimadzu, Duisburg) inkubiert. Die Bakterien wurden anschließend für 10 min auf Eis inkubiert und zentrifugiert (10 min, $4{ }^{\circ} \mathrm{C}, 3000$ UpM; Beckmann JA-14, München). Der Überstand wurde dekantiert und das Zellpellet mit $50 \mathrm{ml}$ eiskalter, sterilfiltrierter $50 \mathrm{mM}$ $\mathrm{CaCl}_{2}$-Lösung vorsichtig resuspendiert und erneut für $30 \mathrm{~min}$ auf Eis inkubiert. Nach einer erneuten Zentrifugation (10 min, $4{ }^{\circ} \mathrm{C}, 3000 \mathrm{UpM}$; Beckmann JA-14, München) wurde das Pellet in $10 \mathrm{ml}$ eiskalter $50 \mathrm{mM} \mathrm{CaCl} /$ Glycerin (15\% v/v)-Lösung aufgenommen. Die Suspension wurde aliquotiert und in flüssigem Stickstoff schockgefroren. Bis zum Gebrauch wurden die Aliquots bei $-80^{\circ} \mathrm{C}$ gelagert.

\subsubsection{Transformation kompetenter E. coli}

Durch Transformation werden Plasmide in kompetente E. coli-Zellen übertragen. $30 \mu \mathrm{l}$ kompetente $\mathrm{DH} 5 \alpha$-Bakterien (2.11.3) wurden auf Eis aufgetaut und mit $10 \mu \mathrm{l}$ eines Ligationsansatzes (2.16.2) oder $0,5 \mu \mathrm{g}$ Plasmid-DNA versehen. Nach 30-minütiger Inkubation auf Eis wurde die Suspension $30 \mathrm{sec}$ bei $42{ }^{\circ} \mathrm{C}$ hitzegeschockt. Die Bakterien wurden für 2 min auf Eis gehalten und nach Zugabe von $500 \mu$ LB-Medium (2.9) für $1 \mathrm{~h}$ bei $37^{\circ} \mathrm{C}$ und 250 UpM im Schüttelinkubator (Thermomixer compact, Eppendorf, Köln) inkubiert. Zur Ausplattierung auf $\mathrm{LB}_{\mathrm{Amp}}$-Agarplatten (2.9) wurden $50 \mu \mathrm{l}$ verwendet.

Die Transformation von BL21(DE3)pLys-Bakterien (2.11.3) mit GST-Fusionskonstrukten (2.11.1) erfolgte mit einem Hitzeschock für $30 \mathrm{sec}$ bei $37^{\circ} \mathrm{C}$. Die Ausplattierung von $30 \mu \mathrm{l}$

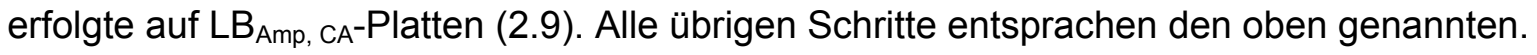

Bei Verwendung von XL1-Blue-Bakterien (2.11.3; „Quick change site directed mutagenesis kit“, Stratagene, Heidelberg) wurden $50 \mu$ Bakterien eingesetzt, die mit $1 \mu$ des PCRProduktes versetzt wurden. Nach einer 30-minütigen Inkubation auf Eis erfolgte ein Hitzeschock für $45 \mathrm{sec}$ bei $40{ }^{\circ} \mathrm{C}$. Nach weiteren 2 min Inkubation auf Eis wurde $500 \mu \mathrm{l}$ NZYBroth (2.9) zugegeben und der Ansatz für $1 \mathrm{~h}$ bei $37^{\circ} \mathrm{C}$ im Schüttelinkubator bei $250 \mathrm{UpM}$ gemischt (Thermomixer compact, Eppendorf, Köln). Anschließend wurde der gesamte

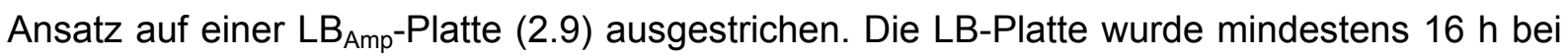
$37^{\circ} \mathrm{C}$ inkubiert. 


\subsubsection{Minipräparation von Plasmid-DNA (Le-Gouill et al., 1994)}

Hierbei werden Plasmide aus E. coli-Kulturen isoliert, die aus einer Einzelkolonie von einer LB-Agarplatte angeimpft wurden (2.9 und 2.17.2). Mit diesem modifizierten Protokoll der alkalischen Lyse wurden transformierte Bakterienzellen auf die Anwesenheit rekombinanter Plasmide getestet. Dazu wurde eine 5 ml LB Amp -Kultur mit einer Einzelkolonie transformierter Bakterien (2.17.2) inokuliert und ü.N. $\left(15-16\right.$ h) bei $37{ }^{\circ} \mathrm{C}$ und $200 \mathrm{UpM}$ im Inkubationsschüttler (Inova 4300, NBS, USA) aufgezogen. $800 \mu \mathrm{l}$ dieser Bakterienkultur wurden mit $200 \mu \mathrm{l}$ 87\%-igem (v/v) Glycerin versetzt und als Dauerkultur bei $-80{ }^{\circ} \mathrm{C}$ gelagert. $1,5 \mathrm{ml}$ der Bakteriensuspension wurden zur Plasmid-Präparation in ein Eppendorfgefäß überführt und für 5 min bei RT mit 6000 UpM (Biofuge pico, Heraeus, Hamburg) zentrifugiert. Das Sediment wurde in $100 \mu \mathrm{l}$ Lysozym-Lösung (2 mg Lysozym/5 ml Lösung 1) resuspendiert und 10 min auf Eis inkubiert. Nach rascher Zugabe von $200 \mu \mathrm{l} \mathrm{NaOH/SDS-}$ Lösung wurde der Präparationsansatz 5 mal durch Invertierung gemischt und 5 min auf Eis inkubiert. Dem Ansatz wurden zur Neutralisation langsam $150 \mu \mathrm{l} 3 \mathrm{M}$ Natriumacetat pH 4.8 zugegeben. Durch mehrmaliges Invertieren wurde der Ansatz durchmischt und 5 min auf Eis inkubiert. Anschließend erfolgte eine 5-minütige Zentrifugation bei RT und 10000 UpM (Biofuge pico, Heraeus, Hamburg). Bakterielle Zelltrümmer, genomische DNA und Proteine hafteten als kompakte, weiße Masse an der Gefäßwand. Die obere DNA-haltige Phase wurde in ein neues Eppendorfgefäß überführt und eine Phenol/Chloroform/IsoamylalkoholExtraktion durchgeführt (2.12.2). Die Proben wurden zwischen den einzelnen Extraktionschritten kurz gevortext. Die nach dem letzten Extraktionsschritt erhaltene obere DNA-haltige Phase wurde mit zwei Volumenanteilen eiskaltem absolutem Ethanol und mit 1/10 Volumenanteil $3 \mathrm{M}$ Natriumacetat $\mathrm{pH} 4.8$ versetzt. Nach einer 5-minütigen Fällung der DNA bei $-20{ }^{\circ} \mathrm{C}$ wurde der Ansatz bei RT für $10 \mathrm{~min}$ und 14000 UpM (Eppendorfzentrifuge 5417R, Hamburg) zentrifugiert. Das Pellet wurde zur Entfernung des Ethanols für 10 min bei $37^{\circ} \mathrm{C}$ getrocknet und nach Zugabe von $20 \mu \mathrm{l}$ 0,1 mg/ml RNase A Lösung (2.9) für 40-45 min bei $37^{\circ} \mathrm{C}$ inkubiert, um mitgefällte RNA zu entfernen. Die gewonnene Plasmid-DNA wurde nach Kontrollrestriktionsverdau (2.16.1) im Agarosegel (2.13.1) überprüft und zur DNA-Sequenzierung (2.18) oder zur Subklonierung von DNA-Fragmenten (2.17) eingesetzt. Die Lagerung positiver Klone erfolgte bei $-20^{\circ} \mathrm{C}$.

Lösung 1

$\begin{array}{lll}\text { 1M Tris/HCl pH } 8.0 & 2,5 & \mathrm{ml} \\ \text { 0,5 M EDTA pH } 8.0 & 2 & \mathrm{ml} \\ \text { Glukose (wasserfrei) } & 0,9 \mathrm{~g} \\ \mathrm{H}_{2} \mathrm{O} & \text { ad } 100 \mathrm{ml}\end{array}$

$\underline{\mathrm{NaOH} / \mathrm{SDS}-L o ̈ s u n g}$

$\begin{array}{llc}1 \mathrm{~N} \mathrm{NaOH} & 1 & \mathrm{ml} \\ 10 \% \mathrm{SDS} & 500 & \mu \mathrm{l} \\ \mathrm{H}_{2} \mathrm{O} & \text { ad } & 5 \mathrm{ml}\end{array}$




\subsubsection{Maxipräparation von Plasmid-DNA (Sambrook et al., 1989)}

Die Isolierung großer Mengen reiner Plasmid-DNA, z.B. für transiente Transfektionen (2.21.4) oder in vitro Transkription/Translation (2.19.2), erfolgte durch Cäsiumchlorid-Dichtegradienten-Zentrifugation eines Plasmid-Rohextraktes.

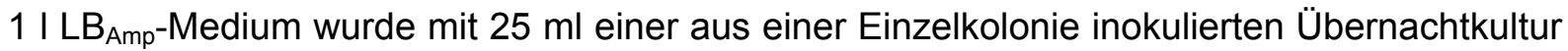
beimpft und bei $37^{\circ} \mathrm{C}$ mit $200 \mathrm{UpM}$ im Schüttelinkubator (Inova 4300, NBS, USA) bis zu einer $\mathrm{OD}_{600}=0,6$ aufgewachsen. Zur Erhöhung der Replikationsrate des Plasmids wurde der Proteinbiosynthese-Hemmstoff Chloramphenicol (Endkonzentration: $200 \mu \mathrm{\mu g} / \mathrm{ml}$ ) hinzugesetzt. Chloramphenicol hemmt die Replikation des Bakterienchromosoms, nicht aber die des Plasmides (Sambrook et al., 1989). Nach 12-stündiger Inkubation bei $37^{\circ} \mathrm{C}$ und 200 UpM im Schüttelinkubator wurde die Kultur auf vier $250 \mathrm{ml}$ Zentrifugenbecher (Beckmann, München) aufgeteilt und für $10 \mathrm{~min}$ bei $4{ }^{\circ} \mathrm{C}$ mit 4500 UpM (Beckmann JA-14 Rotor, München) sedimentiert. Das Pellet wurde in $11,25 \mathrm{ml}$ iso-osmotischer STE-Lösung resuspendiert, jeweils zwei der Suspensionen in eine $50 \mathrm{ml}$-Zentrifugengefäß vereinigt und zum Abbau der Bakterienzellwand für 20 min auf Eis mit $1,5 \mathrm{ml}$ Lysozymlösung $(60 \mathrm{mg} / \mathrm{ml}$ STE) versetzt. Die entstandenen Sphäroblasten wurden durch 5-minütige Inkubation mit 1,8 $\mathrm{ml}$ einer 0,5 M EDTA-Lösung ( $\mathrm{pH} \mathrm{8,0)}$ auf Eis und anschließender Zugabe von 14,4 ml Triton-Mix für weitere $30 \mathrm{~min}$ auf Eis unter regelmäßigem Schwenken lysiert. Durch einstündige Zentrifugation der Suspension bei $4{ }^{\circ} \mathrm{C}$ und 14000 UpM (Beckmann JA-20 Rotor, München) wurden die Zelltrümmer von der DNA getrennt. Die DNA-haltigen Überstände wurden in einem $250 \mathrm{ml}$ Zentrifugenbecher vereinigt und die DNA durch Zugabe von je $40 \mathrm{ml}$ PEG-6000-Lösung für mindestens $1 \mathrm{~h}$ auf Eis präzipitiert. Nach Zentrifugation für $10 \mathrm{~min}$ bei $4{ }^{\circ} \mathrm{C}$ mit 10000 UpM (Beckmann Ja-14 Rotor, München) wurde das DNA-Pellet in je $10 \mathrm{ml}$ TNE-Puffer aufgenommen und nach Zugabe von 10,9 g Cäsiumchlorid und $150 \mu \mathrm{l}$ Ethidiumbromid-Lösung (10 mg/ml) in Quick-Seal Röhrchen (Beckmann, München) überführt. Die Röhrchen wurden auf $0,05 \mathrm{~g}$ genau austariert, verschweißt und für $20 \mathrm{~h}$ bei $20{ }^{\circ} \mathrm{C}$ mit 60000 UpM (Beckmann TI-70.1 Rotor, München) zentrifugiert. Die Interkalation von Ethidiumbromid zwischen die Basen von DNA führt zur Entwindung der DNA-Doppelhelix. Lineare und zirkuläre DNA weisen Unterschiede in der Menge gebundenen Ethidiumbromids auf, was für eine Trennung in der Cäsiumchlorid-Dichtegradienten Ultrazentrifugation ausgenutzt wird. Die zirkuläre Plasmid-DNA bildet eine distinkte Bande, die unter Verwendung einer Kanüle aus dem Gradienten isoliert wurde. Das Ethidiumbromid wurde über eine Isoamylalkohol-Extraktion aus der DNA-haltigen Lösung entfernt. Durch Dialyse (2.12.4) der DNA-haltigen Lösung gegen TE-Puffer (2.9) wurde das Cäsiumchlorid aus der Präparation beseitigt. Die dialysierte Plasmid-DNA wurde im Restriktionsverdau (2.16.1) überprüft, ihre Konzentration photometrisch bestimmt $(2.12 .5)$ und bei $-20^{\circ} \mathrm{C}$ gelagert. 
STE-Lösung

Tris, $\mathrm{pH} 8,0$

Saccharose

EDTA, pH 8,0

Triton-Mix

Tris, $\mathrm{pH} 8,0$

EDTA, pH 8,0

Triton $X-100$

$\begin{array}{ll}50 & \mathrm{mM} \\ 25 & \%(\mathrm{w} / \mathrm{v}) \\ 1 & \mathrm{mM}\end{array}$

1- $\mathrm{mM}$

$\begin{array}{lll}\text { PEG } 6000 & 30 & \%(w / v) \\ \mathrm{NaCl} & 1,5 & \mathrm{M}\end{array}$

\section{TNE-Puffer}

$\begin{array}{lll}\text { Tris, } \mathrm{pH} 8,0 & 10 & \mathrm{mM} \\ \mathrm{NaCl} & 10 & \mathrm{mM} \\ \text { EDTA, pH 8,0 } & 1 & \mathrm{mM}\end{array}$

Alternativ wurden für die Maxi-Präparation von Plasmiden auch Säulen des „Jetstar-Plasmid Maxi-Kits“ (Jetstar-Plasmid Maxi-Kit 20 2.0, Genomed, Hess. Oldendorff) nach den Herstellerangaben verwendet.

Das Prinzip der Isolierung der Plasmid-DNA über die Silikat-Säulen besteht darin, dass die nach der Präzipitation eines großen Teils der Bakterienproteine und der genomischen DNA und dem Abbau der RNA durch RNasen noch im Zellysat vorhandenen Bestandteile sukzessiv eluiert werden. Die Säulen enthalten Kieselerdepartikel, die kovalent mit einer hydrophilen Substanz beschichtet sind. Durch die hohe Ladungsdichte auf der Oberfläche der Partikel entsteht ein weites Separationsspektrum; durch Veränderung des $\mathrm{pH}$-Wertes und der lonenstärke der Puffer werden nacheinander Proteine, Metaboliten, Polysaccharide, dNTP's, dann RNA und einzelsträngige DNA und schließlich doppelsträngige Plasmid-DNA eluiert (Produktinformation).

\subsection{DNA-Sequenzierung}

Die DNA-Sequenzierung wurde nach dem Kettenabbruchverfahren (Sanger et al., 1977) mit Fluoreszenzfarbstoff-markierten Primern durchgeführt. Eine hitzestabile DNA-Polymerase verlängert die Primer mit den vier dNTP's (dATP, dCTP, dGTP, dTTP) entlang einer einzelsträngigen Matrize in der Sequenzierreaktion. Durch den Einbau von Didesoxynukleotiden (ddNTP's), die in einem statistisch balancierten Verhältnis im Reaktionsgemisch zu den dNTP's vorliegen, kommt es zum Abbruch der DNAStrangsynthese. Es entstehen Fragmente mit unterschiedlicher Länge, die nach elektrophoretischer Auftrennung im Größenvergleich die relativen Positionen der einzelnen Basen entlang der sequenzierten DNA anzeigen. Eine Erweiterung des Sanger-Prinzips stellt das "Cycle Sequencing" dar, bei dem mit wiederholten Reaktionszyklen aus thermaler DNA-Denaturierung, „Primer Annealing” und DNA-Elongation/Termination gearbeitet wird. 
Dieses Prinzip bietet den Vorteil der Signalverstärkung bei gleichzeitig geringen Mengen an benötigtem DNA-Ausgangsmaterial. Alle Sequenzierreaktionen wurden mit dem „Thermo Sequenase Fluorescent Labeled Primer Cycle Sequencing Kit" (Amersham, Braunschweig) unter Verwendung der Thermo Sequenase DNA-Polymerase und IRD800-markierten Sequenzierprimem (Tab. 5) durchgeführt. Mit dieser Methode wurden sowohl subklonierte PCR-Produkte als auch Reportergen- oder Expressionsplasmide sequenziert, die mittels DNA-Minipräparation (2.17.3) oder DNA-Maxipräparation (2.17.4) isoliert worden waren. Diese Technik erlaubte die Sequenzierung von 500-800 bp pro Sequenzierreaktion. Es wurden je DNA-Probe 4 Parallelreaktionen durchgeführt, die sich nur in ihrer ddNTP-Komponente unterschieden:

$\begin{array}{lll}\text { Plasmid-DNA }(100 \mathrm{ng} / \mu \mathrm{l}) & 2 & \mu \mathrm{l} \\ \text { 5'-IRD800-Primer }(1 \mathrm{pmol} / \mu \mathrm{l}) & 0,5 & \mu \mathrm{l} \\ \text { A/C/G/T-Reagenz (Amersham) } & 1 & \mu \mathrm{l} \text { (jeweils in vier Parallelreaktionen) }\end{array}$

Die Reaktion wurde zügig auf Eis in $0,5 \mathrm{ml}$ Eppendorfgefäße (Roche Diagnostics, Mannheim) pipettiert und mit je einem Tropfen Mineralöl (Promega, Mannheim) überschichtet.

Die Reaktionszyklen wurden im TRIO-Thermoblock (Biometra, Göttingen) durchgeführt.

\begin{tabular}{llll}
\hline 5'-IRD-800-Primer & 1. Denaturierung & Zyklus-Temperaturprofil & Zyklen \\
\hline T7Promotor & $95^{\circ} \mathrm{C} / 5 \mathrm{~min}$ & $95^{\circ} \mathrm{C} / 30 \mathrm{sec}, 55^{\circ} \mathrm{C} / 20 \mathrm{sec}, 72^{\circ} \mathrm{C} / 45 \mathrm{sec}$ & 25 \\
LucPFlu & $95^{\circ} \mathrm{C} / 5 \mathrm{~min}$ & $95^{\circ} \mathrm{C} / 30 \mathrm{sec}, 55^{\circ} \mathrm{C} / 20 \mathrm{sec}, 72^{\circ} \mathrm{C} / 45 \mathrm{sec}$ & 25 \\
$\mathrm{CMV}$ & $95^{\circ} \mathrm{C} / 5 \mathrm{~min}$ & $95^{\circ} \mathrm{C} / 30 \mathrm{sec}, 65^{\circ} \mathrm{C} / 20 \mathrm{sec}, 72{ }^{\circ} \mathrm{C} / 45 \mathrm{sec}$ & 25 \\
\hline
\end{tabular}

Tab. 10: Temperaturprofile der Sequenzierreaktion. Die initiale Denaturierungstemperatur sowie deren Dauer sind der Spalte „1. Denaturierung « zu entnehmen. Das Temperaturprofil der Sequenzierreaktion und deren Zyklenanzahl ist in den Spalten „Zyklus-Temperaturprofil“ und „Zyklen“ zusammengefaßt.

Nach Reaktionsende wurden die Proben mit $1 \mu$ l eines EDTA/Formamid-Puffers versetzt, lichtgeschützt und weitgehend auf Eis gehalten. Die Proben wurden bis zur Elektrophorese bei $-20{ }^{\circ} \mathrm{C}$ gelagert. Mit Hilfe eines denaturierenden Polyacrylamidgels wurde das FragmentGemisch elektrophoretisch aufgetrennt (2.13.3), die Auswertung der Bandenmuster erfolgte mit Base ImagIR-Software. 
Alternativ wurden die Proben nach der Dye Terminator Cycle-Sequenzierungs Methode mit einem DNA-Sequenzierungsgerät der Firma ABI PRISM (3100 Genetic Analyzer, Applied Biosystems, Darmstadt) sequenziert:

Bei dieser Methode werden vier mit unterschiedlichen Fluoreszenz-Farbstoffen gekoppelte Didesoxynukleotide (ddNTP) mit nicht markierten Desoxynukleotiden (dNTP) gemischt und eine Sequenzier-PCR-Reaktion durchgeführt. Bei diesem Verfahren wird nur ein Primer (Tab. 6) eingesetzt, so dass ein Strang wiederholt abgeschrieben wird. Die Zyklen von Denaturierung, Anlagerung sowie die Elongation werden 25-mal durchlaufen. Dabei entstehen unterschiedlich lange am 3'-Ende mit basenspezifischen Farbstoffen markierte Fragmente.

Ein Ansatz zur Sequenzierungs-PCR enthielt folgende Komponenten:

$\begin{array}{ll}\mathrm{H}_{2} \mathrm{O} & 6 \mu \mathrm{l} \\ \text { Plasmid-DNA }(100 \mathrm{ng} / \mu \mathrm{l}) & 1 \mu \mathrm{l} \\ \text { Primer }(10 \mathrm{pmol} / \mu \mathrm{l}) & 1 \mu \mathrm{l} \\ \text { Big Dye-Mix (Applied Biosystems, } & 2 \mu \mathrm{l} \\ \text { Darmstadt) } & \end{array}$

(Im Big Dye-Mix enthalten sind: Fluoreszenz-Farbstoff-gekoppelte ddNTP's, dNTP's, eine Polymerase, 10 x Puffer)

Die PCR zur Sequenzierung wurde in einem Gradienten Cycler (PTC-200, Biozym Diagnostik, Hess. Oldendorf) nach folgendem Temperaturprofil durchgeführt:

\begin{tabular}{llllll} 
Segment & Zyklen & \multicolumn{2}{l}{ Temperatur } & & Zeit \\
\hline 1 & 1 & 94 & ${ }^{\circ} \mathrm{C}$ & 2 & $\mathrm{~min}$ \\
2 & 25 & 96 & ${ }^{\circ} \mathrm{C}$ & 15 & $\mathrm{sec}$ \\
& & 56,5 & ${ }^{\circ} \mathrm{C}$ & 15 & $\mathrm{sec}$ \\
& & 60 & ${ }^{\circ} \mathrm{C}$ & 15 & $\mathrm{sec}$ \\
3 & 1 & 60 & ${ }^{\circ} \mathrm{C}$ & 4 & $\mathrm{~min}$ \\
4 & & 4 & ${ }^{\circ} \mathrm{C}$ & $\infty$ &
\end{tabular}

Nach Abschluß der Sequenzier-Reaktion wurde der Sequenzieransatz auf $40 \mu \mathrm{l}$ mit $\mathrm{H}_{2} \mathrm{O}$ aufgefüllt und über einen Sephadex-Filter (Sephadex G-50, Amersham Biosciences, Freiburg) gereinigt. Die DNA-Fragmente wurden über ein Gel-Kapillarsystem elektrophoretisch der Größe nach aufgetrennt. Die vier unterschiedlichen FluoreszenzFarbstoffgruppen, die jeweils an ein bestimmtes Nukleotid gekoppelt waren, wurden durch einen Laser angeregt und die Fluoreszenzsignale durch ein Detektorsystem des DNA- 
Sequenzers anhand ihrer unterschiedlichen Emissionswellenlänge identifiziert und quantifiziert.

\subsection{Proteinbiochemische Methoden}

\subsubsection{Bakterielle Expression und Aufreinigung von GST-Pax6-PD}

Die Aufreinigung des rekombinanten, bakteriell überexprimierten Proteins GST-Pax6-PD (Tab. 8) erfolgte über Affinitäts-Chromatographie. Die Expression von GST-Fusionsproteinen der Glutathion S-Transferase (26 kDa) aus Schistosoma japonicum steht unter der Kontrolle eines IPTG induzierbaren Promotors. Das Plasmid trägt neben einem Ampicillinresistenzgen auch die kodierenden Abschnitte für das laq $1^{q}$-Gen. Durch Zugabe des synthetisch hergestellten Induktors IPTG wird die Wirkung des laq-Repressors aufgehoben und die tac-Promotoraktivität induziert. Die rekombinanten Proteine wurden in Protein-DNA-Bindungsstudien (EMSA, 2.20) eingesetzt.

Nach Transformation der entsprechenden Vektoren in BL21-Zellen (2.11.3) wurden $100 \mathrm{ml}$ $\mathrm{LB}_{\mathrm{Amp}, \mathrm{CA}-M e d i u m ~(2.9)}$ mit einer Kolonie angeimpft und bei $37^{\circ} \mathrm{C}$ mit 200 UpM (Inova 4300,

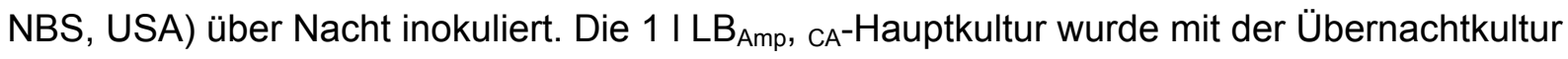
beimpft und bei $37{ }^{\circ} \mathrm{C}$ und 200 UpM (Inova 4300, NBS, USA) bis zu einer optischen Dichte von $\mathrm{OD}_{600}=0,6$ hochgewachsen. Für die SDS-PAGE-Analyse wurde ein $50 \mu$ l-Aliquot entnommen (2.19.5). Zur Induktion wurde IPTG in einer Endkonzentration von $1 \mathrm{mM}$ zugefügt und die Kultur für weitere $3 \mathrm{~h}$ bei $37^{\circ} \mathrm{C}$ und 200 UpM (Inova 4300, NBS, USA) inkubiert. Es wurde erneut ein $50 \mu$-Aliquot für die SDS-PAGE (2.19.5) entnommen und die Zellen bei $4{ }^{\circ} \mathrm{C}$ mit 3500 UpM für 15 min sedimentiert (Beckmann JA-14 Rotor, München). Das Sediment wurde in $40 \mathrm{ml} 1$ x PBS (inkl. $1 \mathrm{mM}$ DTT, $1 \mathrm{mM} \mathrm{PMSF}$; 2.9) resuspendiert und für einen verbesserten Zellaufschluß über Nacht bei $-80^{\circ} \mathrm{C}$ eingefroren. Die Zellsuspension wurde nach langsamem Auftauen auf Eis $(\sim 3 \mathrm{~h})$ in ein $50 \mathrm{ml}$ Polypropylen-Röhrchen (Blue Max, Falcon, Becton Dickinson, U.K.) überführt. Der Aufschluß der Zellen erfolgte durch Sonifizieren der Suspension für 9 mal $20 \mathrm{~s}$ bei 400 Watt (Labsonic 1510, Braun, Melsungen) mit jeweils einer 30-sekündigen Abkühlpause, wobei die Probe während der gesamten Ultraschallbehandlung in Eiswasser gehalten wurde. Zellfragmente wurden durch eine Zentrifugation bei $4{ }^{\circ} \mathrm{C}$ mit $10000 \mathrm{Upm}$ für 10 min (Beckmann JA-20 Rotor, München) von löslichen Bestandteilen getrennt. Sowohl vom Pellet als auch vom Überstand wurde ein $50 \mu \mathrm{l}$-Aliquot für die SDS-PAGE (2.19.5) entnommen. Der Überstand wurde mit $500 \mu \mathrm{l}$ Glutathion-gekoppelter Agarose (50 mM; Sigma, München) für $2 \mathrm{~h}$ bei $4{ }^{\circ} \mathrm{C}$ unter leichtem Schwenken (2.5 Zyklen/min, Mini Rocking Platform, Biometra, Göttingen) inkubiert. Die proteingebundene Agarose wurde durch eine Zentrifugation bei $4{ }^{\circ} \mathrm{C}$ für 3 min mit $1000 \mathrm{UpM}$ 
(Sigma 4K-1, Aichach) sedimentiert, in $10 \mathrm{ml}$ eiskaltem $1 \times$ PBS (inkl. $1 \mathrm{mM}$ DTT, $1 \mathrm{mM}$ PMSF; 2.9) aufgenommen und erneut wie oben zentrifugiert. Diese Waschprozedur wurde insgesamt dreimal wiederholt, wobei nach jedem Waschschritt ein $50 \mu$ l-Aliquot für die SDSPAGE (2.19.5) entnommen wurde. Die Agarose wurde in $1 \mathrm{ml} 1 \mathrm{x}$ PBS (inkl. $1 \mathrm{mM}$ DTT, $1 \mathrm{mM}$ PMSF; 2.9) resuspendiert und in Polypropylen-Säulen („Poly-Prep Chromatography Coloumns“ Bio-Rad, München; 2.5) überführt, in denen die Agarose $15 \mathrm{~min}$ bei RT sedimentierte. Die Elution des gebundenen GST-Pax6-PD-Konstrukts erfolgte durch Zugabe von $2 \mathrm{ml}$ frisch angesetztem Elutionspuffer. Nach einer Inkubation der Agarose mit dem Elutionspuffer für 10 min bei RT wurde der untere Säulenverschluß geöffnet und das Eluat in $200 \mu \mathrm{l}$ Fraktionen in Eppendorf-Reaktionsgefäßen gesammelt. Der Proteingehalt der einzelnen Fraktionen wurde durch Zusatz von $100 \mu \mathrm{l}$ Coomassie Brilliant Blue G-250 Reagenz (1:5 verdünnt, Bio-Rad, München; 2.19.4) zu je $5 \mu$ l Eluat in Mikrotiter-Platten (Microplatte $96 \mathrm{~K}$, Greiner Labortechnik $\mathrm{GmbH}$, Solingen) getestet. Proteinhaltige EluatFraktionen wurden vereint und $3 \mathrm{~h}$ bei $4{ }^{\circ} \mathrm{C}$ unter einmaligem Pufferwechsel gegen 2 । Dignam-Puffer D (2.19.3) dialysiert (2.12.4). Nach Bestimmung der Proteinkonzentration (2.19.4) und Entnahme einer Probe für die SDS-PAGE Analyse (2.19.5) wurde das Gesamteluat aliquotiert und bis zum Gebrauch bei $-80^{\circ} \mathrm{C}$ gelagert.

$\begin{array}{lll}\text { Elutionspuffer } & & \\ \text { Hepes, pH 7,5 } & 20 & \mathrm{mM} \\ \mathrm{NaCl} & 200 & \mathrm{mM} \\ \text { DTT } & 1 & \mathrm{mM} \\ \text { PMSF } & 1 & \mathrm{mM} \\ \text { Glutathion } & 50 & \mathrm{mM}\end{array}$

Zur Voräquilibrierung der Glutathion-gekoppelten Agarose-Matrix wurde die GlutathionAgarose nach Herstellerangaben mit $\mathrm{H}_{2} \mathrm{O}$ versetzt und nach 2-stündiger Quellung 2 mal mit $10 \mathrm{ml} 1 \mathrm{x}$ PBS gewaschen und anschließend in 1 x PBS (inkl. $1 \mathrm{mM}$ DTT, $1 \mathrm{mM}$ PMSF) bei $4{ }^{\circ} \mathrm{C}$ äquilibriert.

\subsubsection{In vitro Transkription und Translation}

Mit dem „TnT Coupled Reticulocyte Lysate System“ (Promega, Mannheim) ist es möglich, Plasmid-DNA in vitro zu transkribieren und die so erzeugte mRNA im Retikulozyten-Lysat zellfrei zu translatieren. Zu diesem Zweck wurde die Protein-kodierende DNA-Sequenz in einen Vektor kloniert (pcDNA3, Promega, Mannheim; 2.11.1), in dem sie unter Kontrolle eines prokaryotischen T7-RNA-Polymerase-Promotors steht. Das Lysat aus KaninchenRetikulozyten enthält eine T7-RNA-Polymerase und alle zur Translation erforderlichen Proteine, Aminosäuren und Zellbestandteile. In einem einzigen Reaktionsansatz findet mit 
Hilfe der RNA-Polymerase die in vitro Transkription statt und das Transkript wird simultan translatiert. Durch Zugabe von $\left[{ }^{35} \mathrm{~S}\right]$-markierten Methionin wurde das Translationsprodukt markiert und konnte so in der Autoradiographie (2.14.2) nachgewiesen werden. Die radioaktiv markierten Proteine wurden anschließend im EMSA eingesetzt (2.20).

Ein $50 \mu \mathrm{l}$ Reaktionsansatz enthielt folgende Komponenten:

$\begin{array}{lcl}\text { TnT Retikulozyten Lysat } & 25 & \mu \mathrm{l} \\ \text { TnT Reaktions-Puffer } & 2 & \mu \mathrm{l} \\ \text { TnT T7-RNA-Polymerase } & 1 & \mu \mathrm{l} \\ \text { Aminosäure-Mix ohne Met }(1 \mathrm{mM}) & 1 & \mu \mathrm{l} \\ \text { RNasin }(40 \mathrm{U} / \mu \mathrm{l}) & 1 & \mu \mathrm{l} \\ \alpha-\left[{ }^{35} \text { S]-Met }(1200 \mathrm{Ci} / \mathrm{mmol})\right. & 4 & \mu \mathrm{l} \\ \text { Plasmid-DNA } & 1 & \mu \mathrm{g} \\ \mathrm{H}_{2} \mathrm{O} & \text { ad } 50 & \mu \mathrm{l}\end{array}$

Der Reaktionsansatz wurde 90 min bei $30{ }^{\circ} \mathrm{C}$ inkubiert. Nach Ende der Inkubation wurde das Lysat mit $20 \%(\mathrm{v} / \mathrm{v})$ Glycerin versetzt und bei $-20{ }^{\circ} \mathrm{C}$ gelagert. Die Analyse der Translationsreaktion und die Quantifizierung der Translationsprodukte erfolgten durch SDSPAGE (2.19.5) unter Verwendung von $5 \mu \mathrm{l}$ des Reaktionsansatzes. Nach der SDS-PAGE erfolgte die Detektion der $\left[{ }^{35} \mathrm{~S}\right]-$ markierten in vitro transkribierten/translatierten Proteine durch Autoradiographie mit Hilfe des Phosphor-Imagers und Exposition eines Röntgenfilms für 1 Tag (2.14.2).

2.19.3 Kernproteinisolierung aus transfizierten Tumorzelllinien (Dignam et al., 1983; modifiziert)

Für die Kernproteinisolierung wurden 10 Gewebekulturschalen $(\varnothing 150 \mathrm{~mm}$ ) mit JEG-3-Zellen kultiviert und pro Schale mit $20 \mu \mathrm{g}$ der Expressionsplasmide für Pax6-WT, -dHD, -dH3, -3Ala, -dPD oder dPD/E6 nach der Calcium-Phosphat-Methode (2.21.4) transfiziert. $48 \mathrm{~h}$ nach der Transfektion wurde das Medium abgesaugt und die kultivierten Zellen mit $10 \mathrm{ml}$ eiskaltem 1 x PBS (2.9) gewaschen. Die Zellen wurden in $10 \mathrm{ml} 1$ x PBS mit einem Gummiabzieher vom Boden der Gewebekulturschale abgelöst und in ein vorgekühltes $50 \mathrm{ml}$ PolypropylenRöhrchen (Blue Max, Falcon, Becton Dickinson, U.K.) überführt und für 10 min bei $4{ }^{\circ} \mathrm{C}$ und 2000 UpM (Sigma 4K-1, Sigma, Aichach) zentrifugiert. Der Überstand wurde abgesaugt, das Sediment im 5-fachen Volumen eiskaltem Puffer A resuspendiert und 10 min auf Eis inkubiert. Nach erneuter Zentrifugation (10 min, $4{ }^{\circ} \mathrm{C}, 2000 \mathrm{UpM}$ ) wurde das Zellsediment in zweifachem Volumen Puffer A aufgenommen. Die Zellen wurden in einen vorgekühlten Glashomogenisator (B-Typ Pistill, Wheaton, Millville, USA) überführt und durch 18 Hübe aufgeschlossen. Das Lysat wurde in einen $50 \mathrm{ml}$ Beckmann-Zentrifugenbecher überführt und 
10 min bei $4{ }^{\circ} \mathrm{C}$ und 2000 UpM (Sigma 4K-1, Sigma, Aichach) zentrifugiert. Der cytosolische Überstand wurde gründlich abgesaugt. Zur Abtrennung cytosolischer Restverunreinigungen wurde die sedimentierte Kernfraktion in zweifachem Volumen eiskaltem Puffer A resuspendiert und $20 \mathrm{~min}$ bei $4{ }^{\circ} \mathrm{C}$ und 14500 UpM (Beckmann JA-20 Rotor, München) zentrifugiert. Die sedimentierten Kerne wurden in $1 \mathrm{ml}$ eiskaltem Puffer $\mathrm{C}$ resuspendiert und in einem vorgekühlten Glashomogenisator (B-Typ Pistill, Wheaton, Millville, USA) mit 10 Hüben aufgeschlossen. Nach der Überführung in ein Becherglas wurde die Suspension 30 min bei $4{ }^{\circ} \mathrm{C}$ gerührt und anschließend 30 min bei $4{ }^{\circ} \mathrm{C}$ und 14500 UpM (Beckmann JA-20 Rotor, München) zentrifugiert. Der klare Überstand wurde in ein Becherglas gegeben und festes Ammoniumsulfat $(0,33 \mathrm{~g} / \mathrm{ml}$ Extrakt) in mehreren Portionen langsam unter Rühren zugegeben (Kühlraum, $4^{\circ} \mathrm{C}$ ). Die Lösung wurde weitere 30 min gerührt und anschließend 20 min bei $4{ }^{\circ} \mathrm{C}$ und 14000 UpM (Eppendorfzentrifuge $5417 \mathrm{R}$, Köln) zentrifugiert. Der Überstand wurde vorsichtig abgesaugt. Das Proteinpellet wurde in $200 \mu \mathrm{l}$ Puffer D aufgenommen und $5 \mathrm{~h}$ bei $4{ }^{\circ} \mathrm{C}$ gegen $1 \mathrm{I}$ Puffer $\mathrm{D}$ dialysiert (2.12.4). Das Dialysat wurde für 20 min bei 14000 UpM (Eppendorfzentrifuge 5417 R, Hamburg) zentrifugiert. Der Überstand mit den Kernproteinen wurde in $10 \mu \mathrm{l}$ Aliquots in flüssigem Stickstoff schockgefroren und bei $-20{ }^{\circ} \mathrm{C}$ gelagert. Zur Konzentrationsbestimmung der Proteine (2.19.4) wurde $1 \mu \mathrm{l}$ des Kernproteinextrakts eingesetzt.

Puffer A

Hepes pH 7,9

$\mathrm{MgCl}_{2}$

$\mathrm{KCl}$

DTT

$\begin{array}{cc}10 & \mathrm{mM} \\ 1,5 & \mathrm{mM} \\ 10 & \mathrm{mM} \\ 0,5 & \mathrm{mM}\end{array}$

\section{Puffer C}

$\begin{array}{lll}\text { Hepes pH 7,9 } & 20 & \mathrm{mM} \\ \text { Glycerin } & 27 & \%(\mathrm{v} / \mathrm{v}) \\ \mathrm{NaCl} & 420 & \mathrm{mM} \\ \mathrm{MgCl}_{2} & 1,5 & \mathrm{mM} \\ \text { EDTA pH 8,0 } & 0,2 & \mathrm{mM} \\ \text { DTT } & 0,5 & \mathrm{mM} \\ \text { PMSF } & 0,5 & \mathrm{mM}\end{array}$

\section{$\underline{\text { Puffer D }}$}

$\begin{array}{lll}\text { Hepes pH 7,9 } & 20 & \mathrm{mM} \\ \text { Glycerin } & 20 & \%(\mathrm{v} / \mathrm{v}) \\ \mathrm{KCl} & 0,1 & \mathrm{M} \\ \text { EDTA pH 8,0 } & 0,2 & \mathrm{mM} \\ \text { DTT } & 0,5 & \mathrm{mM} \\ \text { PMSF } & 0,5 & \mathrm{mM}\end{array}$


2.19.4 Konzentrationsbestimmung von Proteinlösungen (Bradford, 1976)

Die Proteinkonzentration wurden unter Verwendung des "Bio-Rad Protein Assays" (2.5) bestimmt. Der BioRad-Farbstoff (Coomassie Brilliant blue G-250) wurde über Faltenfilter $\left(597^{1} \frac{1}{2}, \varnothing 150 \mathrm{~mm}\right.$, Schleicher \& Schuell, Dassel) filtriert und mit $\mathrm{H}_{2} \mathrm{O} 1: 5$ verdünnt. Die Bestimmung wurde in Mikrotiter-Platten durchgeführt. Zur Konzentrationsbestimmung wurden $20 \mu \mathrm{l}$ einer 1:40-, 1:20- und 1:4-Verdünnungen der Proteinlösung hergestellt, mit 280 $\mu \mathrm{l}$ des verdünnten Farbreagenz versetzt und mit $\mathrm{H}_{2} \mathrm{O}$ auf $300 \mu$ aufgefüllt. Durch die Bindung des Farbstoffes an Proteine verschiebt sich das Absorptionsspektrum des Farbstoffes von $\lambda=465 \mathrm{~nm}$ nach $\lambda=595 \mathrm{~nm}$. Die Proben wurden zur Bildung des Farbkomplexes für $5 \mathrm{~min}$ bei RT inkubiert und die Extinktion bei einer Wellenlänge von $\lambda=550 \mathrm{~nm}$ (Molecular Devices, Kinetic microplate reader) gegen den Pufferleerwert photometrisch ermittelt. Die Bestimmung der Proteinkonzentration erfolgte anhand einer BSA-Eichkurve, die bei jeder Messung durch eine definierte Verdünnungsreihe mit BSA (2.1) erhalten wurde. Die Eichkurve wurde mit BSA-Konzentrationen von 0-100 $\mu \mathrm{g} / \mathrm{ml}$ erstellt, die aus einer $1 \mathrm{mg} / \mathrm{ml}$ BSA-Stammlösung angesetzt wurden.

2.19.5 SDS-Polyacrylamid-Gelelektrophorese (SDS-PAGE) von Proteinen (Laemmli, 1970)

Zur Auftrennung von Proteinen unter denaturierenden Bedingungen wurde eine SDSPolyacrylamid-Gelelektrophorese durchgeführt. Unter denaturierenden Bedingungen, d.h. in der Gegenwart von SDS, wandern Proteine umgekehrt proportional zum Logarithmus ihres Molekulargewichts durch die Polyacrylamid-Matrix zur Anode. Das negativ geladene SDS lagert sich an positiv geladene Aminosäurereste und hydrophobe Seitenketten der Proteine an, so dass die Proteine nach SDS-Behandlung negativ geladen sind. Zusätzlich wird DTT zugegeben, wodurch Disulfidbrücken reduziert werden und sich die Proteine entfalten. In der Modifikation nach Laemmli (1970) wird zusätzlich ein diskontinuierliches Puffersystem zur besseren Trennung der Proteinbanden verwendet. Eine besonders gute Auftrennung der Proteine mit klar abgegrenzten Banden bekommt man mit der diskontinuierlichen Elektrophorese, bei der Proteine erst in einem Sammelgel (4\%) konzentriert werden, ehe sie im Trenngel (5-15 \% Acrylamid, in Abhängigkeit vom relativen Molekulargewicht des zu analysierenden Proteins) aufgetrennt werden. Standardmäßig wurde ein $10 \%$-iges Acrylamidgel verwendet.

Die Trenngellösung wurde gleich nach Zugabe von TEMED und APS in die Gießvorrichtung (Mighty Small-System, SE 250, Hoefer, San Francisco, USA) mit den zusammengesetzten Einzelgelkammern gegeben und mit $\mathrm{H}_{2} \mathrm{O}$ überschichtet. Nach der Polymerisation (30 min, 
RT) wurde das $\mathrm{H}_{2} \mathrm{O}$ abgegossen, mehrfach mit Sammelgelpuffer gespült und das polymerisierte Trenngel mit dem Sammelgel überschichtet. Sofort nach dem Gießen wurde ein Kamm in das Sammelgel eingesetzt. Nach $1 \mathrm{~h}$ Polymerisationszeit bei RT war das Gel gebrauchsfertig und konnte in eine Gelelektrophoresekammer (SE 250, Hoefer, San Francisco, USA) gespannt werden. Die Elektrodenkammern wurden mit 1 x SDS-Laufpuffer gefüllt. Die Proteinproben wurden mit 2 x SDS-Probenpuffer (Endkonzentration $1 \mathrm{x}$ ) versetzt, für 5 min bei $95{ }^{\circ} \mathrm{C}$ denaturiert und auf das Gel aufgetragen. Die elektrophoretische Auftrennung erfolgte bei einer konstanten Stromstärke von $25 \mathrm{~mA} / \mathrm{Gel}$ und konnte durch mitlaufende Protein-Molekulargewichtstandards (2.11.2) verfolgt werden. Nach Ende des Gellaufs wurde das Gel von den Glasplatten gelöst und das Sammelgel verworfen. Handelte es sich um Gele mit nicht radioaktiv markierten Proteinen (2.19.1), so wurden die Gele anschließend durch Coomassie-Lösung (2.19.6) gefärbt. Diente die SDS-PAGE zur Analyse und quantitativen Bestimmung von radioaktiv markierten in vitro TranskriptionsTranslationsprodukten, so wurde das Gel unter Vakuum (Vakuumtrockner G200, Fröbel, Blaufelden) für $1,5 \mathrm{~h}$ bei $65^{\circ} \mathrm{C}$ getrocknet. Zur Autoradiographie (2.14.2) wurde für $10 \mathrm{~min}$ ein Phosphor-Imager-Screen aufgelegt und anschließend für 1 Tag ein Röntgenfilm.

\section{$2 \times$ SDS-Probenpuffer}

Tris, $\mathrm{pH} 6,8$

Bromphenolblau

SDS

Glycerin

DTT
$125 \mathrm{mM}$

$0,1 \%(w / v)$

$4 \%(w / v)$

$20 \%(\mathrm{v} / \mathrm{v})$

$1,25 \%(w / v)$

\section{$5 \times$ SDS-Laufpuffer}

Tris, $\mathrm{pH} 8,3$

$125 \mathrm{mM}$

Glycin

$960 \mathrm{mM}$

SDS

Acrylamidlösung (30\% (w/v)

Acrylamid

$29,2 \mathrm{~g}$

Bisacrylamid

$0,8 \quad g$

$\mathrm{H}_{2} \mathrm{O}$ ad $100 \mathrm{ml}$

Lagerung bei $4{ }^{\circ} \mathrm{C}$.

Sammelgellösung $4 \%$

Acrylamidlösung

Tris, pH 6,8 (0,5 M)

SDS $(10 \%, w / v)$

$\mathrm{H}_{2} \mathrm{O}$

APS $(10 \%$, w/v)

TEMED

$\begin{array}{ll}670 & \mu \mathrm{l} \\ 1,25 & \mathrm{ml} \\ 50 & \mu \mathrm{l} \\ 2,98 & \mathrm{ml} \\ 50 & \mu \mathrm{l} \\ 2,4 & \mu \mathrm{l}\end{array}$

Trenngellösung $10 \%$

$\begin{array}{lll}\text { Acrylamidlösung } & 3,33 & \mathrm{ml} \\ \text { Tris, pH 8,8 (1,5 M) } & 2,5 & \mathrm{ml} \\ \text { SDS }(10 \%, \mathrm{w} / \mathrm{v}) & 100 & \mu \mathrm{l} \\ \mathrm{H}_{2} \mathrm{O} & 4 & \mathrm{ml} \\ \text { APS }(10 \%, \mathrm{w} / \mathrm{v}) & 100 & \mu \mathrm{l} \\ \text { TEMED } & 6 & \mu \mathrm{l}\end{array}$

Die Angaben der Gellösungen beziehen sich auf 2 Minigele ( $80 \mathrm{~mm}$ x $70 \mathrm{~mm}$ x 0,75 mm). 


\subsubsection{Coomassie-Färbung von Proteinen im SDS-Polyacrylamidgel}

Zum Nachweis von Proteinen im SDS-Polyacrylamidgel (2.19.5) wird die Eigenschaft von Coomassie Brilliant Blue R-250 ausgenutzt, unlösliche Farbstoff-Protein-Komplexe zu bilden. Die untere Nachweisgrenze bei diesem Verfahren liegt bei 200-400 ng/0,5 cm Bande. Nach der Elektrophorese wurden die Gele zum Fixieren (d.h. denaturieren und ausfällen) und Anfärben für 15 min in der Färbelösung geschwenkt (2,5 Zyklen/min, Mini Rocking Platform, Blometra $\mathrm{GmbH}$, Göttingen). Zur Entfernung des nicht an Proteine gebundenen Farbstoffs wurden die Gele in Entfärber bei mehrfachem Wechsel der Lösung geschwenkt (2,5 Zyklen/min, Mini Rocking Platform, Biometra $\mathrm{GmbH}$, Göttingen), bis sich die Proteinbanden deutlich vom Hintergrund abhoben. Die Dokumentation erfolgte mittels einer Geldokumentationsanlage (E.A.S.Y. store, Herolab GmbH Laborgeräte, Wiesloch). Zur Lagerung wurden die Gele luftblasenfrei in Zellophanpapier eingeschlagen, zwischen zwei Plexiglasplatten gelegt und 5 Tage an der Luft getrocknet.

$\begin{array}{lll}\text { Färbelösung } & & \\ \text { Coomassie Brilliant Blue R-250 } & 0,25 & \%(\mathrm{w} / \mathrm{v}) \\ \text { Essigsäure } & 10 & \%(\mathrm{v} / \mathrm{v}) \\ \text { Methanol } & 45 & \%(\mathrm{v} / \mathrm{v}) \\ & & \\ \text { Entfärber } & & \\ \text { Essigsäure } & 10 & \%(\mathrm{v} / \mathrm{v}) \\ \text { Methanol } & 45 & \%(\mathrm{v} / \mathrm{v})\end{array}$

Alle Lösungen wurden mit $\mathrm{H}_{2} \mathrm{O}$ angesetzt.

2.20

\section{Electrophoretic Mobility Shift Assay (EMSA) (Knepel et al., 1990b, modifiziert)}

Im EMSA werden DNA-Protein-Interaktionen untersucht. Die Proteine und die markierte DNA werden zusammen inkubiert und anschließend elektrophoretisch im nativen Polyacrylamidgel analysiert. Diese Methode beruht auf der Tatsache, dass Protein-DNAKomplexe in einem nicht-denaturierenden Polyacrylamid-Gel langsamer wandern als freie, ungebundene DNA-Fragmente. Die verlangsamte Wanderungsgeschwindigkeit des ProteinDNA-Komplexes (Retardierung) ist in der Elektrophorese durch eine abweichende Bandenposition („bandshift“) gekennzeichnet. In dieser Arbeit wurde der EMSA eingesetzt, um die Bindung 
- von rekombinanten, bakteriell exprimierten GST-Pax6-PD-Fusionsproteinen (2.19.1; Tab. 8),

- von in vitro transkribierten/translatierten Proteinen (2.19.2; Tab. 8)

- von Kernproteinen aus mit den Expressionsvektoren für die Pax6-Mutanten transfizierten JEG-3-Zellen (2.19.3; Tab. 8)

an $\left[\alpha^{32}\right.$-P]-dCTP-markierten Oligonukleotid-Sonden (Tab. 2) zu charakterisieren.

\subsubsection{Bindungsreaktion}

Alle Pipettierschritte und Inkubationen wurden auf Eis durchgeführt. Für die Bindungsreaktion mit bakteriell exprimiertem GST-Pax6-Fusionsprotein in steigender Konzentration $(0,25 \mu \mathrm{g} ; 0,5 \mu \mathrm{g} ; 1 \mu \mathrm{g} ; 2 \mu \mathrm{g})$ bzw. $20 \mu \mathrm{g}$ JEG-3-Kernextrakt bzw. $10 \mu \mathrm{l}$ in vitro Transkriptions-Translationsansatz für Pax6-WT, -dHD, -dH3, -3Ala wurde der Bindungspuffer modifiziert nach Knepel et al., 1990b verwendet: 20 mM Hepes (pH 7,9), 140 mM KCl, 1 mM EDTA (pH 8,0), 0,5 mM DTT und 10\% (v/v) Glycerin. In einem Eppendorfgefäß wurde den Reaktionsansätzen mit bakteriell exprimiertem Protein jeweils $0,2 \mu \mathrm{g}$, den Reaktionsansätzen mit Kernproteinextrakten jeweils $2 \mu \mathrm{g}$ und den Reaktionsansätzen mit in vitro transkribierten/translatiertem Protein jeweils $2,5 \mu \mathrm{g}$ des Nukleotidpolymers poly ( $\mathrm{dl}-\mathrm{dC}$ ) (Sigma, München) zur Minderung unspezifischer DNA-Bindungen zugesetzt und für $10 \mathrm{~min}$ auf Eis inkubiert. Anschließend wurde der $20 \mu \mathrm{l}$ Gesamtansatz mit 5-10 fmol (15000-30000 $\mathrm{cpm}$ ) einer radioaktiv markierten Oligonukleotid-Sonde (Tab. 2) komplettiert, für 15 min auf Eis inkubiert, mit 6 x Stopp-Mix (2.9) (Enkonzentration $1 \mathrm{x}$ ) versetzt und auf einem nativen Polyacrylamidgel (2.20.2) aufgetrennt.

\subsubsection{Nicht-denaturierende Auftrennung der Protein-DNA-Komplexe}

Protein-DNA-Komplexe aus den Bindungsreaktionen (2.20.1) wurden zur Erhaltung ihrer nativen Struktur unter nicht-denaturierenden Bedingungen und unter Verwendung von Puffern niedriger lonenstärke elektrophoretisch aufgetrennt. Das Gel wurde mit Glasplatten der Größe $18 \mathrm{~cm}$ x $16 \mathrm{~cm}$ x 1,5 mm und Elektrophoresekammern (SE 600, Hoefer, San Francisco, USA) präpariert. Nach der Zugabe von TEMED und APS wurde die Gellösung zügig und luftblasenfrei zwischen die mit abs. Ethanol gereinigten Glasplatten gegossen und ein Teflonkamm für die Auftragstaschen eingesetzt. Nach Polymerisation (1 h) wurde das Gel in die Elektrophoresekammer eingesetzt, die Pufferkammern mit 0,5 x TBE (2.9) als Laufpuffer gefüllt und die Geltaschen anschließend damit gründlich gespült. Es wurde eine konstante Spannung von $180 \mathrm{~V}$ bei RT angelegt und nach $1 \mathrm{~h}$ Vorlauf die Spannung 
unterbrochen, die Proben aufgetragen und die Elektrophorese mit identischen Bedingungen fortgesetzt. Zum Trocknen wurde das Gel auf zwei Lagen Whatman-Papier gelegt und mit Frischhaltefolie bedeckt. Das Gel wurde unter Vakuum (Vakuumtrockner G200, Fröbel, Blaufelden) für $1,5 \mathrm{~h}$ bei $65{ }^{\circ} \mathrm{C}$ getrocknet und die Protein-DNA-Komplexe autoradiographisch nachgewiesen (2.14.2).

$\begin{array}{lll}\text { Acrylamidlösung } 40 \%(\mathrm{w} / \mathrm{v}) & & \\ \text { Acrylamid } & 38 & \mathrm{~g} \\ \text { Bisacrylamid } & 2 & \mathrm{~g} \\ \mathrm{H}_{2} \mathrm{O} & \text { ad } & 100 \mathrm{ml}\end{array}$

Die Lösung wurde filtriert, bei $4^{\circ} \mathrm{C}$ und lichtgeschützt gelagert.

Das 5 \%-ige-Gel (Knepel et al., 1990b, modifiziert) bestand aus folgenden Komponenten:

\begin{tabular}{lll}
\hline Polyacrylamid-Gellösung & \multicolumn{2}{l}{ Knepel et al., 1990b } \\
\hline Acrylamidlösung 40\% (w/v) & $6,25 \mathrm{ml}$ \\
$5 \times$ TBE & $5,00 \mathrm{ml}$ \\
$\mathrm{H}_{2} \mathrm{O}$ & $38,50 \mathrm{ml}$ \\
APS 10\% (w/v) & $0,5 \mathrm{ml}$ \\
TEMED & $50 \quad \mu l$ \\
\hline
\end{tabular}

\subsection{Methoden zur Behandlung eukaryotischer Zellkulturen}

Sämtliche Arbeiten in der Zellkultur erforderten sterile Bedingungen. Unter einer sterilen Werkbank (Baker, Labotect $\mathrm{GmbH}$, Göttingen) wurden daher ausschließlich sterile, vor Benutzung auf $37{ }^{\circ} \mathrm{C}$ vorgewärmte Kulturmedien (2.10) und Pufferlösungen (2.9) verwendet. Die verwendeten Gefäße und Pipettenspitzen wurden vor der Verwendung trocken sterilisiert $\left(4 \mathrm{~h}\right.$ bei $180{ }^{\circ} \mathrm{C}$ ) und direkt vor Benutzung unter der Werkbank abgeflammt. Alle Zentrifugationsschritte erfolgten für 2 min bei RT mit 1300 UpM (Megafuge 1.0, Hereaus Sepatech $\mathrm{GmbH}$, Hamburg).

\subsubsection{Kultivierung eukaryotischer Zellen}

Die Kultivierung von aTC2-, InR1G9- und JEG-3-Zellen (2.11.4) erfolgte in $30 \mathrm{ml}$ des jeweiligen Kulturmediums (2.10) in $15 \mathrm{~cm}$-Kulturschalen (2.8). Die Zellen wurden bei $37^{\circ} \mathrm{C}$, 
$\mathrm{CO}_{2}$-Begasung (5\%) und $93 \%$ relativer Luftfeuchtigkeit im Brutschrank (Steri-Kult Inkubator, Labotect $\mathrm{GmbH}$, Göttingen) kultiviert. Nach Erreichen einer Konfluenz von 80 \% wurden die Zellen passagiert. Nach Absaugen des Kulturmediums wurden die Zellen zur Beseitigung abgestorbener Zellen und des restlichen Kulturmediums mit $10 \mathrm{ml} 1$ x PBS-Puffer gewaschen. Das Ablösen der Zellen erfolgte unter Zugabe von $3 \mathrm{ml}$ Trypsin/EDTA (GIBCO BRL, Karlsruhe) und 2-3 min Inkubation im Brutschrank. Der Trypsinverdau wurde durch Zugabe von $7 \mathrm{ml}$ des entsprechenden Kulturmediums abgestoppt. Die Zellsuspension wurde zentrifugiert, das Sediment in $10 \mathrm{ml}$ Kulturmedium aufgenommen und erneut zentrifugiert. Auf frische $15 \mathrm{~cm}$-Kulturschalen wurden jeweils $25 \mathrm{ml}$ des Kulturmediums verteilt und mit je $5 \mathrm{ml}$ des resuspendierten Zellpellets auf $30 \mathrm{ml}$ Endvolumen aufgefüllt, so dass eine Teilungsrate von 1: 4 ( $\alpha$ TC2-Zellen), 1:6 (InR1G9-Zellen) bzw. 1:7 (JEG-3-Zellen) erfolgte. Nach einer Wachstumsphase von 3-5 Tagen im Brutschrank wurden die Zellen erneut passagiert oder in transienten Transfektionen (2.21.4) eingesetzt.

\subsubsection{Gefrierkonservierung von Zellen}

Zur langfristigen Lagerung von eukaryotischen Kulturzellen wurden Gefrierstocks angelegt, die bei $-196{ }^{\circ} \mathrm{C}$ in flüssigem Stickstoff konserviert wurden. Die Zellen wurden nach Ablösen von der Kulturschale zentrifugiert und mit DMSO-haltigem (10\%, v/v) Kulturmedium gewaschen. Der Zusatz von DMSO (2.1) dient beim Einfriervorgang als Schutz der Zellen gegen Eiskristalle. Nach nochmaliger Zentrifugation wurde das Zellpellet in $10 \mathrm{ml}$ des DMSO-haltigen Mediums aufgenommen, in Einfrierröhrchen (Nalgene, Hereford, U.K.) zu je $1 \mathrm{ml}$ aliquotiert und für $24 \mathrm{~h}$ bei $-80{ }^{\circ} \mathrm{C}$ in einem Styroporbehalter gelagert. Die Langzeitlagerung erfolgte in einem Stickstofftank (GT 140, Schütt Labortechnik Göttingen).

\subsubsection{Revitalisierung von Zellen}

Die Revitalisierung der Zellen wurde zügig durchgeführt, um die durch den Konservierungsstoff DMSO (2.1) auftretenden toxischen Effekte auf die Zellen zu vermeiden. Ein Einfrierröhrchen mit in $-80{ }^{\circ} \mathrm{C}$ eingefrorenen Zellen wurde in einem $37{ }^{\circ} \mathrm{C}$ Wasserbad geschwenkt, bis nur noch ein kleiner Eiskern sichtbar war. Die Zellen wurden in $15 \mathrm{ml}$ vorgewärmten Kulturmedium aufgenommen, zentrifugiert und mit 1 x PBS gewaschen. Das Zellsediment wurde nach erneuter Zentrifugation in $10 \mathrm{ml}$ Kulturmedium resuspendiert, auf eine $10 \mathrm{~cm}$-Kulturschale gebracht und im Brutschrank bei $37^{\circ} \mathrm{C}$ kultiviert. Nach $12 \mathrm{~h}$ wurde das Medium gewechselt, um restliches DMSO, tote Zellen und Zelltrümmer zu entfernen. 
Nach 3-5 Tagen Kultivierung wurden die Zellen zur weiteren Vermehrung auf 15 $\mathrm{cm}-$ Kulturschalen verteilt.

\subsubsection{Transiente Transfektionen eukaryotischer Zelllinien}

Mittels Transfektion wird unverpackte, exogene DNA in eukaryotische Zellen eingeschleust. Bei der transienten Transfektion wird die Fremd-DNA zwar in den Zellkern der Zelle eingebracht, aber nicht in das Genom der Zelle integriert. Die Expression transient transfizierter DNA kann daher nur bis zu $72 \mathrm{~h}$ nach Transfektion nachgewiesen werden, da die Zellen die exogene DNA nach einer Kinetik 1. Ordnung wieder abgeben. Für die transiente Transfektion stehen verschiedene chemische Methoden zur Verfügung. Die Transfektion von $\alpha \mathrm{TC2}$ - und InR1G9-Zellen erfolgte mit dem kationischen Polymer DEAE-Dextran (2.1). Bei dieser Transfektionsmethode wird die DNA im Komplex mit DEAE-Dextran mittels Endocytose über einen noch nicht geklärten Mechanismus aufgenommen. JEG-3-Zellen wurden mit Hilfe der Calcium-Phosphat-Methode transfiziert. Dabei wird die DNA in Form feinkörniger Calcium-Phosphat-Präzipitate auf die Zellen aufgebracht und von diesen vermutlich über Phagocytose aufgenommen. Die Präparation der Zellextrakte (2.21.5) wurde in allen Fällen 48-55 h nach Transfektion vorgenommen.

Transfektion mittels DEAE-Dextran (Sambrook et al, 1989, modifiziert)

Nachdem die aTC2-oder InR1G9-Zellen auf einer $15 \mathrm{~cm}$-Schale zu $80 \%$ konfluent gewachsen waren, wurden sie durch eine Trypsin/EDTA-Behandlung (2.21.1) von der Kulturschale abgelöst. Die Reaktion wurde durch Gabe von $7 \mathrm{ml}$ des entsprechenden, inkompletten Mediums (Medium ohne Serum, 2.10) gestoppt. Die Zellsuspension wurde mehrfach vorsichtig auf- und abpipettiert, um die Zellen zu vereinzeln, und anschließend zentrifugiert. Das Zellpellet wurde in $10 \mathrm{ml}$ TD-Puffer gewaschen, zentrifugiert und die Zellen in dem gewünschten Volumen TD-Puffer aufgenommen. Standardmäßig wurden die Zellen einer $15 \mathrm{~cm}$-Schale auf zwölf $6 \mathrm{~cm}$-Schalen aufgeteilt. Dazu wurden sie in $12 \mathrm{ml}$ TD-Puffer aufgenommen, mit $60 \mu$ DEAE-Dextran (5 $\mu$ l DEAE-Dextran/ $6 \mathrm{~cm}$-Kulturschale) versetzt und leicht geschwenkt. Je $1 \mathrm{ml}$ dieser Suspension wurde auf 12 Polypropylenröhrchen verteilt, in welche bereits die zu transfizierenden Reportergen-Plasmide (je $2 \mu \mathrm{g}$, Tab. 7) vorgelegt worden waren. Die Ansätze wurden durch Schwenken gut durchmischt und für 15 min bei RT inkubiert. In dieser Zeit erfolgte die Aufnahme der DNA in die Zellen. Anschließend wurden den Ansätzen jeweils $2 \mathrm{ml}$ Kulturmedium zugefügt, die Zellen zentrifugiert und mit je $2 \mathrm{ml}$ Kulturmedium gewaschen. Nach erneuter Zentrifugation wurden die Zellsedimente in 
$5,5 \mathrm{ml}$ Kulturmedium aufgenommen und die Zellen auf die $6 \mathrm{~cm}$-Kulturschalen $(5 \mathrm{ml}$ Zellsuspension/ $6 \mathrm{~cm}$ Kulturschale) ausgesät. Die Schalen wurden nach $48 \mathrm{~h}$ Inkubation bei $37{ }^{\circ} \mathrm{C}$ zur Zellextraktpräparation (2.21.5) geerntet. Anschließend wurde die Luciferase Reportergen-Aktivität in den Zellextrakten bestimmt (2.21.6). Durch Cotransfektion von 0,5 $\mu \mathrm{g} / 6 \mathrm{~cm}$-Kulturschale des pGFPtpz-cmv [R] control vector-Reportergen-Plasmids (Tab. 7) wurden die Transfektionseffizienz sowie der Einfluß unspezifischer Effekte auf das Luciferase-Reportergen („Squelching") überprüft. Um die Plasmidmengen zwischen den einzelnen Versuchsgruppen konstant zu halten, wurde mit dem pBluescript-Vektor (Stratagene, Heidelberg) ausbalanciert.

$\begin{array}{lll}\text { TD-Puffer } & & \\ \text { Tris, pH 7,4 } & 25 & \mathrm{mM} \\ \mathrm{NaCl} & 140 & \mathrm{mM} \\ \mathrm{KCl} & 5 & \mathrm{mM} \\ \mathrm{K}_{2} \mathrm{HPO}_{4} & 0.7 & \mathrm{mM}\end{array}$

DEAE-Dextran

$60 \mathrm{mg} / \mathrm{ml} \mathrm{H}_{2} \mathrm{O}$

Die Lösung wurde sterilfiltriert.

Der Puffer wurde vor Benutzung autoklaviert.

Transfektion mittels Calcium-Phosphat (Ausubel et al, 1987)

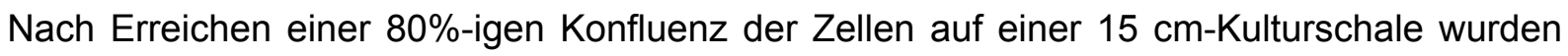
JEG-3-Zellen 16-20 h vor einer Transfektion auf sechzehn $6 \mathrm{~cm}$-Kulturschalen (5 ml Medium/ $6 \mathrm{~cm}$-Kulturschale) aufgeteilt und bis zur Transfektion bei $37^{\circ} \mathrm{C}, 5 \% \mathrm{CO}_{2}$ und $93 \%$ relativer Luftfeuchtigkeit im Brutschrank (Steri-Kult Inkubator, Labotect $\mathrm{GmbH}$, Göttingen) kultiviert. Zur Herstellung der Präzipitate wurden je $3 \mu \mathrm{g}$ Reportergen-Plasmid/6 cm-Kulturschale mit 207 ng, 23 ng bzw. 3 ng der jeweiligen Expressionsplasmide (Tab. 8) in einem Gesamtvolumen von $150 \mu \mathrm{H}_{2} \mathrm{O}$ aufgenommen und mit $150 \mu \mathrm{l} 0,5 \mathrm{M} \mathrm{CaCl}_{2}$-Lösung zu einem Endvolumen von $300 \mu \mathrm{l}$ aufgefüllt. Nach dem Zusammenpipettieren wurde dieser Ansatz unter permanentem Schütteln (Vortexen) zu $300 \mu \mathrm{l} 2$ x HeBS pipettiert und 30 min bei RT inkubiert. In dieser Zeit bildete sich das DNA-Calcium-Phosphat-Präzipitat, was an einer leichten Trübung der Lösung zu erkennen war. Anschließend wurden je $590 \mu \mathrm{l}$ des Ansatzes auf eine $6 \mathrm{~cm}$-Kulturschale mit JEG-3-Zellen aufgetropft, durch leichtes Schwenken der Schale gemischt und bei $37^{\circ} \mathrm{C}$ im Brutschrank inkubiert. Nach 4-5 h wurde das Kulturmedium abgesaugt, die Zellen zur Entfernung nicht-aufgenommener DNA-Präzipitate zweimal mit $1 \times$ PBS gespült und mit $5 \mathrm{ml}$ frischem DMEM-Medium (2.10) überschichtet. Die Zellen wurden für weitere $48 \mathrm{~h}$ bei $37^{\circ} \mathrm{C}$ im Brutschrank kultiviert, zur Zellextrakt-Präparation (2.21.5) geerntet und die Luciferase- und GFP-Aktivitäten (2.21.6 und 2.21.7) bestimmt. Die Kontrolle der Transfektionseffizienz erfolgte bei JEG-3-Zellen durch 
50 ng pGFPtpz-cmv[R] control vector-Plasmid/6 cm-Kulturschale (Tab. 7). Um die Plasmidmengen zwischen den einzelnen Versuchsgruppen konstant zu halten, wurde mit dem pBluescript-Vektor (Stratagene, Heidelberg) ausbalanciert.

$\begin{array}{lcc}\underline{2 \times \text { HeBS }} & & \\ \text { Hepes } & 50 & \mathrm{mM} \\ \mathrm{NaCl} & 140 & \mathrm{mM} \\ \mathrm{Na}_{2} \mathrm{HPO}_{4} & 1,5 & \mathrm{mM} \\ \text { Der pH-Wert wurde mit } 5 \mathrm{~N} \mathrm{NaOH} \text { auf 7,05-7,12 eingestellt. }\end{array}$

\subsubsection{Zellextrakt-Präparation nach einer Transfektion}

Nach einer Inkubation von $48-55$ h bei $37{ }^{\circ} \mathrm{C}$ im Brutschrank wurden die transfizierten Zellen geerntet. Das Kulturmedium wurde abgesaugt, die Zellen mit 1 x PBS (2.9) gewaschen und in $1,5 \mathrm{ml}$ Kratzpuffer mit einem Gummischaber von der Schale abgelöst. Die Zellsuspension wurde in ein Eppendorfgefäß überführt und für $5 \mathrm{~min}$ bei $4{ }^{\circ} \mathrm{C}$ mit $7000 \mathrm{UpM}$ (Eppendorfzentrifuge, 5417 R, Hamburg) zentrifugiert. Das Zellsediment wurde in $150 \mu \mathrm{l}$ Kaliumphosphat-Puffer aufgenommen und zum Zellaufschluß in flüssigem Stickstoff eingefroren, bei $37^{\circ} \mathrm{C}$ wieder aufgetaut und unter starkem Schütteln (VF2, IKA-Labortechnik, Staufen i. Br.) resuspendiert. Insgesamt wurden drei Frier-Auftau-Zyklen durchgeführt. Zur Beseitigung von Zelltrümmern wurde die Suspension für 5 min bei $4{ }^{\circ} \mathrm{C}$ mit $14000 \mathrm{UpM}$ (Eppendorfzentrifuge $5417 \mathrm{R}$, Hamburg) zentrifugiert und je $50 \mu \mathrm{l}$ des Überstandes für die Bestimmung von Luciferase- und GFP-Reportergen-Aktivitäten (2.21.6 und 2.21.7) eingesetzt.

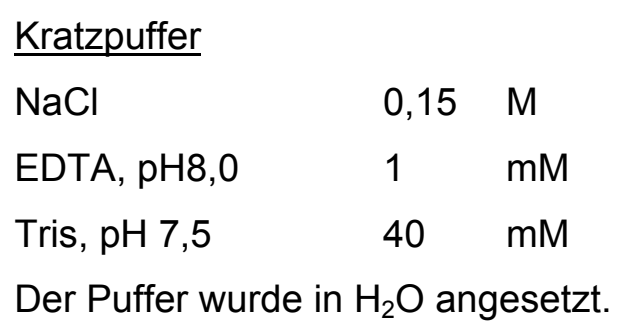

2.21.6 Bestimmung der Luciferase-Aktivität in transfizierten Tumorzelllinien

Die Grundlage des Luciferase-Nachweises ist die enzymkatalysierte Chemilumineszenz. Durch Verwendung des Luciferase-Assays wurde Luciferase des nordamerikanischen Leuchtkäfers (Photinus pyralis) in transfizierten Zellen nachgewiesen. Dabei bildet das 
Enzym Luciferase in Gegenwart von ATP und $\mathrm{Mg}^{2+}$-lonen mit seinem Substrat Luciferin einen Luciferase gebundenen Luciferyl-AMP-Komplex, welcher nach oxidativer Decarboxylierung zu freier Luciferase, Oxyluciferin und AMP zerfällt, Licht der Wellenlänge $562 \mathrm{~nm}$ sowie $\mathrm{CO}_{2}$ freisetzt (De Wet et al., 1987). Die Lichtemission ist durch einen Überschuß an Luciferin, dem Luciferase-Substrat, proportional zur Luciferasekonzentration und kann im Luminometer (AutoLumat LB 953, E\&G Berthold, Bad Wildbad) quantitativ bestimmt werden. Die aus Zellextrakten transfizierter Zellen quantifizierte Luciferasekonzentration erlaubte daher bei Beachtung von Kontrollen Rückschlüsse auf die Aktivität und Stärke der Promotoren transfizierter Luciferase-Reportergen-Plasmide (Tab. 7). Für den Nachweis der Luciferase-Aktivität transfizierter Zellen wurden $50 \mu l$ des präparierten Zellextraktes (2.21.5) zu $368 \mu$ l gekühltem Luciferase-Assay-Mix in ein Luminometerröhrchen (Sarstedt, Nürnbrecht) gegeben. Zu diesem Ansatz wurden im Luminometer (AutoLumat LB 953, E\&G Berthold, Bad Wildbad) automatisch $200 \mu$ l gekühlte Luciferin-Lösung injiziert. Die Lichtemission der Luciferase-Reaktion wurde bei einer Wellenlänge von $560 \mathrm{~nm}$ über einen Zeitraum von $20 \mathrm{sec}$ gemessen und als relative Luciferase-Einheit dargestellt. Reine Luciferin-Lösung diente als Referenz- bzw. Nullwert.

\section{Glycylglycin-Puffer}

Glycylglycin, $\mathrm{pH} 7,8$

$\mathrm{MgSO}_{4}$

EDTA, pH 8,0

Luciferin-Lösung

Luciferin

DTT

in Glycylglycin-Puffer
Kalium-Phosphat-Puffer (KP)

$\begin{array}{lll}\mathrm{K}_{2} \mathrm{HPO}_{4} & 100 & \mathrm{mM} \\ \mathrm{KH}_{2} \mathrm{PO}_{4} & 100 & \mathrm{mM}\end{array}$

Der pH-Wert wurde durch Vorlegen der basischen Lösung und Titration mit der sauren Lösung auf 7,8 eingestellt.

\section{Luciferase-Assay-Mix}

KP-Puffer $\quad 16,5 \quad \mathrm{mM}$

Glycylglycin-Puffer $\quad 82,4 \%(\mathrm{v} / \mathrm{v})$

DTT $\quad 1,1 \quad \mathrm{mM}$

ATP $\quad 2,2 \quad \mathrm{mM}$

\subsubsection{Bestimmung der GFP-Reportergen-Aktivität in transfizierten Zelllinien}

Das "Green Fluorescent Protein" (GFP) ist ein Protein mit Autofluoreszenz, welches aus der Quallenart Aequoria victoria stammt. Unter aeroben Bedingungen wird durch Oxidation und Protonierung spezifischer Aminosäurereste des Proteins die Fluoreszenz erzeugt (Cubitt et al., 1995; Heim et al., 1994). Im pGFPtpz-cmv [R] control vector-Reportergen-Plasmid (Canberra-Packard, Dreieich; Tab. 7) steht die Expression des GFP unter der Kontrolle eines CMV-Promotors und wurde routinemäßig in transienten Transfektionen cotransfiziert 
(2.21.4). Die Transfektionseffizienz sowie die Stärke unspezifischer Effekte auf die Luciferase-Reportergen-Aktvität („Squelching") durch die Expression cotransfizierter Plasmide wurde durch die Stärke des Fluoreszenzsignals aus präparierten Zellextrakten (2.2.10.4) abgeschätzt. Zur Fluoreszenzbestimmung wurden $50 \mu \mathrm{l}$ Zellextrakt (2.21.5) in Rundboden-Mikrotiterplatten (96 K, Greiner GmbH, Frickenhausen) pipettiert. Die Fluoreszenz wurde bei einer Excitation von $485 \mathrm{~nm}$ und einer Emissionswellenlänge von 530 nm mit Software-Unterstützung (Plate Reader Software version 3.0, Packard Inc., Meriden, USA) mit einem Fluorocount-Fluorometer bestimmt (Fusion, Packard, Dreieich). Routinemäßig wurden eine Signalverstärkung von $1100 \mathrm{~V}$ und eine Meßdauer von je $1 \mathrm{sec}$ verwendet.

\subsection{Software zur Sequenzanalyse}

Sequenzvergleiche und Datenabfragen wurden mit Hilfe der jeweiligen Unterprogramme der „,Genetics Computer Groups (GCG)"-Software (Wisconsin Package Version 9.1, Genetics Computer Groups (GCG), Madison, Wisconsin, USA) durchgeführt.

Die Diagramme wurden mit dem Programm SigmaPlot 4.01 der Firma SPSS Inc. erstellt. 
Es wurden die folgenden Konstrukte hergestellt (vgl. 2.11.1; Tab. 7 und 8):

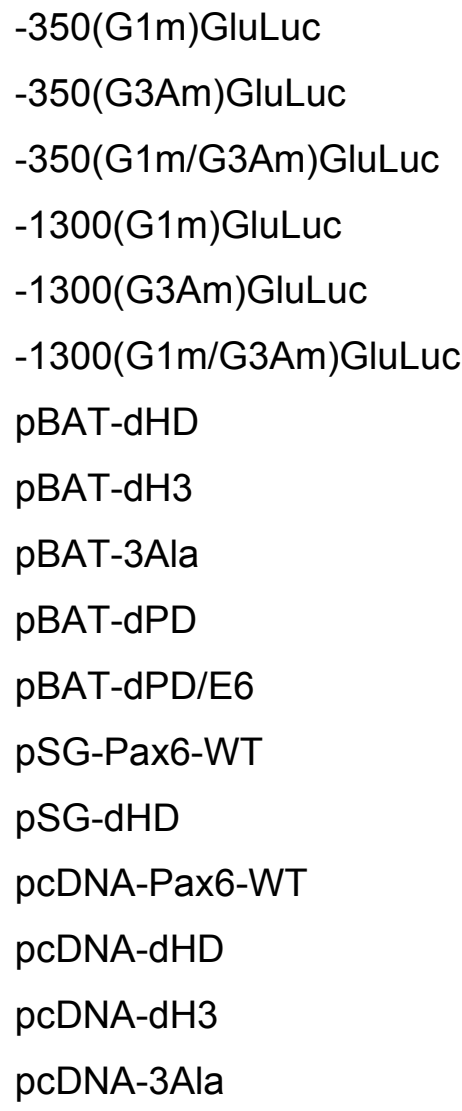

Nach der Herstellung wurde die Identität der Konstrukte durch Restriktionsverdau (2.16.1) und durch Sequenzierung (2.18) überprüft.

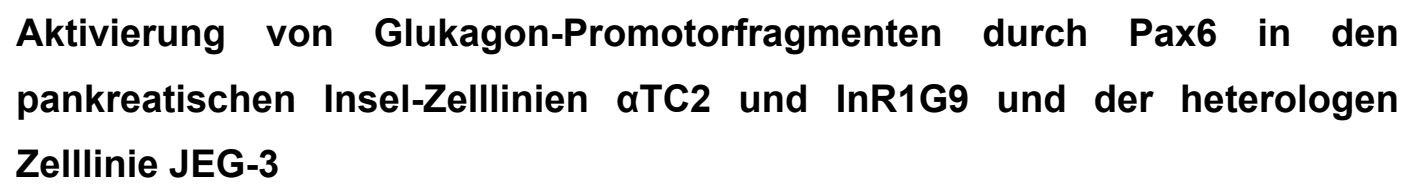
pankreatischen Insel-Zelllinien aTC2 und InR1G9 und der heterologen Zelllinie JEG-3

Für transiente Cotransfektionsexperimente wurde als eine nicht-glukagonproduzierende und nicht-Pax6-exprimierende Zelllinie die humane Chorionkarzinom-Zelllinie JEG-3 ausgewählt. Um zu prüfen, ob heterologe JEG-3-Zellen ein geeignetes Modell für die Untersuchung der Aktivierung von Glukagon-Promotorfragmenten der Ratte durch exogenes Pax6 in Abwesenheit weiterer $\alpha$-zellspezifischer Faktoren ist, wurden Kontrolltransfektionen mit Luciferase-Reportergen-Plasmiden durchgeführt: Einerseits wurde in den glukagonproduzierenden pankreatischen Insellzellinien aTC2 und InR1G9 (2.11.4) die 
Aktivierung von Glukagon-Promotor-Reportergenen durch endogenes Pax6 untersucht und andererseits die Aktivierung von Glukagon-Promotor-Reportergenen durch in der heterologen Zellinie JEG-3 (2.11.4) exprimiertes Pax6. Außerdem wurde geprüft, welchen Einfluß die selektive Mutation der Pax6-Paired-Domänen-Bindungsstellen im G1- oder G3-Element auf die transkriptionelle Aktivität des Glukagon-Gens der Ratte hat. Dazu wurden LuciferaseFusionsgene mit 350 oder 1300 Basenpaaren der 5'-flankierenden Region des GlukagonGens der Ratte mit einem vier-Basenpaar-Austausch im PISCES-Motiv (pancreatic islet cell specific enhancer sequence) des G3A-Elements (Knepel et al., 1990) und/oder einer Punktmutation im PISCES-Motiv des G1-Elements (Morel et al., 1995; Andersen et al., 1999) hergestellt.

3.2.1 Wirkung von Mutationen innerhalb des G1- und G3-Elements auf die Aktivierung des Glukagon-Promotors in den pankreatischen Insel-Zelllinien $\alpha$ TC2 und $\ln \mathrm{R} 1 \mathrm{G} 9$

Im Reporterfusionsgen -1300GluLuc steht die Expression des Luciferase-Gens unter der Kontrolle von 1300 bp der 5'-flankierenden Region des Glukagon-Gens der Ratte.

Die Reportergen-Plasmide -1300GluLuc, -1300(G1m)GluLuc, -1300(G3Am)GluLuc oder $-1300($ G1m/G3Am)GluLuc (Abb. 6; Tab 7) wurden transient in die glukagonproduzierenden Zelllinien aTC2 und InR1G9 transfiziert.

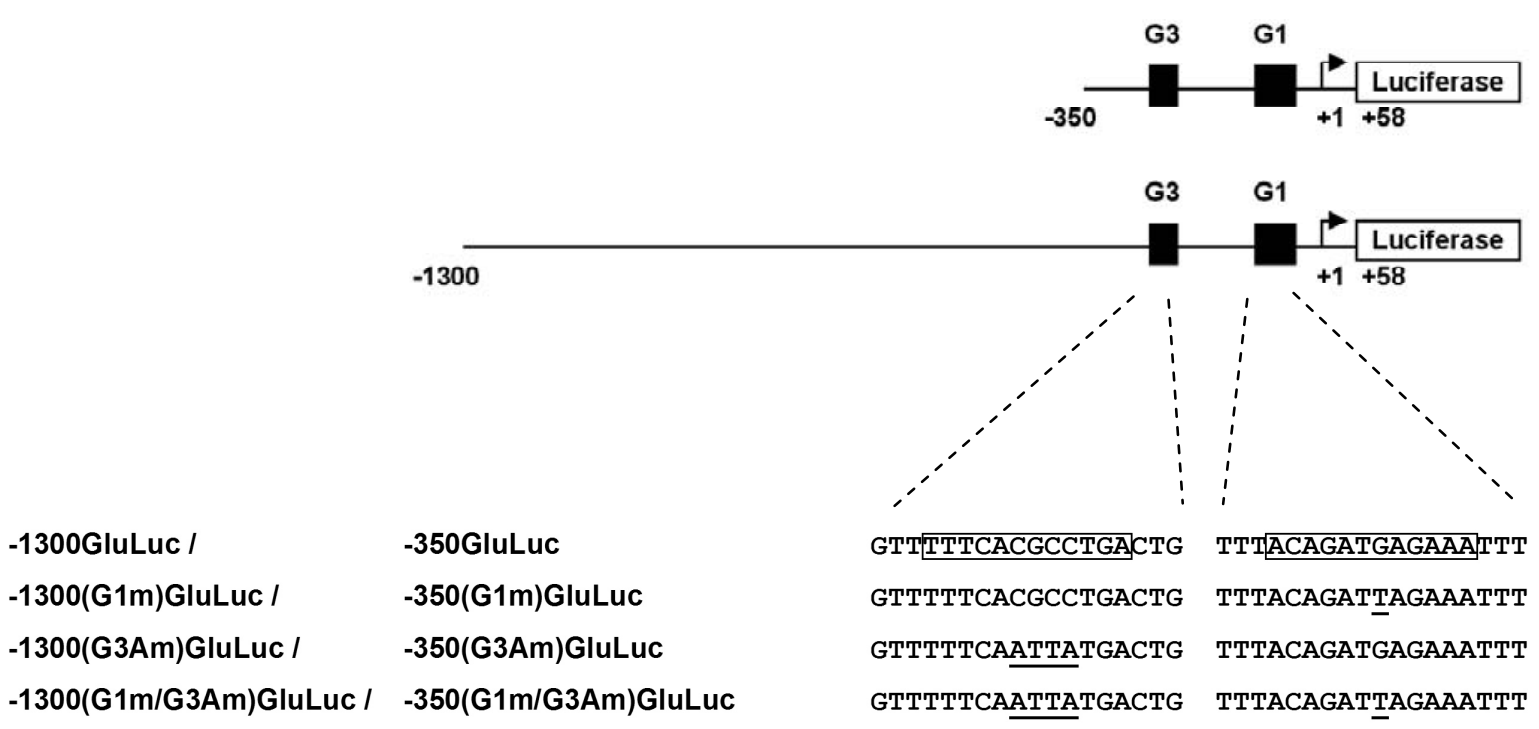

Abb. 6: Glukagon-Reporterfusionsgene mit Mutationen innerhalb des G1- und G3-Elements. Die Expression des Luciferase-Gens erfolgt unter Kontrolle von 350 bzw. 1300 Basenpaaren der 5'flankierenden Region des Glukagon-Gens der Ratte. Innerhalb des Glukagon-Promotors wurde die Pax6-Paired-Domänen-DNA-Bindungsstelle in G1 (Punktmutation, G1m) oder G3 (vier-BasenpaarMutation, G3Am) oder G1 und G3 (G1m/G3Am) selektiv mutiert. G1, Glukagon-Element 1; G3, Glukagon-Element 3. Die Länge des Promotorfragments wird im weiteren durch das Präfix „-350“ bzw. "-1300“ gekennzeichnet. Eingerahmt ist das PISCES-Motiv. 
Bezogen auf die Basalaktivität von -1300GluLuc in aTC2-Zellen verminderte sowohl die Punktmutation im G1-Element als auch die vier-Basenpaar-Mutation im G3-Element die transkriptionelle Aktivität des Luciferase-Gens um 70-80 \% (Abb. 7A). Nach der Mutation des G1- und G3-Elements zeigte sich eine Abnahme um etwa $90 \%$ (Abb. 7A). Ähnliche Ergebnisse wurden in InR1G9-Zellen erhalten (Abb. 7B).

A

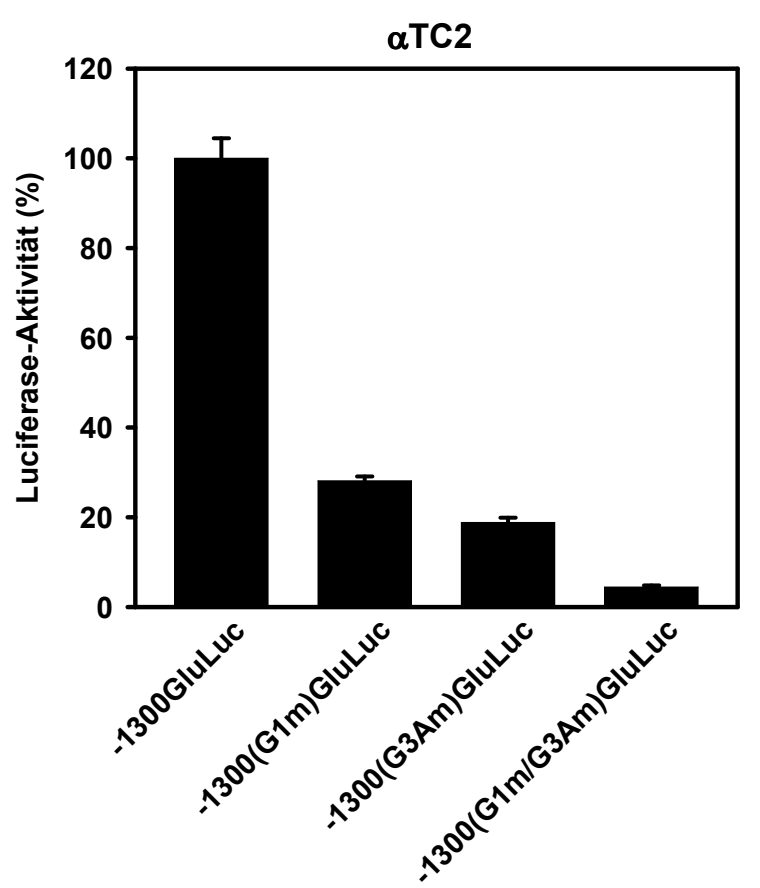

B

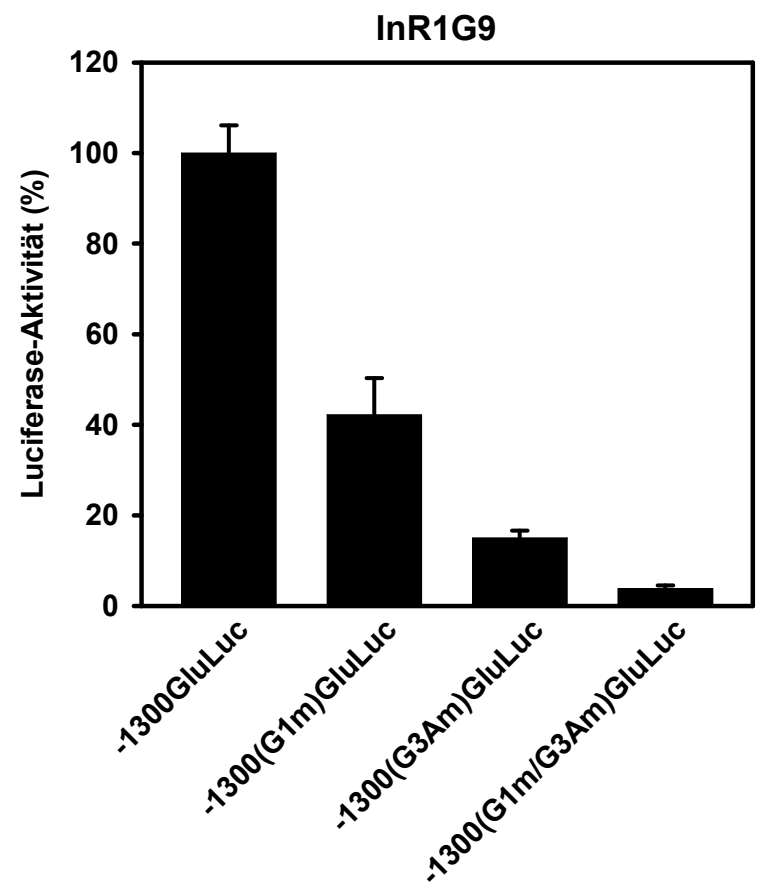

Abb. 7: Die Mutation des G1 und/oder G3-Elements des Glukagon-Promotors der Ratte vermindert die Aktivität eines 1300 bp-Promotorfragments in den glukagonproduzierenden Zellinien $\alpha$ TC2 und InR1G9. Die Reportergen-Plasmide -1300GluLuc, -1300(G1m)GluLuc, -1300(G3Am)GluLuc oder -1300(G1m/G3Am)GluLuc (je $2 \mu \mathrm{g} / \mathrm{Schale}$ ) wurden mittels DEAE-Dextran transient in die glukagonproduzierenden Zelllinien des $\alpha$-Phänotyps $\alpha$ TC2 (A) und InR1G9 (B) transfiziert. Die Luciferase-Aktivität bezieht sich in (A) und (B) auf die Aktivität des -1300GluLucPlasmids, dessen absoluter Wert als $100 \%$ definiert wurde. Die Ergebnisse der Transfektionen sind Mittelwerte und SEM aus drei unabhängigen Experimenten mit Doppelbestimmung.

In analogen Untersuchungen wurden die Reportergen-Plasmide -350GluLuc, -350(G1m)GluLuc, -350(G3Am)GluLuc oder -350(G1m/G3Am)GluLuc (Abb. 6; Tab. 7) transient in InR1G9-Zellen transfiziert. Bezogen auf die Basalaktivität von -350GluLuc führten sowohl die Punktmutation innerhalb des G1-Elements als auch die vier-Basenpaar-Mutation im G3-Element zu einer Abnahme der Luciferase-Aktivität um 75-80 \% (Abb. 8). Nach Mutation des G1- und G3-Elements zeigte sich eine Abnahme der Aktivität um 96 \% (Abb. 8). 


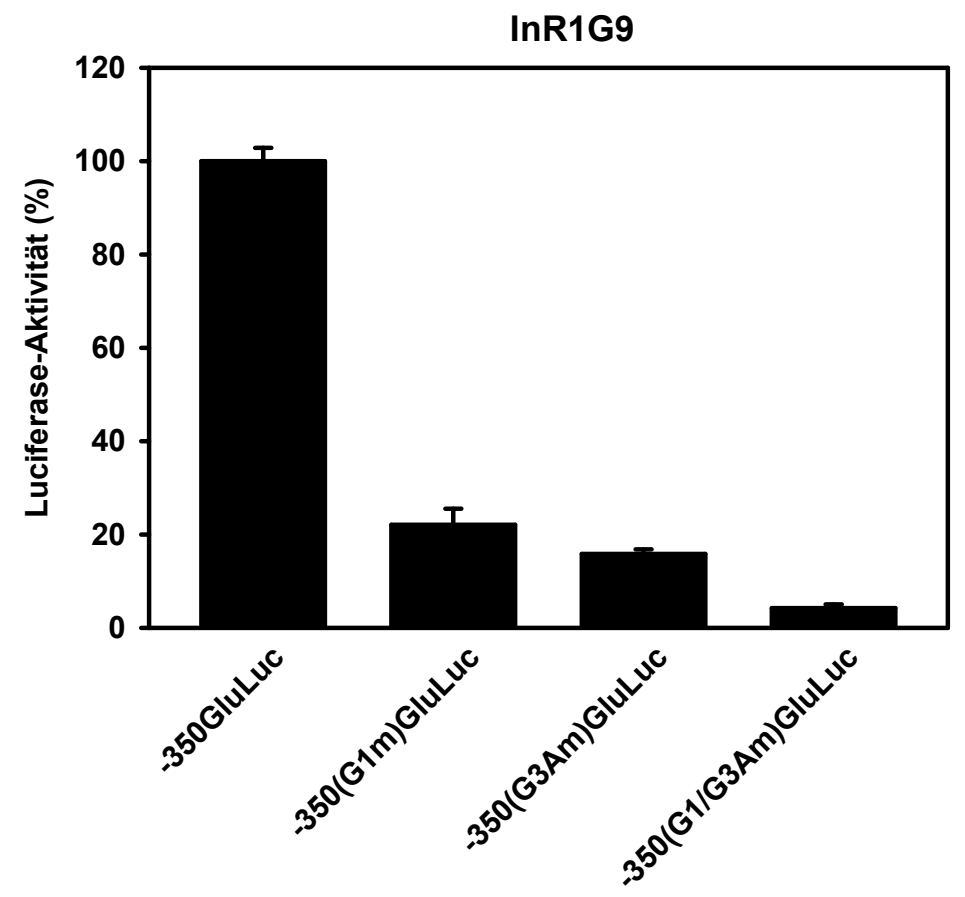

Abb. 8: Die Mutation des $\mathbf{G 1}$ und/oder G3-Elements des Glukagon-Promotors der Ratte vermindert die Aktivität eines 350 bp-Promotorfragments in der glukagonproduzierenden Zelllinie InR1G9. Die Reportergen-Plasmide -350GluLuc, -350(G1m)GluLuc, -350(G3Am)GluLuc oder $-350(\mathrm{G} 1 \mathrm{~m} / \mathrm{G} 3 \mathrm{Am}$ )GluLuc (je $2 \mathrm{\mu g} / \mathrm{Sch}$ ale) wurden mittels DEAE-Dextran transient in die glukagonproduzierende Zelllinie des $\alpha$-Phänotyps InR1G9 transfiziert. Die Luciferase-Aktivität bezieht sich auf die Aktivität des -350GluLuc-Plasmids, dessen absoluter Wert als $100 \%$ definiert wurde. Die Ergebnisse der Transfektionen sind Mittelwerte und SEM aus drei unabhängigen Experimenten mit Doppelbestimmung.

3.2.2 Wirkung von Mutationen innerhalb des G1- und G3-Elements auf die Aktivierung des Glukagon-Promotors durch Pax6 in der heterologen Zellinie JEG-3

Zusammen mit verschiedenen Konzentrationen des Pax6-WT-Expressionsplasmids (Abb. 10; Tab. 8) wurden die Reportergen-Plasmide -1300GluLuc, -1300(G1m)GluLuc, -1300(G3Am)GluLuc oder -1300(G1m/G3Am)GluLuc bzw. -350GluLuc, -350(G1m)GluLuc, -350(G3Am)GluLuc oder -350(G1m/G3Am)GluLuc (Abb. 6; Tab. 7) transient in die heterologe Zelllinie JEG-3 (2.11.4) cotransfiziert. Die Abbildung 9A zeigt die relative Luciferase-Aktivität bei Verwendung der 1300 bp-Reportergen-Plasmide. In der Abbildung sind die gemessenen Werte auf die durch Cotransfektion von -1300GluLuc und 207 ng Pax6-WT erhaltene Aktivität normiert. Die Luciferase-Aktivtät von -1300GluLuc wurde durch 207 ng des Pax6-WTExpressionsplasmids 50-fach induziert (Abb. 9A). Die Punktmutation innerhalb des G1Elements verminderte die Aktivierung durch Pax6 um rund $45 \%$ und die vier-BasenpaarMutation im G3-Element um $65 \%$. Nach der Mutation von G1 und G3 zeigte sich eine Abnahme der Aktivierung durch Pax6 um 80 \% (Abb. 9A). 
A

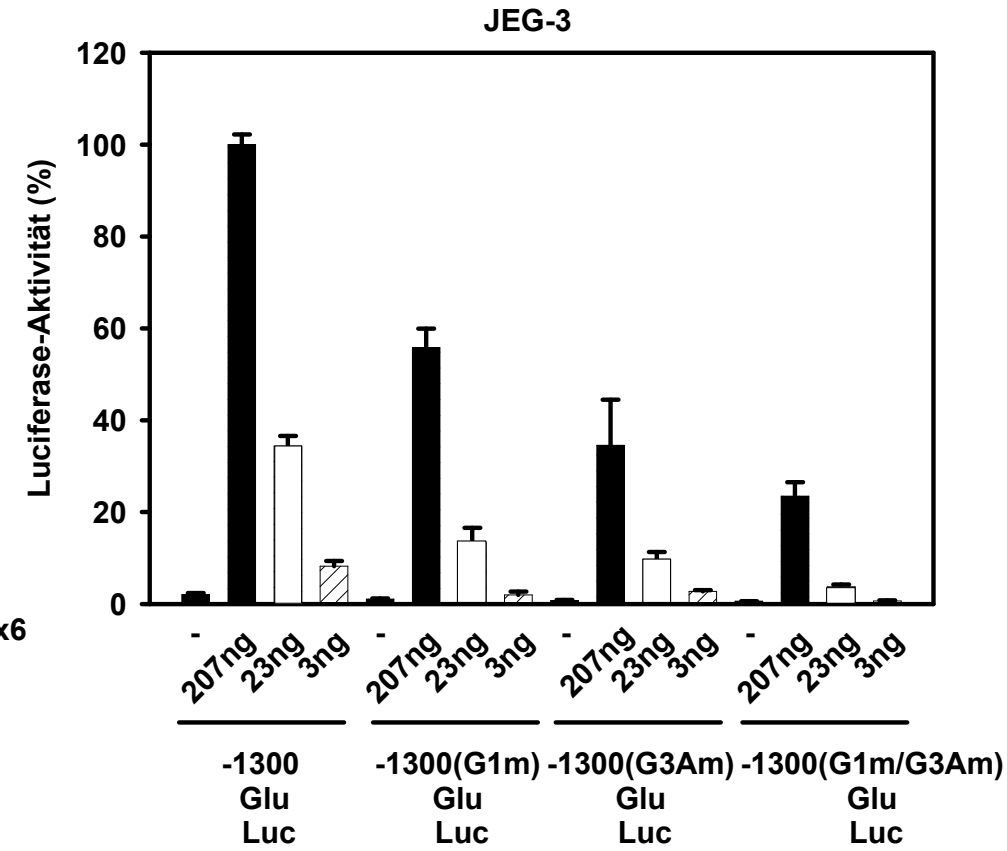

B

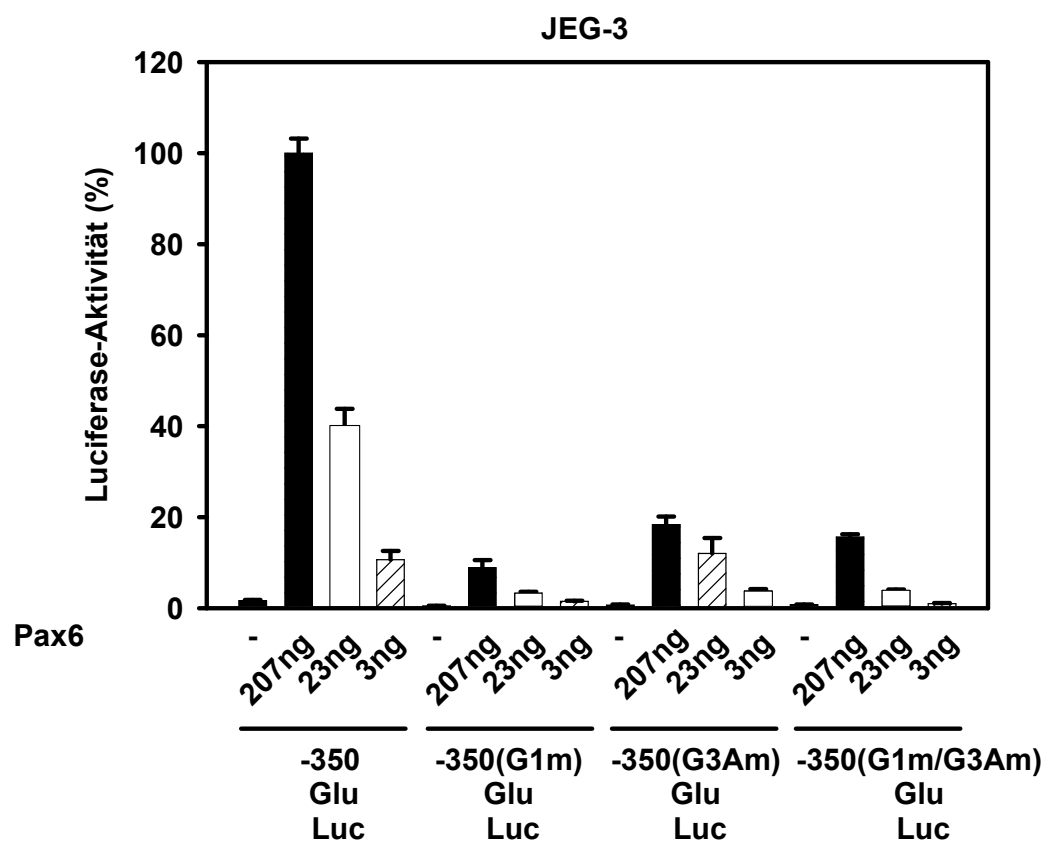

Abb. 9: Die Mutation des G1 und/oder G3-Elements vermindert die Aktivierung des GlukagonPromotors durch Pax6 in der heterologen Zelllinie JEG-3. Die Reportergen-Plasmide -1300GluLuc, -1300(G1m)GluLuc, -1300(G3Am)GluLuc oder -1300(G1m/G3Am)GluLuc (3 $\mu \mathrm{g} / \mathrm{Schale})$ (A) bzw. -350GluLuc, -350(G1m)GluLuc, -350(G3Am)GluLuc oder -350(G1m/G3Am)GluLuc (3 $\mu \mathrm{g} / \mathrm{Schale})(\mathrm{B})$ wurden zusammen mit unterschiedlichen Mengen $(0,207,23,3 \mathrm{ng} / \mathrm{Sch}$ ale $)$ eines Pax6-WT-Expressionsvektors (pBAT-Pax6-WT) mittels Calcium-Phosphat-Präzipitation transient in die humane Chorionkarzinom-Zelllinie JEG-3 cotransfiziert. Die Luciferase-Aktivität bezieht sich in (A) auf die durch Pax6-WT induzierte Aktivität des -1300GluLuc-Plasmids und in (B) auf die durch Pax6 induzierte Aktivität des -350GluLuc-Plasmids, deren absoluten Werte als $100 \%$ definiert wurden. Die Ergebnisse sind Mittelwerte und SEM aus drei unabhängigen Experimenten mit Doppelbestimmung. 
Die relativen Basalaktivitäten der mutierten -1300GluLuc Reportergen-Plasmide betrugen $2 \% \pm 0,4 \%$ bei -1300 GluLuc, $1,1 \% \pm 0,1 \%$ bei $-1300(\mathrm{G} 1 \mathrm{~m})$ GluLuc, $0,7 \% \pm 0,1 \%$ bei $-1300($ G3Am)GluLuc und 0,6 \% $\pm 0,02 \%$ bei $-1300(G 1 \mathrm{~m} / \mathrm{G} 3 \mathrm{Am})$ GluLuc.

Die Abbildung 9B zeigt die relative Luciferase-Aktivität bei Verwendung der 350 bpReportergen-Plasmide. In der Abbildung sind die gemessenen Werte auf die durch Cotransfektion von -350GluLuc und 207 ng Pax6-WT erhaltene Aktivität normiert. Das Reportergen-Plasmid -350GluLuc wurde durch die höchste Menge des cotransfizierten Pax6WT-Expressionsplasmids (207 ng) rund 63-fach stimuliert (Abb. 9B). Die Punktmutation im G1-Element verminderte die transkriptionelle Aktivität des Reportergens um rund $90 \%$ (Abb. 9B). Der vier-Basenpaar-Austausch und die Mutation des G1- und G3-Elements führten zu einer Abnahme der transkriptionellen Aktivität des Luciferase-Gens um rund $80 \%$ (Abb. 9B). Die Basalaktivitäten der mutierten -350GluLuc Reportergen-Plasmide betrugen 1,6 \% \pm $0,2 \%$ bei -350 GluLuc, $0,5 \% \pm 0,1 \%$ bei $-350(\mathrm{G} 1 \mathrm{~m})$ GluLuc, $0,7 \% \pm 0,1 \%$ bei $-350($ G3Am)GluLuc und 0,8 \% \pm 0,1 \% bei $-350(\mathrm{G} 1 \mathrm{~m} / \mathrm{G} 3 \mathrm{Am}) \mathrm{GluLuc}$. Bei Verwendung von 23 ng bzw. 3 ng Pax6-WT-Expressionsplasmid ergaben sich entsprechende Abhängigkeiten der Luciferase-Aktivitäten von den cotransfizierten mutierten Reportergen-Plasmiden (Abb. 9A und B).

\section{Bedeutung der Pax6-Homöodomäne für die Aktivierung des Glukagon- Promotors der Ratte durch Pax6}

Die Bedeutung der Pax6-Homöodomäne für die Aktivierung des Glukagon-Gens durch Pax6 war zentrale Frage dieser Arbeit. Zur Untersuchung der Frage, ob die Pax6-Homöodomäne für die Aktivierung des Glukagon-Gens durch Pax6 von Bedeutung ist, wurden Cotransfektionsexperimente mit Expressionsvektoren für Pax6-Mutanten (Abb. 10; Tab. 8; 2.11.1) und Glukagon-Promotor-Reportergen-Plasmide durchgeführt.

Nachfolgend werden die verwendeten Pax6-Expressionsplasmide aufgelistet:

Pax6-WT: Dieser Expressionsvektor kodiert das gesamte Pax6-Protein der Maus mit der Wildtyp-Sequenz

Pax6-dHD: Der Expressionsvektor kodiert für das Pax6-Protein der Maus mit Ausnahme der Homöodomäne. Von der Homöodomäne beibehalten wurden lediglich drei Aminosäuren am Aminoterminus der Homöodomäne, da diese zu einem Motiv gehören, das in der Wachtel als eines von zwei Kernerkennungssignalen des Pax6-Proteins identifiziert wurde (Carrière et al., 1995). 
Pax6-dH3: Der Expressionsvektor kodiert für das gesamte Pax6-Protein der Maus bis auf die Helix 3, der DNA-Erkennungshelix, am carboxyterminalen Ende der Homöodomäne.

Pax6-3Ala: Der Expressionsvektor kodiert für das Pax6-Protein der Maus, jedoch wurden in Helix 3 der Homöodomäne drei Aminosäuren zu Alanin mutiert: Valin-47, Serin-50, Asparagin-51 (Wilson et al., 1995). Diese drei Aminosäuren der Homöodomäne sind im Drosophila Paired-Protein für die DNA-Bindung notwendig und wurden deshalb gezielt mutiert.

Pax6-dPD: Der Expressionsvektor kodiert für das Pax6-Protein der Maus mit Ausnahme der Paired-Domäne.

Pax6-dPD/E6: Dieser Expressionsvektor kodiert für ein Pax6-Protein, in dem die gesamte Pax6-Paired-Domäne außer der durch Exon 6 kodierten Region der PairedDomäne deletiert wurde, da in Exon 6 (= Exon 5 der Wachtel) eine Kernerkennungssequenz von Pax6 vermutet wird (Carrière et al., 1995).

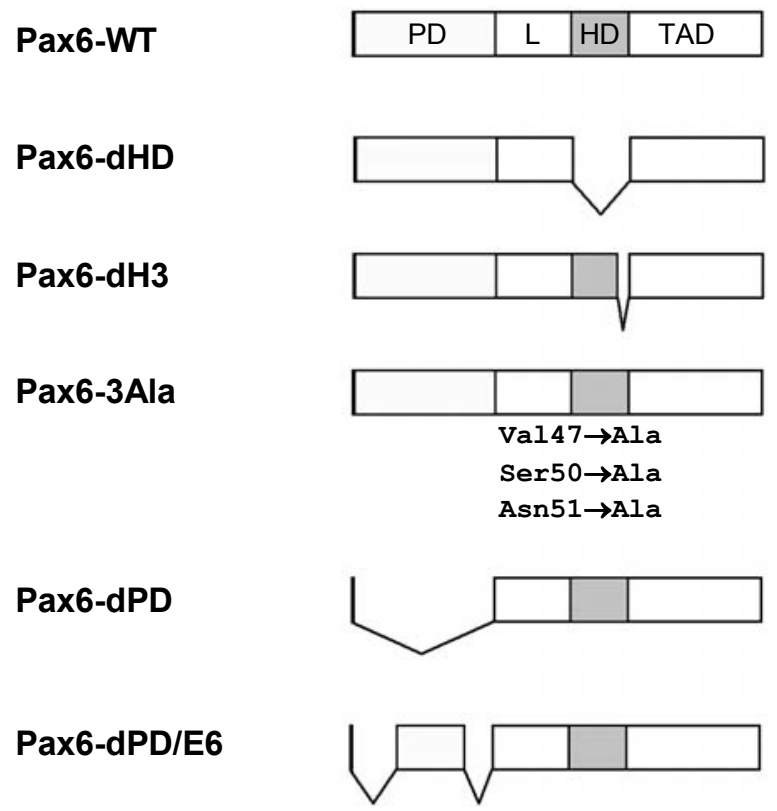

Abb. 10: Pax6 und hergestellte Pax6-Mutanten. Es wurden Expressionsvektoren hergestellt, die für die folgenden Proteine kodieren: Pax6-WT (Pax6-Wildtyp); Pax6-dHD (Deletion der gesamten Pax6Homöodomäne); Pax6-dH3; (Deletion der Helix 3, der DNA-Erkennungshelix der Homöodomäne); Pax6-3Ala (Mutation von drei Aminosäuren, Valin-47, Serin-50, Asparagin-51) der Helix 3 der Pax6Homöodomäne in Alanin; Pax6-dPD (Deletion der gesamten Pax6-Paired-Domäne); Pax6-dPD/E6 (Deletion der gesamten Pax6-Paired-Domäne außer Exon6 kodierter Abschnitte). PD, PairedDomäne; L, Linker; HD, Homöodomäne; TAD, Transaktivierungsdomäne. 
3.3.1 Wirkung einer Deletion bzw. Mutation der Pax6-Homöodomäne auf die Aktivierung von Glukagon-Promotorfragmenten durch Pax6 im heterologen Zellsystem JEG-3

Die Luciferase-Reportergen-Plasmide -1300GluLuc oder -350GluLuc (Abb. 6; Tab. 7) wurden mit verschiedenen Konzentrationen der Expressionsvektoren für Pax6-WT, -dHD, -dH3 -3Ala, dPD oder dPD/E6 (Abb. 10; Tab. 8) transient in die heterologe Zelllinie JEG-3 cotransfiziert. Die Abbildung 11A zeigt die relative Luciferase-Aktivität bei Verwendung des 1300 bpReportergen-Plasmids. In der Abbildung sind die gemessenen Werte auf die durch Cotransfektion von -1300GluLuc und 207 ng Pax6-WT erhaltene Aktivität bezogen (100 \% \pm $5 \%$ ). Die Luciferase-Aktivität von -1300GluLuc wurde durch 207 ng des Pax6Expressionsplasmids rund 31-fach stimuliert (Abb. 11A). Die Deletion der gesamten Homöodomäne bzw. die Deletion der DNA-Erkennungshelix (dH3) bzw. die Mutation von drei Aminosäuren der DNA-Erkennungshelix in Alanin führten zu einer etwa 80 \%-igen Abnahme der transkriptionellen Aktivität des Luciferase-Gens (Abb. 11A). Die Expressionsplasmide $\mathrm{dPD}$ und $\mathrm{dPD} / \mathrm{E6}$ verursachen keine Luciferase-Genexpression (Abb. 11A).

In Abbildung 11B ist die relative Luciferase-Aktivität bei Verwendung des 350 bpReportergen-Plasmids gezeigt. In der Abbildung sind die gemessenen Werte auf die durch Cotransfektion von -350GluLuc und 207 ng Pax6-WT erhaltene Aktivität normiert (100 \% \pm 3,3 \%). Die Luciferase-Aktivität von -350GluLuc wurde durch die Cotransfektion von 207 ng Pax6-WT 193-fach gesteigert (Abb. 11B). Die durch 207 ng Pax6 vermittelte ReportergenExpression wurde als Bezugsniveau festgelegt. Die Deletion der gesamten Homöodomäne bzw. die Deletion der DNA-Erkennungshelix (dH3) bzw. die Mutation von drei Aminosäuren der DNA-Erkennungshelix in Alanin führten ebenfalls zu einer etwa $80 \%$-igen Reduktion der transkriptionellen Aktivität des Luciferase-Gens (Abb. 11B). Die Expressionsvektoren dPD und dPD/E6 führten zu keiner Induktion der Luciferase-Aktivität (Abb. 11B). Bei der Cotransfektion von 23 ng der Pax6-Expressionsplamide wurden entsprechende Abhängigkeiten der Luciferase-Aktivität von den cotransfizierten Reportergen-Plasmiden -1300 GluLuc und -350 GluLuc beobachtet (Abb. 11A und B). 
A

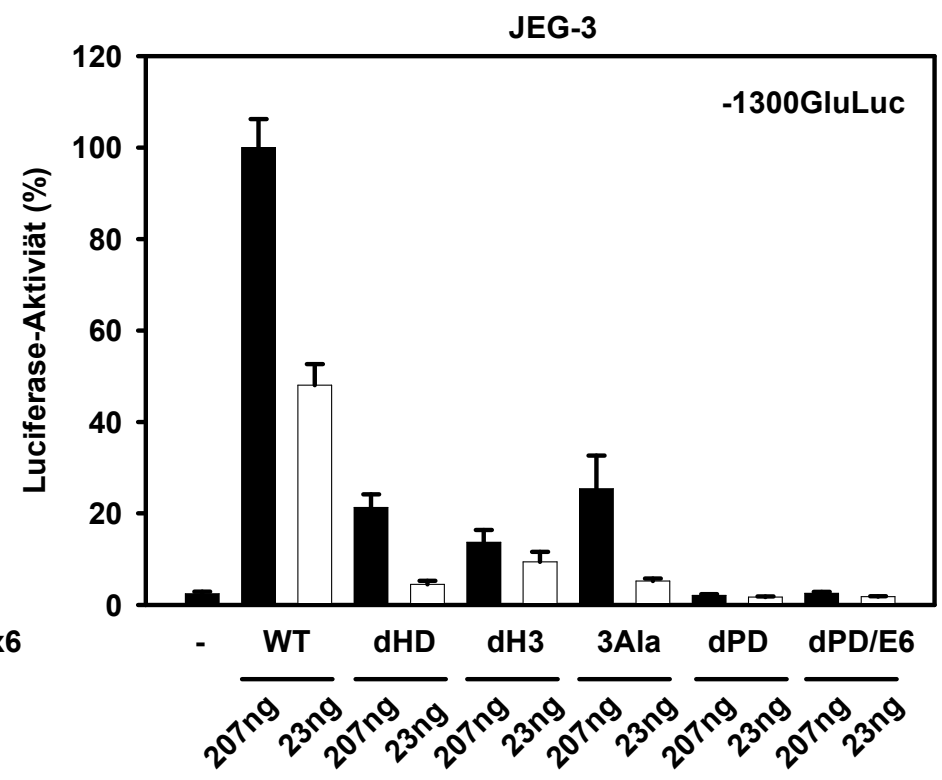

B

JEG-3

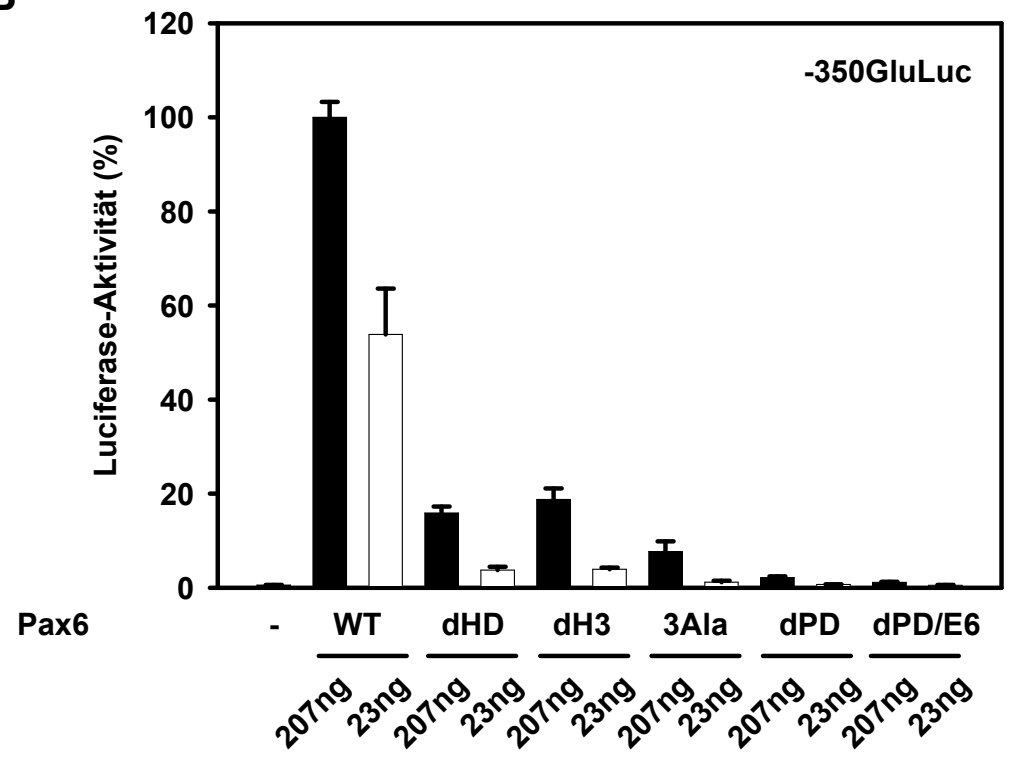

Abb. 11: Die Deletion bzw. Mutation der Pax6-Homöodomäne verringert die Aktivierung des Glukagon-Promotors der Ratte durch Pax6 in der heterologen Zelllinie JEG-3. Das ReportergenPlasmid -1300GluLuc (A) oder -350GluLuc (B) (3 $\mu \mathrm{g} / \mathrm{Schale}$ ) wurde mit unterschiedlichen Mengen (0 ng, 207 ng, 23 ng/Schale) eines Expressionsvektors für Pax6-WT (pBAT-Pax6-WT), dHD (pBATdHD), dH3 (pBAT-dH3), 3Ala (pBAT-3Ala), dPD (pBAT-dPD) oder dPD/E6 (pBAT-dPD/E6) mittels Calcium-Phosphat-Präzipitation transient in die humane Chorionkarzinom-Zelllinie JEG-3 cotransfiziert. Die Luciferase-Aktivität bezieht sich in (A) auf die durch Pax6 induzierte Aktivität des -1300GluLuc-Plasmids und in (B) auf die durch Pax6 WT induzierte Aktivität des -350GluLucPlasmids, deren absoluten Werte als $100 \%$ definiert wurden. Die Ergebnisse der Transfektionen sind Mittelwerte und SEM aus drei unabhängigen Experimenten mit Doppelbestimmung. 
3.3.2 Untersuchung des Expressionsgrades und der Kerngängigkeit der Pax6Homöodomänen-Mutanten

In EMSA-Studien und Transfektionsstudien wurde überprüft, ob die beobachtete Abnahme der transkriptionellen Aktivität von Pax6 am Glukagon-Gen nach der Deletion der Homöodomäne bzw. der Helix 3 oder nach der Mutation der Helix 3 der Pax6-Homöodomäne auf einen geringen Expressionsgrad oder eine verminderte Kerngängigkeit der Pax6Homöodomänen-Mutanten zurückzuführen ist.

Untersuchung der Bindung von in JEG-3 exprimierten Pax6-Proteinen mit deletierter oder mutierter Homöodomäne mittels EMSA

Mit Hilfe eines Electrophoretic mobility shift assays (EMSA, 2.20) wurde der Expressionsgrad der Pax6-Homöodomänen-Mutanten untersucht. Indirekt wurde auch deren Kerngängigkeit geprüft, da zur Herstellung der für den EMSA notwendigen Pax6-Proteine die Expressionsvektoren, die für Pax6-WT oder die Pax6-Homöodomänen-Mutanten dHD, dH3 oder 3Ala oder für die Paired-Domänen-Mutanten dPD oder dPD/E6 (Abb. 10; Tab. 8) kodieren, transient in die heterologe Zelllinie JEG-3 transfiziert wurden (2.21.4). Aus den transfizierten JEG-3-Zellen wurden anschließend die entsprechenden Kernproteinextrakte isoliert (2.19.3; Dignam et al., 1983). Die Bindungsanalysen im EMSA wurden mit einer radioaktiv markierten G3A-Oligonukleotid-Sonde durchgeführt (2.11.1; Tab. 2), da die Proteine der Pax6-Homöodomänen-Mutanten dHD, dH3 und 3Ala eine Paired-Domäne enthalten über die prinzipiell eine Bindung an die Sequenz der Domäne A des G3-Elements des Glukagon-Promotors der Ratte möglich ist.

Kernproteinextrakt mit dHD-, dH3-, 3Ala-, dPD oder dPD/E6-Proteinen wurde mit der [ $\left.{ }^{32} \mathrm{P}\right]-$ radioaktiv markierten G3A-Oligonukleotidsonde inkubiert. Zur Kontrolle der Bindungsspezifität wurden Kernproteine aus nicht-transfizierten JEG-3-Zellen mit der G3ASonde inkubiert. Nach Inkubation der JEG-3-Kernextrakte, die Proteine für den Pax6-WT oder die Pax6-Homöodomänen-Mutanten dHD, dH3 oder 3Ala enthielten, mit der G3AOligonukleotid-Sonde wurden spezifische Protein-DNA-Komplexe detektiert (Abb. 12, Bahn 2, 3, 4 und 5). Keine Protein-DNA-Komplexbildung wurde bei Inkubation der G3AOligonukleotid-Sonde mit Kernextrakten aus dPD, dPD/E6-transfizierten oder nichttransfizierten JEG-3-Zellen beobachtet (Abb. 12, Bahn 1, 6 und 7). Verglichen mit der Bande des Pax6-WT-DNA-Komplexes zeigten $\mathrm{dHD}$ und $\mathrm{dH} 3$ eine erhöhte bzw. 3Ala eine vergleichbare Menge an Protein-DNA-Komplexen. 


\section{G3A 5'-GATCCTCACGCCTGACTGAGCG-3'}

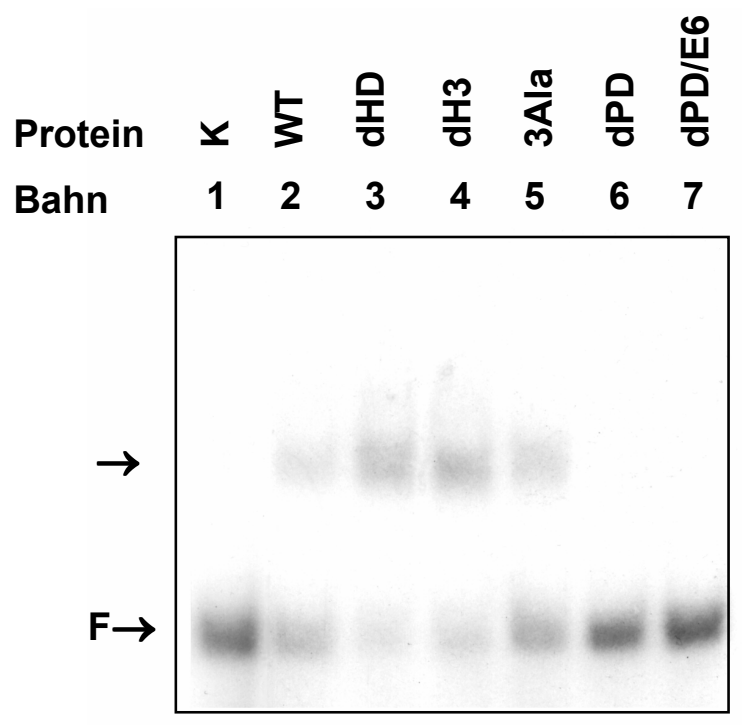

Abb. 12: Pax6-Proteine mit deletierter oder mutierter Homöodomäne zeigen im EMSA eine Bindung an das G3A-Element des Glukagon-Promotors der Ratte. Radioaktiv markierte G3AOligonukleotid-Sonde wurde mit $20 \mu \mathrm{g}$ isolierten Kernproteinen aus mit Pax6-WT -oder den Expressionsplasmiden für die Pax6-Mutanten transfizierten JEG-3-Zellen inkubiert. Die Reaktionsansätze wurden in einem $5 \%$-igen Polyacrylamidgel unter nicht-denaturierenden Bedingungen aufgetrennt. Radioaktiv markierte DNA wurde anschließend autoradiographisch detektiert. Der Pfeil markiert an G3A bindende Proteinkomplexe. F, freie Sonde; K, Kontrolle; WT (pBAT-WT), dHD (pBAT-dHD), dH3 (pBAT-dH3), 3Ala (pBAT-3Ala), dPD (pBAT-dPD) oder dPD/E6 (pBAT-dPD/E6).

Wirkung einer Deletion bzw. Mutation der Homöodomäne auf die durch Pax6 induzierte transkriptionelle Aktivität des G3A-Elements des Glukagon-Promotors der Ratte

Das Reportergen-Plasmid 4xG3AT81Luc (Abb. 13, Tab 7) wurde transient mit $207 \mathrm{ng}$ der Expressionsplasmide für Pax6-WT, dHD, dH3, 3Ala, dPD oder dPD/E6 (Abb. 10; Tab. 8) in JEG-3-Zellen cotransfiziert. Das dabei verwendete Reportergen-Plasmid 4xG3AT81Luc enthält vor dem Luciferase-Reportergen vier Kopien des Abschnitts A des G3-Elements vor einem minimalen Thymidinkinasepromotor (Basenpaar -81 bis +52 ) des Herpes-Simplex Virus.

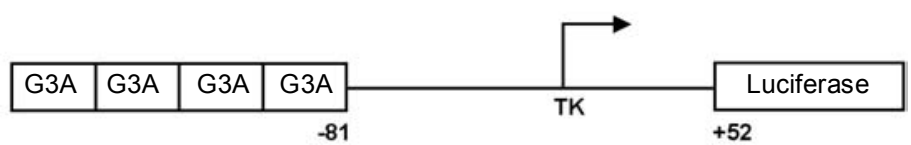

Abb. 13: Reporterfusionsgen des G3A-Elements des Glukagon-Gens. Die Expression des Luciferase-Gens steht unter der Kontrolle von vier Kopien des G3A-Elements des Glukagon-Gens der Ratte (Wrege et al., 1995), die vor einen trunkierten Thymidin-Kinase-Promotor (TK, bp -81 bis +52 ; Nordeen, 1988) kloniert sind. 
Die Cotransfektion der höheren Konzentration des Pax6-Expressionsvektors (207 ng) führte zu einer rund 125-fachen Steigerung der Aktivität von 4xG3AT81Luc (Abb. 14). Wurde diese durch Pax6 induzierte Luciferase-Aktivität als Ausgangsniveau festgelegt (100 \% $\pm 6,8 \%$ ), so verursachte die Cotransfektion des dHD-Expressionsplasmids eine Aktivität von $135 \%$, die des $\mathrm{dH} 3$-Expressionsplasmids eine von $171 \%$ und die des 3Ala-Expressionsplasmids eine von $88 \%$ (Abb. 14). Die Cotransfektion von Pax6-dPD bzw. -dPD/E6 führte zu keiner Stimulation der Luciferase-Aktivität (Abb. 14).

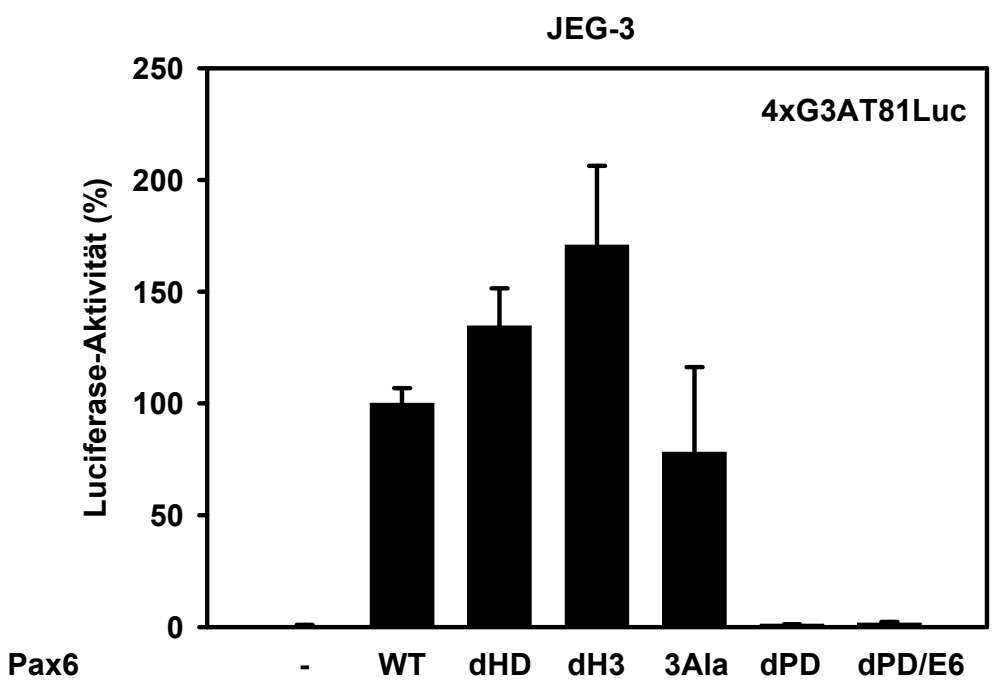

Abb. 14: Die Deletion oder Mutation der Homöodomäne hat keinen Einfluß auf die durch Pax6 induzierte Aktivität des G3A-Elements in heterologen JEG-3-Zellen. Das Reportergen-Plasmid 4xG3AT81Luc (3 $\mathrm{\mu g} / \mathrm{Schale)}$ wurde zusammen mit einem Expressionsvektor für Pax6-WT (pBATPax6-WT), -dHD (pBAT-dHD), -dH3 (pBAT-dH3), -3Ala (pBAT-3Ala), -dPD (pBAT-dPD) oder -dPD/E6 (pBAT-dPD/E6) mittels Calcium-Phosphat-Präzipitation transient in die humane ChorionkarzinomZellinie JEG-3 transfiziert. Die Luciferase-Aktivität bezieht sich auf die durch Pax6-WT induzierte Aktivität des 4xG3AT81Luc-Plasmids, dessen absoluter Wert als $100 \%$ definiert wurde. Die Ergebnisse der Transfektionen sind Mittelwerte und SEM aus fünf unabhängigen Experimenten mit Doppelbestimmung.

\section{Charkterisierung der Bindung von Pax6-Proteinen mit deletierter oder mutierter Homöodomäne an das G1- oder G3-Element des Glukagon- Promotors der Ratte}

Um die Bedeutung der Homöodomäne bei der Bindung von Pax6 an das G3-Element oder das G1-Element des Glukagon-Promotors zu untersuchen, wurde im EMSA die Bindung der Pax6-Homöodomänen-Mutanten $\mathrm{dHD}, \mathrm{dH} 3$ und 3Ala an das G3- oder G1-Element betrachtet. Dazu wurden Pax6-WT und die bereits funktionell charakterisierten Homöodomänen-Mutanten Pax6-dHD, Pax6-dH3 und Pax6-3Ala (Abb. 10; Tab. 8) in vitro 
transkribiert/translatiert (2.19.2) und zusammen mit einer radioaktiv markierten G3Oligonukleotid-Sonde bzw. einer radioaktiv markierten G1-Oligonukleotid-Sonde im EMSA (2.20) eingesetzt.

3.4.1 In vitro Transkription und Translation von Pax6-WT, Pax6-dHD, Pax6-dH3 und Pax6-3Ala und Darstellung der Expressionsprodukte in der SDS-PAGE

Zur Herstellung der Proteine Pax6-WT, dHD, dH3 und 3Ala wurden die Expressionsplasmide pcDNA-Pax6-WT, pcDNA-dHD, pcDNA-dH3 und pcDNA-3Ala (2.11.1; Tab. 8) in zellfreien Kaninchen-Retikulozyten-Lysaten unter Verwendung der T7-RNA-Polymerase in vitro transkribiert/translatiert (2.19.2). Das in vitro transkribierte/translatierte Protein Pax6-WT zeigte eine Proteinbande in der Größe von 47 kDa (Abb. 15, Bahn 2). Die Proteine Pax6$\mathrm{dHD}, \mathrm{dH} 3$ und 3Ala migrierten bei $40 \mathrm{kDa}, 45 \mathrm{kDa}$ und $47 \mathrm{kDa}$ (Abb. 15, Bahn 3, 4 und 5). In einem Kontrollansatz mit Retikulozyten-Lysat ohne Expressionsplasmid waren keine Proteinbanden detektierbar (Abb. 15, Bahn 6). Zusätzlich wurden niedermolekulare Fragmente nachgewiesen (Abb. 15, Bahn 2, 3, 4 und 5).

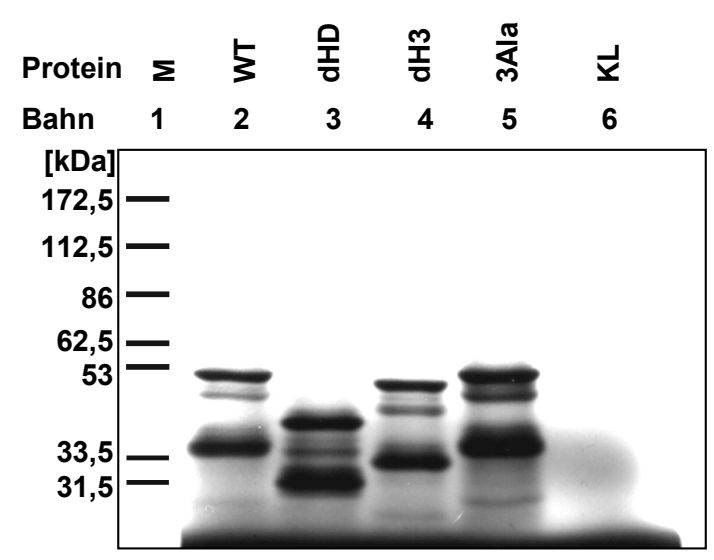

Abb. 15: In vitro Transkription/Translation von Pax6-WT, Pax6-dHD, Pax6-dH3 und Pax6-3Ala in zellfreien Retikulozyten-Lysaten. Für die in vitro Transkription/Translation von Pax6-WT, -dHD, -dH3 und -3Ala in Kaninchen-Retikulozyten-Lysaten wurde je $1 \mu \mathrm{g}$ der Expressionsplasmide pcDNA-Pax6WT, pcDNA-dHD, pcDNA-dH3 oder pcDNA-3Ala unter Verwendung von $\left.{ }^{35} \mathrm{~S}\right]-$ Methionin eingesetzt. Je 5 ul des Reaktionsansatzes (Bahn 2-5) wurden zusammen mit einem Kontrollansatz ohne Expressionsplasmid (Bahn 6) und einem Molekulargewichtstandard (Bahn 1) mittels SDS-PAGE (10 \%-iges Gel) elektrophoretisch aufgetrennt. Die Proteinbanden wurden durch Autoradiographie detektiert. WT (Pax6-Wildtyp), dHD (Deletion der gesamten Pax6-Homöodomäne); dH3 (Deletion der Helix 3 der Pax6-Homöodomäne); 3Ala (Mutation von 3 AS der Helix 3 der Pax6-Homöodomäne in Alanin); KL, Kontroll-Lysat ohne Expressionsplasmid. 
3.4.2 Analyse der Bindung von in vitro transkribiertem/translatiertem Pax6-WT, Pax6$\mathrm{dHD}$, Pax6-dH3 und Pax6-3Ala an das G3-Element oder das G1-Element mittels EMSA

Retikulozyten-Lysate mit in vitro transkribiertem/translatiertem Pax6-WT, Pax6-dHD, Pax6$\mathrm{dH} 3$ oder Pax6-3Ala (2.19.2) wurden mit der radioaktiv markierten G3-Oligonukleotid-Sonde oder mit der radioaktiv markierten G1-Oligonukleotid-Sonde (2.11.1; Tab. 2) inkubiert.

In Gegenwart der G3-Sonde zeigten die in vitro-exprimierten Proteine WT, dHD, dH3 und 3Ala eine verlangsamte Bandenmigration (Abb. 16, Bahn 2, 3, 4 und 5). Die detektierten Signale von dHD, dH3 und 3Ala (Abb. 16, Bahn 3, 4 und 5) entsprachen der Stärke des Signals des WT-DNA-Komplexes (Abb. 16, Bahn 2), wie die Quantifizierung der Radioaktivität mittels Phosphor-Imager ergab. Bei Verwendung des Kontroll-Lysats, welches kein Expressionsplasmid enthielt oder bei Einsatz der freien DNA-Sonde wurde keine Bande nachgewiesen (Abb. 16, Bahn 1 und 6). Die Abstufungen in der Migration der Protein-DNAKomplexe entsprechen den Größenunterschieden der Proteine (Abb. 15).

Bei Verwendung der G1-Oligonukleotid-Sonde zeigten die in vitro exprimierten Proteine Pax6-WT, -dHD, -dH3 und -3Ala eine verlangsamte Bandenmigration (Abb. 16, Bahn 8, 9, 10 und 11). Das Signal, das für die Pax6-dHD-, -dH3-, -3Ala-DNA-Komplexe nach Inkubation mit der G1-Sonde detektiert wurde, war jedoch schwächer als das des Pax6-WT-DNAKomplexes. Die Quantifizierung erfolgte mit Hilfe des Phosphor-Imagers. Zusätzlich zu den WT-, dHD-, dH3- und 3Ala-DNA-Komplexen ließ sich eine langsamer migrierende Bande detektieren, die aber auch bei Verwendung des Kontroll-Lysats erschien (Abb. 16, Bahn 12) und daher unspezifisch ist. Die Abstufungen in der Migration der Protein-DNA-Komplexe entsprechen den Größenunterschieden der Proteine (Abb. 15). 


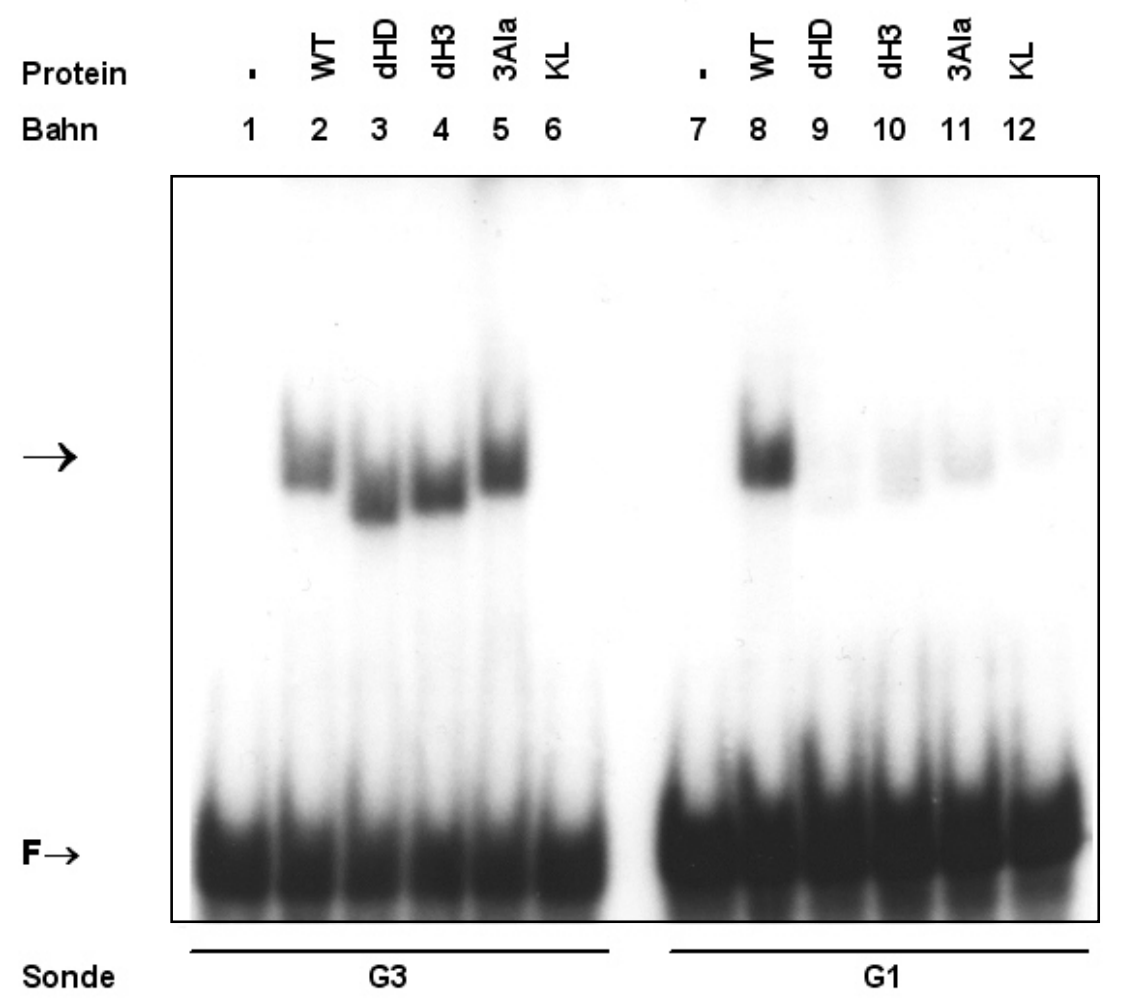

Abb. 16: Pax6 mit deletierter oder mutierter Homöodomäne zeigt im EMSA eine geringere Bindung an das G1-Element des Glukagon-Promotors als Pax6-WT. Radioaktiv markierte G1- und G3-Oligonukleotid-Sonde wurden mit je $10 \mu \mathrm{l}$ des in vitro transkribierten/translatierten Pax6-WT, dHD, $\mathrm{dH} 3$ oder 3Ala oder einem Kontroll-Lysat inkubiert. Der obere Teil zeigt die Sequenzen der eingesetzten Sonden; die unterstrichenen Sequenzen stellen den 5'-Überhang dar. Die Reaktionsansätze wurden auf einem 5 \%-igen Polyacrylamidgel unter nicht-denaturierenden Bedingungen aufgetrennt. Radioaktiv-markierte DNA wurde anschließend autoradiographisch detektiert. Der Pfeil markiert die DNA-bindenden Pax6-Proteinkomplexe. F, freie Sonde.

\section{Bedeutung der Pax6-Homöodomäne für die Aktivierung des Glukagon-Gens der Ratte durch Pax6 allein über das G1-Element oder allein über das G3- Element}

In transienten Cotransfektionen wurde getestet, welche Wirkung die Deletion bzw. Mutation der Pax6-Homöodomäne auf die Aktivierung des Glukagon-Gens durch Pax6 über das G1oder das G3-Element hat. Zu diesem Zweck wurden Glukagon-Promotorkonstrukte mit 350 Basenpaaren der 5'-flankierenden Region des Glukagon-Gens der Ratte, die entweder Pax6-bindungshemmende Mutationen innerhalb des G1- und/oder des G3-Elements enthielten oder in denen das G1- oder G3-Element durch Deletion entfernt worden war, mit 
den Expressionsplasmiden für Pax6-WT, -dHD, -dH3, -3Ala, -dPD oder -dPD/E6 (Abb. 10, Tab. 8) transient in die humane Chorionkarzinom-Zelllinie JEG-3 cotransfiziert.

3.5.1 Aktivierung des Glukagon-Promotors mit mutierter Pax6-Bindungsstelle innerhalb des G1- oder des G3-Elements durch Pax6 oder Pax6 mit deletierter oder mutierter Homöodomäne

Die Aktivierung des Glukagon-Gens durch die Pax6-Homöodomänen-Mutanten oder die Paired-Domänen-Mutanten allein über das G1- oder das G3-Element wurde mit Hilfe von Reportergen-Plasmiden untersucht, in denen die Luciferase-Expression unter der Kontrolle von 350 bp der 5'-flankierenden Region des Glukagon-Gens der Ratte mit mutierten Pax6Bindungsstelle im G1- und/oder G3-Element steht (Abb. 6; Tab. 7).

Analyse der Aktivierung des Glukagon-Promotors mit intern mutiertem G3-Element durch Pax6 oder Pax6 mit deletierter oder mutierter Homöodomäne

Das Reportergen-Plasmid -350(G3Am)GluLuc (Abb. 6; Tab. 7) enthält nur noch die Pax6Bindungsstelle im G1-Element. Es wurde mit zwei verschiedenen Konzentrationen der Expressionsplasmide für Pax6-WT, -dHD, -dH3, -3Ala, -dPD oder -dPD/E6 (Abb. 10; Tab. 8) transient in JEG-3-Zellen cotransfiziert. Die Abbildung 17 zeigt die relative LuciferaseAktivität bei Verwendung des Reportergen-Plasmids -350(G3Am)GluLuc. In der Abbildung sind die gemessenen Werte auf die durch Cotransfektion von -350(G3Am)GluLuc und $207 \mathrm{ng}$ Pax6-WT erhaltene Aktivität normiert (100\% 0,8\%). Die Cotransfektion von $207 \mathrm{ng}$ des Pax6-WT-Expressionsplasmids induzierte die Aktivität von -350(G3Am)GluLuc um den Faktor 17 (Abb. 17). Die Deletion oder Mutation der Homöodomäne führte zu einer rund 65 \%-igen Abnahme der transkriptionellen Aktivität des Luciferase-Gens (Abb. 17). Die Deletion der Paired-Domäne bzw. Teile der Paired-Domäne führte zu einer Reduktion der Luciferase-Aktivität um rund 90 \% (Abb. 17). Bei der Cotransfektion von 23 ng der Pax6Expressionsplasmide ergaben sich entsprechende Abhängigkeiten der Luciferase-Aktivität von dem cotransfizierten mutierten Reportergen-Plasmid (Abb. 17). 


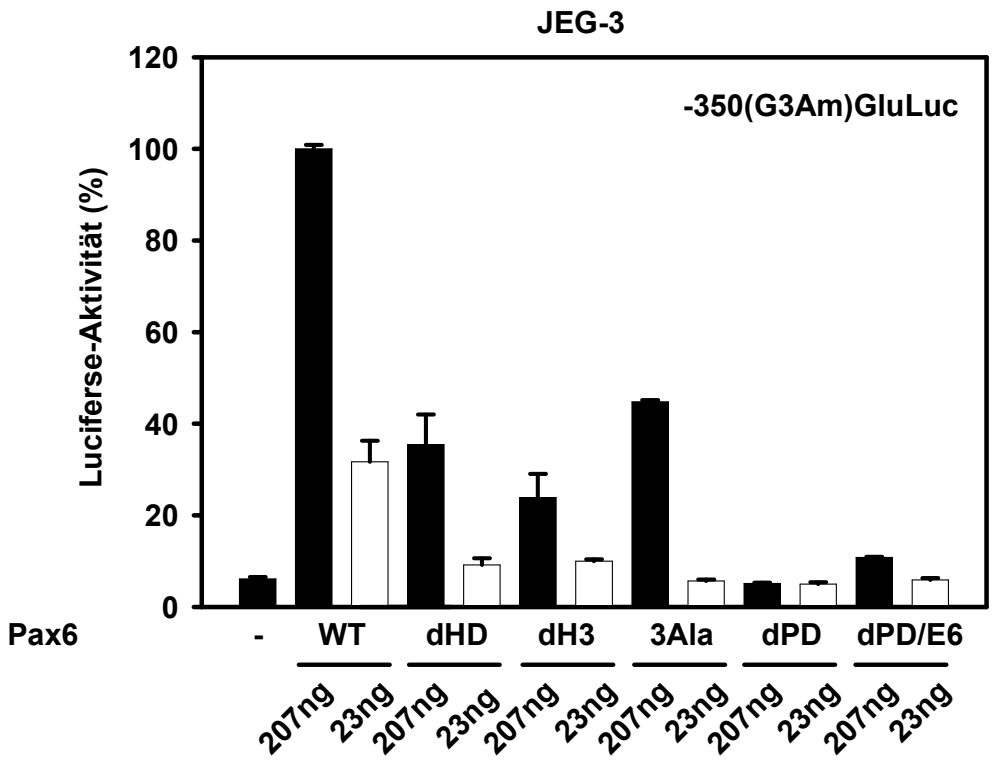

Abb. 17: Die Deletion bzw. Mutation der Pax6-Homöodomäne verringert die Aktivierung des Glukagon-Promotors der Ratte mit intern mutiertem G3-Element durch Pax6 in der heterologen Zelllinie JEG-3. Das Reportergen-Plasmid -350(G3Am)GluLuc (3 $\mathrm{\mu g} / \mathrm{Schale}$ ) wurde zusammen mit unterschiedlichen Mengen (0, 207, 23 ng/Schale) eines Expressionsvektors für Pax6-WT (pBAT-Pax6WT), dHD (pBAT-dHD), dH3 (pBAT-dH3), 3Ala (pBAT-3Ala), dPD (pBAT-dPD) oder dPD/E6 (pBAT$\mathrm{dPD} / \mathrm{E} 6$ ) mittels Calcium-Phosphat-Präzipitation transient in die humane Chorionkarzinom-Zellinie JEG-3 transfiziert. Die Luciferase-Aktivität bezieht sich auf die durch Pax6-WT induzierte Aktivität des -350(G3Am)GluLuc-Plasmids deren absoluter Wert als $100 \%$ definiert wurde. Die Ergebnisse sind Mittelwerte und SEM aus drei unabhängigen Experimenten mit Doppelbestimmung.

Analyse der Aktivierung des Glukagon-Promotors mit intern mutiertem G1-Element durch Pax6 oder Pax6 mit deletierter oder mutierter Homöodomäne

Das Reportergen-Plasmid -350(G1m)GluLuc (Abb. 6; Tab. 7) enthält nur noch die Pax6Bindungsstelle im G3-Element. Es wurde zusammen mit dem Expressionsplasmiden oder für WT, dHD, dH3, 3Ala, dPD oder dPD/E6 (Abb. 10; Tab. 8) transient in heterologe JEG-3Zellen cotransfiziert. In Abbildung 18 ist die relative Luciferase-Aktivität bei Verwendung des Reportergen-Plasmids $-350(\mathrm{G} 1 \mathrm{~m})$ GluLuc dargestellt. In der Abbildung wurden die gemessenen Werte auf die durch Cotransfektion von -350(G1m)GluLuc und 207 ng Pax6WT erhaltene Aktivität bezogen (100\% $\pm 2 \%$ ). Die Cotransfektion von $-350(G 1 \mathrm{~m})$ GluLuc und 207 ng des Pax6-WT-Expressionsplasmids steigerte die Luciferase-Aktivität von $-350(\mathrm{G} 1 \mathrm{~m})$ GluLuc um den Faktor 16 (Abb. 18). 


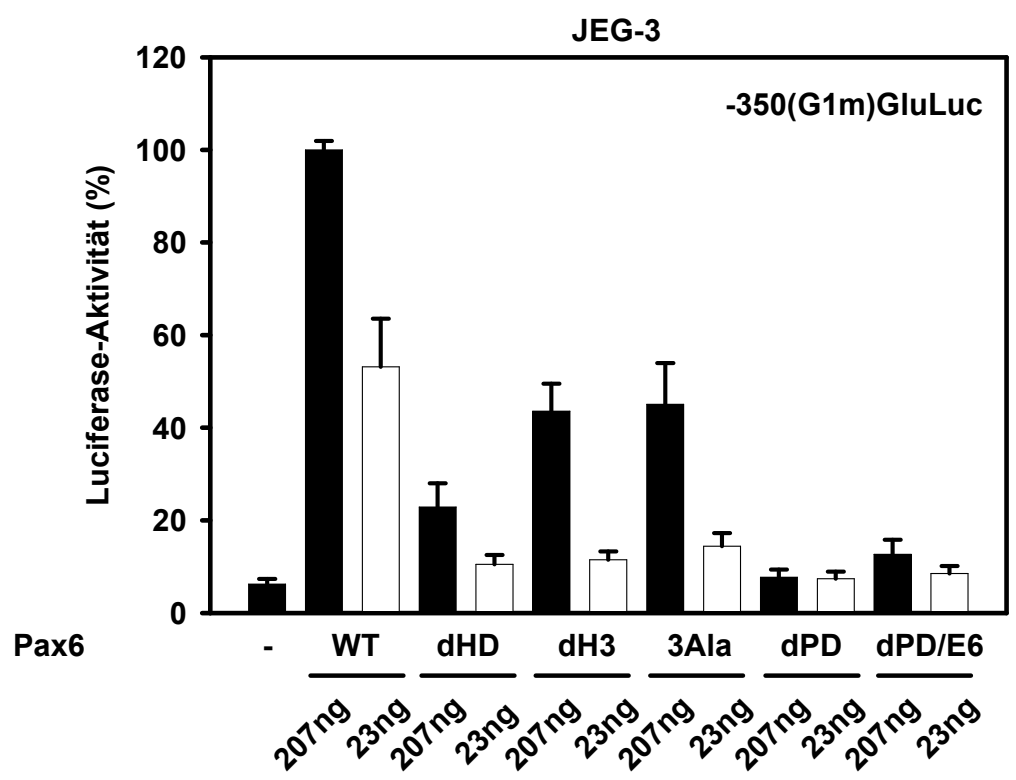

Abb. 18: Die Deletion bzw. Mutation der Pax6-Homöodomäne verringert die Aktivierung des Glukagon-Promotors der Ratte mit intern mutiertem G1-Element durch Pax6 in der heterologen Zelllinie JEG-3. Das Reportergen-Plasmid $-350(\mathrm{G} 1 \mathrm{~m})$ GluLuc $(3 \mu \mathrm{g} / \mathrm{Schale})$ wurde zusammen mit einem Expressionsvektor für Pax6-WT (pBAT-Pax6-WT), dHD (pBAT-dHD), dH3 (pBAT-dH3), 3Ala (pBAT-3Ala), dPD (pBAT-dPD) oder dPD/E6 (pBAT-dPD/E6) (0, 207, 23 ng/Schale) mittels CalciumPhosphat-Präzipitation transient in die humane Chorionkarzinom-Zelllinie JEG-3 transfiziert. Die Luciferase-Aktivität bezieht sich auf die durch Pax6-WT induzierte Aktivität des -350(G1m)GluLucPlasmids und dessen absoluter Wert als $100 \%$ definiert wurde. Die Ergebnisse sind Mittelwerte und SEM aus drei unabhängigen Experimenten mit Doppelbestimmung.

Die Deletion der Homöodomäne bewirkte eine Abnahme der transkriptionellen Aktivität des Luciferase-Gens um 80 \% (Abb. 18). Die Deletion der Helix 3 oder die Mutation in der Helix 3 bewirkten eine Abnahme der Aktivität um rund $60 \%$ (Abb. 18).

Die Deletion der Paired-Domäne oder Teile davon führte zu einer um etwa $90 \%$ verringerten transkriptionellen Aktivität. Die Cotransfektion von 23 ng der Expressionsplasmide ergab eine vergleichbare Abhängigkeit der relativen Luciferase-Aktivitäten von dem mutierten Reportergen-Plasmid (Abb. 18).

Analyse der Aktivierung des Glukagon-Promotors mit intern mutiertem G1- und G3-Element durch Pax6-WT oder die Pax6-Homöodomänen-Mutanten

Im Reportergen-Plasmid -350(G1m/G3Am)GluLuc (Abb. 6; Tab. 7) wurden sowohl innerhalb des G1- als auch innerhalb des G3-Elements die Pax6-Bindungsstellen mutiert. Die heterologe Zellinie JEG-3 wurde transient mit -350(G1m/G3Am)GluLuc und zwei verschiedenen Konzentrationen der Expressionsvektoren für Pax6-WT, -dHD, -dH3, -3Ala, 
-dPD oder -dPD/E6 (Abb. 10; Tab. 8) cotransfiziert. Die Abbildung 19 zeigt die relative Luciferase-Aktivität bei Verwendung des Reportergen-Plasmids -350(G1m/G3Am)GluLuc. In der Abbildung wurden die gemessenen Werte auf die durch Cotransfektion von -350(G1m/G3Am)GluLuc und 207 ng Pax6-WT erhaltene Aktivität normiert (100 \% \pm 5,9\%). Die Cotransfektion der größeren Menge Pax6-WT steigerte die Luciferasegen-Aktivität von -350(G1m/G3Am)GluLuc um den Faktor 6 (Abb. 19). Deletion oder Mutation der Pax6Homöodomäne, Deletion der Paired-Domäne oder Teile davon führten zu einer etwa 80 \%-igen Abnahme der transkriptionellen Aktivität des Reportergens (Abb. 19).

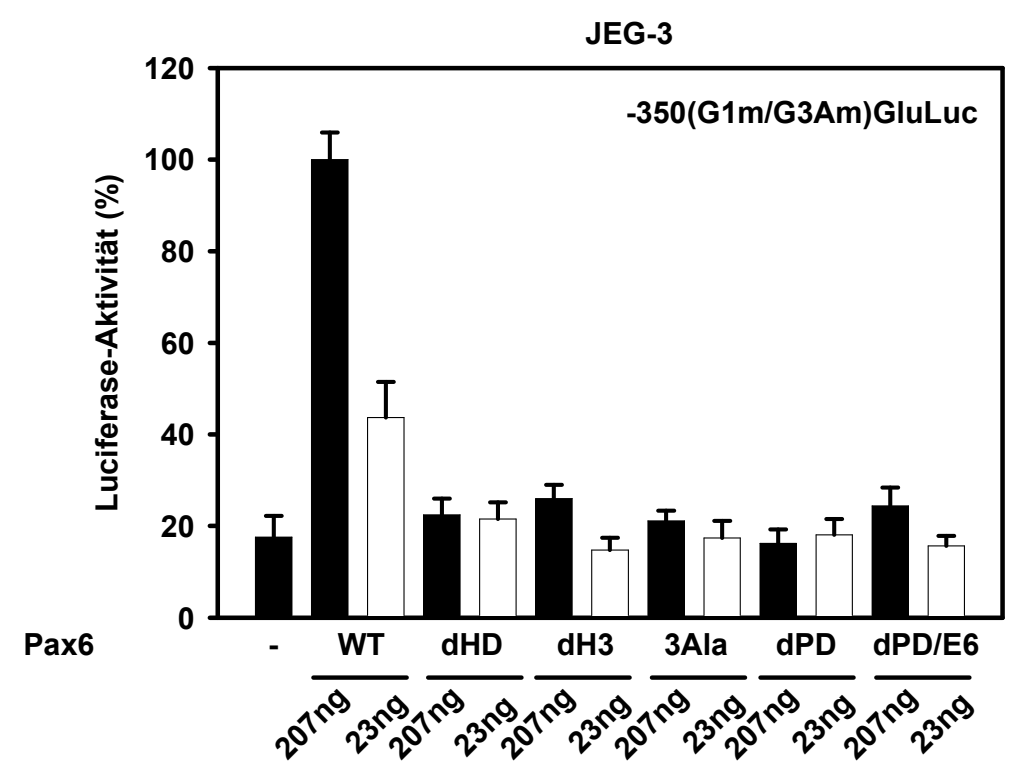

Abb. 19: Die Deletion bzw. Mutation der Pax6-Homöodomäne verringert die Aktivierung des Glukagon-Promotors der Ratte mit intern mutiertem G1- und G3-Element durch Pax6 in der heterologen Zelllinie JEG-3. Das Reportergen-Plasmid -350(G1m/G3Am)GluLuc (3 $\mu \mathrm{g} / \mathrm{Schale})$ wurde zusammen mit einem Expressionsvektor für Pax6-WT (pBAT-Pax6-WT), dHD (pBAT-dHD), dH3 (pBAT-dH3), 3Ala (pBAT-3Ala), dPD (pBAT-dPD) oder dPD/E6 (pBAT-dPD/E6) (0, 207, $23 \mathrm{ng} / \mathrm{Schale)}$ mittels Calcium-Phosphat-Präzipitation transient in die humane ChorionkarzinomZelllinie JEG-3 transfiziert. Die Luciferase-Aktivität bezieht sich auf die durch Pax6-WT induzierte Aktivität des $-350(\mathrm{G} 1 \mathrm{~m} / \mathrm{G} 3 \mathrm{Am})$ GluLuc-Plasmids dessen absoluter Wert als $100 \%$ definiert wurde. Die Ergebnisse sind Mittelwerte und SEM aus drei unabhängigen Experimenten mit Doppelbestimmung. 
3.5.2 Aktivierung des Glukagon-Promotors der Ratte mit deletiertem G3- oder G1Element durch Pax6 oder Pax6 mit deletierter oder mutierter Homöodomäne

Analyse der transkriptionellen Aktivierung von Glukagon-Promotorfragmenten mit deletiertem G3-Element durch Pax6-WT oder die Pax6-Homöodomänen-Mutanten

Mit Hilfe von 5'-Deletionsmutanten des 350 bp-Glukagon-Promotorkonstruktes wurde die Aktivierung des Glukagon-Gens über das G1-Element durch die Pax6-HomöodomänenMutanten getestet. In den 5'-Deletionsmutanten des 350 bp-Glukagon-Promotorfragments steht die Luciferase-Expression unter der Kontrolle von 292, 238, 200, 169 oder 60 Basenpaaren des Glukagon-Promotors der Ratte (Fürstenau et al., 1997). Die 5'Deletionsmutanten wurden ausgehend von 350 Basenpaaren der 5'-flankierenden Region des Glukagon-Gens der Ratte vom 5'-Ende her verkürzt, so dass in den ReportergenPlasmiden -238GluLuc, -200GluLuc, -169GluLuc und -60GluLuc das G3-Element mit der Pax6-Bindungsstelle fehlt und nur noch die Pax6-Bindungsstelle im G1-Element existiert (Abb. 20).

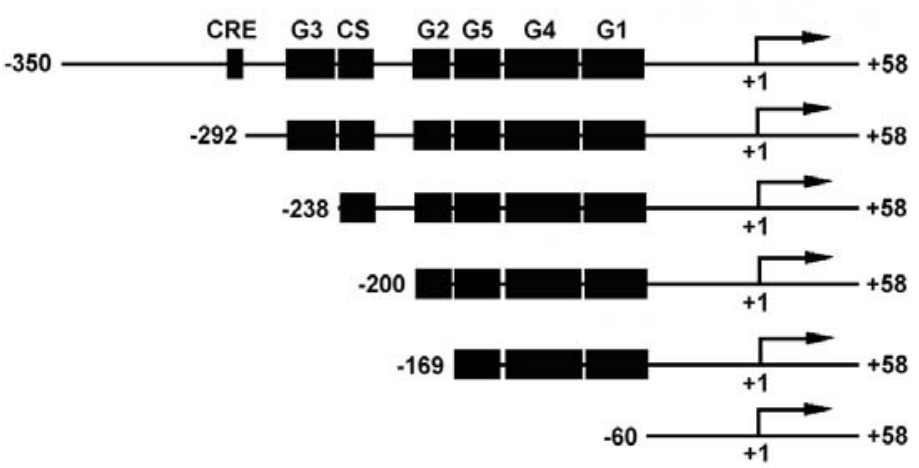

Abb. 20: 5'-Deletionen der 5'-flankierenden Region des Glukagon-Gens der Ratte. Die Expression des Luciferase-Reportergens steht unter Kontrolle von verschiedenen Abschnitten des Glukagon-Gens der Ratte, die 350 bp (-350GluLuc), 292 bp (-292GluLuc), 238 bp (-238GluLuc), 200 bp (-200GluLuc), 169 bp (-169GluLuc) bzw. 60 bp (-60GluLuc) der 5'-flankierenden Region und 58 bp des ersten Exons (+58) umfassen (Schwaninger et al., 1993; Wrege et al., 1995; Fürstenau et al., 1997). Gezeigt sind folgende Kontrollelemente der 5'-flankierenden Region des Glukagon-Gens: CRE, cAMP-responsives Element; CS, C/EBP-Bindungsstelle; G1, Glukagon-Element 1; G2, Glukagon-Element 2; G3, Glukagon-Element 3; G4, Glukagon-Element 4; G5, Glukagon-Element 5. 
Die heterologe Zelllinie JEG-3 wurde mit 207 ng des Expressionsplasmids für Pax6-WT oder für dHD (Abb. 10; Tab. 8) und -350GluLuc bzw. den 5'-verkürzten GlukagonPromotorkonstrukten (Abb. 20; Tab. 7) transient cotransfiziert.

Die Abbildung 21A zeigt die relative Luciferase-Aktivität bei Verwendung der 5'Deletionsmutanten. In der Abbildung wurden die gemessenen Werte auf die durch Cotransfektion von -350GluLuc und 207 ng Pax6-WT erhaltene Aktivität normiert (100 \% \pm 5,1\%). Die Aktivität von -350GluLuc wurde durch die Cotransfektion von Pax6-WT rund 20fach stimuliert (Abb. 21A). Die Deletion der Homöodomäne führte zu einer Abnahme der transkriptionellen Aktivität des Luciferase-Gens um rund 60 \% (Abb. 21A). Bei Cotransfektion der 5'-Deletionsmutanten und des Pax6-WT-Expressionsplasmids wurde ein Niveau von etwa $40 \%$ erreicht (Abb. 21A). Die Deletion der Homöodomäne verminderte die transkriptionelle Aktivität auf rund $5 \%$ (Abb. 21A). Die Basalaktivitäten waren 4,9\% 0,6\% bei -350GluLuc, 1,5\% 0,3\% bei -292GluLuc, $2 \% \pm 0,6 \%$ bei -200 GluLuc, 1,9 \% 0,3\% bei -169 GluLuc und $3,7 \% \pm 0,6 \%$ bei -60 GluLuc.

Um zu überprüfen, wie sich die verschiedenen Mutationen der Homöodomäne in Pax6-dHD, Pax6-dH3 und Pax6-3Ala auf die Aktivierung des Glukagon-Gens über das G1-Element durch Pax6 auswirken, wurden diese (Abb. 10; Tab.8) mit dem Reportergen-Plasmid -169GluLuc in heterologe JEG-3-Zellen cotransfiziert. Die Aktivität von -169GluLuc wurde durch 207 ng Pax6-WT um Faktor 22 gesteigert und als Ausgangsniveau festgelegt (100 \% \pm 2,7 \%) (Abb. 21B). Die Deletion oder Mutation der Pax6-Homöodomäne, Deletion der PairedDomäne oder Teile davon führte zu einer etwa 90 \%-igen Abnahme der transkriptionellen Aktivität des Reportergens (Abb. 21B). Cotransfektion von 23 ng der Expressionsplasmide ergab eine vergleichbare Abhängigkeit der relativen Luciferase-Aktivitäten von dem cotransfizierten Reportergen-Plasmid (Abb. 21B). 
A

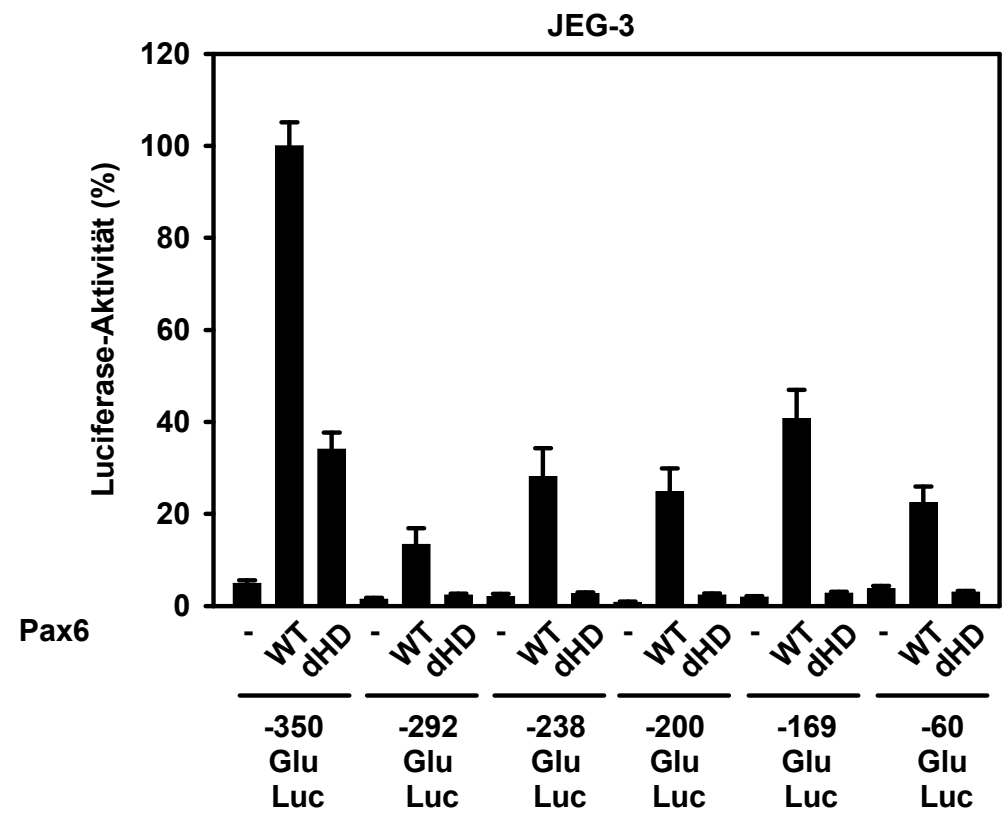

B

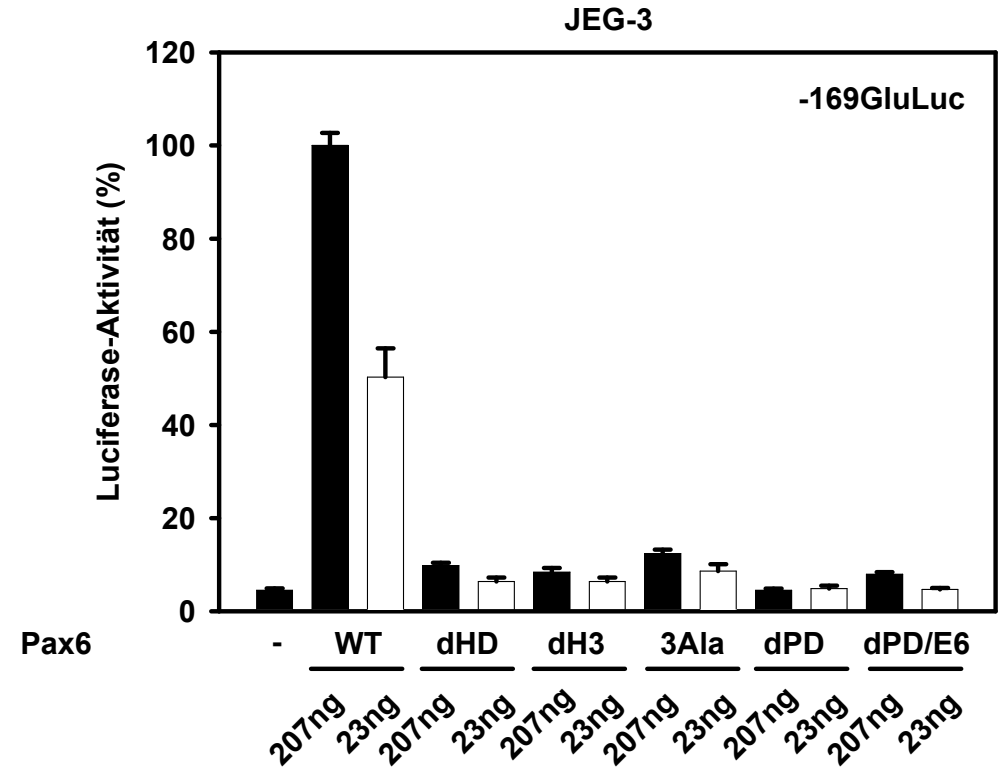

Abb. 21: Die Deletion oder Mutation der Pax6-Homöodomäne vermindert die Aktivierung des Glukagon-Promotors der Ratte durch Pax6 nach Deletion des G3-Elements in der heterologen Zelllinie JEG-3. (A) Die Reportergen-Plasmide -350GluLuc, -292GluLuc, -238GluLuc, -200GluLuc, -169GluLuc oder -60GluLuc (3 $\mathrm{\mu g} / \mathrm{Schale}$ ) wurden zusammen mit Expressionsvektoren für Pax6-WT (pBAT-Pax6-WT) oder dHD (pBAT-dHD) (207 ng/Schale) mittels Calcium-Phosphat-Präzipitation transient in die humane Chorionkarzinom-Zelllinie JEG-3 transfiziert. Die Luciferase-Aktivität bezieht sich auf die durch Pax6 induzierte Aktivität des -350GluLuc-Plasmids, dessen absoluter Wert als $100 \%$ definiert wurde. (B) Das Reportergen-Plasmid -169GluLuc (3 $\mu \mathrm{g} / \mathrm{Schale})$ wurde zusammen mit Expressionsvektoren für Pax6-WT (pBAT-Pax6-WT), dHD (pBAT-dHD), dH3 (pBAT-dH3), 3Ala (pBAT3Ala), dPD (pBAT-dPD) oder dPD/E6 (pBAT-dPD/E6) (0, 207, 23 ng/Schale) mittels CalciumPhosphat-Präzipitation transient in die humane Chorionkarzinom-Zelllinie JEG-3 transfiziert. Die Luciferase-Aktivität bezieht sich auf die durch Pax6-WT induzierte Aktivität des -169GluLuc-Plasmids, dessen absoluter Wert als $100 \%$ definiert wurde. Die Ergebnisse sind in (A) und (B) Mittelwerte und SEM aus drei unabhängigen Experimenten mit Doppelbestimmungen. 
Analyse der transkriptionellen Aktivierung von Glukagon-Promotorfragmenten mit deletiertem G1-Element durch Pax6-WT oder die Pax6-Homöodomänen-Mutanten

In den 3'-Deletionsmutanten des Glukagon-Promotors der Ratte (Abb. 22) wurde der Glukagon-Promotor vom 3'-Ende her deletiert und mit einem minimalen Thymidin-KinasePromotor fusioniert (Fürstenau et al., 1997). Die Reportergen-Plasmide -350/-210GluLuc, -350/-150GluLuc, -350/-91GluLuc enthalten nur das G3-Element als Pax6-Bindungsstelle, da das G1-Element durch Deletion entfernt wurde. Die heterologe Zelllinie JEG-3 wurde mit den Reportergen-Plasmiden -350GluLuc, -350/-210GluLuc, -350/-150GluLuc, -350/-91GluLuc oder -350/-49GluLuc (Abb. 22; Tab. 7) und zwei verschiedenen Konzentrationen der Expressionsvektoren für Pax6-WT oder -dHD (Abb. 10; Tab. 8) transient in heterologe JEG3-Zellen cotransfiziert.

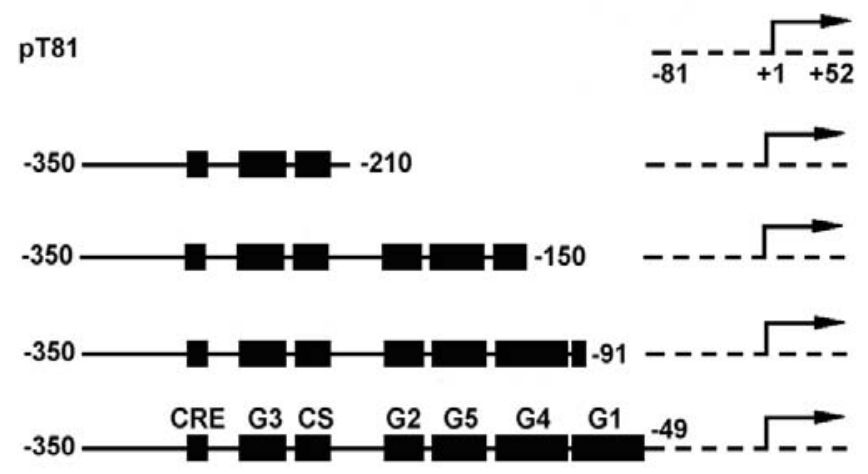

Abb. 22: 3'-Deletionen der 5'-flankierenden Region des Glukagon-Gens der Ratte. Die Expression des Luciferase-Reportergens steht unter Kontrolle eines minimalen Thymidinkinase-Promotors (-81 bis +52, pT81), der mit den jeweiligen Abschnitten der 5'-flankierenden Region des Glukagon-Gens der Ratte, bp -350 bis -210 (-350/-210GluLuc), bp -350 bis -150 (-350/-150GluLuc), bp -350 bis -91 (-350/-91GluLuc), bp -350 bis -49 (-350/-49GluLuc) fusioniert wurde. Gezeigt sind folgende Kontrollelemente der 5'-flankierenden Region des Glukagon-Gens: CRE, cAMP-responsives Element; CS, C/EBP-Bindungsstelle; G1, Glukagon-Element 1; G2, Glukagon-Element 2; G3, GlukagonElement 3; G4, Glukagon-Element 4, G5, Glukagon-Element 5.

Die Abbildung 23A zeigt die relative Luciferase-Aktivität bei Verwendung der 3'Deletionsmutanten. In der Abbildung wurden die gemessenen Werte auf die durch Cotransfektion von -350GluLuc und 207 ng Pax6-WT erhaltene Aktivität bezogen (100 \% \pm 10,5 \%). Die transiente Transfektion von -350GluLuc zusammen mit 207 ng Pax6-WT führte zu einer rund 32-fachen Steigerung der Luciferase-Aktivität von -350GluLuc (Abb. 23A). Die Deletion der Homöodomäne führte zu einer Reduktion der transkriptionellen Aktivität des Reportergens um rund 75 \%. Bei Cotransfektion der 3'-Deletionsmutanten und des Pax6-WTExpressionsplasmids wurde ein Niveau von etwa $40 \%$ erreicht (Abb. 23A). Die Deletion der Pax6-Homöodomäne verringerte die transkriptionelle Aktivität auf etwa 20-30 \% (Abb. 23A). 
Zur Spezifitätskontrolle wurde das Reportergen-Plasmid pT81Luc eingesetzt (Abb. 22). In pT81Luc steht das Luciferase-Gen unter der Kontrolle des minimalen ThymidinkinasePromotors (bp -81 bis +58). Eine Pax6-Bindungsstelle innerhalb des Promotors ist nicht bekannt. Die Cotransfektion von Pax6-WT und Pax6-dHD hatte einen geringen Einfluß auf die transkriptionelle Aktivität des Reportergens von pT81Luc (Abb. 23A). Die Basalaktivitäten der 3'-Deletionsmutanten betrugen 3,1\% 0 0,3\% bei -350GluLuc, 6,7 \% 0,6\% bei -350/-49GluLuc, 5,6 \% $\pm 0,9 \%$ bei $-350 /-91$ GluLuc, 9,1 \% $\pm 1 \%$ bei $-350 /-150 G l u L u c, 6,1 \%$ $\pm 1,3 \%$ bei $-350 /-210$ GluLuc und $6,3 \% \pm 0,7 \%$ bei pT81Luc.

Um zu untersuchen, welche Wirkung die verschiedenen Mutationen der Homöodomäne in Pax6-dHD, Pax6-dH3 und Pax6-3Ala auf die Aktivierung des Glukagon-Gens über das G3Element durch Pax6 haben, wurden diese (Abb. 10; Tab. 8) mit dem Reportergen-Plasmid -350/-150GluLuc in heterologen JEG-3-Zellen transient cotransfiziert. In Abbildung 23B sind die erhaltenen relativen Luciferase-Aktivitäten dargestellt. Sie sind auf die durch $207 \mathrm{ng}$ induzierte Luciferase-Aktivität von -150/-350GluLuc (100\% $\pm 2,6 \%$ ) bezogen. Durch die Cotransfektion von 207 ng Pax6-WT wurde die Aktivität von -350/-150GluLuc um den Faktor 9 gesteigert (Abb. 23B). Die Deletion oder Mutation der Pax6-Homöodomäne sowie die Deletion der Paired-Domäne oder Teile davon führte zu einer 80-90 \%-igen Abnahme der transkriptionellen Aktivität des Luciferasegens (Abb. 23B). Cotransfektion von 23 ng der Expressionsplasmide ergab eine vergleichbare Abhängigkeit der relativen LuciferaseAktivitäten von dem cotransfizierten Reportergen-Plasmid (Abb. 23B). 
A

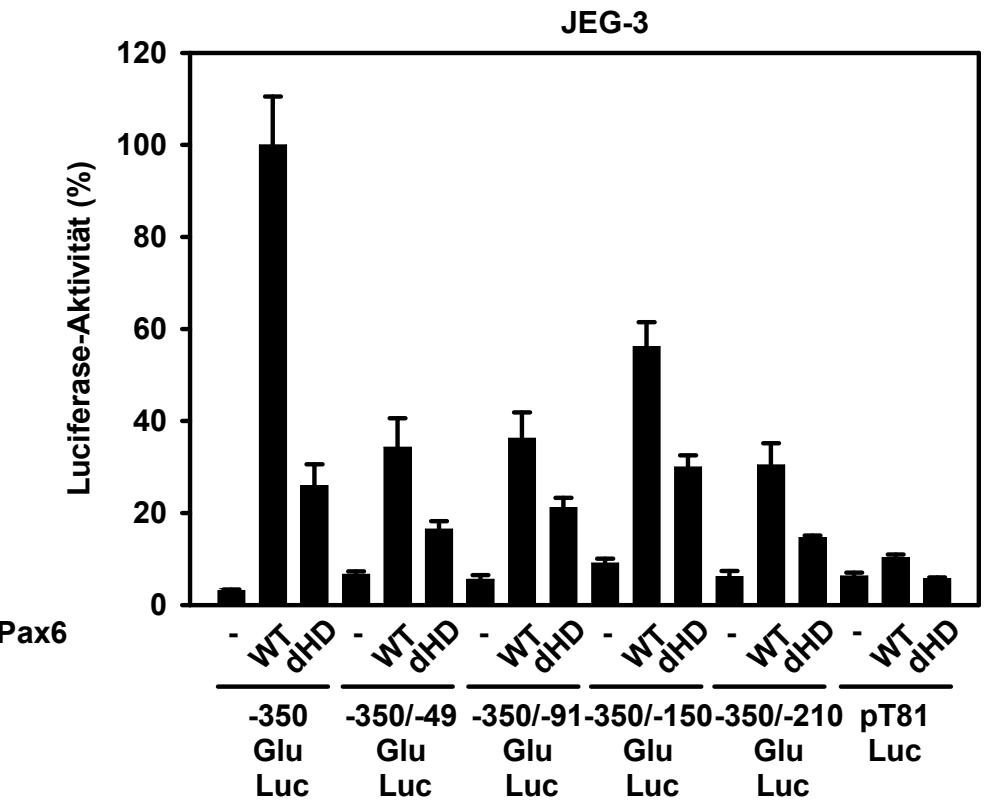

B

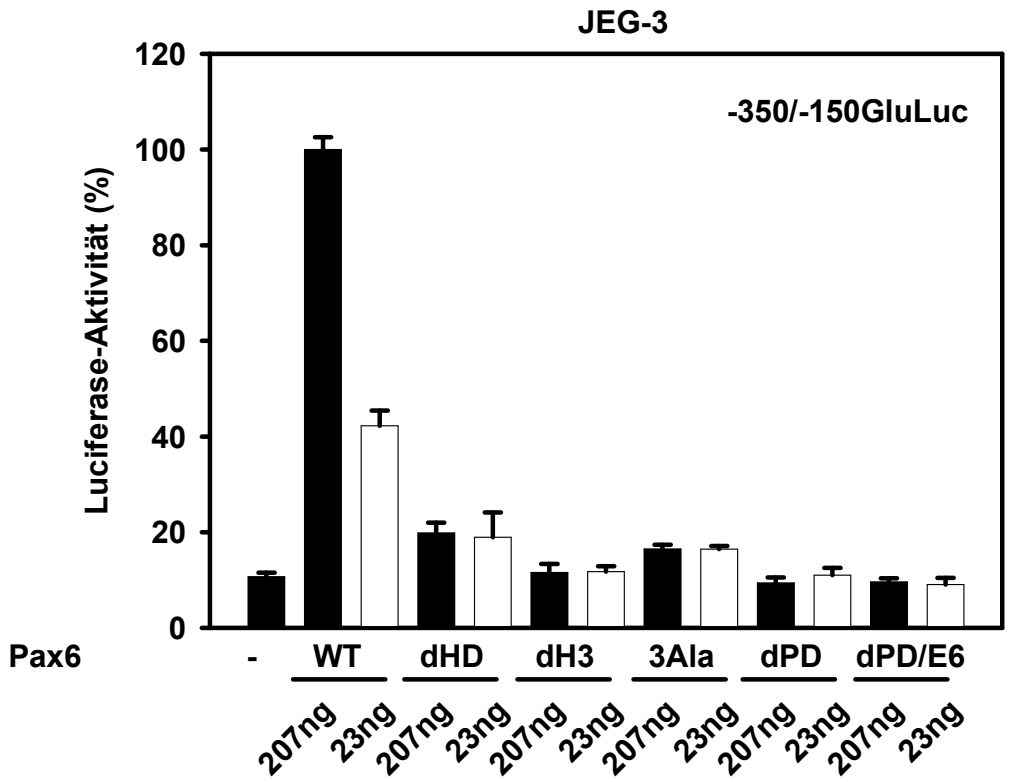

Abb. 23: Die Deletion oder Mutation der Pax6-Homöodomäne vermindert die Aktivierung des Glukagon-Promotors der Ratte durch Pax6 nach Deletion des G1-Elements in der heterologen Zelllinie JEG-3. (A) Die Reportergen-Plasmide -350GluLuc, -350/-210GluLuc, -350/-150GluLuc, -350/-91GluLuc oder -49/-350GluLuc (3 $\mu \mathrm{g} / \mathrm{Schale}$ ) wurden zusammen mit Expressionsvektoren für Pax6-WT (pBAT-Pax6-WT) oder -dHD (pBAT-dHD) (207 ng/Schale) mittels Calcium-PhosphatPräzipitation transient in die humane Chorionkarzinom-Zelllinie JEG-3 transfiziert. Die LuciferaseAktivität bezieht sich auf die durch Pax6-WT induzierte Aktivität des -350GluLuc-Plasmids, dessen absoluter Wert als $100 \%$ definiert wurde. (B). Das Reportergen-Plasmid -350/-150GluLuc (3 $\mu \mathrm{g} / \mathrm{Schale}$ ) wurde zusammen mit Expressionsvektoren für Pax6-WT (pBAT-Pax6-WT), -dHD (pBATdHD), -dH3 (pBAT-dH3), -3Ala (pBAT-3Ala), -dPD (pBAT-dPD) oder -dPD/E6 (pBAT-dPD/E6) (0, 207, $23 \mathrm{ng} / \mathrm{Schale}$ ) mittels Calcium-Phosphat-Präzipitation transient in die humane ChorionkarzinomZelllinie JEG-3 transfiziert. Die Luciferase-Aktivität bezieht sich auf die durch Pax6 induzierte Aktivität des -350/-150GluLuc-Plasmids, dessen absoluter Wert als $100 \%$ definiert wurde. Die Ergebnisse aus (A) und (B) sind Mittelwerte und SEM aus drei unabhängigen Experimenten mit Doppelbestimmungen. 


\subsection{Bedeutung der Domäne B des G3-Elements des Glukagon-Promotors für die Glukagon-Gen-Aktivierung durch Pax6}

Die Pax6-Homöodomäne ist für die Bindung von Pax6 an das G3-Element des GlukagonGens der Ratte nicht von Bedeutung (3.4.2); sie ist aber für die Aktivierung des GlukagonGens durch Pax6 über das G3-Element essentiell (3.5). In der Pax6-HomöodomänenMutante Pax6-3Ala (Abb. 10) wurden die Aminosäuren Valin-47, Serin-50 und Asparagin-51 zu Alanin mutiert. Diese Aminosäuren interagieren im Drosophila Paired-Protein direkt mit Basen der optimalen Paired-Homöodomänen-Bindungsstelle P3 (Wilson et al., 1995). Da diese Mutationen innerhalb der Homöodomäne die Aktivierung des Glukagon-Promotors durch Pax6 über das G3-Element verminderte, könnte die Bedeutung der Homöodomäne am G3-Element in einer DNA-Bindung liegen, zusätzlich zu der der Paired-Domäne. Im G3Element in Domäne B des Glukagon-Promotors befindet sich benachbart zur Pax6-PairedDomänen-Bindungsstelle in Domäne $A$, eine Bindungsstelle für einen Heterodimerkomplex der Homöodomänen-Transkriptionsfaktoren Pbx/Prep1 (Herzig et al., 2000).

Mit Hilfe von Promotor-Mutationsanalysen wurde überprüft, ob Domäne $B$ eine Bindungsstelle für die Pax6-Homöodomäne ist. Es wurde zunächst die Bedeutung der Domäne B des G3-Elements für die Aktivierung des Glukagon-Gens der Ratte durch Pax6 untersucht.

3.6.1 Untersuchung der Wirkung von Mutationen in Domäne B auf die transkriptionelle Aktivität des G3-Elements in der pankreatischen Inselzelllinie aTC2

Die Reportergen-Plasmide 4xG3T81Luc, 4xG3M1T81Luc, 4xG3M2T81Luc, 4xG3AT81Luc oder 4xG3BT81Luc (Abb. 24; Tab. 7) wurden transient in die Zelllinie aTC2 (2.11.4) transfiziert. Die Reportergen-Plasmide enthielten jeweils vier Kopien des G3-Elements vor einem minimalen Thymidinkinasepromotor (Basenpaar -81 bis +52) des Herpes-SimplexVirus fusioniert mit dem Luciferase-Reportergen.

Innerhalb des G3-Elements waren entweder drei Basenpaare im G3B-Element (4xG3M1T81Luc) oder die gesamte Domäne G3B (4xG3M2T81Luc) mutiert. Die Reportergen-Plasmide 4xG3AT81Luc oder 4xG3BT81Luc enthielten vier Kopien der isolierten Domäne A oder der isolierten Domäne B des G3-Elements. 


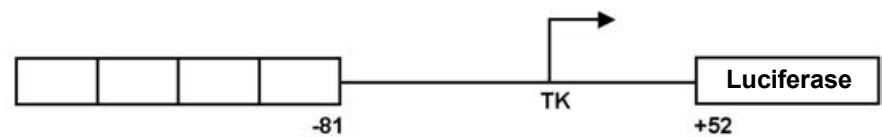

\begin{tabular}{|c|c|c|}
\hline & A & B \\
\hline G3 & \multicolumn{2}{|c|}{ TGAAGTAGTTTTTCACGCCTGACTGAGATTGAAGGGTGTAGA } \\
\hline G3M1 & \multicolumn{2}{|c|}{ TGAAGTAGTTTTTCACGCCTGACTGAGATTAGCGGGTGTAGA } \\
\hline G3M2 & \multicolumn{2}{|c|}{ TGAAGTAGTTTTTCACGCCTGACTGAGAACGCGCAGGCTCAA } \\
\hline G3A & \multicolumn{2}{|c|}{ TAGTTTTTCACGCCTGACTG } \\
\hline G3B & & TTGAAGGGTGT \\
\hline
\end{tabular}

Abb. 24: Reporterfusionsgene des G3-, G3A- und G3B-Elements des Glukagon-Gens. Die Expression des Luciferase-Gens wird von je vier Kopien des G3-Elements, des G3-Elements mit einer drei Basenpaar-Mutation in Abschnitt B (G3M1) bzw. mit einer ausgedehnten Mutation in Abschnitt B (G3M2) oder des G3A-Elements oder des G3B-Elements dirigiert, die vor einen minimalen Thymidinkinase-Promotor (TK, Basenpaar -81 bis +52 ; Nordeen, 1988) kloniert sind. Mutationen innerhalb des G3-Elements. G1, Glukagon-Element 1; G3, Glukagon-Element 3.

Bezogen auf die Aktivität des Reportergen-Plasmids 4xG3T81Luc (Abb. 25; $100 \% \pm 4 \%$ ) verursachte die drei-Basenpaar-Mutation in Domäne B eine $40 \%$-ige und die Mutation der gesamten Domäne B eine knapp 90 \%-ige Abnahme der transkriptionellen Aktivität des Luciferasegens (Abb. 25). Die vier Kopien des G3A-Elements in 4xG3AT81Luc führten zu einer Luciferase-Aktivität von $183 \%$ und die des G3B-Elements führten zu einer Aktivität von $11 \%$ (Abb. 25). Die Luciferase-Aktivität des zur Kontrolle cotransfizierten ReportergenPlasmids pT81Luc betrug $6 \%$ (Abb. 25).

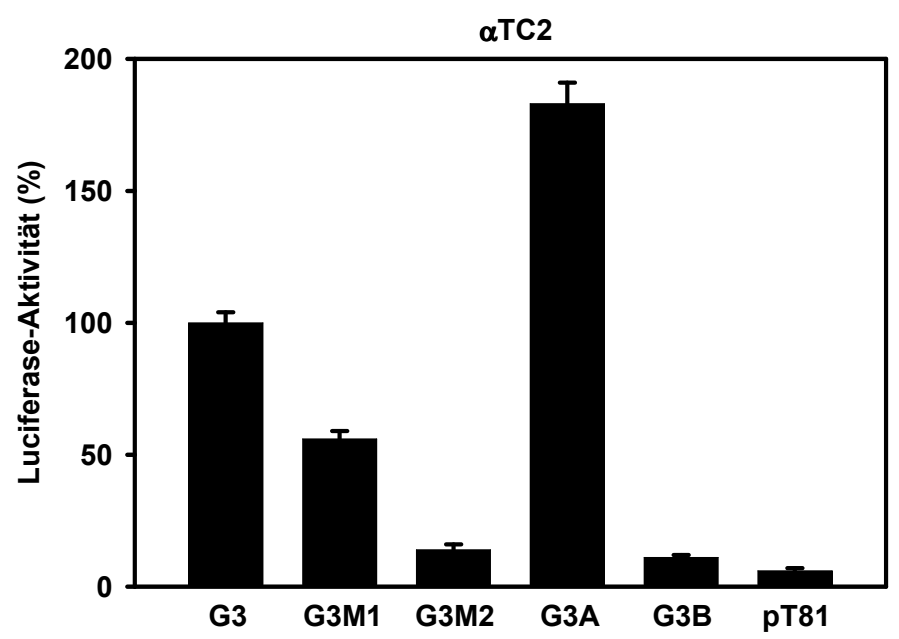

Abb. 25: Mutationen innerhalb Domäne B vermindern die Aktivität des G3-Elements in der glukagonproduzierenden Zelllinie $\boldsymbol{\alpha T C 2}$. Die Reportergen-Plasmide 4xG3T81Luc (G3), 4xG3M1T81Luc (G3M1), 4xG3M2T81Luc (G3M2), 4xG3AT81Luc (G3A) oder 4xG3BT81Luc (G3B) $(2 \mu \mathrm{g} / \mathrm{Schale})$ wurden mittels DEAE-Dextran transient in die glukagonproduzierende Zelllinie des $\alpha$ Phänotyps $\alpha$ TC2 transfiziert. Die Luciferase-Aktivität bezieht sich auf die Aktivität des 4xG3T81LucPlasmids, dessen absoluter Wert als $100 \%$ definiert wurde. Die Ergebnisse sind Mittelwerte und SEM aus drei unabhängigen Experimenten mit Doppelbestimmung. 
3.6.2 Untersuchung der Wirkung von Mutationen in Domäne B auf die durch exogenes Pax6 vermittelte Aktivität des G3-Elements in heterologen JEG-3-Zellen

23 ng des Pax6-WT-Expressionsplasmids (Abb. 10; Tab. 8) wurden mit den ReportergenPlasmiden 4xG3T81Luc, 4xG3M1T81Luc, 4xG3M2T81Luc, 4xG3AT81Luc oder 4xG3BT81Luc (Abb. 24; Tab. 7) transient in heterologe JEG-3-Zellen cotransfiziert.

Die Abbildung 26 zeigt die relative Luciferase-Aktivität bei Verwendung dieser G3-OligomerKonstrukte. In der Abbildung wurden die gemessenen Werte auf die durch Cotransfektion von 4xG3T81Luc und Pax6-WT erhaltene Aktivität bezogen (100\% 7,4\%). Die dreiBasenpaar-Mutation in Domäne B führte zu einer 98 \%-igen und die Mutation der gesamten Domäne B zu einer knapp 90 \%-igen Abnahme der transkriptionellen Aktivität des Luciferasegens (Abb. 26). Die Cotransfektion von 4xG3AT81Luc zeigte eine um rund $40 \%$ verringerte Aktivität (Abb. 26). Die Expression von Pax6-WT hatte keinen Einfluß auf die Luciferase-Aktivität von 4xG3BT81Luc. Die Basalaktivitäten der G3-Oligomer-Konstrukte betrugen $4,3 \% \pm 0,6 \%$ bei $4 \times$ G 3T81Luc, 0,8 \% $\pm 0,07 \%$ bei 4xG3M1T81Luc, $3 \% \pm 0,6 \%$ bei 4xG3M2T81Luc, $1,8 \% \pm 0,3 \%$ bei 4xG3AT81Luc und $2 \% \pm 4 x G 3 B T 81$ Luc.

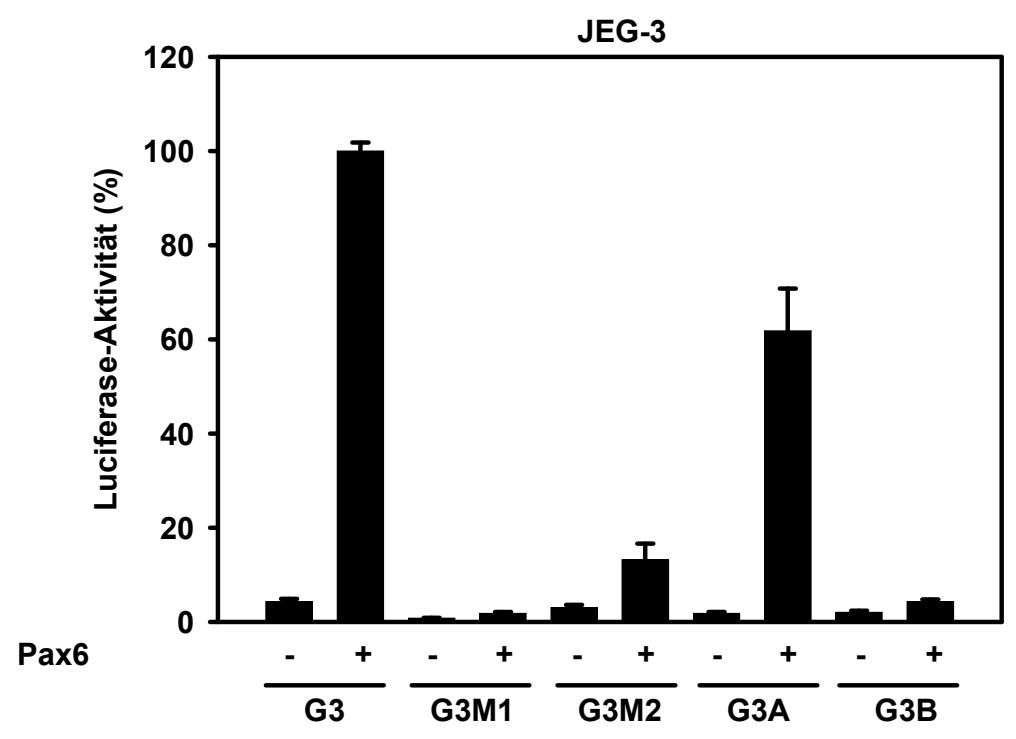

Abb. 26: Mutationen der Domäne B vermindern die durch Pax6 induzierte Aktivität des G3Elements in heterologen JEG-3-Zellen. Die Reportergen-Plasmide 4xG3T81Luc (G3), 4xG3M1T81Luc (G3M1), 4xG3M2T81Luc (G3M2), 4xG3AT81Luc (G3A) oder 4xG3BT81Luc (G3B) ( $3 \mu \mathrm{g} / \mathrm{Schale}$ ) wurden zusammen mit $23 \mathrm{ng}$ eines Expressionsvektors für Pax6-WT (pBAT-Pax6-WT) mittels Calcium-Phosphat-Präzipitation transient in die humane Chorionkarzinom-Zelllinie JEG-3 transfiziert. Die Luciferase-Aktivität bezieht sich auf die durch Pax6-WT induzierte Aktivität des -350GluLuc-Plasmids, dessen absoluter Wert als $100 \%$ definiert wurde. Die Ergebnisse sind Mittelwerte und SEM aus fünf unabhängigen Experimenten mit Doppelbestimmung. 
3.6.3 Untersuchung der Wirkung einer Mutation in Domäne B des G3-Elements auf die Aktivierung des Glukagon-Gens in den Pankreasinsel-Zelllinien InR1G9 und aTC2

Die Reportergen-Plasmide -350GluLuc, -350(G3Bm)GluLuc, -350(G3Am)GluLuc und -350(mutG3)GluLuc (Abb. 27; Tab. 7) wurden transient in InR1G9-Zellen transfiziert. In den Reporterfusionsgenen wird die Expression des Luciferase-Gens von 350 bp der 5'flankierenden Region des Glukagon-Gens der Ratte kontrolliert. Innerhalb des G3-Elements von -350(G3Bm)GluLuc wurden sechs Basenpaare in Domäne B mutiert, im G3A-Element von -350(G3Am)GluLuc wurden vier Basenpaare und in -350(mutG3)GluLuc wurde die gesamte Sequenz des G3A-Elements mutiert (Abb. 27).

-350GluLuc

$-350(G 3 A m)$ GluLuc

$-350(\mathrm{GBBm})$ GluLuc

-350 (mutG3)GluLuc

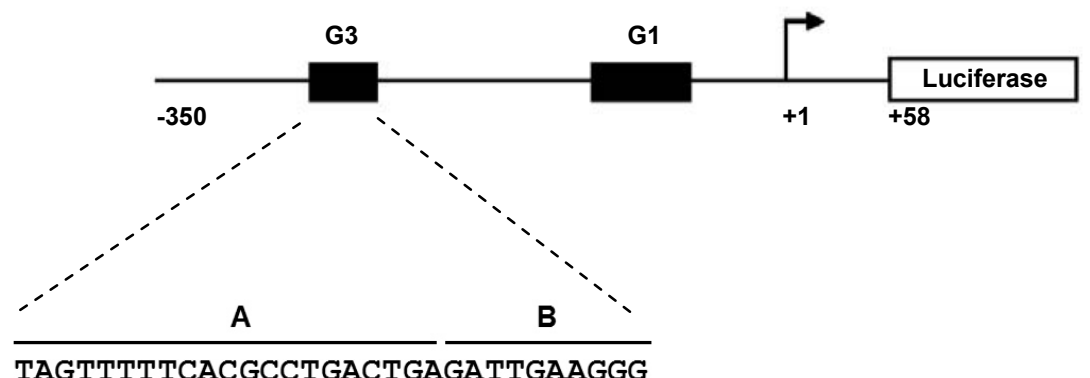

TAGTTTTTCACGCCTGACTGAGATTGAAGGG

TAGTTTTTCAATTATGACTGAGATTGAAGGG

TAGTTTTTCACGCCTGACTGAGAGAATTCGG

TCTAGACGGAGTACTGTCCTCCGTTGAAGGG

Abb. 27: Reporterfusionsgene der 5'-flankierenden Region des Glukagon-Gens der Ratte mit Mutationen innerhalb des G3-Elements. In den Reportergen-Plasmiden -350GluLuc, -350(G3Bm)GluLuc, -350(G3Am)GluLuc und -350(mutG3)GluLuc steht die Expression des LuciferaseGens unter der Kontrolle des Glukagon-Promotors der Ratte von bp -350 bis +58 . Innerhalb der 350 Basenpaare wurde selektiv die Pax6-Paired-Domänen-DNA-Bindungsstelle in Domäne A des G3Elements (vier Basenpaare-Mutation) oder selektiv sechs Basenpaare in Domäne B des G3-Elements oder die gesamte Sequenz der Domäne A des G3-Elements mutiert. G1, Glukagon-Element 1; G3, Glukagon-Element 3.

Bezogen auf die Basalaktivität von -350GluLuc führte die Mutation von sechs Basenpaaren in Domäne B zu einer um 40 \% reduzierten transkriptionellen Aktivität des LuciferaseReportergens (Abb. 28A). Ein ähnliches Ergebnis wurde auch in der glukagonproduzierenden, Pax6-exprimiernden Zelllinie $\alpha \mathrm{TC2}$ erhalten (Abb. 28B). Die Mutationen der Domäne A verminderte die transkriptionelle Aktivität um 70-80\% in InR1G9Zellen (Abb. 28A). 
A

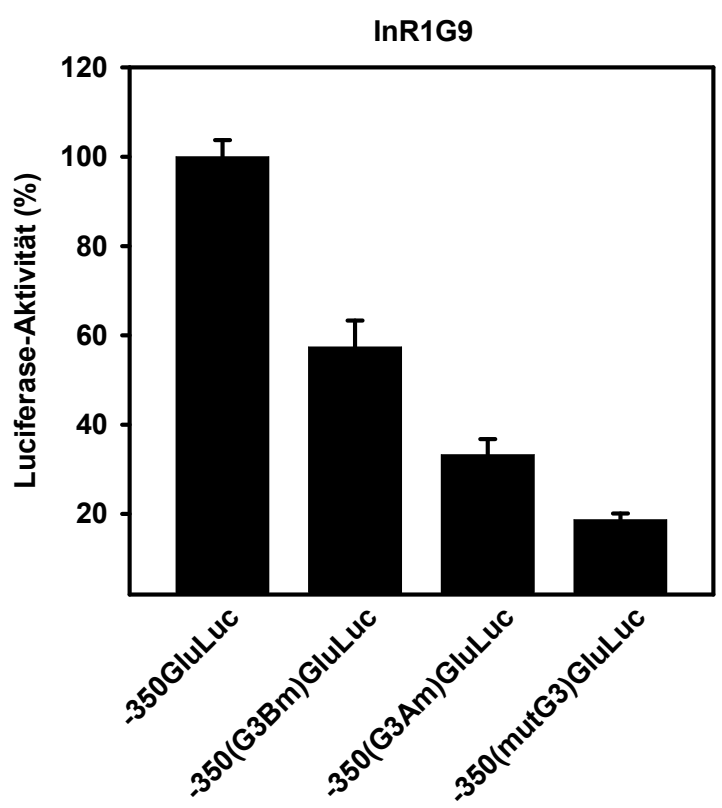

B

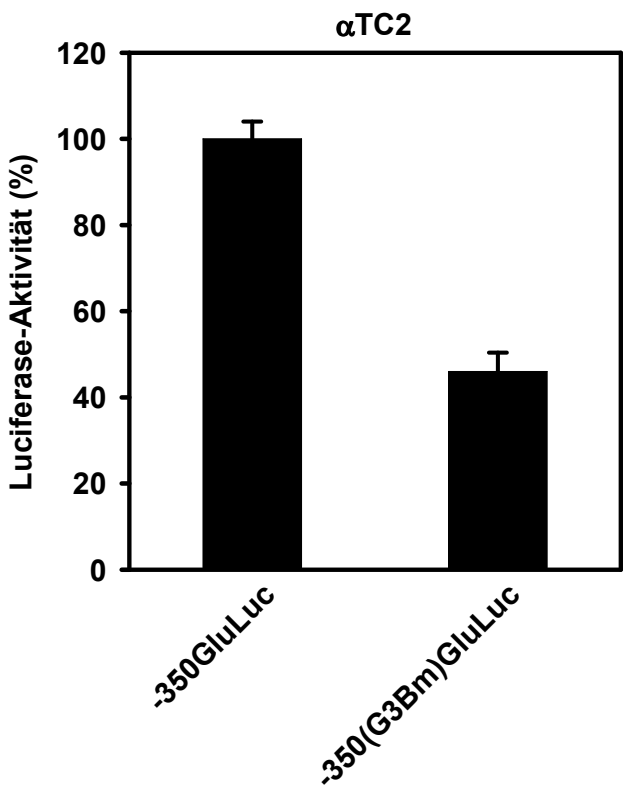

Abb. 28: Die Mutation des G3B-Elements vermindert die Aktivität des Glukagon-Promotors in den glukagonproduzierenden Zelllinien InR1G9 und $\alpha$ TC2. Die Reportergen-Plasmide -350GluLuc, -350(G3Bm)GluLuc, -350(G3Am)GluLuc oder -350(mutG3)GluLuc (A) oder -350GluLuc und -350(G3Bm)GluLuc (B) (2 $\mu \mathrm{g} / \mathrm{Schale})$ wurden mittels DEAE-Dextran transient in die glukagonproduzierenden Zelllinien des $\alpha$-Phänotyps InR1G9 (A) oder $\alpha \mathrm{TC2}$ (B) transfiziert. Die Luciferase-Aktivität bezieht sich in (A) und (B) auf die Aktivität des -350GluLuc-Reportergen-Plasmids, dessen absoluter Wert als $100 \%$ definiert wurde. Die Ergebnisse sind Mittelwerte und SEM aus drei unabhängigen Experimenten mit Doppelbestimmung.

3.6.4 Untersuchung der Aktivierung des Glukagon-Gens mit mutierter Domäne B des G3-Elements durch exogenes Pax6 in der heterologen Zellinie JEG-3

Die Reportergen-Plasmide -350GluLuc, -350(G3Bm)GluLuc, -350(G3Am)GluLuc oder -350(mutG3)GluLuc (Abb. 27; Tab. 7) wurden mit verschiedenen Mengen des Expressionsplasmids für Pax6-WT (Abb. 10; Tab. 8) in heterologe JEG-3 Zellen cotransfiziert. Abbildung 29 zeigt die relativen Luciferase-Aktivitäten, wobei die Werte auf die durch 207 ng erhaltene Aktivität von -350GluLuc bezogen sind. Cotransfektion der größten Menge Pax6-WT induzierte die Aktivität von -350GluLuc rund 100-fach (Abb. 29; $100 \% \pm$ 4,8 \%). Die Mutation in der Domäne B verursachte eine $60 \%$-ige Abnahme der transkriptionellen Aktivität des Luciferasegens (Abb. 29). Die Mutationen der Domäne A führten zu einer 70 \%-igen Abnahme (Abb. 29). Die Basalaktivitäten der -350GluLucMutanten betrugen $1 \% \pm 0,2 \%$ bei -350 GluLuc, $1,2 \% \pm 0,2 \%$ bei -350 (G3Am)GluLuc, $0,9 \% \pm 0,2 \%$ bei $-350($ G3Bm)GluLuc und 1,5\% $\pm 0,2 \%$ bei -350 (mutG3)GluLuc. Nach Cotransfektion von $23 \mathrm{ng}$ oder $3 \mathrm{ng}$ des Pax6-WT-Expressionsplasmids wurden 
entsprechende Abhängigkeiten der Luciferase-Aktivitäten von den cotransfizierten mutierten Reportergen-Plasmiden nachgewiesen (Abb. 29).

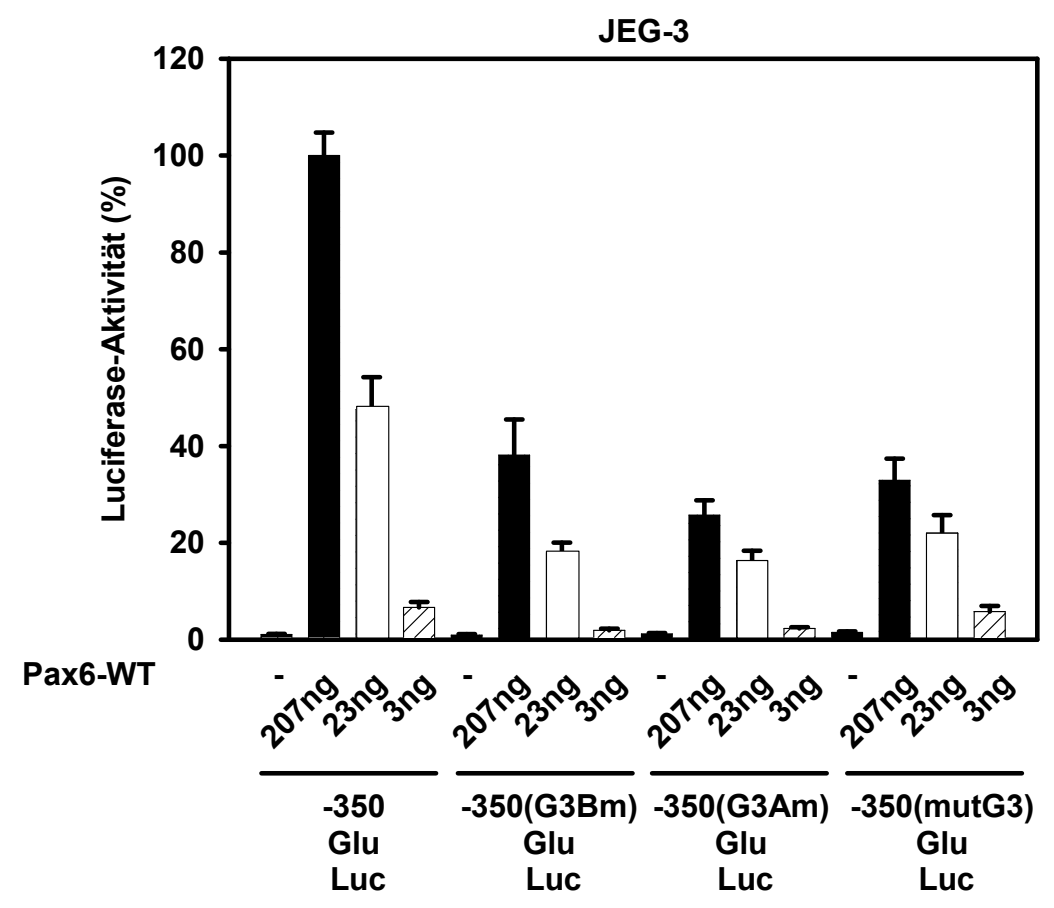

Abb. 29: Die Mutation von Domäne B des G3-Elements verringert die Aktivierung des GlukagonPromotors durch Pax6 in der heterologen Zelllinie JEG-3. Die Reportergen-Plasmide -350GluLuc, -350(G3Bm)GluLuc, -350(G3Am)GluLuc oder -350(mutG3)GluLuc (3 $\mu \mathrm{g} / \mathrm{Schale}$ ) wurden zusammen mit unterschiedlichen Mengen (0, 207, 23, 3 ng/Schale) eines Expressionsvektors für Pax6-WT (pBATPax6-WT) mittels Calcium-Phosphat-Präzipitation transient in die humane Chorionkarzinom-Zelllinie JEG-3 transfiziert. Die Luciferase-Aktivität bezieht sich auf die durch $207 \mathrm{ng}$ Pax6-WT induzierte Aktivität des -350GluLuc-Plasmids, dessen absoluter Wert als $100 \%$ definiert wurde. Die Ergebnisse sind Mittelwerte und SEM aus fünf unabhängigen Experimenten mit Doppelbestimmung.

3.7 Bedeutung der Domäne B des G3-Elements für die Aktivierung des Glukagon-Gens durch Pax6 mit deletierter oder mutierter Homöodomäne

3.7.1 Wirkung von Deletionen bzw. Mutation der Pax6-Homöodomäne auf die durch Pax6 induzierte Aktivität eines G3-Element-Oligomers in heterologen JEG-3Zellen

Es wurde untersucht, welchen Einfluß die Deletion oder die Mutation der Pax6Homöodomäne auf die transkriptionelle Aktivität des isolierten G3- Elements hat. Dazu wurde das Reportergen-Plasmid 4xG3T81Luc (Abb. 24; Tab. 7) mit zwei verschiedenen Mengen 
der Expressionplasmide für Pax6-WT, Pax6-dHD, Pax6-dH3, Pax6-3Ala, Pax6-dPD oder Pax6-dPD/E6 (Abb. 10; Tab. 8) in heterologe JEG-3-Zellen cotransfiziert.

Die Abbildung 30 zeigt die relative Luciferase-Aktivität. In der Abbildung wurden die gemessenen Werte auf die durch Cotransfektion von 4xG3T81Luc und $207 \mathrm{ng}$ Pax6-WT erhaltene Aktivität bezogen (100\% 10,5\%). Die Aktivität von 4xG3T81Luc wurde durch die höchste Menge an Pax6-WT 13,5-fach stimuliert (Abb. 30). Die Deletion der Homöodomäne bzw. der Helix 3 der Homöodomäne führte zu einer transkriptionellen Aktivität des Reportergens von 191 \% bzw. 215 \% (Abb. 30). Die Mutation von drei Aminosäuren der Helix 3 führte zu einer Aktivität von 100 \% (Abb. 30). Eine Induktion der Luciferase-GenAktivität durch Pax6-dPD und Pax6-dPD/E6 konnte nicht detektiert werden (Abb. 30). Nach Cotransfektion von 23 ng der Pax6-Mutanten wurden entsprechende Abhängigkeiten der Luciferase-Aktivitäten von dem cotransfizierten Reportergen-Plasmid 4xG3T81Luc detektiert (Abb. 30).

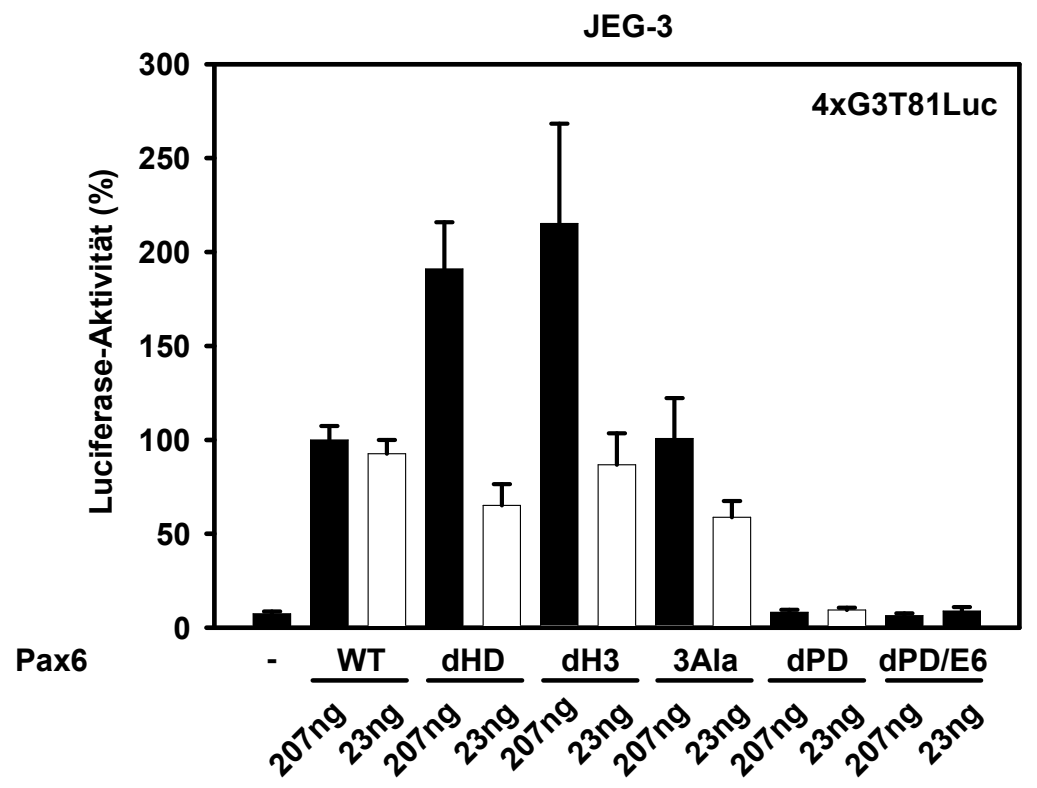

Abb. 30: Die Deletion bzw. Mutation der Pax6-Homöodomäne hat keinen Einfluß auf die durch Pax6 induzierte Aktivität eines G3-Element-Oligomers in heterologen JEG-3-Zellen. Das Reportergen-Plasmid 4xG3T81Luc ( $3 \mu \mathrm{g} / \mathrm{Schale}$ ) wurde zusammen mit unterschiedlichen Mengen (0, 207, 23 ng/Schale) eines Expressionsvektors für Pax6-WT (pBAT-Pax6-WT), dHD (pBAT-dHD), dH3 (pBAT-dH3), 3Ala (pBAT-3Ala), dPD (pBAT-dPD) oder dPD/E6 (pBAT-dPD/E6) mittels CalciumPhosphat-Präzipitation transient in die humane Chorionkarzinom-Zelllinie JEG-3 transfiziert. Die Luciferase-Aktivität bezieht sich auf die durch 207 ng Pax6-WT induzierte Aktivität des 4xG3T81LucPlasmids, dessen absoluter Wert als $100 \%$ definiert wurde. Die Ergebnisse der Transfektion sind Mittelwerte und SEM aus vier unabhängigen Experimenten mit Doppelbestimmung. 
3.7.2 Wirkung von Mutationen der Domäne B auf die durch die Pax6-HomöodomänenMutanten induzierte Aktivität eines G3-Element-Oligomers im heterologen Zellsystem JEG-3

Um festzustellen, ob die Bedeutung der Domäne B des G3-Elements für die Aktivierung des Glukagon-Gens durch Pax6 in einer Bindung der Pax6-Homöodomäne liegt, wurden die Reportergen-Plasmide 4xG3T81Luc, 4xG3M1T81Luc, 4xG3M2T81Luc, 4xG3AT81Luc und 4xG3BT81Luc (Abb. 24; Tab. 7) mit unterschiedlichen Mengen der Expressionsvektoren die für Pax6-dHD, dH3, 3Ala oder dPD (Abb. 10; Tab. 8) kodieren, transient in die humane Chorionkarzinom-Zelllinie JEG-3 cotransfiziert.

Abbildung 31A zeigt die nach Cotransfektion von Pax6-dHD und den G3-OligomerKonstrukten erhaltenen relativen Luciferase-Aktivitäten, wobei die Werte auf die LuciferaseAktivität bei Cotransfektion von 4xG3T81Luc mit 207 ng Pax6-dHD (100 \% \pm 3,1 \%) bezogen sind. Die Cotransfektion von 207 ng des Pax6-dHD-Expressionsplasmids mit dem Reportergen-Plasmid 4xG3T81Luc führte zu einer Erhöhung der Aktivität von 4xG3T81Luc um den Faktor 33 (Abb. 31A). Bei Pax6 mit deletierter Homöodomäne verminderte die Mutationen der Domäne B die Aktivität des G3-Elements um 80-90 \% (Abb. 31A). Vier Kopien des G3B-Elements zeigten keine Aktivität und vier Kopien des G3A-Elements zeigten eine Aktivität von etwa $60 \%$ (Abb. 31A).

Abbildung 31B zeigt die nach Cotransfektion von Pax6-dH3 und den G3-OligomerKonstrukten erhaltenen relativen Luciferase-Aktivitäten, wobei die Werte auf die LuciferaseAktivität bei Cotransfektion von 4xG3T81Luc mit 207 ng Pax6-dH3 (100 \% \pm 6,1 \%) bezogen sind. Die Cotransfektion von $207 \mathrm{ng}$ des Pax6-dH3-Expressionsplasmids mit dem Reportergen-Plasmid 4xG3T81Luc führte zu einer Erhöhung der Aktivität von 4xG3T81Luc um den Faktor 83 (Abb. 31B). Bei Pax6 mit deletierter Helix 3 der Homöodomäne verminderte die Mutationen der Domäne B die Aktivität des G3-Elements um 80-90\% (Abb. 31B). Vier Kopien des G3A-Elements zeigten eine Aktivität von etwa 90 \% (Abb. 31B). Vier Kopien des G3B-Elements zeigten keine Aktivität (Abb. 31B).

Die Abbildung 31C zeigt die nach Cotransfektion von Pax6-3Ala und den G3-OligomerKonstrukten erhaltenen relativen Luciferase-Aktivitäten, wobei die Werte auf die LuciferaseAktivität bei Cotransfektion von 4xG3T81Luc mit 207 ng Pax6-3Ala (100 \% $\pm 3,5 \%$ ) bezogen sind. Die Cotransfektion von $207 \mathrm{ng}$ des Pax6-3Ala-Expressionsplasmids mit dem Reportergen-Plasmid 4xG3T81Luc führte zu einer Erhöhung der Aktivität von 4xG3T81Luc um den Faktor 28 (Abb. 31C). Bei Pax6 mit mutierter Homöodomäne verminderte die Mutationen der Domäne B die Aktivität des G3-Elements um 80-90 \% (Abb. 31C). Vier Kopien des G3B-Elements zeigten keine Aktivität und vier Kopien des G3A-Elements zeigten eine Aktivität von etwa $40 \%$ (Abb. 31C). 
A

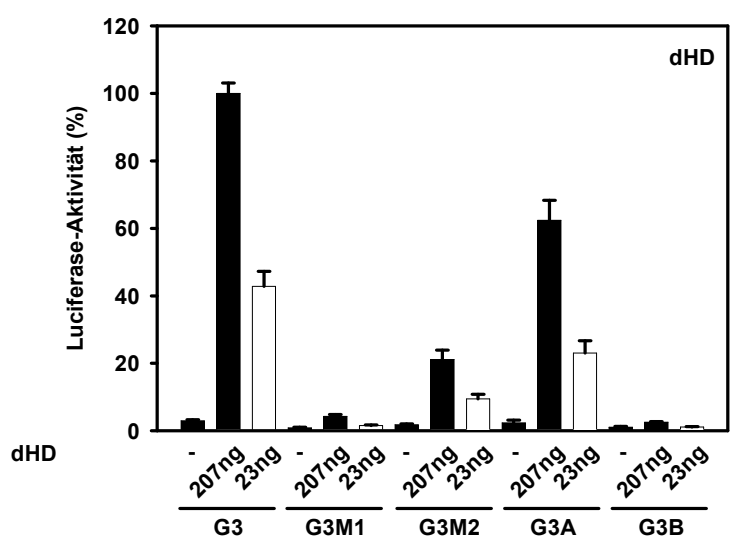

C

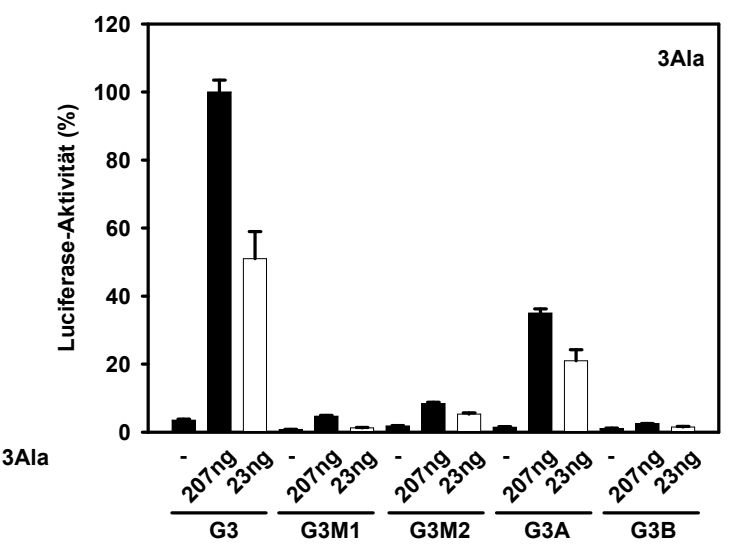

B

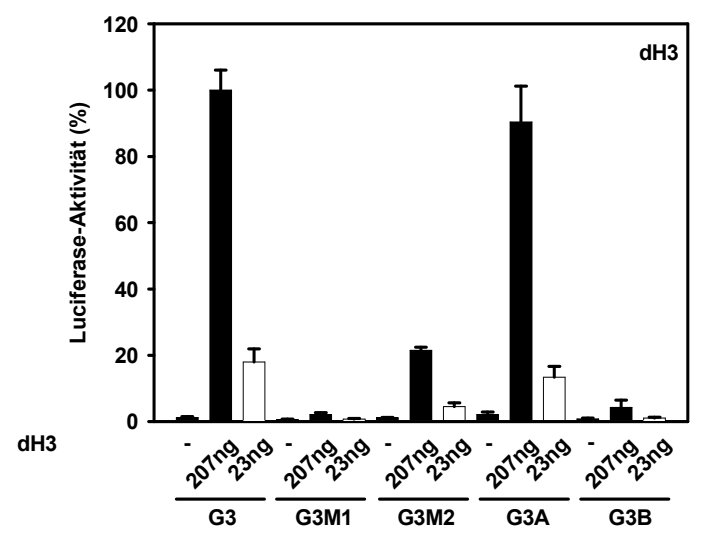

D

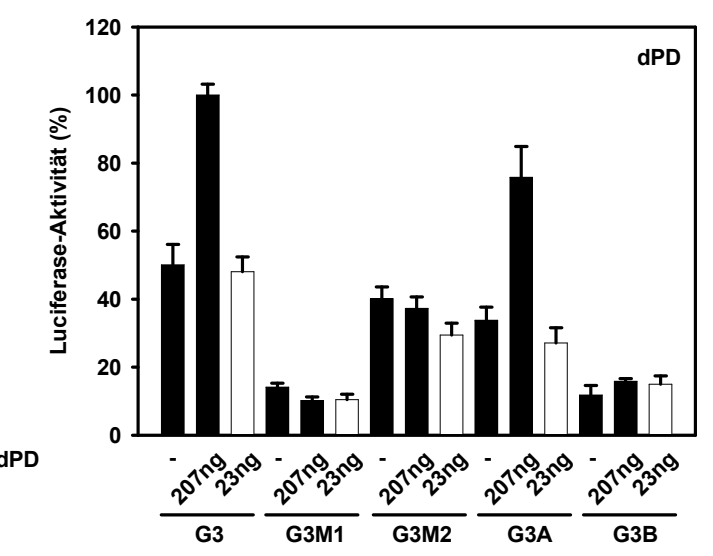

Abb. 31: Mutationen in Domäne B führen zu einer Abnahme der durch Pax6-HomöodomänenMutanten induzierten Aktivität des G3-Elements in heterologen JEG-3-Zellen. Die ReportergenPlasmide 4xG3T81Luc (G3), 4xG3M1T81Luc (G3M1), 4xG3M2T81Luc (G3M2), 4xG3AT81Luc (G3A) oder 4xG3BT81Luc (G3B) wurden zusammen mit den Expressionsplasmiden für dHD (pBAT-dHD), dH3 (pBAT-dH3), 3Ala (pBAT-3Ala) oder dPD (pBAT-dPD) mittels Calcium-Phosphat-Präzipitation transient in die humane Chorionkarzinom-Zelllinie JEG-3 transfiziert. Die Luciferase-Aktivität bezieht sich auf die durch $207 \mathrm{ng}$ Pax6-dHD, -dH3, -3Ala oder -dPD induzierte Aktivität des 4xG3T81Luc Plasmids (G3), dessen absoluter Wert als $100 \%$ definiert wurde. Die Ergebnisse sind Mittelwerte und SEM aus vier unabhängigen Experimenten mit Doppelbestimmung.

In Abbildung 31D sind die nach Cotransfektion von Pax6-dPD und den G3-OligomerKonstrukten erhaltenen relativen Luciferase-Aktivitäten dargestellt, wobei die Werte auf die Luciferase-Aktivität bei Cotransfektion von 4xG3T81Luc mit 207 ng Pax6-dPD (100 \% ะ 3,2 \%) bezogen sind. Die Cotransfektion von $207 \mathrm{ng}$ des Pax6-dPD-Expressionsplasmids mit dem Reportergen-Plasmid 4xG3T81Luc führte zu einer Erhöhung der Aktivität von 4xG3T81Luc um den Faktor 2 (Abb. 31D). Pax6-PD hatte keinen Einfluß auf die transkriptionelle Aktivität des isolierten G3-Elements mit Mutationen der Domäne B 
(Abb. 31D). Vier Kopien des G3B-Elements zeigten keine Aktivität und vier Kopien zeigten eine Aktivität von etwa 60 \% (Abb. 31D). Die Cotransfektion von 23 ng der Pax6Expressionsplasmide induzierte entsprechende Abhängigkeiten der Luciferase-Aktivitäten von den cotransfizierten Reportergen-Plasmiden (Abb. 31A, B, C und D).

3.7.3 Wirkung einer Mutation von Domäne G3B auf die Aktivierung des GlukagonPromotors der Ratte durch die Pax6-Homöodomänen-Mutanten im heterologen Zellsystem JEG-3

Die Reportergen-Plasmide -350GluLuc, -350(G3Am)GluLuc, -350(G3Bm)GluLuc oder -350(mutG3)GluLuc (Abb. 27; Tab. 7) wurden mit verschiedenen Mengen der Expressionsplasmide für die Pax6-Mutanten dHD, dH3, 3Ala oder dPD (Abb. 10; Tab. 8) transient in die heterologe Zelllinie JEG-3 cotransfiziert.

Abbildung 32A zeigt die nach Cotransfektion von Pax6-dHD und den Reportergen-Plasmiden erhaltenen relativen Luciferase-Aktivitäten, wobei die Werte auf die Luciferase-Aktivität bei Cotransfektion von -350GluLuc mit 207 ng Pax6-dHD (100\% $\%$ 9,7\%) bezogen sind. Cotransfektion von -350GluLuc und 207 ng Pax6-dHD-Expressionsplasmid führte zu einer rund 25-fachen Steigerung der Reportergen-Aktivität von -350GluLuc (Abb. 32A). Die Mutation der Domäne B verminderte die Aktivierung des Glukagon-Promotors durch Pax6 mit deletierter Homöodomäne um rund 60 \% (Abb. 32A). Mutationen der Pax6-Paired-DomänenBindungsstelle in Domäne G3A verminderten die Luciferase-Aktivität um rund $80 \%$ (Abb. 32A).

Abbildung 32B zeigt die nach Cotransfektion von Pax6-dH3 und den Reportergen-Plasmiden erhaltenen relativen Luciferase-Aktivitäten, wobei die Werte auf die Luciferase-Aktivität bei Cotransfektion von -350GluLuc mit 207 ng Pax6-dH3 (100\% \pm 5,9\%) bezogen sind. Cotransfektion von -350GluLuc und 207 ng Pax6-dH3-Expressionsplasmid führte zu einer rund 25-fachen Steigerung der Reportergen-Aktivität von -350GluLuc (Abb. 32B). Bei Pax6 mit deletierter Helix 3 der Homöodomäne verminderte die Mutation der Domäne $B$ die induzierte Luciferase-Aktivität um 65 \% (Abb. 32B). Mutationen der Pax6-Paired-DomänenBindungsstelle in Domäne G3A verminderten die Luciferase-Aktivität um rund $85 \%$ (Abb. 32B).

Abbildung 32C zeigt die nach Cotransfektion von Pax6-3Ala und den Reportergen-Plasmiden erhaltenen relativen Luciferase-Aktivitäten, wobei die Werte auf die Luciferase-Aktivität bei Cotransfektion von -350GluLuc mit 207 ng Pax6-d3Ala (100\% 2,8 \%) bezogen sind. Cotransfektion von -350GluLuc und 207 ng Pax6-3Ala-Expressionsplasmid führte zu einer rund 100-fachen Steigerung der Reportergen-Aktivität von -350GluLuc (Abb. 32C). Bei Pax6 
mit mutierter Homöodomäne verminderten die Mutationen der Domäne B die induzierte Luciferase-Aktivität um 80 \% (Abb. 32C). Die Mutationen der Pax6-Paired-DomänenBindungsstelle in Domäne A des G3-Elements verminderten die Luciferase-Aktivität um rund $90 \%$ (Abb. 32C).

A

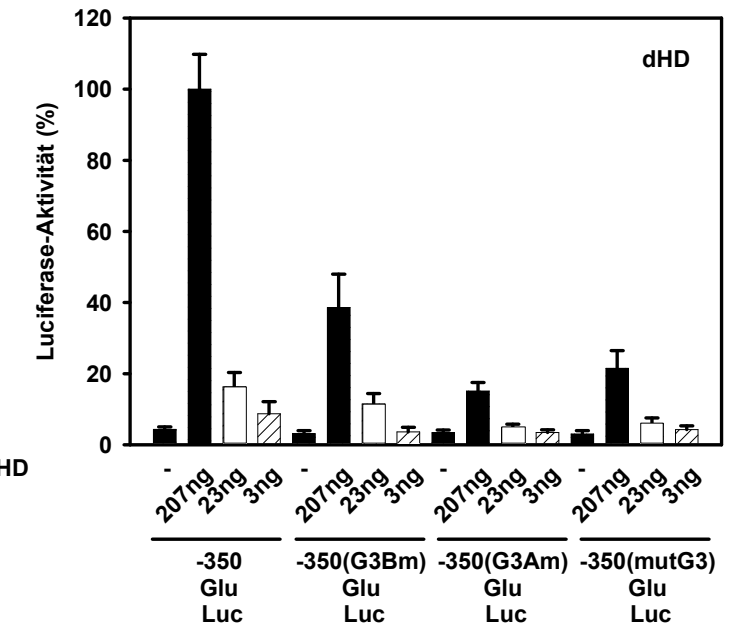

C

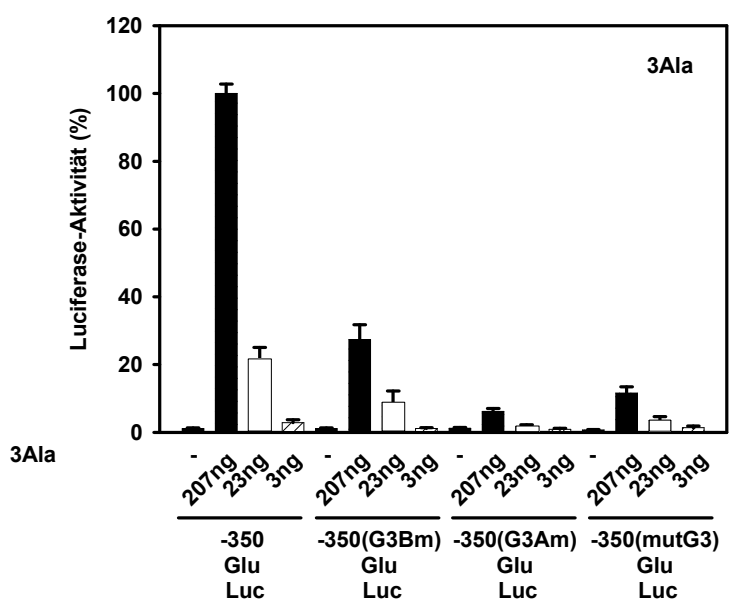

B

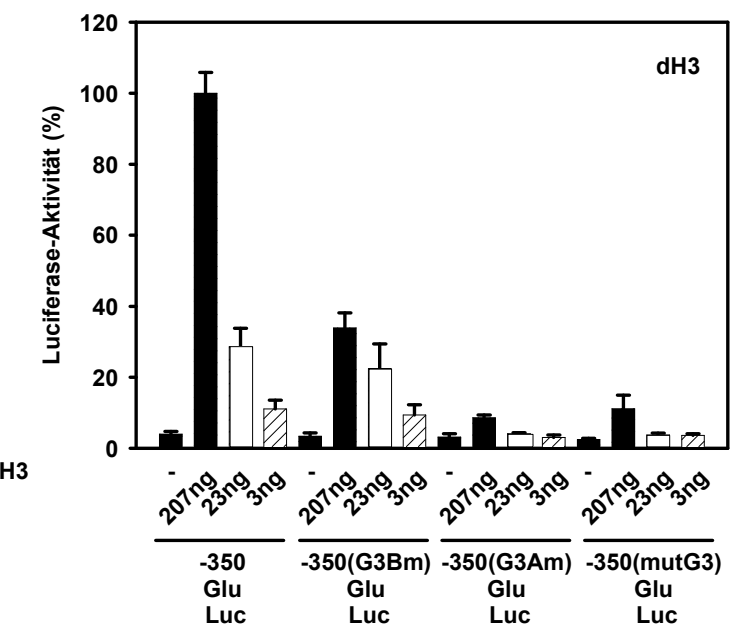

D

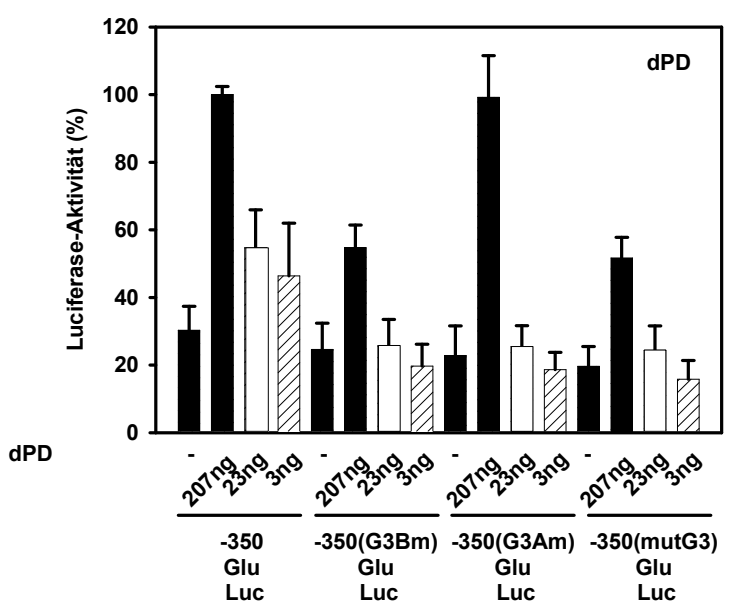

Abb. 32: Mutationen der Domäne A und B des G3-Elements hemmen die Aktivierung des Glukagon-Promotors durch die Pax6-Homöodomänen-Mutanten in der heterologen Zelllinie JEG-3. Die Reportergen-Plasmide -350GluLuc, -350(G3Bm)GluLuc, -350(G3Am)GluLuc oder -350(mutG3)GluLuc (3 $\mu \mathrm{g} / \mathrm{Schale}$ ) wurden zusammen mit unterschiedlichen Mengen $(0,207,23$, $3 \mathrm{ng} / \mathrm{Schale}$ ) eines Expressionsvektors für dHD (pBAT-dHD), dH3 (pBAT-dH3) 3Ala (pBAT-3Ala) oder dPD (pBAT-dPD) mittels Calcium-Phosphat-Präzipitation transient in die humane ChorionkarzinomZellinie JEG-3 transfiziert. Die Luciferase-Aktivität bezieht sich auf die durch $207 \mathrm{ng}$ dHD, dH3, 3Ala oder dPD induzierte Aktivität des -350GluLuc-Plasmids, dessen absoluter Wert als $100 \%$ definiert wurde. Die Ergebnisse der Transfektionen sind Mittelwerte und SEM aus vier unabhängigen Experimenten mit Doppelbestimmung. 
Abbildung 32D zeigt die nach Cotransfektion von Pax6-dPD und den Reportergen-Plasmiden erhaltenen relativen Luciferase-Aktivitäten, wobei die Werte auf die Luciferase-Aktivität bei Cotransfektion von -350GluLuc mit 207 ng Pax6-dPD (100\% $\%$ 2,4\%) bezogen sind. Die Cotransfektion von -350GluLuc und 207 ng Pax6-dPD-Expressionsplasmid führte zu einer 3-fachen Steigerung der Reportergen-Aktivität von -350GluLuc (Abb. 32D). Bei Pax6 mit deletierter Paired-Domäne verminderte die Mutation der Domäne $B$ die induzierte LuciferaseAktivität um $45 \%$ (Abb. 32D). Bei Cotransfektion von $23 \mathrm{ng}$ bzw. $3 \mathrm{ng}$ der Expressionsplasmide für die Pax6-Homöodomänen-Mutanten waren entsprechende Abhängigkeiten der Luciferase-Aktivitäten von den cotransfizierten mutierten ReportergenPlasmiden (Abb. 32A, B, C und D) zu beobachten.

Vergleich der Wirkung der Deletion oder Mutation der Pax6-Homöodomäne auf die Aktivierung des Glukagon-Promotors mit mutiertem G3B-Element in heterologen JEG-3Zellen

Zum direkten Vergleich der Wirkung einer Mutation in Domäne B des G3-Elements auf die Aktivierung des Glukagon-Gens durch die Pax6-Homöodomänen-Mutanten wurde das Reportergen-Plasmid -350(G3Bm)GluLuc (Abb. 27; Tab. 7) mit zwei verschiedenen Mengen der Expressionsplasmide für Pax6-WT, Pax6-dHD, Pax6-dH3, Pax6-3Ala, Pax6-dPD oder Pax6-dPD/E6 (Abb. 10; Tab. 8) transient in heterologe JEG-3-Zellen cotransfiziert. Die Abbildung 33 zeigt die relative Luciferase-Aktivität bei Verwendung von -350(G3Bm)GluLuc. In der Abbildung wurden die gemessenen Werte auf die durch Cotransfektion von -350(G3Bm)GluLuc und Pax6-WT erhaltene Aktivität bezogen. Der Pax6-WT (207 ng) stimulierte die Luciferase-Aktivität von -350(G3Bm)GluLuc rund 30-fach (Abb. 33).

Die Deletion der Homöodomäne oder der Helix 3 der Homöodomäne führte zu einer Abnahme der transkriptionellen Aktivität um rund $60 \%$ (Abb. 33). Die Mutation von drei Aminosäuren der Helix 3 der Homöodomäne verminderte die Aktivität um etwa 80 \% (Abb. 33). Die Expressionsplasmide dPD und dPD/E6 hatten keinen Einfluß auf die Aktivität von -350(G3Bm)GluLuc (Abb. 33). Bei Verwendung von 23 ng der Pax6-Expressionsplasmide ergaben sich entsprechende Abhängigkeiten der Luciferase-Aktivitäten (Abb. 33). 


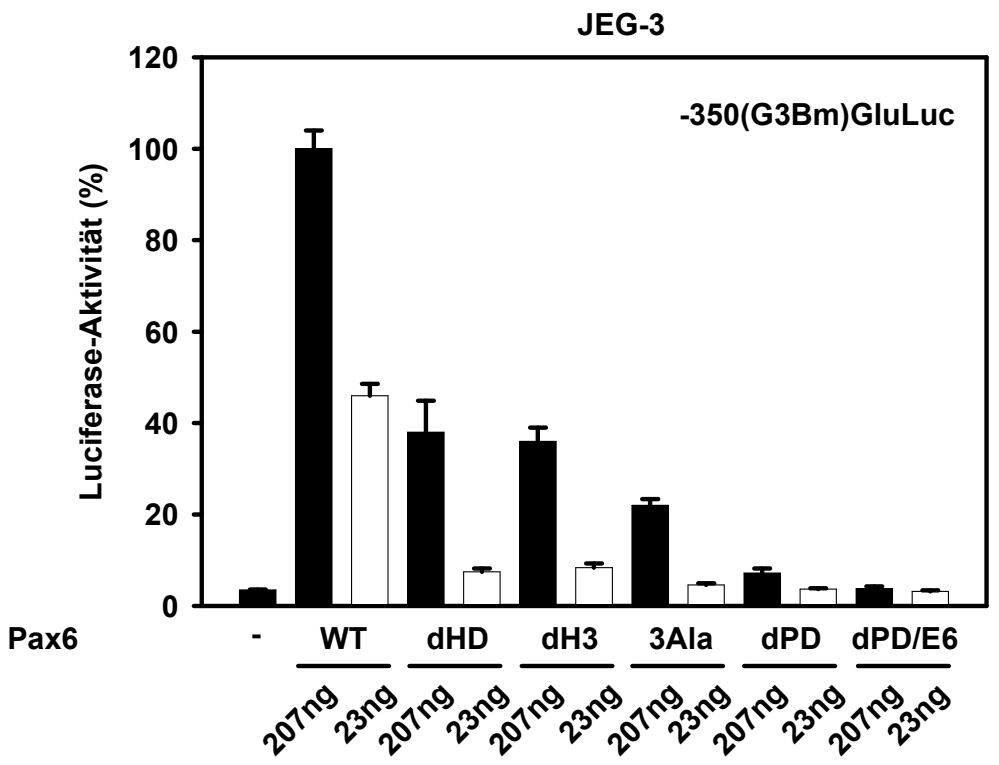

Abb. 33: Die Mutation innerhalb des G3B-Elements vermindert die Aktivierung des GlukagonPromotors durch die Pax6-Homöodomänen-Mutanten in der heterologen Zelllinie JEG-3. Das Reportergen-Plasmid -350(G3Bm)GluLuc (3 $\mu \mathrm{g} / \mathrm{Schale}$ ) wurde mit unterschiedlichen Mengen $(0,207$, $23 \mathrm{ng} / \mathrm{Schale}$ ) eines Expressionsvektors für Pax6-WT (pBAT-Pax6-WT) Pax6-WT, dHD (pBAT-dHD), dH3 (pBAT-dH3) 3Ala (pBAT-3Ala), dPD (pBAT-dPD) oder dPD/E6 (pBAT-dPD/E6) mittels CalciumPhosphat-Präzipitation transient in die humane Chorionkarzinom-Zelllinie JEG-3 transfiziert. Die Luciferase-Aktivität bezieht sich auf die durch $207 \mathrm{ng}$ Pax6-WT induzierte Aktivität des -350(G3Bm)GluLuc-Plasmids, dessen absoluter Wert als $100 \%$ definiert wurde. Die Ergebnisse sind Mittelwerte und SEM aus drei unabhängigen Experimenten mit Doppelbestimmung.

3.8 Charakterisierung der Bindung der Pax6-Paired-Domäne an Domäne B des G3-Elements des Glukagon-Gens der Ratte

Es wurde untersucht, ob Domäne B des G3-Elements eine Bindungsstelle für die Pax6Paired-Domäne ist. Dazu wurde im EMSA die Wirkung der funktionell charakterisierten Mutationen in Domäne B des G3-Elements auf die Bindung von bakteriell exprimierter Pax6Paired-Domäne an das G3-Element untersucht. Expression von GST-Pax6-PD-Fusionsproteinen und Darstellung der Expressionsprodukte in der SDS-PAGE

Zur bakteriellen Expression von GST-Pax6-PD oder GST wurden die Plasmide pGEX-Pax6PD und pGEX-2T (Tab. 8; 2.11.1) in den E. coli-Stamm BL21(DE3)pLys transformiert (2.17.2). Nach dem Aufwuchs der Bakterienzellen wurde die Protein-Expression durch IPTG induziert (2.19.1). 


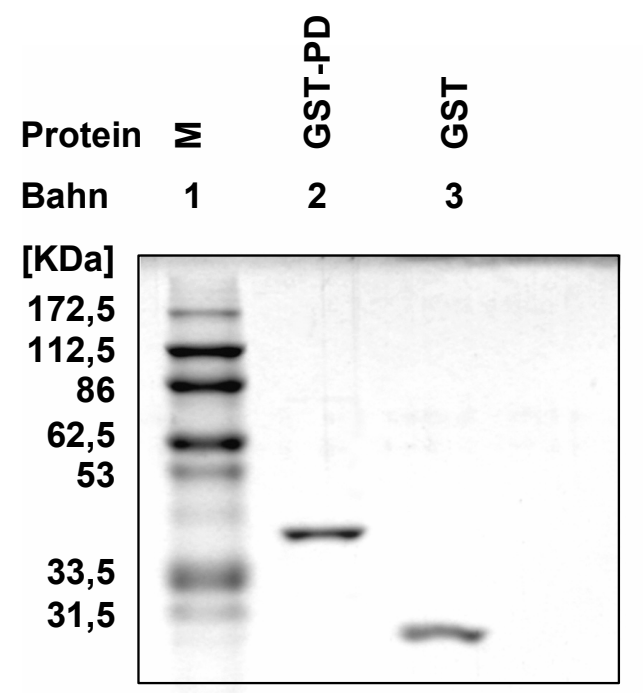

Abb. 34: Bakterielle Expression von rekombinantem GST-Pax6-PD-Fusionsprotein. Das GSTPax6-PD-Fusionsprotein oder GST allein wurde in BL21(DE3)pLys-Bakterien exprimiert und über eine Glutathion-gekoppelte Agarose-Matrix aufgereinigt. Nach der Dialyse wurde ein $5 \mu$ Aliquot der Proteinlösungen (Bahn 2 und 3) und ein Protein-Molekulargewichtstandard (Bahn 1) mittels SDSPAGE (12\%-iges Gel) elektrophoretisch aufgetrennt. Die Proteinbanden wurden durch CoomassieFärbung sichtbar gemacht. PD, Paired-Domäne; M, Protein-Molekulargewichtstandard 7B.

Die Bakterien wurden durch Sonifizierung aufgeschlossen und das GST-Fusionsprotein bzw. GST über Glutathion-Agarose aufgereinigt (2.19.1). Zur Analyse der Protein-Expression wurde jeweils ein $5 \mu$-Aliquot der proteinhaltigen Lösungen zusammen mit einem Molekulargewichtstandard auf ein $12 \%$-iges SDS-Polyacrylamidgel aufgetragen (2.19.5). Die Proteinbanden wurden anschließend durch Coomassie-Färbung (2.19.6) sichtbar gemacht. Nach der IPTG-Induktion zeigte sich eine spezifische GST-Pax6-PD-Proteinbande (Abb. 34, Bahn 2), die in einer Höhe von 42 kDa (GST 26 kDa, Pax6-PD 14 kDa, Epstein et al., 1994) migrierte. GST migrierte entsprechend seiner Größe bei 26 kDa (Abb. 34, Bahn 3). 


\subsubsection{Analyse der Bindung von GST-Pax6-PD an das G3-Element mit Mutationen innerhalb Domäne B}

Die $\left[{ }^{32} \mathrm{P}\right]-$ markierten Oligonukleotid-Sonden G3, G3Bm, G3M1 und G3M2 (2.11.1; Tab. 2) wurden zusammen mit steigenden Mengen des bakteriell aufgereinigten GST-Pax6-PDFusionsproteins (2.19.1) inkubiert.

Das bakteriell exprimierte GST-Pax6-PD-Fusionsprotein zeigte abhängig von der eingesetzten Proteinmenge eine Bindung an die radioaktiv markierten Oligonukleotid-Sonden G3, G3Bm, G3M1 und G3M2 (Abb. 35A, Bahn 3, 4, 5, 6, 10, 11 und 12; Abb. 35B, Bahn 4, 5, 6, 8, 9, 10, 11 und 12). Die Sonden G3Bm und G3M1 zeigten keine Bindung des Fusionsproteins bei Einsatz der niedrigsten Proteinmenge $(0,25 \mu \mathrm{g}$ ) (Abb. 35A, Bahn 9; Abb. 35B, Bahn 3). Bei Verwendung der G3M2-Sonde wurde eine langsamer migrierendere Bande bei Einsatz von $1 \mu \mathrm{g}$ und $2 \mu \mathrm{g}$ GST-PD detekiert. Außerdem wurde eine Bande zusätzlich zu der der freien G3M2-Sonde nachgewiesen, die bei Inkubation der Sonde mit GST, GST-PD und auch bei Verwendung der freien Sonde auftrat. Als spezifische Kontrolle wurden $1 \mu \mathrm{g}$ bakteriell exprimiertes GST-Protein mit den Sonden G3, G3Bm, G3M1 und G3M2 inkubiert. Es wurden keine Protein-DNA-Komplexe detektiert (Abb. 35A, Bahn 2, 8; Abb. 35B, Bahn 2 und 8).

Die Quantifizierung der Radioaktivität erfolgte mit Hilfe des Phosphor-Imagers und ergab bei keiner der eingesetzten Proteinmengen und der eingesetzten Sonden G3Bm, G3M1 und G3M2 einen signifikanten Unterschied der Bandenintensität verglichen mit der Bindung an die G3-Sonde. 
A

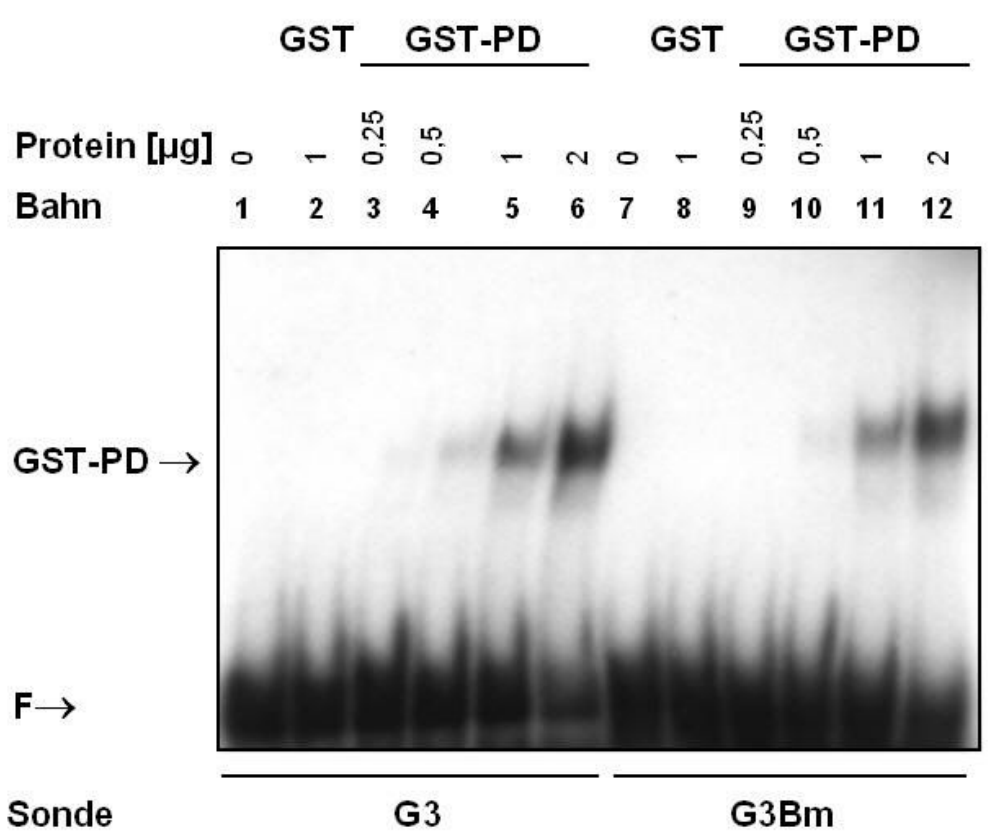

B

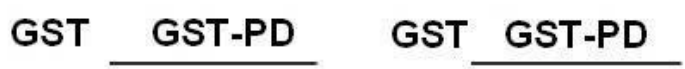

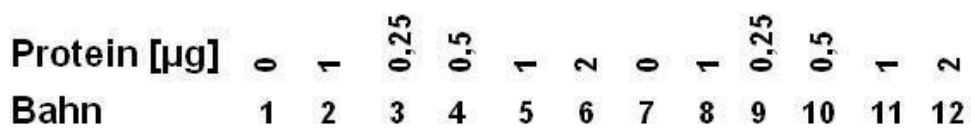

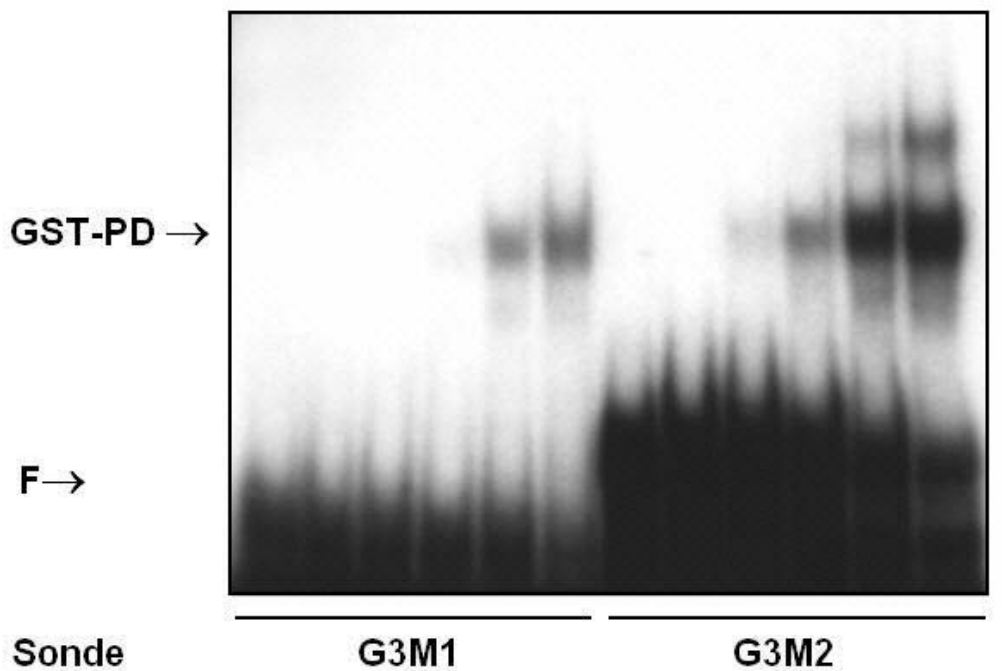

Abb. 35: Die Paired-Domäne von Pax6 zeigt im EMSA eine Bindung sowohl an das G3-Element als auch an des G3-Element mit mutierter Domäne B. Radioaktiv markierte G3-, G3Bm- (A), G3M1und G3M2 (B) -Oligonukleotid-Sonde wurde mit den angegebenen Mengen bakteriell exprimiertem GST-Pax6-PD bzw. mit $1 \mu \mathrm{g}$ GST inkubiert. Die Reaktionsansätze wurden auf $5 \%$-igen Polyacrylamidgelen unter nicht-denaturierenden Bedingungen aufgetrennt. Radioaktiv markierte DNA wurde anschließend autoradiographisch detektiert. Der mit GST-PD gekennzeichnete Pfeil markiert die DNA-bindenden Pax6-PD-Proteinkomplexe. F, freie Sonde; US, unspezifische Banden. 
Mit Hilfe des GAL4-Systems wurde eine Bedeutung der Pax6-Homöodomäne bei der Glukagon-Gentranskription unabhängig von einer DNA-Bindung untersucht. Dazu wurden Expressionsvektoren hergestellt, in denen Pax6-WT und Pax6-dHD (Abb. 10; Tab. 8) aminoterminal mit der DNA-Bindedomäne des Hefetranskriptionsfaktors GAL4 (147 AS) fusioniert sind (Abb. 36; Tab. 8; 2.11.1).

GAL4-Pax6-WT

GAL4-Pax6-dHD

\begin{tabular}{|l|l|l|l|l|}
\hline GAL4 & PD & L & HD & TAD \\
\hline
\end{tabular}

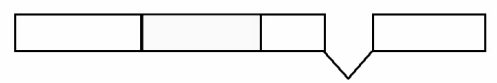

Abb. 36: Hergestellte GAL4-Pax6-Fusionsgene. Es wurden Expressionsvektoren hergestellt, die für GAL4-Pax6-WT- (pSG-Pax6-WT) oder GAL4-dHD- (pSG-dHD) Fusionsproteine kodieren, die aminoterminal mit der DNA-Bindedomäne des Hefetranskriptionsfaktors GAL4 verknüpft sind: GAL4Pax-WT (GAL4 mit Pax6-WT fusioniert), GAL4-Pax6-dHD (GAL4 mit dHD fusioniert); PD, PairedDomäne; L, Linker; HD, Homöodomäne; TAD, Transaktivierungsdomäne.

Die Expressionsplasmide für GAL4-Pax6-WT und GAL4-Pax6-dHD (Abb. 36; Tab. 8) wurden mit dem Reportergen-Plasmid -350(mutG1/G3)GluLuc (Abb. 37; Tab. 7) transient in die Chorionkarzinom-Zelllinie JEG-3 cotransfiziert. In dem Reportergen-Plasmid -350(mutG1/G3)GluLuc (Abb. 37) steht die Luciferase-Expression unter Kontrolle von 350 Basenpaaren der 5'-flankierenden Region des Glukagon-Gens der Ratte. Innerhalb des G1- und G3-Elements sind die Pax6-Paired-Domänen-Bindungsstellen in eine Bindungsstelle für den Hefetranskriptionsfaktor GAL4 (17 bp, CGGAGTACTGTCCTCCG) mutiert worden (Grzeskowiak et al., 2000).

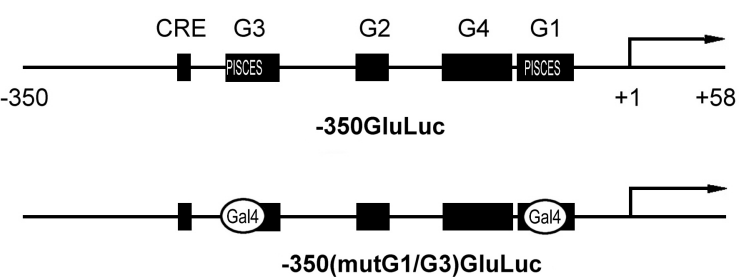

Abb. 37: Reportergenfusionsgene mit in GAL4-DNA-Bindungsstellen mutiertem G1- und G3Element. Im Reportergen-Plasmid -350(mutG1/G3)GluLuc steht die Expression unter der Kontrolle des Glukagon-Promotors der Ratte von bp -350 bis +58 . Innerhalb der 350 bp wurde das PISCESMotiv im G1- und G3-Element in GAL4-Bindungsstellen mutiert. Gezeigt sind außerdem charakteristische Kontrollelemente des Glukagon-Promotors der Ratte: CRE, cAMP-responsives Element; G1, Glukagon-Element 1; G2, Glukagon-Element 2, G3, Glukagon-Element 3; G4, GlukagonElement 4. 
Die Bindung der GAL4-Fusionsproteine an den Glukagon-Promotor erfolgte somit unabhängig von der Bindung der Pax6-Paired-Domäne und unabhängig von der der Pax6Homöodomäne.

Die Abbildung 38 zeigt die beobachtete relative Luciferase-Aktivität, wobei die gemessenen Werte auf die durch Cotransfektion von 207 ng GAL4-Pax6-WT erhaltene Aktivität bezogen ist $(100 \% \pm 10,6 \%)$. Die Deletion der Homöodomäne führte zu einer Steigerung der Luciferase-Aktivität auf 1700 \% (Abb. 38). Die Cotransfektion von -350(mutG1/G3)GluLuc und einem GAL4-Expressionsvektor führte zu einer Luciferase-Aktivität von 17 \% (Abb. 38). Die Ergebnisse zeigen, dass bei Verwendung eines GAL4-Pax6-Fusionsproteins die Deletion der Pax6-Homöodomäne aktivierend auf die Pax6-Aktivität wirkt.

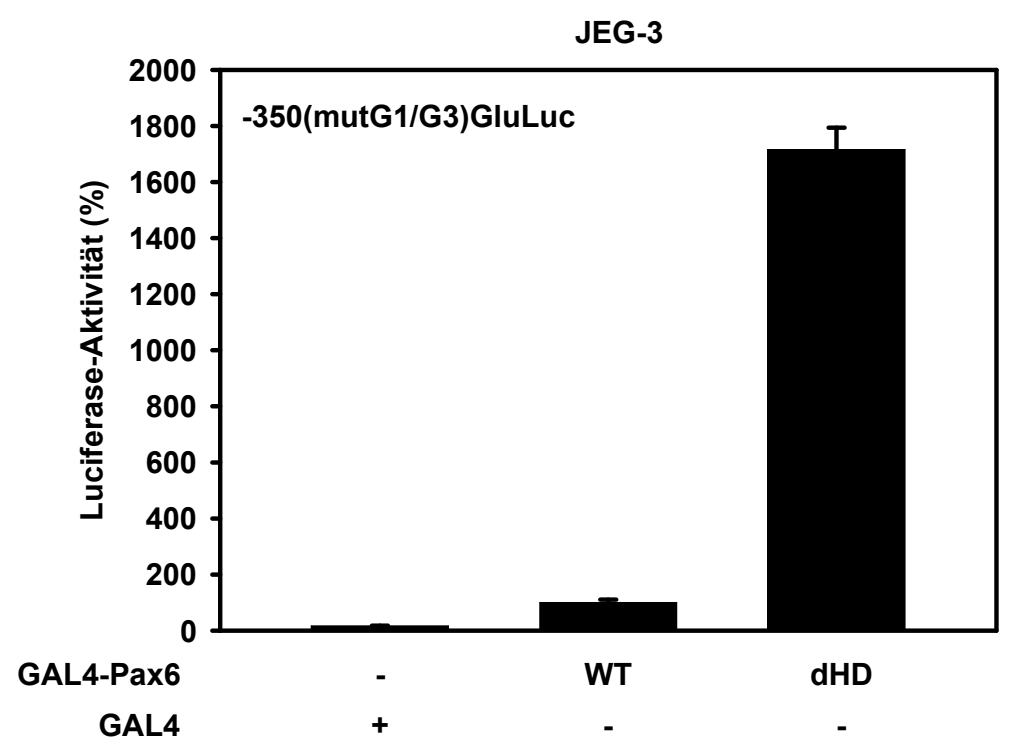

Abb. 38: Die Deletion der Pax6-Homöodomäne steigert die transkriptionelle Aktivität eines GAL4-Pax6-Fusionsproteins am Glukagon-Gen in der heterologen Zelllinie JEG-3. Das Reportergen-Plasmid -350(mutG1/G3)GluLuc wurde zusammen mit Expressionsvektoren für GAL4Pax6-WT (pSG-Pax6-WT), GAL4-Pax6-dHD (pSG-dHD) (207 ng/Schale) mittels Calcium-PhosphatPräzipitation transient in die humane Chorionkarzinom-Zelllinie JEG-3 transfiziert. Die LuciferaseAktivität bezieht sich auf die durch 207 ng GAL4-Pax6-WT-induzierte Aktivität des -350(mutG1/G3)GluLuc -Plasmids, dessen absoluter Wert als $100 \%$ definiert wurde. Die Ergebnisse sind Mittelwerte und SEM aus zwei unabhängigen Experimenten mit Doppelbestimmung. 
4.1

\section{Der paired-Homöodomänen-Transkriptionsfaktor Pax6 aktiviert synergistisch das Glukagon-Gen über die Pax6-Paired-Domäne-DNA- Bindungsstelle im G1- und G3-Element des Glukagon-Promotors}

Methodischer Ansatz zur Untersuchung der Bedeutung der Pax6-Homöodomäne für die Aktivierung des Glukagon-Gens durch Pax6 war die Herstellung von Pax6-Mutanten (Abb. 10; Tab. 8) und deren Cotransfektion mit Glukagon-Reportergen-Plasmiden (Tab. 7) in Tumorzelllinien. Dabei sollte der Einfluß der Mutationen in Pax6 auf die Aktivierung des Reportergens erfasst werden. Ein solches Vorgehen setzt voraus, dass die Wirkung der Mutationen nicht durch die Wirkung von endogenem Pax6 maskiert wird. Ungeeignet waren daher glukagonproduzierende, pankreatische Zellinien, da diese schon Pax6 enthalten. Die transienten Cotransfektionsexperimente wurden deshalb in Abwesenheit von Pax6 und anderen $\alpha$-zellspezifischen Proteinen in einer heterologen Tumorzelllinie, der Zelllinie JEG-3 durchgeführt. Die JEG-3-Zellen stammen von einem humanen Chorionkarzinom ab, das sich aus cerebralen Metastasen gebildet hat (Kohler et al., 1971).

Analoge Cotransfektionen von Reporterfusionsgen-Plasmiden mit 350 oder 1300 Basenpaaren der 5'-flankierenden Region des Glukagon-Gens der Ratte demonstrierten eine Aktivierung des Glukagon-Promotors sowohl durch endogenes Pax6 in den Pax6exprimierenden, glukagonproduzierenden Zelllinien aTC2 und InR1G9 (3.2.1), als auch nach Expression von exogenem Pax6 in der heterologen Zelllinie JEG-3 (3.2.2). Diese Reportergen-Aktivität wurde durch selektive Mutationen des PISCES- (pancreatic islet cell specific enhancer sequence) Motivs innerhalb der Pax6-Bindungsstellen im G1- und G3Element des Glukagon-Promotors deutlich gehemmt (3.2.1 und 3.2.2). Die dabei verwendeten Mutationen sind in der Literatur als Pax6-bindungsinaktivierende Mutationen beschrieben: Eine Punktmutation des G1-Elements (Position -79) verhindert die Bindung von rekombinantem Pax6 an das G1-Element (Andersen et al., 1999), lässt aber die Bindung des direkt benachbart bindenden Transkriptionsfaktors $\mathrm{Cdx} 2 / 3$ weiterhin zu (Andersen et al., 1999); die Mutation von vier Basenpaaren in PISCES des G3A-Elements (Position -259/-256) verhindert die Bindung von Pax6 an das G3-Element (Knepel et al., 1990a). Somit scheint die Zellinie JEG-3 ein geeignetes Zellsystem zu sein, um die Aktivierung des Glukagon-Gens durch Pax6 in Abwesenheit anderer a-zellspezifischer Proteine zu betrachten. Bezüglich der Auswirkung von Mutationen der Pax6-Bindungsstellen im G1- und G3-Element ist gezeigt worden, dass die Mutationen einer $17 \mathrm{bp}-S e q u e n z$ in PISCES innerhalb eines 350 Basenpaar-Promotorfragments der Ratte zu einer deutlichen Abnahme 
der Aktivität in InR1G9-Zellen führt (Grzeskowiak et al., 2000). Dabei ist jedoch nicht auszuschließen, dass durch die ausgedehnte Mutation, zumindest im G1-Element, auch DNA-Bindungsstellen für andere Transkriptionsfaktoren verändert wurden.

Weiterhin zeigte die Promotor-Mutationsanalysen in pankreatischen $\alpha$-Zellen und nach Expression von Pax6 in heterologen JEG-3-Zellen (3.2) eine synergistische Aktivierung des Glukagon-Gens durch Pax6 über die beiden Pax6-Bindungsstellen im G1- und G3-Element des Glukagon-Promotors (3.2.1 und 3.2.2). Das bestätigt, dass das PISCES-Motiv und die Bindung der Pax6-Paired-Domäne an dieses, eine wichtige Rolle bei der Aktivierung des Glukagon-Gens spielen. Bekannt dazu ist, dass ein synthetischer Mini-Enhancer bestehend aus einer oligomeren Pax6-Bindungsstelle, der Domäne $A$ des G3-Elements mit dem PISCES-Sequenzmotiv, in Pax6-exprimierenden, von Pankreasinseln abgeleiteten Zellinien eine hohe zellspezifische Aktivität besitzt (Beimesche et al., 1999; Wrege et al., 1995).

Bei Verwendung von 350 Basenpaaren bzw. 1300 Basenpaaren verminderten die Mutationen im G1- und G3-Element in ähnlichem Ausmaß die Aktivität des GlukagonPromotors (3.2.1 und 3.2.2). Das deutet darauf hin, dass im Bereich zwischen Basenpaar -350 und -1300 des Glukagon-Promotors der Ratte keine weiteren Bindungsstellen existieren, die die Funktion der Pax6-Bindungsstellen innerhalb des G1- und G3-Elements im Glukagon-Promotor übernehmen könnten, wenn durch Mutation der beiden Pax6Bindungsstellen die Bindung von Pax6 gehemmt wurde. Außerdem ersetzt kein Transkriptionsfaktor die Funktion von Pax6 bei der Aktivierung des Glukagon-Gens der Ratte, wenn die Bindungsstellen im G1- und G3-Element durch Mutation ausgeschaltet sind. Belegt ist die Bindung von Pax6 an die Glukagon-Promotorelemente G1 und G3 in vitro sowie die Aktivierung des Glukagon-Gens durch Pax6 (Andersen et al., 1999; Sander et al., 1997). Die Bedeutung von Pax6 für die Regulation des Glukagon-Gens in vivo ist dagegen unklar. Pax6-/- Mäuse zeigen verschiedene Defekte, u.a. fehlen ihnen glukagonproduzierende $\alpha$-Zellen, und sie versterben kurz nach der Geburt (St. Onge et al., 1997). Dabei ist jedoch nicht zu unterscheiden, ob die fehlende Aktivität des Glukagon-Gens auf das Fehlen einer direkten Regulation des Glukagon-Gens durch Pax6 zurückzuführen ist oder lediglich indirekt Folge einer fehlenden Ausdifferenzierung von pankreatischen Inselzellen ist. Im Gegensatz zu Pankreasinselzelllinien sind 350 Basenpaare des GlukagonPromotors der Ratte mit den Promotorelementen G1 und G3 in transgenen Mäusen für eine $\alpha$-zellspezifische Aktivierung der Transkription nicht ausreichend (S. Beimesche, unveröffentlichte Ergebnisse); dazu sind 1300 Basenpaare der 5'-flankierenden Region des Glukagon-Gens notwendig (Efrat et al., 1995). Um zu überprüfen, ob Pax6 in vivo die Glukagon-Gentranskription durch direkte Bindung an das Glukagon-Gen reguliert, sollte die Wirkung einer Mutation der Pax6-Bindungsstellen in den DNA-Kontrollelementen G1 und G3 auf die transkriptionelle Aktivität der 5'-flankierenden Region des Glukagon-Gens in primären 
Pankreasinseln transgener Mäuse untersucht werden. Dazu wurden transgene Mäuse hergestellt, die als Transgen 1300 Basenpaare der 5'-flankierenden Region des GlukagonGens der Ratte fusioniert mit dem Reportergen Luciferase enthielten. Mit dem WildtypKonstrukt wurden insgesamt sieben unabhängige transgene Mauslinien erhalten; jedoch konnte in keiner dieser Linien zuverlässig die Expression des Reportergens in Pankreasinseln gemessen werden. Nur in einer Linie wurden vereinzelt (in 4 von 25 Mäusen) messbare Werte festgestellt (eigene Daten, nicht gezeigt). Daraufhin wurden Mauslinien mit Glukagonpromotor-Mutationen nicht weiter verfolgt. Es ist unklar, warum im Gegensatz zu Efrat et al. (1995) keine Expression in Pankreasinseln detektiert wurde. Mögliche Ursache könnte die Verwendung unterschiedlicher Mäusestämme (B6D2 gegenüber FVB/N) sein. Außerdem wurden unterschiedliche Reportergene eingesetzt: Anstelle des SV40 großes TOnkoproteins wurde hier das Reportergen Luciferase verwendet.

\subsection{Die Pax6-Homöodomäne ist für die Aktivierung des Glukagon-Gens durch Pax6 notwendig}

Die Mehrzahl der Transkriptionsfaktoren besteht aus mindestens zwei oder mehr ProteinDomänen, wobei eine Domäne meistens die DNA-bindende Domäne ist (Langdon et al., 2001). Es gibt aber auch Transkriptionsfaktoren, die mehr als eine DNA-Bindungsdomäne enthalten. Dazu gehört der paired-Homöodomänen-Transkriptionsfaktor Pax6, der zwei potentiell DNA-bindende Protein-Domänen hat: eine Paired-Domäne (Bopp et al., 1986; Treisman et al., 1991) und eine Homöodomäne (Walther und Gruss, 1991).

Die isolierte Pax6-Paired-Domäne und die isolierte Pax6-Homöodomäne binden unterschiedliche DNA-Sequenzen (Epstein et al., 1994b; Wilson et al., 1993). Diese überlappen sich häufig mit DNA-Bindungsstellen, die von Paired-Domänen bzw. Homöodomänen anderer Transkriptionsfaktoren gebunden werden (Ritz-Laser et al., 1999; Andersen et al., 1999; Herzig et al., 2000). Wie eine spezifische Bindung von Pax6 an bestimmte Zielgene erreicht wird, ist nicht bekannt. Da gegenüber jeweils optimalen synthetischen Bindungsstellen die Affinität der Pax6-Paired-Domäne größer ist als die der Pax6-Homöodomäne, gilt die Paired-Domäne als primäre DNA-bindende Domäne von Pax6 (Czerny und Busslinger, 1995). Demgegenüber war die Bedeutung der Pax6-Homöodomäne für die Aktivierung des Glukagon-Gens durch Pax6 nicht klar: So ist für die in vivo Funktion des Drosophila Pax6-Homologs Eyeless die Homöodomäne des Proteins nicht erforderlich, da eine Deletionsmutante von eyeless auch ohne Homöodomäne die Augenbildung zu induzieren vermag (Punzo et al., 2001). Vier der bisher bekannten neun Pax-Proteine des Menschen (Dahl et al., 1997; Mansouri et al., 1999; Underhill, 2000; Walther et al., 1991) besitzen keine Homöodomäne. 
Für eine Bedeutung der Homöodomäne spricht jedoch, dass die Paired-Domäne und die Homöodomäne in vitro kooperieren (Jun und Desplan, 1996). Übereinstimmend damit ist für den mutanten paired-Phänotyp in Drosophila in vivo sowohl die Paired-Domäne als auch die Homöodomäne notwendig (Bertuccioli et al., 1996; Miskiewicz et al., 1996).

Im Zusammenhang mit der Frage, ob die Pax6-Homöodomäne eine Bedeutung bei der Aktivierung des Glukagon-Gens hat, wurde hier erstmalig in Cotransfektionsstudien mit den Pax6-Homöodomänen-Mutanten dHD, dH3 und 3Ala (Abb. 10) gezeigt, dass die Deletion der gesamten Pax6-Homöodomäne bzw. die der DNA-Erkennungshelix der Homöodomäne bzw. eine drei-Aminosäure-Mutation in der DNA-Erkennungshelix der Homöodomäne zu einer deutlich verringerten Aktivierung des Glukagon-Promotors durch Pax6 führt (3.3.1). Dies spricht dafür, dass die Pax6-Homöodomäne neben der Paired-Domäne zur Aktivierung des Glukagon-Gens durch Pax6 notwendig ist.

Hinweise aus Kontrollexperimenten (3.3.2) zeigten, dass die drastische Abnahme der Aktivität von Pax6 am Glukagon-Gen nicht Folge einer verminderten Expression oder verminderter Kerngängigkeit von Pax6 nach Deletion bzw. Mutation der Homöodomäne ist: 1.) Im Electrophoretic mobility shift assay (EMSA) mit Kernextrakten aus mit den Pax6Homöodomänen-Mutanten transfizierten JEG-3-Zellen mit der Oligonukleotid-Sonde G3A ließen sich vergleichbare oder erhöhte Mengen an Protein-DNA-Komplexen (3.3.2) detektieren. 2.) In Cotransfektionsstudien in der heterologen Zelllinie JEG-3 zeigten die Homöodomänen-Mutanten Pax6-dHD, Pax6-dH3 und Pax6-3Ala an einem oligomeren G3AMinienhancer mit vier Kopien der Domäne A des G3-Elements eine ähnliche transkriptionelle Aktivität wie der Pax6-Wildtyp (3.3.2).

\subsection{Bedeutung der Pax6-Homöodomäne bei der Bindung von Pax6 an das G1- oder G3-Element des Glukagon-Promotors der Ratte}

Für die paired-Homöodomäne von Pax6 ist die palindromische P3-Sequenz mit der Basenfolge TAAT(YNR)ATTA (Y: T/C; R: A/G; N: A/C/G/T) (Wilson et al., 1995) die optimale DNA-Bindungsstelle. Die P3-Sequenz reicht aus, um eine Transaktivierung durch Pax6 in Zelllinien zu vermitteln (Czerny und Busslinger, 1995). P3-Erkennungsstellen sind in ZielPromotoren von Augen-spezifischen Genen gefunden worden. So ist z.B. eine P3-Sequenz an der Regulation von gooseberry durch das Drosophila Paired-Protein beteiligt (Li und Noll, 1994). P3-Konsensussequenzen finden sich auch hochkonserviert in Promotoren der Rhodopsin-Gene in Drosophila und Mensch (RCS1-Sequenz). Sie spielen eine wichtige Rolle bei der Aktivierung der Rhodopsin-Gen-Expression in Drosophila (Mismer und Rubin, 1989; Fortini und Rubin, 1990), vermutlich durch die kooperative Bindung von Pax6 (Halder et al., 1995; Wilson und Desplan, 1995), das für die Augenentwicklung nötig ist. Sowohl im 
G1-Element als auch im G3-Element des Glukagon-Promotors der Ratte gibt es, benachbart zur Paired-Domänen-Bindungsstelle, DNA-Bindungsstellen für Homöodomänen-Proteine. So liegen im G1-Element Bindungsstellen für die Homöodomänen-Proteine Cdx2/3, Brain-4 und Isl-1 (Andersen et al., 1999; Ritz-Laser et al., 1999; Hussain et al., 1997; Wang und Drucker, 1995). Das G3-Element ist in zwei DNA-Domänen unterteilt: Domäne A (5'-CGCCTGA-3') die Paired-Domäne-Bindungsstelle (Sander et al., 1997) und Domäne B (5'GATTGAAGGGTGTA-3') (Knepel et al., 1990a). Domäne B zeigt Ähnlichkeiten mit Bindungsstellen von Mitgliedern der Homöodomäne-Protein-Familie, z.B. mit der als PRS („Pbx-responsive Sequenz“) bezeichneten in vitro Bindungsstelle von Pbx (Kamps et al., 1990; Nourse et al., 1990; Lu et al., 1994) und wurde als Bindungsstelle für ein Heterodimer aus Homöodomänen-Proteinen der PBC-Familie Pbx1/2 (Monica et al., 1991) und dem ubiquitären Homöodomänen-Protein Prep-1 (Berthelsen et al., 1998) identifiziert (Herzig et al., 2000).

In der vorliegenden Arbeit wurde untersucht, ob die Pax6-Homöodomäne bei der Bindung von Pax6 an das G3-Element oder an das G1-Element des Glukagon-Promotors der Ratte von Bedeutung ist. Protein-DNA-Bindungsanalysen mit in vitro transkribierten/translatierten Pax6-Homöodomänen-Mutanten (3.4.1) zeigten, dass die Deletion oder Mutation der Homöodomäne keinen Einfluß auf die Bindung von Pax6 an das G3-Element hat (3.4.2). Somit ist die Pax6-Homöodomäne für die Bindung von Pax6 an das G3-Element nicht notwendig. Die Untersuchung der Bindung von Pax6-WT bzw. der Pax6-HomöodomänenMutanten an das G1-Element demonstrierte jedoch eine deutlich geringere Bindung von Pax6 nach Deletion oder Mutation der Homöodomäne (3.4.2). Das deutet darauf hin, dass die Pax6-Homöodomäne für die Bindung von Pax6 an das G1-Element notwendig ist und zur Gesamtaffinität von Pax6 an G1 beiträgt. Demnach ist die Pax6-Homöodomäne bei der Bindung des Pax6-Proteins an das G1- oder das G3-Element des Glukagon-Promotors unterschiedlich bedeutsam. Obwohl die Pax6-Bindungsstellen in den Promotorelementen G1 und G3 eine eindeutige Homologie in ihrer Sequenz zeigen (Abb. 2), haben sie nur 8 von 16 Nukleotiden gemeinsam (Philippe et al., 1995). Auch außerhalb der Pax6-Bindungsstellen des G1- und G3-Elements sind die DNA-Sequenzen stark unterschiedlich, was eine Erklärung für funktionelle Unterschiede in der Protein-DNA-Interaktion sein könnte. Bereits in der Literatur beschrieben ist die Bindung einzelner Proteindomänen von Pax6 an das G1oder G3-Element des Glukagon-Promotors der Ratte (Ritz-Laser et al., 1999). Dabei wurde die isolierte Paired-Domäne oder die Paired-Domäne plus Linker plus Homöodomäne verwendet; die carboxyterminale Transaktivierungsdomäne von Pax6 fehlte jeweils. Die isolierte Paired-Domäne besaß eine geringere Affinität für das G1-Element, wohingegen das Fusionsprotein aus Paired-Domäne, Linker und Homöodomäne eine starke Bindung an das G1-Element zeigte. Dieser Literaturbefund mit isolierten Pax6-Proteindomänen ist konsistent mit den Ergebnissen der vorliegenden Arbeit. Im Unterschied zu Ritz-Laser et al. (2000), die 
die Bindung der gesamten Homöodomäne an das G1- oder G3-Element untersucht haben, wurde in vorliegenden Untersuchungen die Bindung der Pax6-Homöodomänen-Mutanten an das G1- und G3-Element charakterisiert. Die aus Bindungsanalysen mit der Homöodomänen-Mutante 3Ala erhaltenen Befunde (3.4.2) erlauben es, die drei Aminosäuren Valin-47, Serin-50 und Asparagin-51 als essentiell für die Bindung von Pax6 an das G1-Element zu identifizieren. Diese Aminosäuren gehen bei der Bindung der Homöodomäne des Drosophila Paired-Proteins an die P3-Sequenz sequenzspezifische Kontakte mit der großen Furche der DNA ein (Wilson et al., 1995). Valin-47 geht über seine Seitenkette durch hydrophobe Interaktionen direkte Kontakte mit Thymidin 4 des Motivs TAATNNN ein (Wilson et al., 1996). Asparagin-51 interagiert über zwei Wasserstoffbrückenbindungen direkt mit dem Adenosin an Position 3. Die Aminosäure an Position 50 der Homöodomäne charakterisiert die Subklassen der paired-HomöodomänenTranskriptionsfaktoren und vermittelt eine spezifische DNA-Bindung. In den meisten pairedHomöodomänen-Transkriptionsfaktoren befindet sich an Position 50 ein Glutamin, z.B. in Mix-1 oder repo (Wilson et al., 1993). Pax6 und das Drosophila Paired-Protein besitzen an dieser Stelle die Aminosäure Serin (Wilson et al., 1993). Die Aminosäure 50 geht van-derWaals-Kontakte mit den Basen 5, 6, 7 im 3'-Bereich des TAAT-Motivs ein, die für die spezifische Bindung der Homöodomäne an DNA entscheidend ist (Wilson et al., 1996).

\subsection{Zur Aktivierung des Glukagon-Gens durch Pax6 über das G1-Element und/oder das G3-Element ist die Pax6-Homöodomäne notwendig}

Die Homöodomäne von Pax6 ist sowohl für die Aktivierung des Glukagon-Gens durch Pax6 notwendig (3.3.1), als auch für die Bindung von Pax6 an das G1-Element (3.4.2 und 4.3). Es stellte sich die Frage, ob die Abnahme der Aktivierung des Glukagon-Gens durch Pax6 nach der Deletion oder der Mutation der Pax6-Homöodomäne allein auf eine daraus resultierende verminderte Bindung von Pax6 an das G1-Element zu erklären ist. Die Cotransfektion der Pax6-Homöodomänen-Mutanten zusammen mit 5'-Deletionsmutanten des GlukagonPromotors der Ratte (Abb. 20) bzw. mit Promotorfragmenten mit im G3-Element mutierter Pax6-Bindungsstelle (Ab. 6) demonstrierten, dass die Homöodomäne von Pax6 für die Aktivierung des Glukagon-Gens über das G1-Element durch Pax6 notwendig ist (3.5.1 und 3.5.2). Diese Befunde sind in Übereinstimmung mit den Bindungseigenschaften der Pax6Homöodomänen-Mutanten an das G1-Element (3.4.2). Entgegen dem Bindungsverhalten der Pax6-Homöodomänen-Mutanten am G3-Element (3.4.2), zeigten Cotransfektionen mit Glukagon-Promotorfusionsgenen mit deletiertem G1-Element (Abb. 22) oder mit im G1Element mutierter Pax6-Bindungsstelle (Abb. 6), dass die Homöodomäne auch für die Aktivierung des Glukagon-Promotors durch Pax6 über das G3-Element relevant ist (3.5.1 
und 3.5.2). Somit ist die beobachtete Abnahme der Glukagon-Gen-Aktivierung durch Pax6 nach Deletion oder Mutation der Homöodomäne nicht allein aus einer geringeren Affinität von Pax6 an das G1-Element zu erklären.

Die erhaltenen Befunde (3.5.1 und 3.5.2) belegen auch, dass die Homöodomäne unabhängig vom Synergismus zwischen den zwei Pax6-Bindungsstellen im Glukagon-Gen für die Aktivierung des Glukagon-Gens durch Pax6 notwendig ist. Die Deletion der Pax6Homöodomäne vermindert auch dann die Aktivierung des Glukagon-Promotors, wenn die Pax6-Bindungsstelle entweder im G1- oder G3-Element durch Deletion oder interne Mutationen zerstört wird, so dass Pax6 nur noch an eine einzige Pax6-Bindungsstelle binden kann.

Bei Transfektionsexperimenten (3.5.2) zeigten Pax6-WT und Pax6-dHD eine deutlich geringere transkriptionelle Aktivität an der 3'-Deletionsmutanten des Glukagon-Promotors -350/-49GluLuc (Abb. 22) als an -350GluLuc (3.5.2). Bezüglich dieses unterschiedlichen Verhaltens ist zu beachten, dass für -350/-49GluLuc und die anderen 3'- Deletionsmutanten ein anderer Promotor verwendet wurde als bei -350GluLuc. Als heterologer Promotor wurde dabei der minimale Thymidinkinase-Promotor (bp -81 bis +52) mit den entsprechenden Abschnitten der 5'-flankierenden Region des Glukagon-Gens der Ratte fusioniert (Fürstenau et al., 1997).

Bei der Verwendung von 5'-Deletionsmutanten (Abb. 20) des Glukagon-Promotors der Ratte wurde eine Abnahme der transkriptionellen Aktivität bei Verkürzung des Glukagon-Promotors von 350 Basenpaaren auf 292 Basenpaare beobachtet (3.5.2). In dem deletierten Bereich liegt das Kontrollelement CRE (Meyer und Habener, 1993). Im Rahmen dieser Untersuchungen (3.5) zeigte sich, dass bei Mutation und Deletion beider Pax6Bindungsstellen im Glukagon-Promotor die Deletion der Homöodomäne zu einer Abnahme der Aktivität des Glukagon-Gens führt (3.5.1 und 3.5.2). Ein Grund dafür könnte eine residuale Bindung von Pax6 an nicht mutierte Bereiche des Glukagon-Promotors sein.

\subsection{Die Domäne $B$ des G3-Elements ist unabhängig von der Pax6- Homöodomäne für die Aktivierung des Glukagon-Gens durch Pax6 notwendig}

In der Pax6-Homöodomänen-Mutante Pax6-3Ala sind die drei für eine DNA-Bindung der Homöodomäne essentiellen Aminosäuren Valin-47, Serin-50 und Asparagin-51 zu Alanin mutiert (4.3). Pax6-3Ala aktiviert, wie auch die beiden Homöodomänen-Mutanten dHD und $\mathrm{dH}$, in deutlich geringerem Ausmaß das Glukagon-Gen als der Pax6-WT (3.3.1). Die Frage war daher, ob die Funktion der Pax6-Homöodomäne am G3-Element in einer DNA-Bindung zusätzlich zu der der Paired-Domäne liegt. Als mögliche Bindungsstelle für die Pax6- 
Homöodomäne wurde Domäne B des G3-Elements des Glukagon-Promotors der Ratte vermutet, die bereits als Bindungsstelle für Homöodomänen-Proteine identifiziert worden ist (Herzig et al., 2000).

Zunächst wurde getestet, ob Domäne B des G3-Elements eine Bedeutung bei der Aktivierung der Glukagon-Genexpression durch Pax6 hat. Bekannt ist, dass eine Kopie des G3A-Elements (5'-TCACGCCTGACTGAGC-3') keine transkriptionelle Aktivität in glukagonpoduzierenden Zellen zeigt (Wrege et al., 1995). Erst in Kombination mit Domäne B erfolgte eine transkriptionelle Aktivierung, was für einen positiven Beitrag von Domäne $B$ zur Glukagon-Genaktivierung spricht. Anders bei den in der vorliegenden Arbeit verwendeten G3-Oligomer-Konstrukten: In aTC2-Zellen zeigte ein Luciferase-Gen unter der Kontrolle von vier Kopien der Domäne A des G3-Elements eine höhere Aktivität als unter Kontrolle von vier Kopien des G3-Elements (3.6.1). Möglicherweise kann dies auf die räumliche Anordnung der vier oligomerisierten G3A-Elementen in diesem Konstrukt zurückgeführt werden. In der heterologen Zellinie JEG-3 bewirkte die Expression von Pax6 jedoch eine deutlich geringere Stimulation der transkriptionellen Aktivität von G3A, bezogen auf die Aktivität von vier Kopien des G3-Elements (3.6.2). In pankreatischen a-Zellen oder in heterologen JEG-3-Zellen nach Expression von Pax6 mit Glukagon-Promotor-Konstrukten (3.6.3 und 3.6.4) oder G3Oligomer-Konstrukten (3.6.1 und 3.6.2), verminderte die Mutation der Domäne B des G3Elements die transkriptionelle Aktivität deutlich. Insgesamt zeigen die Befunde der vorliegenden Arbeiten (3.6), dass Domäne B des G3-Elements für die Aktivierung des Glukagon-Gens durch Pax6 notwendig ist.

In der Literatur ist auch eine fehlende oder hemmende Funktion des G3B-Elements beschrieben (Knepel et al., 1990a; Gajic und Drucker, 1993; Herzig et al., 2000). So hat eine Mutation in Domäne B des G3-Elements, durch die die Bindung von Proteinen an Domäne B verloren geht, keinen Einfluß auf die transkriptionelle Aktivität des G3-Elements in InR1G9Zellen (Knepel et al., 1990a). In plurihormonalen STC-1-Zellen führt die Deletion des gesamten G3-Elements sogar zu einer Zunahme der Aktivität des Glukagon-Promotors (Gajic und Drucker, 1993); dies impliziert, dass das G3-Element zumindest in STC-1-Zellen ein hemmendes Element ist. Zudem ist Domäne B des G3-Elements eine Bindungsstelle für ein Heterodimer aus den Homöodomänen-Proteinen Pbx/Prep-1, das bei Überexpression in einer nicht-glukagonproduzierenden Zelllinie die Glukagon-Genaktivierung hemmt (Herzig et al., 2000).

Aus den Untersuchungen zur vorliegenden Arbeit wurde kein Hinweis erhalten, dass Domäne B bei der Aktivierung des Glukagon-Promotors für die Funktion der Pax6Homöodomäne von Bedeutung ist (3.7.2 und 3.7.3): Interne Mutationen der Domäne B des G3-Elements verminderten die Aktivierung des Glukagon-Promotors durch Pax6 auch nach der Deletion bzw. Mutation der Pax6-Homöodomäne (3.7.3). Somit scheint die Domäne B des G3-Elements unabhängig von einer Bindung der Pax6-Homöodomäne für die 
Aktivierung des Glukagon-Gen-Promotors durch Pax6 notwendig zu sein. Übereinstimmend damit vermindert sich bei Verwendung von G3-Oligomer-Konstrukten mit Mutationen in Domäne B die durch Pax6 induzierte transkriptionelle Aktivität nach Deletion oder Mutation der Pax6-Homöodomäne deutlich (3.7.2). Es gibt jedoch eine Abweichung zwischen Befunden, die aus Experimenten mit G3-Oligomer-Konstrukten (3.7.1) und GlukagonPromotor-Konstrukten (3.3.1) erhalten wurden: Bei Verwendung eines G3(Wildtyp)Oligomer-Konstrukts in Cotransfektionen wird die durch Pax6 induzierte transkriptionelle Aktivität des G3-Elements nicht durch die Deletion oder Mutation der Pax6-Homöodomäne verändert (3.7.1). Dagegen wird bei Verwendung eines Glukagon-Promotor-Fragments eine deutliche Verringerung der durch Pax6 induzierten transkriptionellen Aktivität nach Deletion oder Mutation der Pax6-Homöodomäne beobachtet (3.3.1 und 4.2). Weshalb beim G3(Wildtyp)-Oligomer-Kontrukt die Deletion oder Mutation der Pax6-Homöodomäne keinen Einfluß auf die transkriptionelle Aktivität hat, bleibt unklar.

\subsection{Die Pax6-Paired-Domäne bindet nicht an Domäne B des G3 Elements}

Die Domäne B des G3-Elements ist für die Aktivierung des Glukagon-Gens notwendig (3.6), jedoch unabhängig von der Pax6-Homöodomäne (3.7.2 und 3.7.3). Möglicherweise liegt die Bedeutung von Domäne $B$ in einer Bindung eines bisher nicht identifizierten Proteins. Eine andere Vermutung war, dass die Domäne B für eine Bindung der Paired-Domäne von Pax6 an das G3-Element notwendig ist. In vitro DNase-I-Footprinting-Experimente mit der isolierten Pax6-Paired-Domäne an einem Konsensusmotiv der Pax6-Paired-Domäne-DNABindungsstelle zeigten eine Protektion, die im 3'-Bereich (nicht im 5'-Bereich) um acht Basenpaare über die Pax6-Paired-Domäne-DNA-Bindungsstelle hinausreichte (Epstein et al., 1994b). Auch wenn Domäne B von G3 außerhalb der typischerweise 20-Basenpaar langen Pax6-Paired-Domäne-DNA-Bindungsstelle liegt (Epstein et al., 1994a), so schließt sie sich doch unmittelbar im 3'-Bereich an. Die Kristallstruktur eines Komplexes aus der Pax6-Paired-Domäne und ihrer optimalen DNA-Bindungsstelle (Xu et al., 1999) deutet auf Wechselwirkungen der Paired-Domäne mit dem DNA-Phosphatrückgrat hin.

Im EMSA wurde die Bindung von bakteriell exprimierten GST-Pax6-PD-Protein (3.8.1) an das G3-Element mit mutierter Domäne B überprüft. Die Bindungsstudien zeigten, dass Mutationen in Domäne B keinen Einfluß auf die Bindung der Pax6-Paired-Domäne an das G3-Element haben (3.8.2). Das bedeutet, dass die Notwendigkeit von Domäne B für eine transkriptionelle Aktivierung des Glukagon-Promotors durch Pax6 nicht aus einer Bindung der Pax6-Paired-Domäne an das G3B-Element erklärbar ist. Möglicherweise ist Domäne B des G3-Elements in glukagonproduzierenden, Pax6-exprimierenden Zellen die Bindungsstelle für ein bisher nicht identifiziertes Protein, was die Abnahme der 
transkriptionellen Aktivität des Glukagon-Promotors nach Mutation der Domäne B erklären könnte.

\subsection{Die Pax6-Homöodomäne wirkt DNA-unabhängig inhibitorisch auf die Glukagon-Genexpression}

Bei vielen biologischen Prozessen spielen Protein-Protein-Interaktionen eine wichtige Rolle, durch die neue biologische Funktionen und Eigenschaften entstehen können. ProteinProtein-Interaktionen haben einen entscheidenden Einfluß auf die transkriptionsaktivierenden bzw. transkriptionsreprimierenden Eigenschaften von Pax-Proteinen, die z.B. durch die Wechselwirkung mit Co-Repressoren die Transkription von Genen unterdrücken können (Eberhard et al., 2000; Hollenbach et al., 1999; Magnaghi et al., 1998). Andererseits führt der Aufbau von Proteinkomplexen an Promotorsequenzen zu einer erhöhten Aktivierung der Transkription (Hussain und Habener, 1999). Pax-Protein-Interaktionspartner können außerdem eine Bindung an nicht optimale Bindungsstellen ermöglichen (Kamachi et al., 2001), was zur Erhöhung der Zahl an Bindungsstellen für die Pax-Proteine führt.

Die Homöodomäne von Pax6 ist unabhängig von einer DNA-Bindung zu direkten ProteinProtein-Wechselwirkungen in der Lage. DNA-unabhängige Wechselwirkungen von Pax6 mit den Homöodomänen-Proteinen Six-3 (Oliver et al., 1995), Lhx2 (Rincon-Limas et al., 1999), En-1 (Joyner und Martin, 1987), Prep-1 (Berthelsen et al., 1998), Prox1 (Zinovieva et al., 1996), Chx10 (Liu et al., 1994), HoxB1 (Acampora et al., 1989), Rax (Furukawa et al., 1997) oder mit einem anderen Pax6-Protein (Mikkola et al., 2001) sind bereits beschrieben (Mikkola et al., 2001). Außerdem interagiert die Homöodomäne mit Pax6 $\triangle$ PD: Pax6 $\triangle$ PD entspricht einer Pax6-Isoform mit einem Molekulargewicht von 33 kDa aus der Neuroretina der Wachtel (Carrière et al., 1993; Mikkola et al., 2001). Interaktionen zwischen Pax6 und dem TATA-Box-bindenden Protein (TBP) oder dem Retinoblastoma-Protein erfolgen ebenfalls über die Pax6-Homöodomäne (Cvekl et al., 1999).

In der vorliegenden Arbeit wurde eine Wirkung der Pax6-Homöodomäne, die unabhängig von einer DNA-Bindung ist mit Hilfe des GAL4-Systems untersucht. Dazu wurden Pax6-WT und Pax6-dHD aminoterminal mit der DNA-Bindedomäne des Hefetranskriptionsfaktors fusioniert, so dass eine Bindung an einen Promotor sowohl unabhängig von der Pax6Paired-Domäne, als auch unabhängig von der Pax6-Homöodomäne über die GAL4Bindedomäne erfolgen kann. Als Reportergen-Plasmid wurde ein 350 bp-GlukagonPromotor-Konstrukt verwendet, in dem die Pax6-Paired-Domänen-Bindungsstellen des G1und des G3-Elements in GAL4-DNA-Bindungsstellen mutiert worden waren, ohne die räumliche Anordnung zu verändern. Nach der Cotransfektion in JEG-3-Zellen zeigte sich, 
dass die Deletion der Pax6-Homöodomäne deutlich die transkriptionelle Aktivität eines GAL4-Pax6-Fusionsproteins steigert (3.9). Dies steht im Gegensatz zu Befunden am nativen Pax6-Protein, wo die Deletion oder Mutation der Homöodomäne zu einer verminderten Aktivierung des Glukagon-Gens der Ratte durch Pax6 führt (3.3.1), und ist ein Hinweis auf eine DNA-unabhängige inhibitorische Wirkung der Pax6-Homöodomäne.

Hinweise auf eine inhibitorische Wirkung der Pax6-Homöodomäne auf die transkriptionelle Aktivität von Pax6 sind mehrfach beschrieben. So besitzt das Fusionsprotein GAL4-Pax6Transaktivierungsdomäne eine größere transkriptionelle Aktivität, als ein Fusionsprotein, das zusätzlich zur Transaktivierungsdomäne die Pax6-Homöodomäne enthält (Mikkola et al., 2001). Auch für Homöodomänen-Transkriptionsfaktoren, die nicht zur Klasse der pairedHomöodomänen-Transkriptionsfaktoren gehören wird eine inhibitorische Funktion der Homöodomäne vermutet: Die Homöodomäne von NK-4, einem HomöodomänenTranskriptionsfaktor der NK-2-Klasse, vermittelt eine inhibitorische Wirkung auf die Transaktivierung (Choi et al., 1999). Diese Daten (3.9) sind außerdem übereinstimmend mit Befunden, denen zufolge die Repressor-Aktivität von HoxA7 (Schnabel und Abate-Shen, 1996) und Msx-1 (Zhang et al., 1996) über deren Homöodomäne vermittelt wird.

\subsection{Modell zur Funktion der Pax6-Homöodomäne bei der Aktivierung des Glukagon-Gens durch Pax6}

Ausgangspunkt der vorliegenden Arbeit war die Frage, ob die Pax6-Homöodomäne für die Aktivierung des Glukagon-Gens von Bedeutung ist. Die Befunde der vorliegenden Arbeit zeigen, dass neben der Paired-Domäne auch die Homöodomäne von Pax6 eine Rolle bei der Aktivierung des Glukagon-Gens durch Pax6 spielt. Die vorliegenden Ergebnisse deuten auf komplexe Wechselwirkungen zwischen den einzelnen funktionellen Domänen von Pax6 bei der pankreasinselspezifischen Aktivierung des Glukagon-Gens hin. Dabei scheint die Homöodomäne sowohl positive, als auch negative Einflüsse auf die Aktivierung des Glukagon-Gens durch Pax6 auszuüben.

Im Folgenden soll ein Modell für diese Wechselwirkungen bei der Aktivierung des GlukagonGens durch Pax6 skizziert werden. In diesem Modell wird zwischen einem DNAungebundenen und einem DNA-gebundenen Zustand von Pax6 unterschieden. 
A

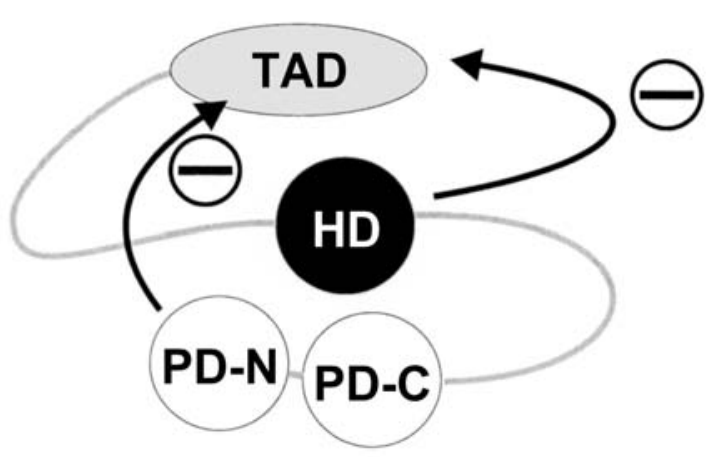

B

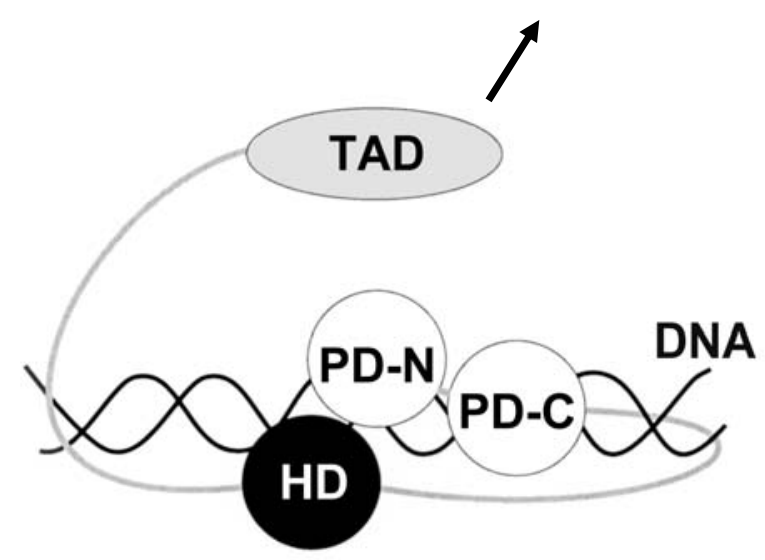

Abb. 39: Modell zur Funktion der Pax6-Homöodomäne bei der Aktivierung des Glukagon-Gens durch Pax6. Im nicht-DNA-gebundenen DNA-Zustand unterliegt die Transaktivierungsdomäne von Pax6 über intramolekulare Protein-Protein-Wechselwirkungen einer Hemmung durch die PairedDomäne und die Homöodomäne (A). Nach der Bindung von Pax6 über seine Paired-Domäne an die PISCES-Motive in G3 und G1 kommt es zu einer Neukonformation von Pax6 am Glukagon-Gen: durch Interaktion der Homöodomäne im 5'-Bereich von PISCES werden die inhibitorischen Wechselwirkungen aufgehoben. Die Transaktivierungsdomäne wird aus der Hemmung entlassen und aktiv (B). HD, Homöodomäne; PD-N, aminoterminale Untereinheit der Paired-Domäne; PD-C, carboxyterminale Untereinheit der Paired-Domäne TAD, Transaktivierungsdomäne; PISCES, pancreatic islet cell specific enhancer sequence.

Im nicht-DNA-gebundenen Zustand (Abb. 39A) unterliegt die carboxyterminale Transaktivierungsdomäne von Pax6 über Protein-Protein-Wechselwirkungen einer Hemmung; diese erfolgt sowohl durch die Pax6-Paired-Domäne als auch durch die Pax6Homöodomäne (Abb. 39A). Die Transfektionsstudien mit Pax6-Homöodomänen-Mutanten legen die Vermutung nahe, dass die Wechselwirkung der Pax6-Homöodomäne mit der Transaktivierungsdomäne von der Helix 3 der Homöodomäne (Erkennungshelix) und den Aminosäuren Valin-47, Serin-50, Asparagin-51 in der Helix 3 abhängig ist. Bei der Bindung von Pax6 an die DNA kommt es zu einer Konformationsänderung von Pax6, die zur Aufhebung der inhibitorischen Wechselwirkungen führt (Abb. 39B). Pax6 bindet über seine Paired-Domäne an das PISCES-Motiv im G3-Element des Glukagon-Promotors. Gleichzeitig interagiert die Pax6-Homöodomäne mit einer DNA-Sequenz im 5'-Bereich des PISCESMotivs.

Die Bindung der Homöodomäne steigert nicht unbedingt die Affinität von Pax6, sondern trägt möglicherweise lediglich zur Positionierung von Pax6 bei der DNA-Bindung bei. Zur Orientierung der Pax6-Homöodomäne aminoterminal zur Pax6-Paired-Domäne könnte neben der Interaktion der Pax6-Homöodomäne mit der DNA auch eine Interaktion der Pax6Homöodomäne mit der Pax6-Paired-Domäne von Bedeutung sein. Durch die DNAabhängige Positionierung der Pax6-Homöodomäne aminoterminal zur Pax6-Paired-Domäne wird nicht nur die inhibitorische Interaktion der Pax6-Homöodomäne mit der 
Transaktivierungsdomäne aufgehoben, sondern auch die Hemmung der Transaktivierungsdomäne durch die Paired-Domäne. Die Transaktivierungsdomäne von Pax6 wird durch diese Neukonformation aus der Hemmung entlassen und kann die Glukagon-Gen-Transkription aktivieren (Abb. 39B).

In dem hier zur Funktion der Homöodomäne bei der Aktivierung des Glukagon-Gens vorgeschlagene Modell wird angenommen, dass die Pax6-Homöodomäne wie auch die Pax6-Paired-Domäne, neben der Vermittlung der DNA-Bindung als Regulatoren der transkriptionellen Aktivität von Pax6 am Glukagon-Gen dienen. Transkriptionsfaktoren, deren Aktivität nicht durch Liganden oder Signalketten reguliert werden (Calkhoven und Ab, 1996) gelten als konstitutiv aktiv, was ein generelles Squelching der Gentranskription bedeuten würde. Das Modell beinhaltet, dass es DNA-abhängig zu einer Steigerung der transkriptionellen Aktivität von Pax6 kommt. Im DNA-ungebundenen, inaktiven Zustand würde die Transaktivierungsdomäne von Pax6 aufgrund der Faltung des Proteins in deutlich geringerem Maße Coaktivatoren rekrutieren. Die vorgeschlagene DNA-abhängige Regulation der Pax6-Transaktivierungsdomäne würde eine Interaktion der Pax6Transaktivierungsdomäne mit Coaktivatoren im nicht-DNA-gebundenen Zustand verhindern und damit auch ein generelles Squelching der Gentranskription.

Das vorgestellte Modell zur Funktion der Pax6-Homöodomäne ist in Übereinstimmung mit den Befunden der vorliegenden Arbeit: Die Hemmung der Aktivierung des Glukagon-Gens durch Pax6 nach der Deletion der Pax6-Homöodomäne (3.3.1) würde aus einer Hemmung der Pax6-Transaktivierungsdomäne durch die Pax6-Paired-Domäne nach dem Wegfall der Homöodomäne folgen. Zusätzlich könnte dadurch die Affinität der Bindung von Pax6 vermindert sein. Die Ergebnisse mit den GAL4-Fusionsproteinen implizieren (3.9), dass die Fusion der GAL4-DNA-Bindedomäne aminoterminal zur Paired-Domäne durch sterische Hinderung einerseits die Hemmung der Transaktivierungsdomäne durch die Paired-Domäne verhindert. Andererseits könnte die Fusion die Positionierung der Homöodomäne aminoterminal zur Paired-Domäne unmöglich machen, was auch nach der Bindung an das Glukagon-Gen die Hemmung der Transaktivierungsdomäe durch die Pax6-Homöodomäne erhält. Die Steigerung der Aktivierung des Glukagon-Gens durch GAL4-Pax6 nach Deletion der Homöodomäne (3.9) wäre demnach die Folge des Wegfalls der Hemmung der Transaktivierungsdomäne durch die Homöodomäne in GAL4-Pax6.

Das vorliegende Modell zur Funktion der Homöodomäne beruht auf der Annahme einer direkten Interaktion zwischen der Pax6-Homöodomäne, der Pax6-Paired-Domäne und der Pax6-Transaktivierungsdomäne (39A und B). Bezüglich der Protein-Protein-Wechselwirkung verschiedener Pax6-Proteindomänen ist aus Literaturbefunden bekannt, dass die PairedDomäne und die Transaktivierungsdomäne, wie die Pax6-Homöodomäne (4.4), zu ProteinProtein-Wechselwirkungen in der Lage sind. Die Paired-Domäne und die Homöodomäne von Pax6 sind an DNA-unabhängigen Wechselwirkungen mit den Homöodomänen- 
Transkriptionsfaktoren Pbx1 (Monica et al., 1991), HoxB1 (Acampora et al., 1989) und Chx10 (Liu et al., 1994) beteiligt, sowie mit dem paired-Homöodomänen Transkriptionsfaktor Rax (Furukawa et al., 1997; Mikkola et al., 2001). Die carboxyterminale Subdomäne der Pax6-Paired-Domäne interagiert mit der Pax6-Homöodomäne (Mikkola et al., 2001). Auch die Homöodomäne des Drosophila Paired-Proteins vermag mit dem Helix-turn-Helix-Motiv der aminoterminalen Subdomäne von Pax6 direkt zu interagieren und damit die Bindung an eine synthetische Paired-Domäne DNA-Bindungsstelle zu steigern (Jun und Desplan, 1996). Die Transaktivierungsdomäne von Pax6 kann ebenfalls Protein-Protein-Wechselwirkungen vermitteln, z.B. mit Maf-Proteinen (Planque et al., 2001). Auch eine DNA-unabhängige Interaktion der Pax6-Transaktivierungsdomäne mit Pax6 wurde untersucht, konnte aber nicht belegt werden (Mikkola et al., 2001). Dieser Befund scheint zunächst im Widerspruch zu der im vorliegenden Modell angenommenen Interaktion der Pax6-Paired-Domäne bzw. der Pax6-Homöodomäne mit der Transaktivierungsdomäne zu stehen. Tatsächlich aber erlaubt das Modell eine Interpretation der Befunde. Demnach geht sowohl die Paired-Domäne, als auch die Homöodomäne eines Pax6-Proteins intramolekulare Wechselwirkungen mit der Transaktivierungsdomäne ein, die sich inhibitorisch auf die Wirkung der Transaktivierungsdomäne auswirken. Da die Paired-Domäne, die Homöodomäne und die Transaktivierungsdomäne bereits in intramolekulare Interaktionen einbezogen sind, ist eine zusätzliche intermolekulare Interaktion mit einer isolierten Pax6-Transaktivierungsdomäne nicht möglich. Während es für die Pax6-Homöodomäne Hinweise auf eine inhibitorische Wirkung gibt (Schnabel und Abate-Shen, 1996; Zhang et al., 1996; Choi et al., 1999, Mikkola et al., 2001; 4.7) sind entsprechende Befunde in der Literatur für die Paired-Domäne nicht bekannt.

Ein essentieller Punkt des Modells ist die Annahme von intramolekularen Wechselwirkungen zwischen den funktionellen Domänen, sowie eine Konformationsänderung von Pax6 (Abb. 39), die nicht belegt ist. In der Literatur wurden jedoch bereits für verschiedene Proteine Modelle zu Interaktionen zwischen funktionellen Protein-Domänen als Grundlage für die Wirkung und Funktion und zur Konformationsänderung beschrieben (Puigserver et al., 1999; Watada et al., 2000; Courtneidge, 2003; Takeda et al., 2003). Für den HomöodomänenTranskriptionsfaktor der NK2-Klasse, Nkx2.2 wird angenommen, dass seine Fähigkeit zur Aktivierung spezifischer Gene durch intramolekulare Interaktionen reguliert wird (Watada et al., 2000). In Nkx2.2 kommt es nach der Bindung eines unbekannten Cofaktors an die hochkonservierte NK-2-spezifische Domäne (NK-2-SD; Harvey et al., 1996), zu einer Konformationsänderung des Proteins, die sich vermutlich destabilisierend auf die Aktivierungsdomäne auswirkt (Watada et al., 2000). Die transkriptionelle Aktivität des PPAR $\gamma$-Coaktivator-1 (PGC-1) wird durch Interaktionen zwischen funktionellen ProteinDomänen beeinflusst (Puigserver et al., 1999). PGC-1 ist ein Coaktivator u.a. von NRF-1 
(nucleic respiratory factor-1) und PPAR $\gamma$ (Puigserver et al., 1998; Wu et al., 1999). Das Andocken von PGC-1 an PPAR $\gamma$ verursacht eine Konformationsänderung in PGC-1, die vermutlich die Bindung der Cofaktoren SRC-1, und CBP/p300 erlaubt und zu einer Zunahme der transkriptionellen Aktivität führt („spring-trap“-Modell) (Puigserver et al., 1999). Auch für Enzyme, wie z.B. die Tyrosin-Kinase Src gibt es Hinweise auf eine Regulation der Aktivität durch intramolekulare Wechselwirkungen verschiedener Protein-Domänen (Courtneidge, 2003). In der inaktiven Form kommt es vermutlich zu intramolekularen Interaktionen zwischen der SH2-Domäne (Bindung von Proteinen mit phosphorylierten Tyrosin-Resten) und einem phosphorylierten Tyrosin-Rest des "Tails“ (zur Auto-Regulation) sowie zwischen der SH3-Domäne (Bindung Prolin-reicher Peptide) und Sequenzen eines Linkers. Die Aktivierung von Src erfolgt wahrscheinlich durch Dephosphorylierung des "Tails“ oder Liganden-Bindung an $\mathrm{SH} 2$ oder $\mathrm{SH} 3$, was die intramolekularen Kontakte zwischen den einzelnen Domänen aufhebt (Courtneidge, 2003). Der Einfluß von Interaktionen zwischen funktionellen Domänen eines Proteins auf die Wirkung und Regulation ist auch für das Funktionsprotein Troponin beschrieben. Troponin spielt eine Rolle bei der Regulation von Skelett- und Herz-Muskel-Kontraktionen durch die intrazelluläre Calcium-Konzentration und ist zusammen mit Tropomyosin an den Aktin-Filamenten lokalisiert. Die Flexibilität und Mobilität von Troponin und Tropomyosin an den Aktinfilamenten scheint von einer Calciuminduzierten Konformationsänderung des Troponins abzuhängen (Takeda et al., 2003).

Als weiteres wird im vorliegenden Modell angenommen, dass die Homöodomäne aminoterminal zur Pax6-Paired-Domäne an das G3-Element bindet (Abb. 39B). Eine DNABindung der Homöodomäne zusätzlich zu der der Paired-Domäne erscheint dort möglich, da das Paired-Protein aus Drosophila, das ebenfalls eine Paired-Domäne und eine Homöodomäne besitzt, in einem Site-selection assay als Bindungsstelle ein synthetisches Oligonukleotid mit der sogenannten PHO-Stelle auswählte (Jun und Desplan, 1996). In diesem Oligonukleotid befindet sich im 5'-Bereich zu einer Paired-Domänen-Bindungsstelle in umgekehrter Orientierung („tail-to-tail“) eine Homöodomäne-DNA-Bindungsstelle. Die Sequenz des Oligonukleotids war folgendermaßen: CAATTAGTCACGC, wobei das ATTACore-Motiv unterstrichen und das PAI-Core-Motiv (Core-Motiv der aminoterminalen Subdomäne der Paired-Domäne) hervorgehoben ist (Jun und Desplan, 1996). Eine PH0ähnliche Stelle wurde bereits im L-Element („late element“) des even-skipped-Gens (eve) in Drosophila entdeckt (Fujioka et al., 1996). Die eve-Expression wird durch direkte Interaktion des Paired-Proteins mit der konservierten Sequenz PTE („Paired Target Element“), die starke Ähnlichkeit zu einer PHO-Sequenz zeigt, positiv reguliert. Bei Mutation dieser Stelle geht die Paired-Protein-abhängige Expression des even-skipped-Gens verloren (Fujioka et al., 1996). Eine Bindung der Pax6-Homöodomäne im 5'-Bereich der Paired-DomänenBindungsstelle wurde auch im Zusammenhang mit L1, einem Zelladhäsions-Molekül, 
diskutiert (Chalepakis et al., 1994): EMSA und Interferenz-Experimente ergaben, dass die Pax6-Paired-Domäne die Basenpaare 7 bis 26 der proximalen Pax6-Bindungsstelle L1-170 des L1-Promotors erkennt, und die Pax6-Homöodomäne die Basenpaare 1 bis 8 im 5'Bereich der Paired-Domänen-Bindungsstelle (Chalepakis et al., 1994).

Die Abbildung 40 zeigt die Modellierung einer Bindung der Pax6-Homöodomäne an das G3Element im 5'-Bereich der Paired-Domänen-Bindungsstelle des Glukagon-Gens. Dabei handelt es sich um eine vorläufige Darstellung, die noch nicht durch Energieberechnung bestätigt ist. Demnach wäre eine Bindung der Pax6-Homöodomäne an den Komplex aus G3 und Pax6-Paired-Domäne mit dem in der folgenden Sequenz 5'TAGTTTTTCACGCCTGACTGAGATTGAAGGG-3' unterstrichenen TT-Motiv als Core der Homöodomäne-Bindungsstelle im 5'-Bereich der Paired-Domänen-Bindungsstelle möglich.

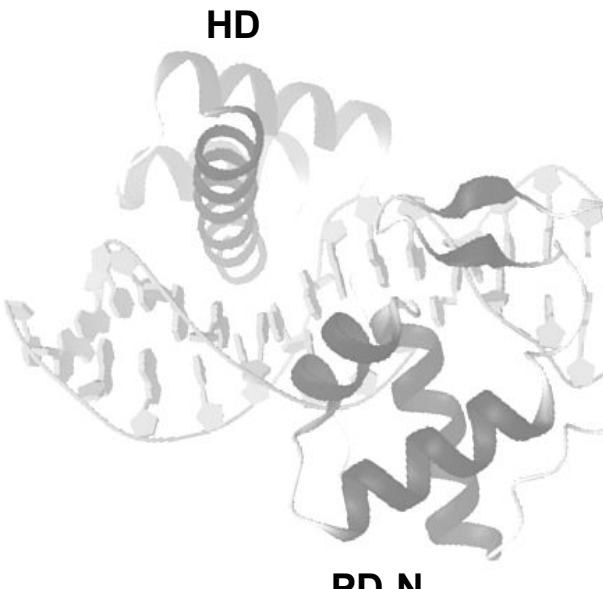

PD-N

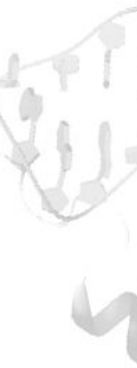

PD-C

Abb. 40: Modellierung einer Bindung der Pax6-Homöodomäne an das G3-Element des Glukagon-Gens. Eine Bindung der Pax6-Homöodomäne (oben links) an den Komplex aus G3 und Pax6-Paired-Domäne (unten: N-terminale Subdomäne links, C-terminale Subdomäne rechts) im 5'Bereich der Paired-Domänen-Bindungsstelle erscheint möglich. Nach R. Krätzner (unveröffentlicht).

Mit der Aufklärung der Bedeutung der Homöodomäne von Pax6 für die Aktivierung des Glukagon-Gens durch Pax6, trägt diese Arbeit zum Verständnis der Mechanismen bei der pankreasinselspezifischen Aktivierung des Glukagon-Gens durch Pax6 bei. Erstmalig wurde gezeigt, dass die Pax6-Homöodomäne für die Aktivierung des Glukagon-Gens durch Pax6 notwendig ist. Es wurde ein Modell zur Funktion der Pax6-Homöodomäne bei der Aktivierung des Glukagon-Gens durch Pax6 entwickelt. Dieses Modell beinhaltet sowohl komplexe Wechselwirkungen der Pax6-Homöodomäne mit DNA-Sequenzen des Glukagon-Promotors 
der Ratte und als auch mit der Pax6-Transaktivierungsdomäne und der Pax6-PairedDomäne. Diese Wechselwirkungen induzieren eine Neukonformation und führen zur Aktivierung von Pax6. Die Aufklärung dieser molekularen Mechanismen der Pax6-DNABindung und Glukagon-Genaktivierung sind ein Beitrag für ein Verständnis der Zielgenspezifität von Pax6. 
Das Pankreasinselhormon Glukagon und sein funktioneller Antagonist Insulin regulieren den Blutglukosespiegel. Die $\alpha$-zellspezifische Aktivierung der Glukagon-Genexpression in den Pankreasinseln wird durch eine Kombination verschiedener Transkriptionsfaktoren bestimmt. Einer der essentiellen Transkriptionsfaktoren ist dabei Pax6, der zwei DNA-Bindungsdomänen enthält: eine Paired-Domäne und eine Homöodomäne. In vitro bindet Pax6 über seine Paired-Domäne an das Sequenzmotiv PISCES (pancreatic islet cell specific enhancer sequence), das sich im proximalen Promotorelement G1 und in Domäne A des mehr distalen Promotorelements G3 des Glukagon-Promotors befindet. In Pankreasinsel-Zelllinien des $\alpha$ Phänotyps und nach Expression von Pax6 in heterologen JEG-3-Zellen wird das GlukagonGen durch Pax6 über die Paired-Domänen-Bindungsstellen in G1 und G3 synergistisch aktiviert. Nicht bekannt war bislang die Bedeutung der Homöodomäne von Pax6. Ziel der vorliegenden Arbeit war es die Bedeutung Homöodomäne für die Aktivierung des GlukagonGens durch Pax6 zu untersuchen.

Transiente Cotransfektionen in heterologen JEG-3-Zellen zeigten, dass die Pax6Homöodomäne für die Aktivierung des Glukagon-Gens durch Pax6 notwendig ist, da die Deletion der gesamten Homöodomäne, die Deletion der DNA-Erkennungshelix bzw. die Mutation von drei Aminosäuren der DNA-Erkennungshelix der Homöodomäne die Aktivierung drastisch vermindert.

Durch Protein-DNA-Bindungsstudien wurde demonstriert, dass die Pax6-Homöodomäne zur Bindung an das G1-Element nötig ist, zur Bindung an das G3-Element jedoch nicht.

Bei der Aktivierung des Glukagon-Gens ist die Pax6-Homöodomäne sowohl an der Aktivierung über das G1- als auch über das G3-Element beteiligt. Somit ist die verminderte Aktivierung des Glukagon-Gens durch Pax6-Homöodomänen-Mutanten nicht auf eine verminderte Bindung von Pax6 an das G1-Element zurückzuführen. Die dazu durchgeführten Cotransfektionen in JEG-3-Zellen mit Promotorkonstrukten mit deletiertem bzw. mit intern mutiertem G1- oder G3-Element belegten auch, dass die Pax6-Homöodomäne unabhängig vom Synergismus zwischen den beiden Pax6-Bindungsstellen in G1 und G3 des GlukagonPromotors für die Aktivierung des Glukagon-Gens durch Pax6 bedeutsam ist.

Aufgrund der Verminderung der Aktivierung des Glukagon-Gens durch Pax6 mit Mutationen von drei Aminosäuren, die für die Bindung der Homöodomäne an eine optimale DNABindungsstelle essentiell sind, wurde vermutet, dass die Pax6-Homöodomäne eine DNABindung vermittelt. Eine Homöodomänen-Bindungsstelle befindet sich im G3-Element in Domäne B, im 3'-Bereich der Domäne A. Bei transienten Cotransfektionen in heterologen JEG-3-Zellen und pankreatischen $\alpha$-Zellen verminderte eine Mutation der Domäne B deutlich die Aktivierung des Glukagon-Gens durch Pax6, was auf eine positive Bedeutung der 
Domäne B bei der Glukagon-Genaktivierung hinweist. Jedoch verminderte diese Mutation in Domäne B gleichzeitig auch die Aktivierung des Glukagon-Promotors durch die Pax6Homöodomänen-Mutanten. Daher scheint Domäne B des G3-Elements, unabhängig von der Pax6-Homöodomäne, für die Aktivierung des Glukagon-Gens durch Pax6 notwendig zu sein. EMSA-Studien zeigten, dass die Paired-Domäne nicht an Domäne B des G3-Elements bindet.

Neben der positiven Wirkung der Pax6-Homöodomäne bei der Aktivierung des GlukagonGens durch Pax6 übt die Pax6-Homöodomäne DNA-unabhängig eine inhibitorische Wirkung aus. Die Deletion der Pax6-Homöodomäne steigerte, wie durch Cotransfektionsstudien in heterologen JEG-3-Zellen gezeigt werden konnte, die transkriptionelle Aktivität eines GAL4Pax6-Fusionsproteins an einem Glukagon-Promotor-Reporterfusionsgen, in dem die Pax6Bindungsstellen im G1- und G3-Element in Bindungsstellen für GAL4 mutiert worden waren. Die Ergebnisse der vorliegenden Arbeit lassen sich zu einem Modell zusammenfügen, das die Funktion der Pax6-Homöodomäne bei der Aktivierung des Glukagon-Gens durch Pax6 beschreiben kann. Das Modell nimmt einerseits komplexe Wechselwirkungen der Homöodomäne mit Pax6-Protein-Domänen an, andererseits mit DNA-Sequenzen. Im nichtDNA-gebundenen Zustand wird die Transaktivierungsdomäne von Pax6 über ProteinProtein-Wechselwirkungen gehemmt, sowohl durch die Pax6-Homöodomäne als auch durch die Pax6-Paired-Domäne. Nach Bindung von Pax6 über seine Paired-Domäne an PISCES im G3-Element kommt es zu einer Neukonformation von Pax6, wobei die Hemmung der Transaktivierungsdomäne durch die Paired-Domäne aufgehoben wird. Durch eine Interaktion der Pax6-Homöodomäne mit der DNA im 5'-Bereich von PISCES werden die inhibitorischen Wechselwirkungen zwischen Homöodomäne und Transaktivierungsdomäne ebenfalls aufgehoben. Zu vermuten ist eine DNA-abhängige Steigerung der transkriptionellen Aktivität von Pax6, so dass im DNA-ungebundenen Zustand ein generelles Squelching verhindert wird.

Die Ergebnisse dieser Arbeit zeigen die grundlegende Bedeutung der Homöodomäne von Pax6 für die Aktivierung der Glukagon-Genexpression. Die Arbeit leistet damit einen Beitrag zur weiteren Aufklärung der molekularen Mechanismen der Pax6-DNA-Bindung und der Aktivierung des Glukagon-Gens und trägt zum Verständnis der Zielgenspezifität von Pax6 bei. 


\section{LITERATURVERZEICHNIS}

Acampora, D., D'Esposito, M., Faiella, A., Pannese, M., Migliaccio, E., Morelli, F., Stornaiuolo, A., Nigro, V., Simeone, A. und Boncinelli, E. (1989) The human HOX gene family. Nucleic Acids. Res. 17: 10385-10402

Alberts (1997) Kontrolle der Genexpression, 475-476. In Molekularbiologie der Zelle (Hrsg. Jaenicke, L.) VCH Verlagsgesellschaft, Weinheim, 3. Auflage

Andersen, F.G., Heller, R.S., Petersen, H.V., Jensen, J., Madsen, O.D. und Serup, P. (1999) Pax6 and Cdx2/3 form a functional complex on the rat glucagon promoter $\mathrm{G} 1$ element. FEBS Lett. 445: 306-310

Ashcroft, F.M. und Ashcroft, S.J.H. (1992) Insulin-Molecular biology to pathology. IRL Press, Oxford, New York, Tokio

Asubel, F. M., Brent, R., Kingston, R. E., Moore, D.D., Seidman, F.G., Smith, J.A. und Struhl, K. (1987) Current protocols in molecular biology. Vol.1. New York, Chichester, Brisbane, Toronto, Singapur: Wiley-Intersciences

Beimesche, S., Neubauer, A., Herzig, S., Grzeskowiak, R., Diedrich, T., Cierny, I., Scholz, D., Alejel, T. und Knepel, W. (1999) Tissue-specific transcriptional activity of a pancreatic islet cell-specific enhancer sequence/Pax6-binding site determined in normal adult tissues in vivo using transgenic mice. Mol. Endocrinol. 13: 718-729

Berthelsen, J., Zappavigna, V., Mavilio, F. und Blasi, F. (1998) Prep1, a novel functional partner of Pbx proteins. EMBO J. 17: 1423-1433

Bertuccioli, C., Fasano, L., Jun, S., Wang, S., Sheng, G. und Desplan, C. (1996) In vivo requirement for the paired domain and homeodomain of the paired segmentation gene product. Development 122: 2673-2685

Billeter, M., Quian, Y.-Q., Otting, G., Müller, M., Gehring, W. J. und Wüthrich, K. (1990) Determination of the three-dimensional structure of the Antennapedia homeodomain from Drosophila in solution by ${ }^{1} \mathrm{H}$ nuclear magnetic resonance spectroscopy. J. Mol. Biol. 214: 183-197 
Bishop, K., Goudreau, G. und O'Leary, D. D. (2000) Regulation of the area identitiy in mammalian neocortex by Emx2 and Pax6. Science 288: 344-349

Blank, V. und Andrews, N.C. (1997) The Maf transcription factors: regulators of differentiation. Trends Biochem. Sci. 22: 437-441

Boncinelli, E., Somma, R., Acampora, D., Pannese, M., D'Esposito, M., Faiella, A. und Simeone, A. (1988) Organization of human homeobox genes. Hum. Reprod. 3: 880-886

Bonner-Weir, S. (1991) Anatomy of the islet of Langerhans, 15-27. In E. Samols (Hrsg.), The endocrine pancreas, Raven Press, New York

Bopp, D., Burri, M., Baumgartner, S., Frigerio, G. und Noll, M. (1986) Conservation of a large protein domain in the segmentation gene paired and functionally related genes of Drosophila. Cell 47: 1033-1040

Bradford, M. M. (1976) A rapid and sensitive method for a quantitation of microgram quantities of protein utilizing the principle of protein-dye binding. Anal. Biochem. 72: 248-254

Burri, M., Tromvoukis, Y., Bopp, D., Frigerio, G. und Noll M. (1989) Conservation of the paired domain in metazoans and its structure in three isolated human genes. EMBO J. 8: $1183-1190$

Calkhoven, F. und Ab, G. (1996) Multiple steps of transcription factor level and activity. Biochem. J. 317: 329-342

Calzone, F.J., Theze, N., Thiebaud, P., Hill, R.L., Britten, R.J. und Davidson., E.H. (1988) Developmental appearance of factors that bind specifically to cis-regulatory sequences of a gene expressed in the sea urchin embryo. Genes Dev. 2: 1074-1088

Carrière, C., Plaza, S., Martin, P., Quatannens, B., Bailly, M., Stehelin, D. und Saule, (1993) Characterization of quail Pax-6 (Pax-QNR) proteins expressed in the neuroretina. Mol. Cell. Biol. 13: 7257-7266

Carrière, C., Plaza, S., Caboche, J., Dozier, C., Bailly, M., Martin, P. und Saule, S. (1995) Nuclear localization signals, DNA binding and transactivation properties of Quail Pax6 (PaxQNR) isoforms. Cell. Growth. Differ. 6: 1531-1540 
Chalepakis, G., Stoykova, A., Wijnholds, J.,Tremblay, P. und Gruss, P. (1993) Pax: gene regulator in the developing nervous system. J. Neurobiol. 24: 1367-1384

Chalepakis, G., Tremblay, P. und Gruss P. (1992) Pax genes, mutants and molecular function. J. Cell. Sci. Suppl.16: 61-67

Chalepakis, G., Wijnholds, J., Giese, P., Schachner, M. und Gruss, P. (1994) Characterization of Pax-6 and Hoxa-1 binding to the promoter region of the neural cell adhesion molecule L1. DNA. Cell. Biol. 13: 891-900

Choi, C.Y., Lee, Y.M., Kim, Y.H., Park, T., Jeon, B.H., Schulz, R.A. und Kim, Y. (1999) The homeodomain transcription factor NK-4 acts as either a transcriptional activator or repressor and interacts with the p300 coactivator and the Groucho corepressor. J. Biol. Chem. 274: 31543-31552

Courtneidge, S.A. (2003) Cancer: Escape from inhibition. Nature 422: 827-828

Cubitt, A.B., Heim, R., Adams, S.R., Boyd, A.E., Gross, L.A. und Tsien, R.Y. (1995) Understanding, improving and using green fluorescent proteins. Trends Biochem. Sci. 20: 448-455

Cvekl, A. und Piatgorsky, J. (1996) Lens development ans crystallin gene expression: many roles for Pax-6. Bioessays 18: 621-630

Cvekl, A., Kashanchi, F., Brady, J.N. und Piatgorski, J. (1999) Pax-6 interactions with TATA-box-binding protein and retinoblastoma protein. Invest. Ophthalmol. Vis. Sci.. 40: $1343-1350$

Czerny, T., Schaffner, G. und Busslinger, M. (1993) DNA sequence recognition by Pax proteins: bipartite structure of the paired domain and ist binding site. Genes Dev. 7: 20482061

Dagert, M. und Ehrlich, S. D. (1979) Prolonged incubation in calcium chloride improves the competence of Escherichia coli cells. Gene 6: 23-28

Dahl, E., Koseki, H. und Balling, R. (1997) Pax genes and organogenesis. Bioessays. 19: 755-765 
De Wet, J. R., Wood, K. V., De Luca, M., Helinski, D. R. und Subramani, S. (1987) Firefly luciferase gene; structure and expression in mammalian cells. Mol. Cell. Biol. 7: 725-737

Diedrich, T., Furstenau, U. und Knepel, W. (1997) Glucagon gene G3 enhancer: evidence that activity depends on combination of an islet-specific factor and a winged helix protein. Biol. Chem. 378: 89-98

Dignam, J.D., Lebovitz, R.M. und Roeder, R.G. (1983) Accurate transcription initiation by RNA polymerase II in a soluble extract from isolated mammalian nuclei. Nucleic Acids Res. 11: $1475-1489$

Drucker , D.J. (1998) Glucagon-like peptides. Diabetes 47: 159-169

Drucker, D.J., Philippe, J., Jepeal, L. und Habener, J.F. (1987) Glucagon gene 5 '-flanking sequences promote islet cell-specific gene-transcription. J. Biol. Chem. 262: 15659-15665

Drucker, D.J. und Asa, S. (1988) Glucagon gene expression in vertebrate brain. J. Biol. Chem. 263: 13475-13478

Duncan, M. K., Haynes, J. I., CvekI, A. und Piatgorski, J. (1998) Dual roles for Pax-6: a transcriptional repressor of lens fiber cell-specific beta-crystallin genes. Mol. Cell. Biol. 18: 5579-5586

Dynan, W.S. (1989) Modularity in promoters and enhancers. Cell 58: 1-4

Eberhard, D. und Busslinger, M. (1999) The partial homeodomain of the transcription factor Pax-5 (BSAP) is an interaction motif for the retinoblastoma and TATA-binding proteins. Cancer Res. 59: 1716s-1725s

Eberhard, D., Jimenez, G., Heavey, B. und Busslinger, M. (2000) Transcriptional repression by Pax5 (BSAP) through interaction with corepressors of the Groucho family. EMBO J. 19: 2292-2303

Efrat, S., Teitelmann, G., Anwar, M., Ruggiero, D. und Hanahan, D. (1988) Glucagon gene regulatory region directs oncoprotein expression to neurons and pancreatic $\alpha$ cells. Neuron 1: 605-613 
Epstein, J.A., Glaser, T., Cai, J., Jepeal, L., Walton, D.S. und Maas, R.L. (1994a) Two independent and interactive DNA-binding subdomains of the Pax6 paired domain are regulated by alternative splicing. Genes Dev. 8: 2022-2034

Epstein, J., Cai, J., Glaser, T., Jepeal, L. und Maas, R. (1994b) Identification of a Pax paired domain recognition sequence and evidence for DNA-dependent conformational changes. J. Biol. Chem. 269: 8355-8361

Fortini, M.E. und Rubin, G.M. (1990) Analysis of cis-acting requirements of the Rh3 and Rh4 genes reveals a bipartite organization to rhodopsin promoters in Drosophila melanogaster. Genes Dev. 4: 444-463

Frankel, A.D. und Kim, P.S. (1991) Modular structure of transcription factors: implications for gene regulation. Cell 65: 717-719

Frigerio, G., Burri, M., Bopp, D., Baumgartner, S. und Noll, M. (1986) Structure of the segmentation gene paired and the Drosophila PRD gene set as part of a gene network. Cell 47: $735-746$

Fürstenau, U., Schwaninger, M., Blume, R., Kennerknecht, I. und Knepel, W. (1997) Characterization of a novel protein kinase $C$ response element in the glucagon gene. Mol. Cell. Biol. 17: 1805-1816

Fujioka, M., Miskiewicz, P., Raj, L., Gulledge, A.A., Weir, M. und Goto, T. (1996) Drosophila Paired regulates late even-skipped expression through a composite binding site for the paired domain and the homeodomain. Development 122: 2697-2707

Furukawa, T., Kozak, C.A. und Cepko, C.L. (1997) rax, a novel paired-type homeobox gene, shows expression in the anterior neural fold and developing retina. Proc. Natl. Acad. Sci. U.S.A 94: 3088-3093

Gajic, D. und Drucker, D.J. (1993) Multiple cis-acting domains mediate basal and adenosine 3',5'-monophosphate-dependent glucagon gene transcription in a mouse neuroendocrine cell line. Endocrinology 132: 1055-1062

Gehring, W.J., Affolter, M. und Burglin, T. (1994) Homeodomain proteins. Annu. Rev. Biochem. 63: 487-526 
Glaser, T., Walton, D. S. und Maas, R.L. (1992) Genomic structure, evolutionary conservation and aniridia mutations in the human PAX6 gene. Nature Genet. 2: 232-239

Goodman, H.M. und MacDonald, R.J. (1979) Cloning of hormone genes from a mixture of cDNA molecules. Methods Enzymol. 68: 75-90

Goulding, M.D., Chalepakis, G., Deutsch, U., Erselius, J.R. und Gruss, P. (1991) Pax-3, a novel murine DNA binding protein expressed during early neurogenesis. EMBO J. 10: $1135-1147$

Graham, A., Papalopulu, N. und Krumlauf, R. (1989) The murine and Drosophila homeobox gene complexes have common features of organization and expression. Cell $\mathbf{5 7}$ : $367-378$

Grzeskowiak, R., Amin, J., Oetjen, E. und Knepel, W. (2000) Insulin responsiveness of the glucagon gene conferred by interactions between proximal promoter and more distal enhancer-like elements involving the paired-domain transcription factor Pax6. J. Biol. Chem. 275: $30037-30045$

Habener, J.F., Drucker, D.J., Mojsov, S., Knepel, W. und Philippe J. (1991) Biosynthesis of glucagon, 53-71. in E. Samols (Hrsg.), The endocrine pancreas, Raven Press, New York

Halder, G., Callaerts, P. und Gehring, W.J. (1995) New perspectives on eye evolution. Curr. Opin. Genet. Dev. 5: 602-609

Harvey, R.P. (1996) NK-2 homeobox genes and heart development. Dev. Biol. 178: 203-216

Heim, R., Prasher, D.C. und Tsien, R.Y. (1994) Wavelength mutations and posttranslational autoxidation of green fluorescent protein. Proc. Natl. Acad. Sci. U.S.A. 91: 12501-12504

Herzig, S., Füzesi, L. und Knepel, W. (2000) Heterodimeric Pbx-Prep1 homeodomain protein binding to the glucagon gene restricting transcription in a cell type-dependent manner. J. Biol. Chem. 275: 27989-27999

Hill, R. E., Favor, J., Hogan, B. L. M., Ton, C. C. T., Saunders, G. F., Hanson, I. M., Prosser, J., Jordan, T., Hastie, N.D. und van Heyningen, V. (1991) Mouse Small eye results from mutations in a paired-like homeobox-containing gene. Nature 354: 522-525 
Hill, M.E., Asa, S.L. und Drucker, D.J. (1999) Essential requirement for Pax6 in control of enteroendocrine proglucagon gene transcription. Mol. Endocrinol. 13: 1474-1486

Hollenbach, A.D., Sublett, J.E., McPherson, C.J. und Grosveld, G. (1999) The Pax3FKHR oncoprotein is unresponsive to the Pax3-associated repressor hDaxx. EMBO J. 18: 3702-3711

Hussain, M. A. und Habener, J. F. (1999) Glucagon gene activation mediated by synergistic interactions of Pax-6 and Cdx-2 with the p300 co-activator. J. Biol. Chem. 274: 28950-28957

Hussain, M. A., Lee, J., Miller, C. P. und Habener, J. F. (1997) POU domain transcription factor brain-4 confers pancreatic a-cell-specific expression of the proglucagon gene through interaction with a novel proximal promoter element G1 element. Mol. Cell. Biol. 17: 71867194

Jin, T. Und Drucker, D.J. (1995) The proglucagon gene upstream enhancer contains positive and negative domains important for tissue-specific proglucagon gene transcription. Mol. Endocrinol. 9: 1306-1320

Jin, T. und Drucker, D.J. (1996) Activation of proglucagon gene transcription through a novel promoter element by the caudal-related homeodomain protein cdx-2/3. Mol. Cell. Biol. 16: $19-28$.

Jin, T., Trinh, D.K., Wang, F. und Drucker, D.J. (1997) The caudal homeobox protein cdx2/3 activates endogenous proglucagon gene expression in InR1-G9 islet cells. Mol. Endocrinol. 11: 203-209

Johnson, P.F. und McKnight, S.L. (1989) Eucaryotic transcriptional regulatory proteins. Annu. Rev. Biochem. 58: 799-839

Jordan, T., Hanson, I., Zaletayev, D., Hodgson, S., Prosser, J., Seawright, A., Hastie, N. und van Heyningen, V. (1992) The human PAX6 gene is mutated in two patents with aniridia. Nature Genet. 1: 328-332 
Joyner, A.L. und Martin, G.R. (1987) En-1 and En-2, two mouse genes with sequence homology to the Drosophila engrailed gene: expression during embryogenesis. Genes Dev. 1: $29-38$

Jun, S. und Desplan, C. (1996) Cooperative interactions between paired domain and homeodomain. Development 122: 2639-2650

Kamachi, Y., Uchikawa, M., Tanouchi, A., Sekido, R. und Kondoh, H. (2001) Pax6 and Sox2 form a co-DNA-binding partner complex that regulates initiation of lens development. Genes Dev. 15: 1272-1286

Kamps, M.P., Murre, C., Sun, X.H. und Baltimore, D. (1990) A new homeobox gene contributes the DNA binding domain of the $t(1 ; 19)$ translocation protein in pre-B ALL. Cell 60 : $547-555$

Kissinger, C.R., Liu, B., Martin-Blanco, E., Kornberg, T.B. und Pabo, C.O. (1990) Crystal structure of an engrailed homeodomain-DNA complex at 2.8 A resolution: A framework for understanding homeodomain-DNA interactions. Cell 63: 579-590

Knepel, W. (1993) Transcriptional control of pancreatic islet hormones gene expression. Exp. Clin. Endocinol. 101: 39-45

Knepel, W. (2001) The a-cell and regulation of glucagon gene transcription. In "Molecular Basis of Endocrine Pancreas Development and Function" (Hrsg. Hussain, M.A., Miller C.P., Habener, J.F.) Kluwer Academic Publishers, Boston: 67-89

Knepel, W., Chafitz, J. und Habener, J. F. (1990a) Transcriptional activation of the rat glucagon gene by the cyclic AMP-responsive element in pancreatic islet cells. Mol. Cell. Biol. 10: $6799-6804$

Knepel, W., Jepeal, L. und Habener J.F. (1990b) A pancreatic islet cell-specific enhancerlike element in the glucagon gene contains two domains binding distinct cellular proteins. J. Biol. Chem. 265: 8725-8735

Knepel, W., Vallejo, M., Chafitz, J. A. und Habener, J. F. (1991) The pancreatic isletspecific glucagon G3 transcription factors recognize cntrol elements in the rat somatostatin and insulin-I genes. Mol. Endocrinol. 5: 1457-1466 
Kohler, P.O. und Bridson, W.E. (1971) Isolation of hormone-producing clonal lines of human choriocarcinoma. J. Clin. Endocrinol. Metab. 32: 683-687

Laemmli, U.K. (1970) Cleavage of structural proteins during the assembly of the head of bacteriophage T4. Nature 227: 680-685

Langdon, R.C., Burr, T., Pagan-Westphal, S. und Hochschild, A. (2001) A chimeric activator of transcription that uses two DNA-binding domains to make simultaneous contact with pairs of recognition sites. Mol. Microbiol. 41: 885-896

Latchman, D.S. (1997) Transcription factors: an overview. Int. J. Biochem. Cell. Biol. 29: $1305-1312$

Lee, Y.C., Asa, S.L. und Drucker, D.J. (1992) Glucagon gene 5'-flanking sequences direct expression of simian virus 40 large $\mathrm{T}$ antigen to the intestine, producing carcinoma of the large bowel in transgeneic mice. J. Biol. Chem. 267: 10705-10708

Léfèbvre, P.J. (1996) Glucagon and diabetis, 115-132. In Léfèbvre, P.J. (Hrsg.), Handbook of experimental pharmacology, Springer-Verlag, Berlin, Heidelberg, Vol. 3

Le Gouill, C., Parent, J. L., Rola-Plesczynski, M. und Stankova, J. (1994) Analysis of recombinant plasmids by a modified alkaline lysis method. Anal. Biochem. 219: 164

Lewis, E.B. (1978) A gene complex controlling segmentation in Drosophila. Nature 276: 565570

Li, X. und Noll, M. (1994) Evolution of distinct developmental functions of three Drosophila genes by acquisition of different cis-regulatory regions. Nature 367: 83-87

Liu, I.S., Chen, J.D., Ploder, L., Vidgen. D., van der Kooy, D., Kalnins, V.I. und McInnes, R.R. (1994) Developmental expression of a novel murine homeobox gene (Chx10): evidence for roles in determination of the neuroretina and inner nuclear layer. Neuron 13: 377-393

Liu, J.J., Kao, W.W. und Wilson, S.E. (1999) Corneal epithelium-specific mouse keratin K12 promoter. Exp. Eye Res. 68: 295-301 
Lu, Q., Wright, D.D. und Kamps, M.P. (1994) Fusion with E2A converts the Pbx1 homeodomain protein into a constitutive transcriptional activator in human leukemias carrying the $t(1 ; 19)$ translocation. Mol. Cell. Biol. 14: 3938-3948

Magnaghi, P., Roberts, C., Lorain, S., Lipinski, M. und Scambler, P.J. (1998) HIRA, a mammalian homologue of Saccharomyces cerevisiae transcriptional co-repressors, interacts with Pax3. Nature Genet. 20: 74-77

Mansouri, A, Goudreau, G. und Gruss, P. (1999) Pax genes and their role in organogenesis. Cancer Res. 59: 1707s-1709s

Marquardt, T., Ashery-Padan, R., Andrejewski, N., Scardigli, R., Guillemot, F. und Gruss, P. (2001) Pax6 is required for the multipotent state of retinal progenitor cells. Cell 105: $43-55$

Matsunaga, E., Araki, I. und Nakamura, H. (2000) Pax6 defines the di-mesencephalic boundary by repressing En1 and Pax2. Development 127: 2357-2365

Matsunami, H. und Takeichi, M. (1995) Fetal brain subdivisions defined by R- and Ecadherin expressions: evidence for the role of cadherin activity in region-specific, cell-cell adhesion. Dev. Biol. 172: 466-478

Matsuo, T, Osumi-Yamashita, N., Noja, S., Ohuchi, H., Koyama, E., Myokai, F., Matsuo, N., Taniguchi, S., Doi, H., Ninomiya, Y., Fujiwara, M., Watanabe, T. und Eto, K. (1993) A mutation in the Pax-6 gene in rat small eye is associated with impaired migration of midbrain crest cells. Nature Genet. 3: 299-304

Maulbecker, C.C. und Gruss, P. (1993) The oncogenic potential of Pax genes. EMBO J. 12: $2361-2367$

McGinnis, W., Levine, M. S., Hafen, E., Kuroiwa, A. und Gehring, W. J. (1984) A conserved DNA sequence in homeotic genes of the Drosophila antennapedia and bithorax complexes. Nature 308: 428-433

McGinnis, W. und Krumlauf, R. (1992) Homeobox genes and axial patterning. Cell 68: 283302. 
Meech, R., Kallunki, P., Edelman, G.M. und Jones, F.S. (1999) A binding site for homeodomain and Pax proteins is necessary for $\mathrm{L} 1$ cell adhesion molecule gene expression by Pax-6 and bone morphogenetic proteins. Proc. Natl. Acad. Sci. U.S.A. 96: 2420-2425

Merika, M. und Thanos, D. (2001) Enhanceosomes. Curr. Opin. Gen. Dev. 11: 205-208

Meyer, T.E. und Habener, J.F. (1993) Cyclic adenosine 3',5'-monophosphate response element binding protein (CREB) and related transcription-activating deoxyribonucleic acidbinding proteins. Endocr. Rev. 14: 269-290

Mikkola, I., Bruun, J.-A., Bjorkoy, G., Holm, T. und Johansen, T. (1999) Phosphorylation of the Transactivation Domain of Pax6 by extracellular signal-regulated kinase and p38 mitogen-activiated protein kinase. J. Biol. Chem. 274: 15115-15126

Mikkola, I., Bruun., J.-A., Holm, T. und Johansen, T. (2001) Superactivation of Pax6mediated transactivation from paired-domain binding sites by DNA-independent recruitment of different homeodomain proteins. J. Biol. Chem. 276: 4109-4118

Miskiewicz, P., Morissey, D., Lan, Y., Raj, L., Kessler, S., Fujoka, M., Goto, T. und Weir, M. (1996) Both the paired domain and homeodomain are required for in vivo function of Drosophila paired. Development 122: 2709-2718

Mismer, D. und Rubin, G.M. (1989) Definition of cis-acting elements regulating expression of the Drosophila melanogaster ninaE opsin gene by oligonucleotide-directed mutagenesis. Genetics 121: 77-87

Mitchell, P.J. und Tijan, R. (1989) Transcriptional regulation in mammalian cells by sequence-specific DNA-binding proteins. Science 245: 371-378

Mojsov, S., Heinrich, G., Wilson, I.B., Ravazzola, M., Orci, L. und Habener, J.F. (1986) Preproglucagon gene expression in pancreas and intestine diversifies at the level of posttranslational processing. J. Biol. Chem. 261: 11880-11889

Monica, K., Galili, N., Nourse, J., Saltman, D.und Cleary, M.L. (1991) PBX2 and PBX3, new homeobox genes with extensive homology to the human proto-oncogene PBX1. Mol. Cell. Biol. 11: 6149-6157 
Morel, C., Cordier-Bussat, M. und Philippe, J. (1995) The upstraeam promoter element of the glucagon gene, G1, confers pancreatic alpha cell-specific expression. J. Biol. Chem. 270: 3046-3055

Nian, M., Drucker, D. und Irwin, D. (1999) Divergent regulation of human and rat proglucagon gene promoters in vivo. Am. J. Physiol. 277: G829-G837

Noll, M. (1993) Evolution and role of Pax genes. Curr. Opin. Genet. Dev. 3: 595-605

Nordeen, S.K. (1988) Luciferase reporter gene vectors for analysis of promoters and enhancers. Bio Techniques 6: 454-457

Nourse, J., Mellentin, J.D., Galili, N., Wilkinson, J., Stanbridge, E., Smith, S.D. und Cleary, M.L. (1990) Chromosomal translocation $t(1 ; 19)$ results in synthesis of a homeobox fusion mRNA that codes for a potential chimeric transcription factor. Cell 60: 535-545

Oliver, G., Mailhos, A., Wehr, R., Copeland, N.G., Jenkins, N.A. und Gruss, P. (1995) Six3, a murine homologue of the sine oculis gene, demarcates the most anterior border of the developing neural plate and is expressed during eye development. Development. 121: 4045-4055

Orskov, C., Holst, J.J., Knuhtsen, S., Baldissera, F.G., Poulsen, S.S. und Nielsen, O.V. (1986) Glucagon-like peptides GLP-1 and GLP-2, predicted products of the glucagon gene, are secreted separately from pig small intestine but not pancreas. Endocrinology 119: 14671475

Otting, G,, Qian, Y.Q., Billeter, M., Muller, M., Affolter, M., Gehring, W.J. und Wuthrich K (1990) Protein-DNA contacts in the structure of a homeodomain-DNA complex determined by nuclear magnetic resonance spectroscopy in solution. EMBO J. 9: 3085-3092

Petersen, H.V., Jorgensen, M.C., Andersen, F.G., Jensen, J., F-Nielsen, T., Jorgensen, R., Madsen, O.D. und Serup, P. (2000) Pax4 represses pancreatic glucagon gene expression. Mol. Cell. Biol. Res. Commun. 3: 249-254

Philippe, J. (1989) Glucagon gene transcription is negatively regulated by insulin in a hamster islet cell line. J. Clin. Invest. 84: 672-677 
Philippe, J., Drucker, D.J., Knepel, W., Jepeal, L., Misoluvi, Z. und Habener J.F. (1988) Alpha-cell-speific expression of the glucagon gene is conferred to the glucagon promoter element by the interactions of DNA-binding proteins. Mol. Cell. Biol. 8: 4877-4888

Philippe, J., Morel, C. und Cordier-Bussat, M. (1995) Islet-specific proteins interact with the insulin-response element of the glucagon gene. J. Biol. Chem. 270: 3039-3045

Philips, C. L., Vershon, A. K. und Dahlquist, F. W. (1991) Secondary structure of the homeodomain of yeast $\alpha 2$ repressor determined by NMR spectroscopy. Genes Dev. 5: 764772

Planque, N., Leconte, L., Conquell, M. F., Benckhelifa, S., Martin, P., FelderSchmittbuhl, M.-P. und Saule, S. (2001) Interaction of Maf transcription factors with Pax-6 results in synergistic activation of the glucagon promoter. J. Biol. Chem. 276: 35751-35760

Powers, A.C., Efrat, S., Mojsov, S., Spector, D., Habener, J.F. und Hanahan, D. (1990) Proglucagon processing similar to normal islets in pancreatic alpha-like cell line derived from transgenic mouse tumor. Diabetes. 39: 406-414

Ptashne, M. (1988) How eukaryotic transcriptional activators work. Nature 335: 683-689

Puigserver, P., Wu, Z., Park, C.W., Graves, R., Wright, M. und Spiegelman, B.M. (1998) A cold-inducible coactivator of nuclear receptors linked to adaptive thermogenesis. Cell 9: 829-839

Puigserver, P., Adelmant, G., Wu, Z., Fan, M., Xu, J., O'Malley, B. und Spiegelman, B.M. (1999) Activation of PPARgamma coactivator-1 through transcription factor docking. Science 286: $1368-1371$

Punzo, C., Kurata, S. und Gehring, W. (2001) The eyeless homeodomain is dispensable for eye development in Drosophila. Genes Dev. 15: 1716-1723

Qian, Y.Q., Furukubo-Tokunaga, K., Resendez-Perez, D., Müller, M., Gehring, W.J. und Wütrich, K. (1994) Nuclear magnetic resonance solution structure of the Fushi Tarazu homeodomain from Drosophila and comparison with the Antennapedia homeodomain. J. Mol. Biol. 238: 333-345 
Redies, C. und Takeichi, M. (1996) Cadherins in the developing central nervous system: an adhesive code for segmental and functional subdivisions. Dev. Biol. 180: 413-423

Regulski, M., Harding, K., Kostriken, R., Karch, F., Levine, M. und McGinnis, W. (1985) Homeo box genes of the Antennapedia and bithorax complexes of Drosophila. Cell 43: 71-80

Reichlin, S. (1983a) Somatostatin (First of two parts). N. Engl. J. Med. 309: 1495-1501

Reichlin, S. (1983b) Somatostatin (Second of two parts). N. Engl. J. Med. 309: 1556-1563

Rincon-Limas, D.E., Lu, C.H., Canal, I., Calleja, M., Rodriguez-Esteban, C., IzpisuaBelmonte, J.C. und Botas, J. (1999) Conservation of the expression and function of apterous orthologs in Drosophila and mammals. Proc. Natl. Acad. Sci. U.S.A. 96: 2165-2170

Ritz-Laser, B., Estreicher, A., Klages, N., Saule, S. und Philippe, J. (1999) Pax-6 and $\mathrm{Cdx}-2 / 3$ interact to activate glucagon gene expression on the $\mathrm{G} 1$ control element. J. Biol. Chem. 274: 4124-4132

Ritz-Laser, B., Estreicher, A., Gauthier, B. und Philippe, J. (2000) The paired homeodomain transcription factor Pax-2 is expressed in the endocrine pancreas and transactivates the glucagon gene promoter. J. Biol. Chem. 275: 32708-32715

Saltiel, A.R. und Olefsky, J.M. (1996) Thiazolidinediones in the treatment of insulin resistance and type II diabetes. Diabetes 45: 1661-1669

Sambrook, J., Fritsch, E. F. und Maniatis, T. (1989) Molecular cloning. A laboratory manual. 2, Auflage. Cold Spring Habor Laboratory

Sander, M., Neubüser, A., Kalamaras, J., Ee, H.C., Martin, G.R. und German, M.S. (1997) Genetic analysis reveals that Pax6 is required for normal transcription of pancreatic hormone genes and islet development. Genes Dev. 11: 1662-1673

Sanger, F., Nicklen, S. und Coulson, A.R. (1977) DNA sequencing with chain-terminating inhibitors. Proc. Natl. Acad. Sci. U.S.A. 74: 5463-5467

Scardigli, R., Schuurmans, C., Gradwohl, G. und Guillemot, F. (2001) Crossregulation between Neurogenin2 and pathways specifying neuronal identity in the spinal cord. Neuron 31: 203-217 
Schinner, S., Dellas, C., Schröder, M., Heinlein, C.A., Chang, C., Fischer, J. und Knepel, W.J. (2002) Repression of glucagon gene transcription by peroxisome proliferator-activated receptor gamma through inhibition of Pax6 transcriptional activity. J. Biol. Chem. 277: 1941-1948

Schnabel, C.A. und Abate-Shen, C. (1996) Repression by HoxA7 is mediated by the homeodomain and the modulatory action of its N-terminal-arm residues. Mol. Cell. Biol. 16: 2678-2688

Schwaninger, M., Lux, G., Blume, R., Oejen, E., Hidaka, H. und Knepel, W. (1993) Membrane depolarization and calcium influx induce glucagon gene transcription in pancreatic islet cells through the cyclic AMP-responsive element. J. Biol. Chem. 268: 51685177

Simpson, T.I. und Price, D.J. (2002) Pax6; a pleiotropic player in development. Bioessays 24: $1041-1051$

Singh, S., Stellrecht, C.M., Tang, H.K. und Saunders, G.F. (2000) Modulation of PAX6 homeodomain function by the paired domain. J. Biol. Chem. 275: 17306-17313

Smith, S.B., Ee, H.C., Conners, J.R. und German, M.S. (1999) Paired-homeodomain transcription factor PAX4 acts as a transcriptional repressor in early pancreatic development. Mol. Cell. Biol. 19: 8272-8280

St-Onge, L., Sosa-Pineda, B., Chowdhury, A.M. und Gruss, P. (1997) Pax6 is required for differentiation of glucagon-producing $\alpha$-cells in mouse pancreas. Nature 387: 406-409

Takaki, R., Ono, J., Nakamura, M., Yokogawa, Y., Kumae, S., Hiraoka, T., Yamaguchi, K., Hamaguchi, K. und Uchida, S. (1986) Isolation of glucagon-secreting cell lines by cloning insulinoma cells. In Vitro Cell. Dev. Biol. 22: 120-126

Takeda, S., Yamashita, A., Maeda, K. und Maeda, Y. (2003) Structure of the core domain of human cardiac troponin in the $\mathrm{Ca}(2+)$-saturated form. Nature 424: $35-41$

Tang, H.K., Singh, S. und Saunders, G.F. (1998) Dissection of the transactivation function of the transcription factor encoded by the eye developmental gene PAX6. J. Biol. Chem. 273: 7210-7221 
Throsby, M., Homo-Delarche, F., Chevenne, D., Goya, R., Dardenne, M. und Pleau, J.M. (1998) Pancreatic hormone expression in the murine thymus: localization in dendritic cells and macrophages. Endocrinology 139: 2399-2406

Tijan, R. und Maniatis, T. (1994) Transcriptional activation: a complex puzzle with few easy pieces. Cell 77: 5-8

Treismann, J., Harris, E. und Desplan, C. (1991) The paired box encodes a second DNAbinding domain in the Paired homeodomain protein. Genes Dev. 5: 594-604

Underhill, D.A. (2000) Genetic and biochemical diversity in the Pax gene family. Biochem. Cell. Biol. 78: 629-638

Unger, R.H., Orci, L. (1981a) Glucagon and the A cell: physiology and pathophysiology (first two parts). N. Engl. J. Med. 304: 1518-1524

Unger, R.H., Orci, L. (1981b) Glucagon and the A cell: physiology and pathophysiology (second of two parts) N. Engl. J. Med. 304: 1575-1580

Walther, C. und Gruss, P. (1991) Pax-6, a murine paired box gene is expressed in the developing CNS. Development 113: 1435-1449

Walther, C., Guenet, J.L., Simon, D., Deutsch, U., Jostes, B., Goulding, M.D., Plachov, D., Balling, R. und Gruss, P. (1991) Pax: a murine multigene family of paired boxcontaining genes. Genomic 11: 424-434

Wang, M. und Drucker, D.J. (1995) The LIM domain homeobox gene isl-1 is a positive regulator of islet-specific proglucagon gene transcription. J. Biol. Chem. 270: 12646-12652

Watada, H., Mirmira, R.G., Kalamaras, J. und German, M.S. (2000) Intramolecular control of transcriptional activity by the NK2-specific domain in NK-2 homeodomain proteins. Proc. Natl. Acad. Sci. U.S.A. 97: 9443-9448

Wilson, D., Sheng, G., Lecuit, T., Dostatni, N. und Desplan, J. (1993) Cooparative dimerization of Paired class homeo domains on DNA. Genes Dev. 7: 2120-2134

Wilson, D.S. und Desplan, C. (1995) High resolution crystal structure of a Paired (Pax) class cooperative homeodomain dimer on DNA. Cell 82: 709-719 
Wilson, D.S., Sheng, G., Jun, S. und Desplan, C. (1996) Conservation and diversification in homeodomain-DNA interactions: a comparative genetic analysis. Proc. Natl. Acad. Sci. U.S.A 93: $6886-6891$

Wolberger, C., Vershon, A.K., Liu, B., Johnson, A.D. und Pabo, C.O. (1991) Crystal structure of a MAT alpha 2 homeodomain-operator complex suggests a general model for homeodomain-DNA interactions. Cell 67: 517-528

Wrege, A., Diedrich, T., Hochhuth, C. und Knepel, W. (1995) Transcriptional activity of domain $A$ of the rat glucagon $\mathrm{G} 3$ element conferred by an islet-specific nuclear protein that also binds to similar pancreatic islet cell-specific enhancer sequences (PISCES). Gene Expr. 4: $205-216$

Wu, Z., Puigserver, P., Andersson, U., Zhang, C., Adelmant, G., Mootha, V., Troy, A., Cinti, S., Lowell, B., Scarpulla, R.C. und Spiegelman, B.M. (1999) Mechanisms controlling mitochondrial biogenesis and respiration through the thermogenic coactivator PGC-1. Cell 98: $115-124$

Xu, H., Rould, M. A., Xu, W., Epstein, J. A., Maas, R. L. und Pabo, C. O. (1999) Crystal structure of the human Pax6 paired domain-DNA complex reveals specific roles for the linker region and carboxy-terminal subdomain in DNA binding. Genes Dev. 13: 1263-1275

Zhang, H., Catron, K.M. und Abate-Shen, C. (1996) A role for the Msx-1 homeodomain in transcriptional regulation: residues in the $\mathrm{N}$-terminal arm mediate TATA binding protein interaction and transcriptional repression. Proc. Natl. Acad. Sci. U.S.A 93: 1764-1769

Zinovieva, R.D., Duncan, M.K., Johnson, T.R., Torres, R., Polymeropoulos, M.H. und Tomarev, S.I. (1996) Structure and chromosomal localization of the human homeobox gene Prox 1. Genomics 35: 517-522 


\section{DANKSAGUNG}

Mein besonderer Dank gilt Herrn Prof. Dr. W. Knepel für die Überlassung des Dissertationsthemas, die fachliche Unterstützung in allen Phasen dieser Arbeit sowie für konstruktive Diskussionen.

Herrn Prof. Dr. R. Hardeland danke ich für die bereitwillige Betreuung der Arbeit seitens der Biologischen Fakultät und sein wissenschaftliches Interesse am Fortgang dieser Arbeit.

Bei Frau Prof. Dr. C. Gatz bedanke ich mich für die Übernahme des Korreferats.

Für viele wissenschaftliche Anregungen, klärende Gespräche und wertvolle Hilfen bei der Bewältigung des Laboralltags danke ich Frau Dr. Elke Oetjen und Herrn Dr. Ralph Krätzner.

Ein ganz großes Dankeschön geht an Frau Corinna Dickel. Ohne ihre tatkräftige Unterstützung wäre manches nicht zu schaffen gewesen. Auch bei Frau Irmgard Cierny, Frau Doris Krause und Herrn Roland Blume, die mir immer mit Tat und Rat zur Seite standen, möchte ich mich bedanken.

Allen Mitarbeiterinnen und Mitarbeitern der Abteilung Molekulare Pharmakologie, speziell auch Ulli, Sven, Cordula, Nikos, Sanjeev, Katharina, Katrin, Regine, Payam, Michaela, Miranda, Silke und Andrei danke ich für eine tolle Arbeitsatmosphäre und die nette Zusammenarbeit.

Für das unermüdliche und hilfreiche Korrekturlesen bedanke ich mich herzlich bei Frau Dr. Ulrike Böer und Herrn Dr. Peter Brechlin.

Nicht zuletzt sei ein ganz besonderer Dank an meine Eltern und meinen Bruder Holger gerichtet, die durch ihre liebevolle Unterstützung und ihr großes Verständnis zum Gelingen dieser Arbeit beigetragen haben. 


\section{LEBENSLAUF}

Angaben zur Person:

Name:

Teichler

Vorname:

Sabine

Geburtsdatum

26.06.1976

Geburtsort:

Stuttgart

Staatsangehörigkeit:

Deutsch

Schulbildung:

1982-1986

1986-1988

1988-1995

Johann-Wolf Grundschule, Nörten-Hardenberg

Orientierungsstufe der Novalis-Schule, Nörten-

Hardenberg

Otto-Hahn-Gymnasium, Göttingen mit Abschluß

Abitur

Studium:

Oktober 1995

Immatrikulation an der Georg-August-Universität, Göttingen, Studienfach Biologie

Oktober 1997

Diplomvorprüfung in den Fächern Botanik, Mikrobiologie, Anorganische Chemie und Physikalische Chemie

Juli 1999

August 1999-Juni 2000

Juli 2000-August 2000

Diplomhauptprüfung in den Fächern Biochemie (Hauptfach), Mikrobiologie und Organische Chemie

Anfertigung der Diplomarbeit am Institut für Biochemie und Molekulare Zellbiologie der GeorgAugust-Universität, Göttingen unter der Leitung von Herrn Prof. Dr. K. Jungermann mit dem Titel:

„Modulation der Glucagon-abhängigen

Phosphoenolpyruvat-Carboxykinase-1-Genexpression durch Sauerstoff: Vermittlung durch die Transkriptionsfaktoren C/EBP $\alpha$ und cJun"

Wissenschaftliche Mitarbeit am Institut für Biochemie und Molekulare Zellbiologie der Georg-AugustUniversität, Göttingen

Oktober 2000

Beginn der experimentellen Arbeiten zur vorliegenden Dissertation im Zentrum Pharmakologie und Toxikologie, Abteilung Molekulare Pharmakologie der Georg-August-Universität Göttingen unter der Leitung von Herrn Prof. Dr. W. Knepel im Rahmen des SFB 402 der Deutschen Forschungsgemeinschaft: „Molekulare und Zelluläre Hepatogastroenterologie“.

Mai 2004 Abgabe der vorliegenden Dissertation 